\title{
PROCESS DEVELOPMENT FOR COMPRESSION MOLDING OF HYBRID CONTINUOUS AND CHOPPED CARBON FIBER PREPREG FOR PRODUCTION OF FUNCTIONALLY GRADED COMPOSITE STRUCTURES
}

\author{
A Thesis \\ presented to \\ the Faculty of California Polytechnic State University, \\ San Luis Obispo
}

In Partial Fulfillment

of the Requirements for the Degree

Master of Science in Mechanical Engineering

by

Corinne Warnock

December 2015 
(C) 2015

Corinne Warnock

ALL RIGHTS RESERVED 


\section{COMMITTEE MEMBERSHIP}

TITLE:

Process Development for Compression Molding of Hybrid Continuous and Chopped Carbon Fiber Prepreg for Production of Functionally Graded Composite Structures

AUTHOR:

DATE SUBMITTED:

COMMITTEE CHAIR:

COMMITTEE MEMBER:
Corinne Warnock

December 2015

Joseph Mello, Ph.D.

Professor of Mechanical Engineering

Timothy Briggs, Ph.D.

R\&D Mechanical Engineer

Sandia National Laboratories, Livermore

COMMITTEE MEMBER: Andrew Davol, Ph.D.

Professor of Mechanical Engineering 


\begin{abstract}
Process Development for Compression Molding of Hybrid Continuous and Chopped Carbon Fiber Prepreg for Production of Functionally Graded Composite Structures

\section{Corinne Warnock}

Composite materials offer a high strength-to-weight ratio and directional load bearing capabilities. Compression molding of composite materials yields a superior surface finish and good dimensional stability between component lots with faster processing compared to traditional manufacturing methods. This experimental compression molding capability was developed for the ME composites lab using unidirectional carbon fiber prepreg composites. A direct comparison was drawn between autoclave and compression molding methods to validate compression molding as an alternative manufacturing method in that lab. A method of manufacturing chopped fiber from existing unidirectional prepreg materials was developed and evaluated using destructive testing methods. The results from testing both the continuous and chopped fiber were incorporated into the design of a functionally graded hybrid continuous and chopped carbon fiber component, the manufacture of which resulted in zero waste prepreg material. 


\section{ACKNOWLEDGMENTS}

This project would not have been possible without the inspired guidance of Dr. Mello, whose insatiable curiosity and constant enthusiasm for trying new things helped to drive this project to the finish line. I would also like to thank Dr. Briggs for his constant encouragement and ability to think past a problem and help me work efficiently through some of this project's big challenges. I would like to thank Dr. Davol for his willingness to help at a moment's notice. I owe thanks especially to Karlos Guzman for providing the means by which to start this project and for seeming to always have time to try one more thing. Thanks to both Nathan Harry and to Alec Bialek, who graciously donated their time and skills to machining two of the molds for my thesis. I am also grateful to Eric Pulse and the entire staff of the Cal Poly Student Machine Shops for their willingness to help me troubleshoot any issue I had. Thanks to Eli Rogers and the ME 412 class for kindly enabling me to test at all hours of the day. I am also grateful to Deep Shah for having just enough knowledge about everything to always have a good answer. Thanks as well to Eric Griess and to Shia LeBeouf for their dependable encouragement to just do it and to always seek a better dream for myself.

I would especially like to express my love and gratitude to my family for their love and support throughout my studies. Thanks to my dad, Jim, for always challenging me to think critically about each of my ideas, and to my mom, Carol, for her persistent excitement to hear about my next tragedy or triumph and for always making sure I got enough sleep. Thanks also to my sister, Sarah, for resisting the urge to call me a nerd every time I talked about carbon fiber. And thanks to George and Carole Leone for their constant support and for being my home away from home.

Finally, I would never have made it through this thesis without the constant care and quick thinking of Matthew Hagan. Thank you for always being my ever dependable sanity check, for so many late nights, and for taking such good care of me. I couldn't have done this without you. 


\section{TABLE OF CONTENTS}

Page

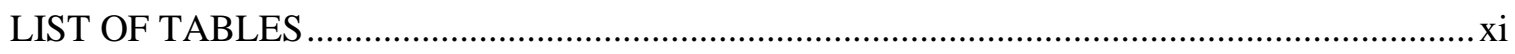

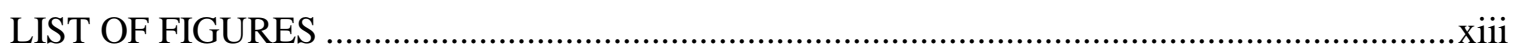

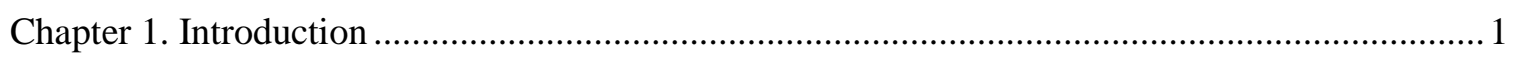

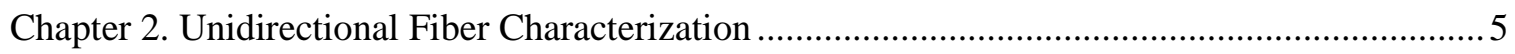

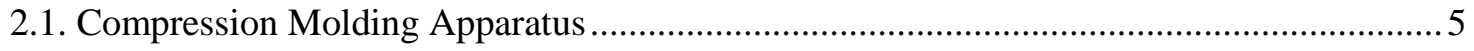

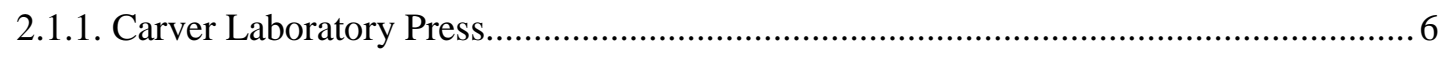

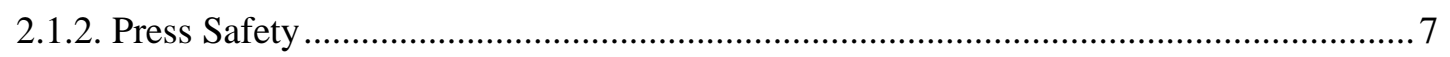

2.1.3. Tensile Specimen Mold Design and Manufacture …................................................. 7

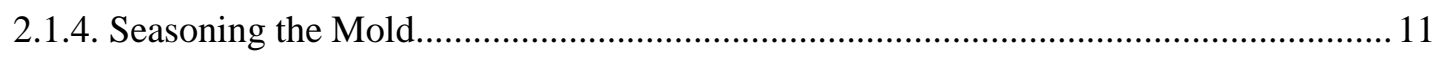

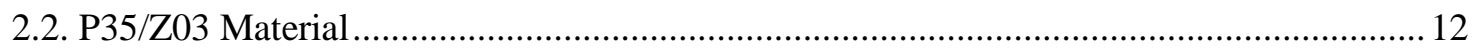

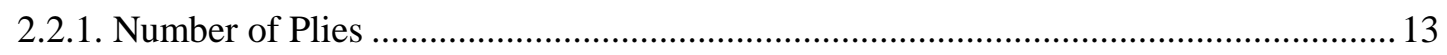

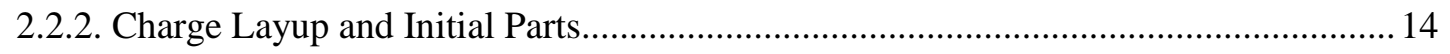

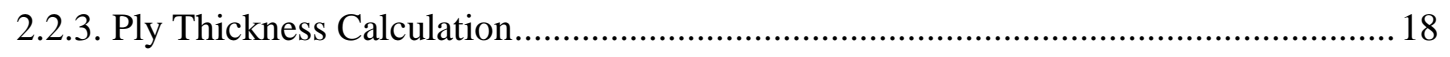

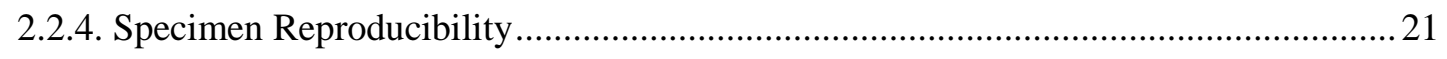

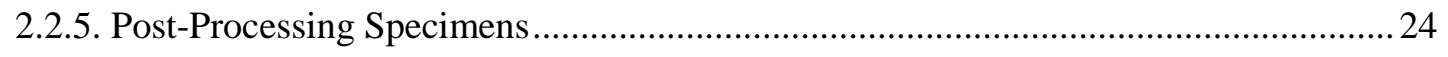

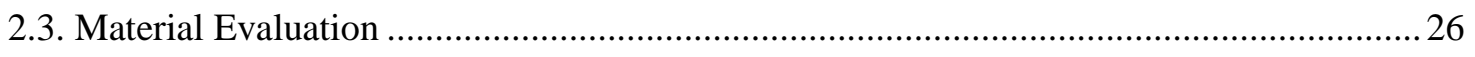

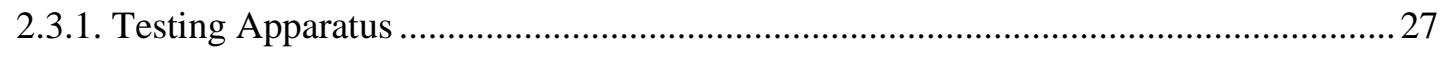

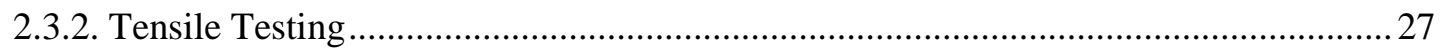

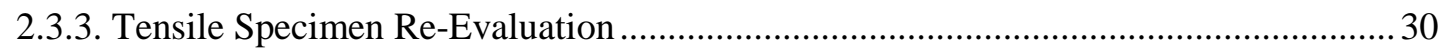




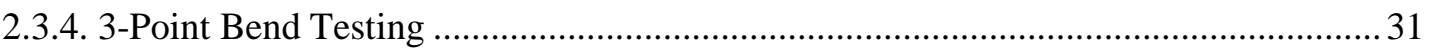

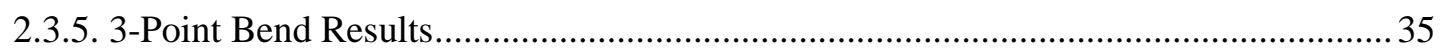

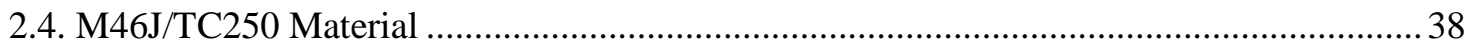

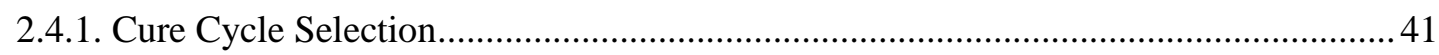

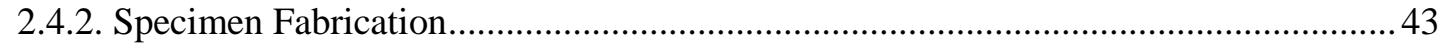

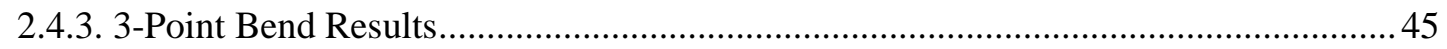

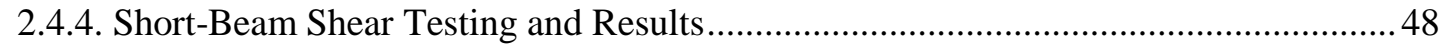

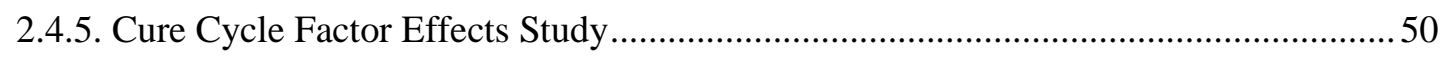

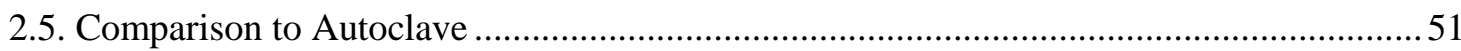

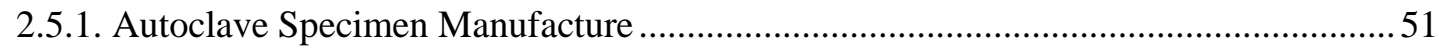

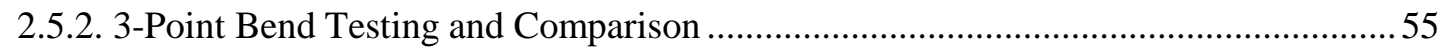

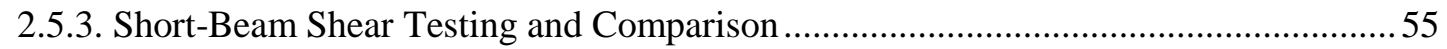

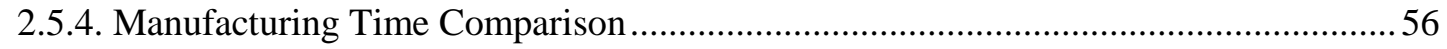

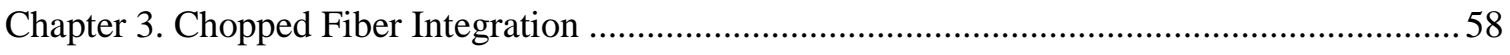

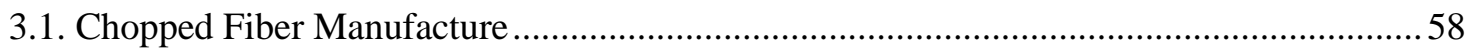

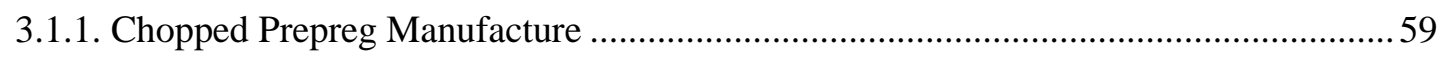

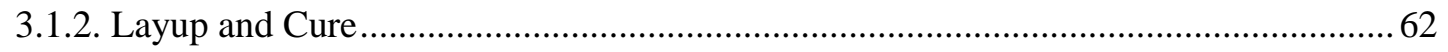

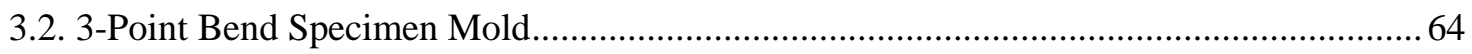

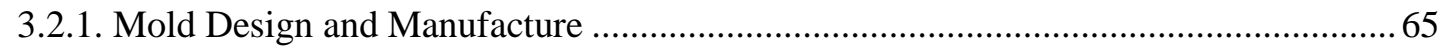

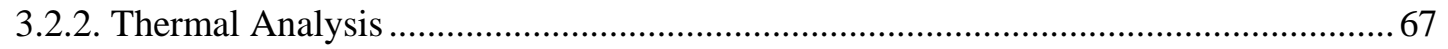

3.3. 3-Point Bend Specimen Manufacture and Evaluation................................................... 72 


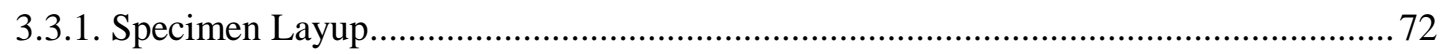

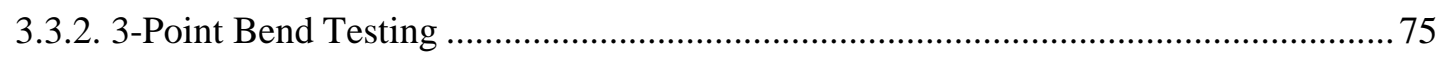

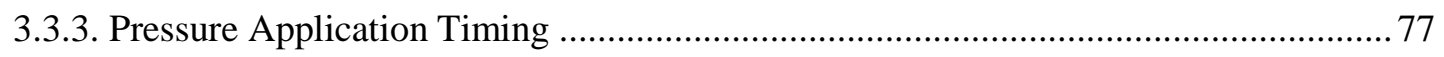

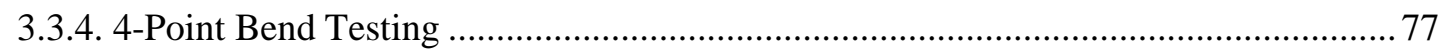

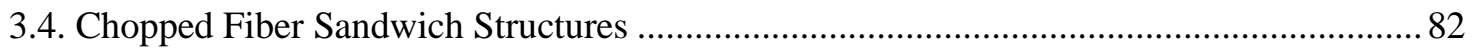

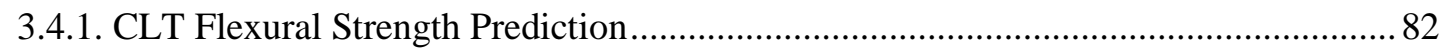

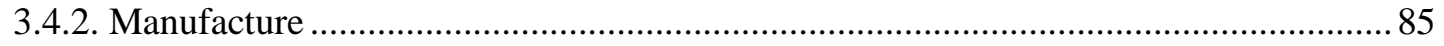

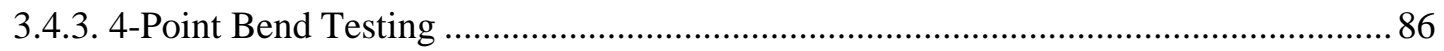

Chapter 4. Hybrid Continuous-Chopped Fiber Component Design ........................................... 90

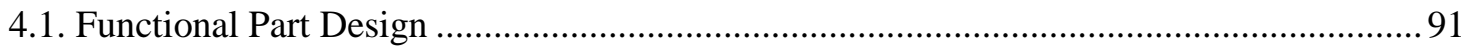

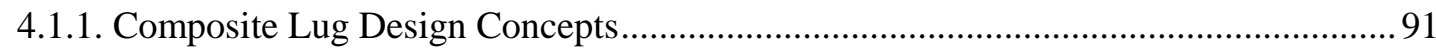

4.1.2. MATLAB Lug Strength Prediction ........................................................................ 92

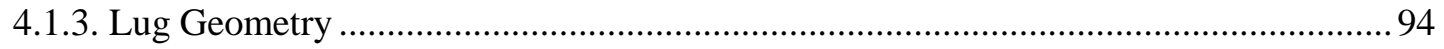

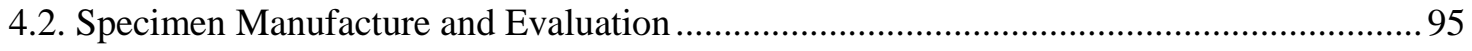

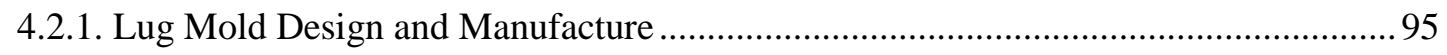

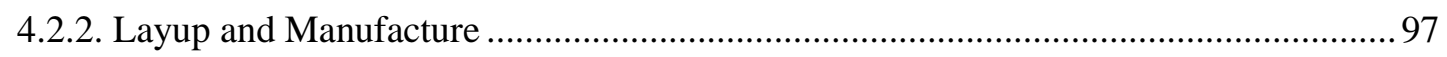

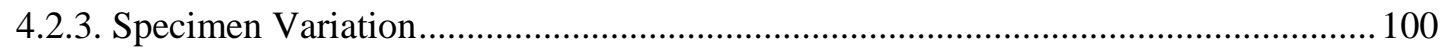

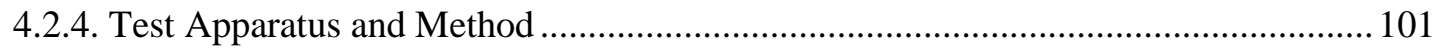

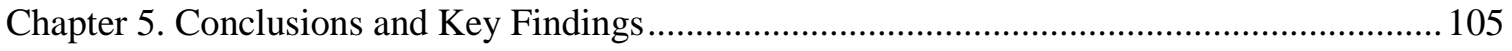

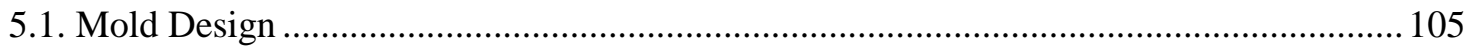

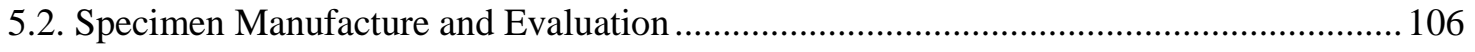




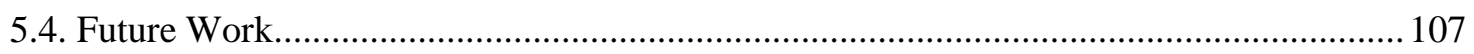

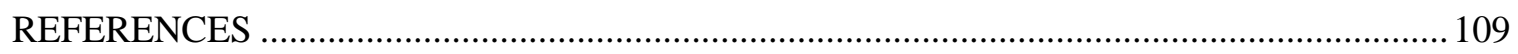

\section{APPENDICES}

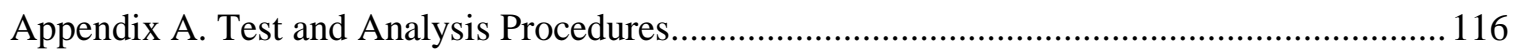

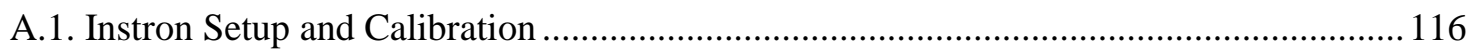

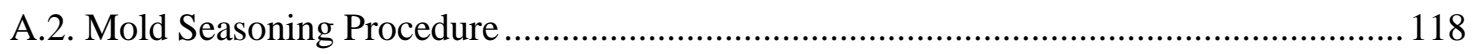

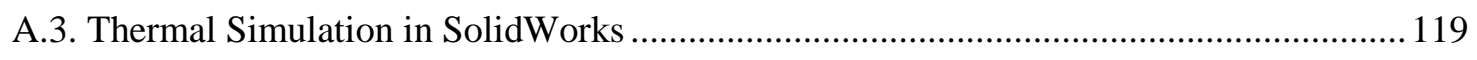

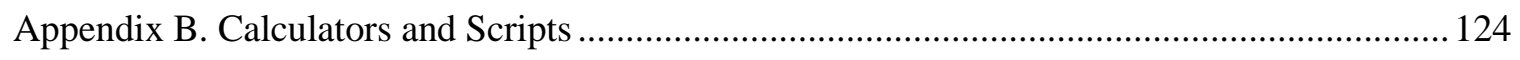

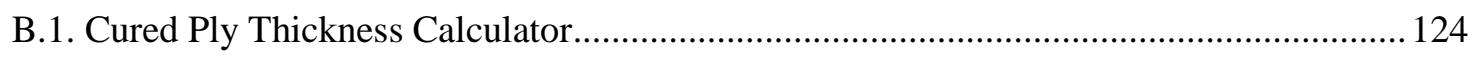

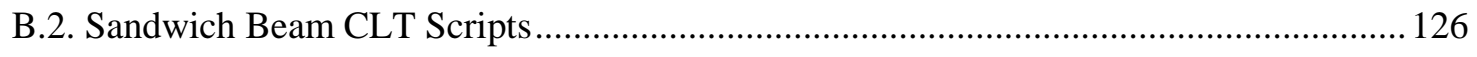

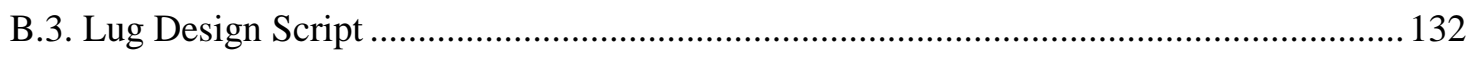

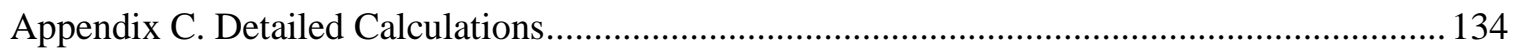

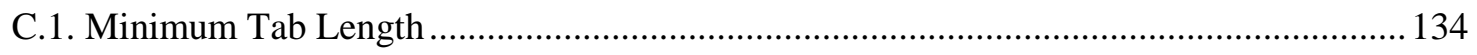

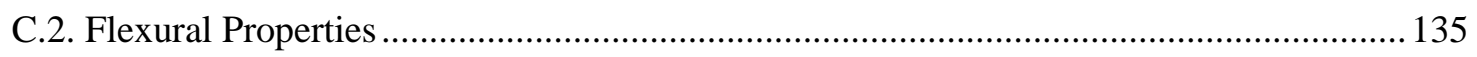

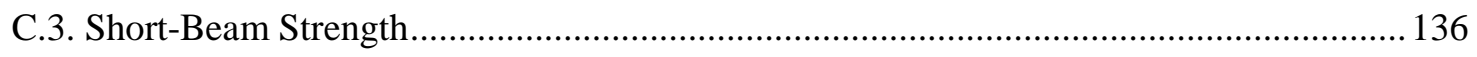

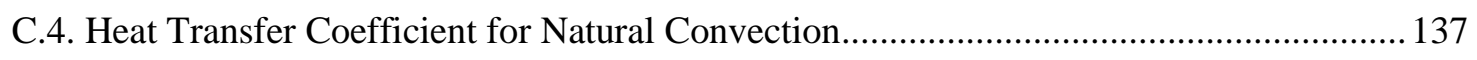

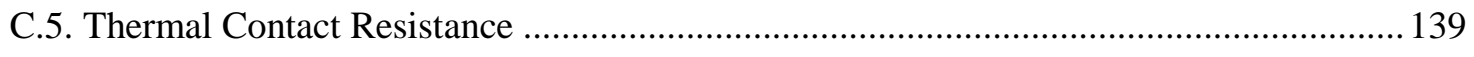

Appendix D. Data Reduction for M46J/TC250 Cure Cycle Analysis ....................................... 140

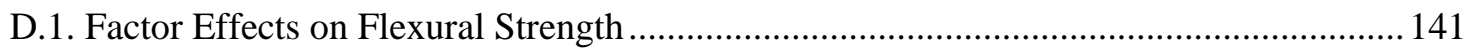

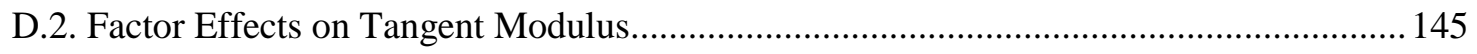


D.3. Factor Effects on Short-Beam Strength.

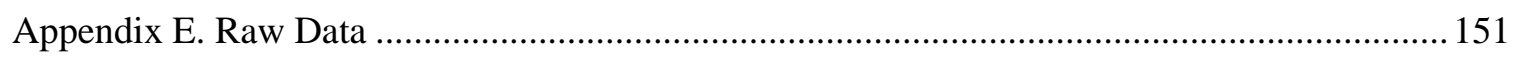

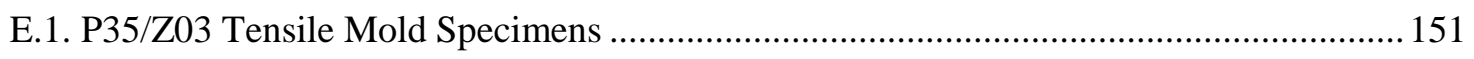

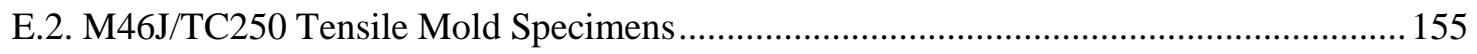

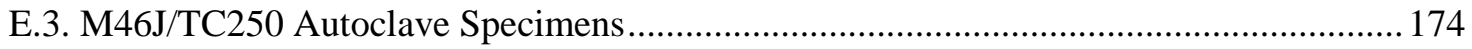

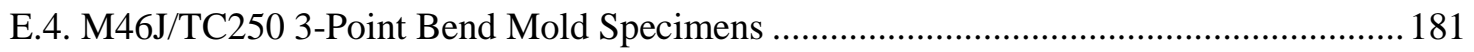

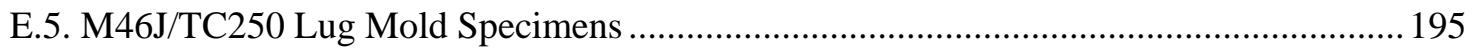




\section{LIST OF TABLES}

Table

Page

Table 2.1. Model scale factors to account for thermal expansion of P35/Z03.

Table 2.2. P35/Z03 prepreg characteristics.

Table 2.3. Tab dimensions used to calculate ply lengths.

Table 2.4. Ply lengths calculated for $\mathrm{t}_{\mathrm{ply}}=0.007 "$ .14

Table 2.5. Thicknesses for gage sections of 14 and 15-ply P35/Z03 tensile specimens. .22

Table 2.6. P35/Z03 mechanical properties provided by Zoltek [18] .26

Table 2.7. Flexural strength, strain, and tangent modulus of $\mathrm{P} 35 / \mathrm{Z} 03$ specimens. .37

Table 2.8. M46J/TC250 prepreg characteristics. .38

Table 2.9. NCAMP certification properties for HTS/TC250 [29]. .41

Table 2.10. Composite properties for M46J fibers with a Toray resin system [30]...... 41

Table 2.11. Factors and levels for the M64J/TC250 cure cycle experiment. .43

Table 2.12. M46J/TC250 specimen thickness measurements. .45

Table 2.13. Flexural strength, strain, and tangent modulus of M46J/TC250 specimens. .47

Table 2.14. Short-beam strength of M46J/TC250 specimens. 49

Table 2.15. Thickness dimensions for 10 and 12-ply M46J/TC250 autoclave specimens. .54

Table 2.16. Flexural strength, strain, and tangent modulus of autoclave specimens. .55

Table 2.17. Short-beam strength of autoclave M46J/TC250 specimens. .56

Table 2.18. Manufacturing time for compression molded and autoclave specimens. .57

Table 3.1. Material properties used for convective heat transfer coefficient calculation. 67 
Table 3.2. Flexural strength, strain, and tangent modulus of initial 3-point bend specimens........76

Table 3.3. Flexural strength, strain, and tangent modulus of 4-point bend specimens................. 81

Table 3.4. Predicted first ply failure locations for sandwich structures...................................... 85

Table 3.5. Flexural strength, strain, and tangent modulus of sandwich structures. ...................... 88

Table 3.6. Experimental and predicted ultimate load for sandwich structures. ............................. 88

Table 4.1. Processing parameters and finished thickness of each pin-loaded tensile specimen.. 100

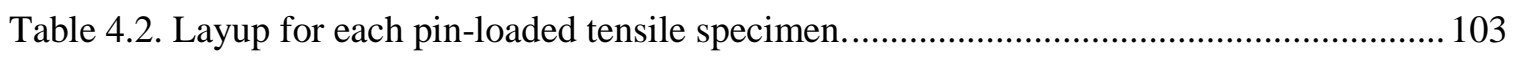

Table 4.3. Failure mode and ultimate load for each pin-loaded tensile specimen...................... 103

Table D.1. Factors, levels, and responses for M46J/TC250 cure cycle analysis. ........................ 140

Table E.1. Consistency measurements for P35/Z03 specimens............................................ 151

Table E.2. Consistency measurements for M46J/TC250 specimens...................................... 155

Table E.3. Consistency measurements for M46J/TC250 autoclave specimens.......................... 174 


\section{LIST OF FIGURES}

Figure

Page

Figure 1.1. Cross section and coordinate system of a unidirectional fiber composite [3]. 1

Figure 1.2. SMC (left) and BMC (right) material forms used for compression molding [6]. ........2

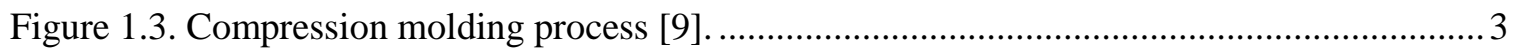

Figure 2.1. Carver press setup used for compression molding. ............................................... 6

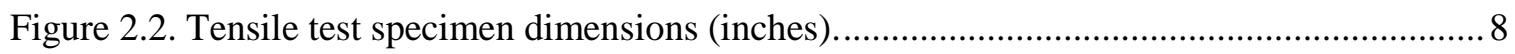

Figure 2.3. Original test specimens as designed with coordinate axes. ...................................... 8

Figure 2.4. Exploded view of mold halves and parts being molded with draft angle check. ......... 9

Figure 2.5. Mold cavity during machining process in Haas VF-3 ........................................... 10

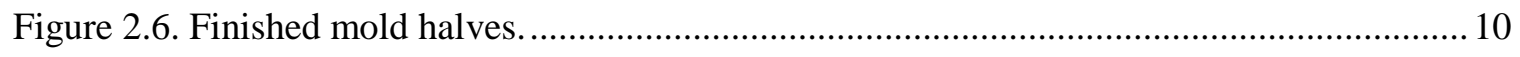

Figure 2.7. Mold seasoning procedure being performed in fume hood..................................... 11

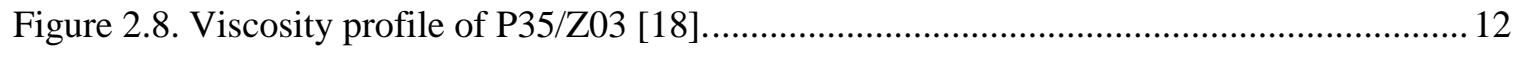

Figure 2.9. Schematic of tensile specimen tab layup........................................................... 13

Figure 2.10. Plies for two tensile specimens and tabs......................................................... 15

Figure 2.11. Lower tabs in place in the mold cavity for tensile specimens. ............................... 15

Figure 2.12. Tensile specimen body in place in mold cavity ................................................. 16

Figure 2.13. Upper tabs in place in the mold cavity for tensile specimens................................ 16

Figure 2.14. Mold core being placed onto mold cavity using alignment pins. ............................ 16

Figure 2.15. First compression molded parts: 10-ply P35/Z03 tensile specimens with tabs. ........ 17

Figure 2.16. Schematic of updated tab layup with positions of additional plies.......................... 19 
Figure 2.17. Cured 14-ply (right) and 15-ply (left) P35/Z03 specimens before demolding.

Figure 2.18. 14-ply P35/Z03 part with holes from machining ejector pins.

Figure 2.19. Locations for specimen measurement to evaluate mold consistency (inches). .21

Figure 2.20. Interfering feature in tensile specimen mold cavity.

Figure 2.21. Wet diamond saw used to trim and rip specimens.

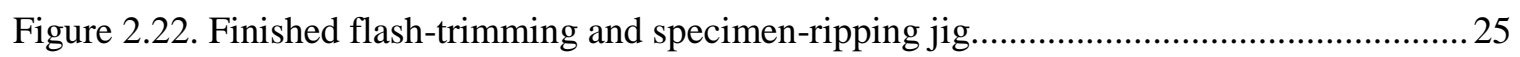

Figure 2.23. Flash-trimming jig clamped to the wet diamond saw with tensile specimen. .25

Figure 2.24. Trimming and ripping jig with alignment shims. .26

Figure 2.25. Instron test machine setup with National Instruments DAQ system. .27

Figure 2.26. Load-deflection curve for a 10-ply P35/Z03 tensile specimen. .28

Figure 2.27. Load curve for a 10-ply P35/Z03 tensile specimen loaded to failure. .29

Figure 2.28. "Brooming" failure mode experienced by a 10-ply P35/Z03 tensile specimen. 29

Figure 2.29. 15-ply P35/Z03 tab "brooming" failure from clamping in Instron grips. 30

Figure 2.30. Tensile specimens trimmed into 3-point bend specimens. .32

Figure 2.31. 3-point bend apparatus used to test specimens per ASTM D790. .32

Figure 2.32. Span of 3-point bend apparatus checked with calipers .33

Figure 2.33. Specimen placement in lower half of 3-point bend apparatus .33

Figure 2.34. 3-point bend apparatus set up on Instron load frame. .34

Figure 2.35. Typical load-displacement curve for 3-point bend test of P35/Z03 specimens .35

Figure 2.36. Microbuckling failure mode of 3-point bend specimens. .36

Figure 2.37. Complete fiber failure of 3-point bend specimens. 36 
Figure 2.38. Rheometry of TC250 resin system subjected to a 5F/min ramp [28].

Figure 2.39. Manufacturer recommended cure cycle for TC250 resin. .40

Figure 2.40. Cure temperatures and times for P35/Z03 cure cycles. 42

Figure 2.41. Projected cure temperatures and times for M46J/TC250 cure cycles. .42

Figure 2.42. Dam tape shutoffs for tab region of mold .43

Figure 2.43. Representative lot of M46J/TC250 unidirectional specimens. .44

Figure 2.44. M46J/TC250 3-point bend specimens prepared for ripping. .44

Figure 2.45. Representative tested M46J/TC250 3-point bend specimens. .46

Figure 2.46. Typical load-displacement curve for 3-point bend M46J/TC250 specimen .46

Figure 2.47. Typical load-displacement curve for short-beam shear M46J/TC250 specimen. .48

Figure 2.48. Autoclave specimens on caul plate, separated by dam tape. .52

Figure 2.49. Individual caul plates for each autoclave specimen. .52

Figure 2.50. Completed vacuum bag ready for vacuum fitting and autoclave cure. .53

Figure 2.51. Fully cured autoclave specimens and used bagging material. .54

Figure 3.1. Method \#1: sliding blade cutter used to cut transverse 0.25 in strips .59

Figure 3.2. Process for cutting 0.25 in squares using Method \#2 60

Figure 3.3. Resulting equipment and material from Method \#2. 61

Figure 3.4. Chopped prepreg preforms placed into mold cavity. 62

Figure 3.5. First compression molded chopped fiber parts .63

Figure 3.6. Preformed 0.25 in strips formed by Method \#3. .64

Figure 3.7. Machined 3-point bend specimen molds fixtured in a Haas VF-3. 66 
Figure 3.8. Finished mold cavity with ejector pin plate.

Figure 3.9. Common roughness parameters $R_{q}$ and $R_{a}$ [41].

Figure 3.10. Typical average roughness parameters for different machining processes [43]....... 70

Figure 3.11. Temperatures of top platen, bottom platen, and inside mold, with respect to time...71

Figure 3.12. Acrylic preform for 3-point bend specimen mold.

Figure 3.13. Filled preform with 3-point bend specimen mold cavity.

Figure 3.14. Resin leaking out of 3-point bend specimen mold upon pressure application.

Figure 3.15. Chopped fiber 3-point bend specimen ejected from mold cavity. .74

Figure 3.16. Chopped fiber 3-point bend specimen failure mode .76

Figure 3.17. Shear and moment diagrams for 3-point and 4-point bend testing [45]. .78

Figure 3.18. 4-point bend apparatus set up in Instron load frame .79

Figure 3.19. Typical chopped fiber specimen failure mode in 4-point bend. 80

Figure 3.20. Typical load displacement curve for chopped fiber specimen in 4-point bend. .80

Figure 3.21. Sandwich structure schematic with failure analysis locations. 82

Figure 3.22. 1-ply face sheet sandwich structure layup. .86

Figure 3.23. Complete fracture failure of sandwich specimen. .87

Figure 3.24. Delamination failure of sandwich specimen. 87

Figure 3.25. Tested sandwich specimens. .89

Figure 4.1. Example of a composite lug which has failed in net-tension [50] 90

Figure 4.2. Common failure modes for bolted composite joints [52]. 91

Figure 4.3. Final pin-loaded tensile specimen dimensions. 94 
Figure 4.4. Exploded view of 3-part lug mold.

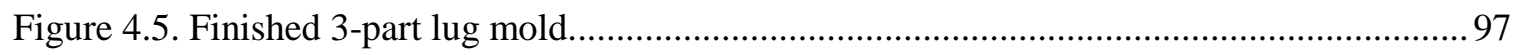

Figure 4.6. Required material for one pin-loaded tensile specimen. ......................................... 98

Figure 4.7. First face sheet placed into pin-loaded tensile specimen mold................................98

Figure 4.8. Demolding process for pin-loaded tensile specimens. ........................................... 99

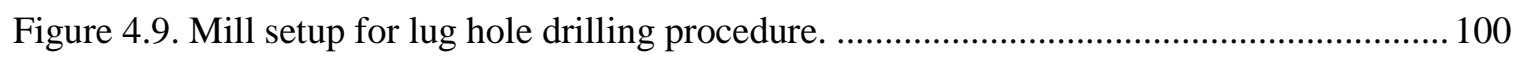

Figure 4.10. Test setup used to evaluate pin-loaded tensile specimens. ..................................... 101

Figure 4.11. Catastrophic cleavage and shear-out failure mode............................................ 102

Figure 4.12. Bearing failure mode caused by quasi-static loading. ......................................... 102

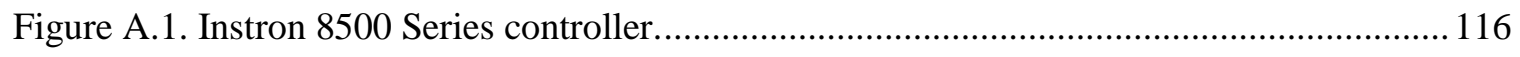

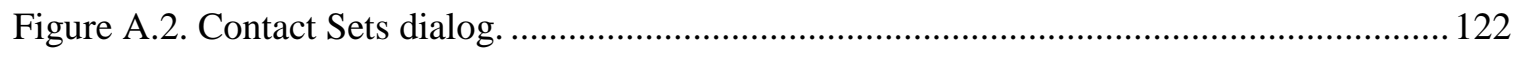

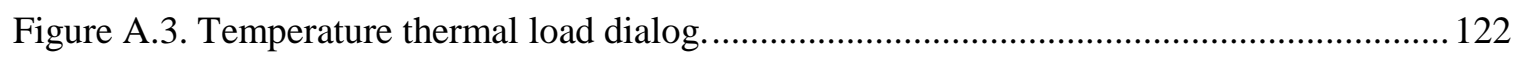

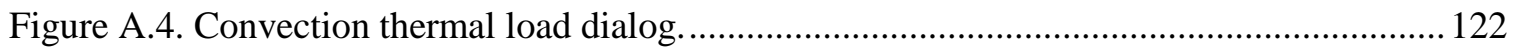

Figure A.5. Heat Power dialog box and heat power setup example. ....................................... 123

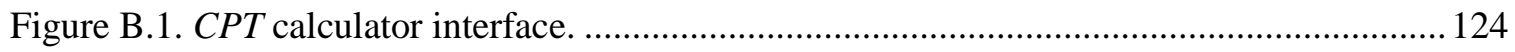

Figure E.1. 3-point bend data for P35/Z03: specimen lot \#1 .................................................. 152

Figure E.2. 3-point bend data for P35/Z03: specimen lot \#2 ................................................ 153

Figure E.3. 3-point bend data for P35/Z03: specimen lot \#3.................................................. 154

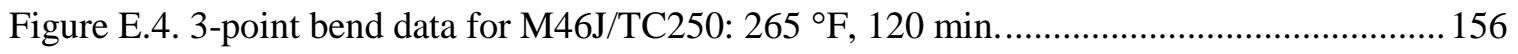

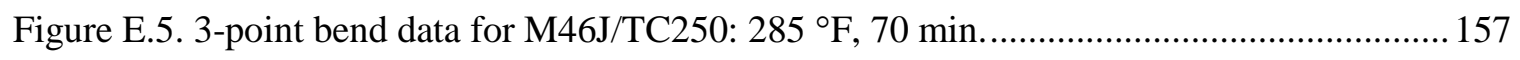

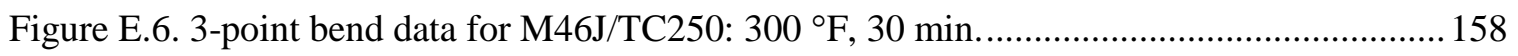


Figure E.7. 3-point bend data for M46J/TC250: $265^{\circ} \mathrm{F}, 60 \mathrm{~min}$. 159

Figure E.8. 3-point bend data for M46J/TC250: $285^{\circ} \mathrm{F}$, $35 \mathrm{~min}$. 160

Figure E.9. 3-point bend data for M46J/TC250: $300^{\circ} \mathrm{F}, 15 \mathrm{~min}$. 161

Figure E.10. Short-beam shear data for M46J/TC250: $265^{\circ} \mathrm{F}, 120 \mathrm{~min}, 10-\mathrm{ply}$. 162

Figure E.11. Short-beam shear data for M46J/TC250: $265^{\circ} \mathrm{F}, 120 \mathrm{~min}, 12-$ ply. 163

Figure E.12. Short-beam shear data for M46J/TC250: $285^{\circ} \mathrm{F}, 70 \mathrm{~min}, 10$-ply. 164

Figure E.13. Short-beam shear data for M46J/TC250: $285^{\circ} \mathrm{F}, 70 \mathrm{~min}, 12-$ ply. 165

Figure E.14. Short-beam shear data for M46J/TC250: $300^{\circ} \mathrm{F}, 30 \mathrm{~min}, 10$-ply. 166

Figure E.15. Short-beam shear data for M46J/TC250: $300^{\circ} \mathrm{F}, 30 \mathrm{~min}, 12-$ ply. 167

Figure E.16. Short-beam shear data for M46J/TC250: $265^{\circ} \mathrm{F}, 60 \mathrm{~min}, 10$-ply. 168

Figure E.17. Short-beam shear data for M46J/TC250: $265^{\circ} \mathrm{F}, 60 \mathrm{~min}, 12$-ply. 169

Figure E.18. Short-beam shear data for M46J/TC250: $285^{\circ} \mathrm{F}, 35$ min, 10-ply. 170

Figure E.19. Short-beam shear data for M46J/TC250: $285^{\circ} \mathrm{F}, 35$ min, 12-ply. 171

Figure E.20. Short-beam shear data for M46J/TC250: $300^{\circ} \mathrm{F}, 15$ min, 10-ply. 172

Figure E.21. Short-beam shear data for M46J/TC250: $300^{\circ} \mathrm{F}, 15$ min, 12-ply. 173

Figure E.22. 3-point bend data for M46J/TC250: autoclave, left side. 175

Figure E.23. 3-point bend data for M46J/TC250: autoclave, right side. 176

Figure E.24. Short-beam shear data for M46J/TC250: autoclave, left side, 10-ply 177

Figure E.25. Short-beam shear data for M46J/TC250: autoclave, left side, 12-ply 178

Figure E.26. Short-beam shear data for M46J/TC250: autoclave, right side, 10-ply. 179 
Figure E.27. Short-beam shear data for M46J/TC250: autoclave, right side, 12-ply. 180

Figure E.28. 3-point bend data for chopped M46J/TC250: $200 \mathrm{lbf}$ closing force, $0 \mathrm{~min}$ 181

Figure E.29. 3-point bend data for chopped M46J/TC250: $200 \mathrm{lbf}$ closing force, $2 \mathrm{~min}$. 182

Figure E.30. 3-point bend data for chopped M46J/TC250: $200 \mathrm{lbf}$ closing force, $4 \mathrm{~min}$ 183

Figure E.31. 3-point bend data for chopped M46J/TC250: $4000 \mathrm{lbf}$ closing force, $0 \mathrm{~min}$. 184

Figure E.32. 3-point bend data for continuous M46J/TC250: 10-ply. 185

Figure E.33. 3-point bend data for continuous M46J/TC250: 12-ply. 186

Figure E.34. 3-point bend data for continuous M46J/TC250: 14-ply. 187

Figure E.35. 4-point bend data for chopped M46J/TC250: $200 \mathrm{lbf}$ closing force, $1 \mathrm{~min}$. 188

Figure E.36. 4-point bend data for chopped M46J/TC250: $200 \mathrm{lbf}$ closing force, $2 \mathrm{~min}$. 189

Figure E.37. 4-point bend data for chopped M46J/TC250: $200 \mathrm{lbf}$ closing force, $3 \mathrm{~min}$. 190

Figure E.38. 4-point bend data for chopped M46J/TC250: $200 \mathrm{lbf}$ closing force, $4 \mathrm{~min}$. 191

Figure E.39. 4-point bend data for M46J/TC250 sandwich: 1-ply face sheets. 192

Figure E.40. 4-point bend data for M46J/TC250 sandwich: 2-ply face sheets 193

Figure E.41. 4-point bend data for M46J/TC250 sandwich: 3-ply face sheets. 194

Figure E.42. Force-displacement data for Lug \#1. 195

Figure E.43. Force-displacement data for Lug \#2. 196

Figure E.44. Force-displacement data for Lug \#3. 197

Figure E.45. Force-displacement data for Lug \#4. 198

Figure E.46. Force-displacement data for Lug \#5. 199 


\section{Chapter 1. Introduction}

A composite material is generally defined as a material consisting of two or more distinct materials with different physical properties [1]. A structural composite, like carbon fiber, is a composite which is designed to have mechanical performance and properties which are superior to those of the constituent materials acting alone [2]. A fiber composite material is characterized by the concentration of its fiber and matrix components in terms of volume or weight percent [1].

Carbon fiber prepreg is a composite material which consists of a thermoset resin matrix reinforced with strong carbon fibers. A common form of prepreg carbon fiber is continuous unidirectional prepreg, in which the reinforcement fibers are oriented in one direction and preimpregnated with a certain percentage of thermoset resin.

Unidirectional composites are exceptionally strong in the fiber direction, while matrix properties dominate the transverse strength and stiffness characteristics of the material. Due to its highly anisotropic properties, it is common convention to define a coordinate system a unidirectional prepreg relative to its fiber direction. A cross section of a unidirectional carbon fiber prepreg and its coordinate system definition is shown schematically in Figure 1.1.

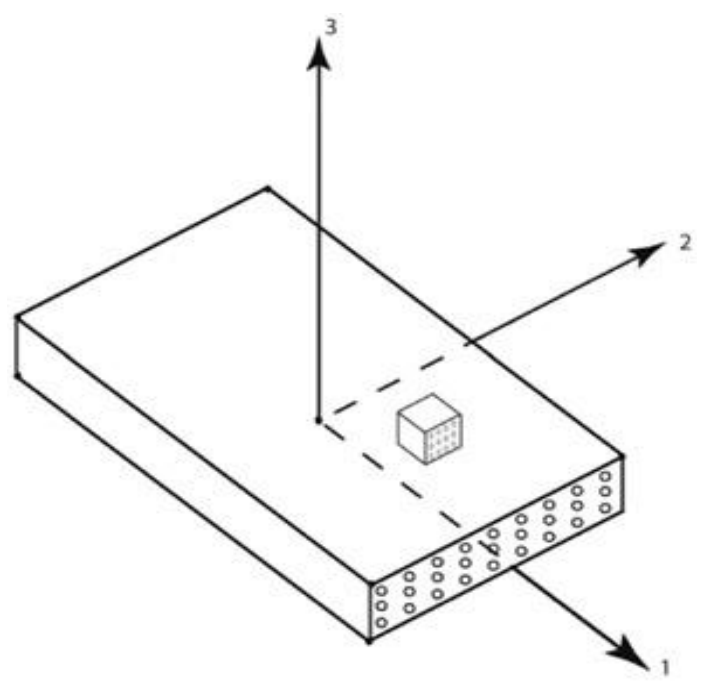

Figure 1.1. Cross section and coordinate system of a unidirectional fiber composite [3]. 
In component design and manufacture, the high directional strength of a unidirectional composite can be oriented in the direction of loading to reinforce the component. Plies of prepreg material are stacked in a specific pattern to create a component with highly tuned mechanical properties. The component is then cured into its final shape with the application of heat and pressure. As the part is heated, the viscosity of the resin initially decreases and the pressure exerted on the part causes the resin to flow to fill any gaps between the fibers. Then, as it is heated further, the thermoset resin begins to crosslink and cure into a hard, final shape. In order to achieve directional mechanical properties, complex shapes are often cut from a continuous roll of material. The scrap from these cutouts is often discarded, producing up to $50 \%$ waste.

Another common form of carbon fiber composite is chopped fiber prepreg. This may come in the form of a sheet molding compound (SMC), which is made of chopped fibers sandwiched by sheet resin, or bulk molding compound (BMC) which is made of unidirectional prepreg that has been chopped into prepreg fibers of a specific length [4]. Chopped prepreg offers a much lower strength than continuous composites, but is highly formable and has superior machinability compared to its continuous counterpart [4]. It also exhibits in-plane isotropic behavior [5] which is much simpler to determine experimentally and to characterize for modeling purposes. SMC and BMC manufactured by Quantum Composites are shown in Figure 1.2.
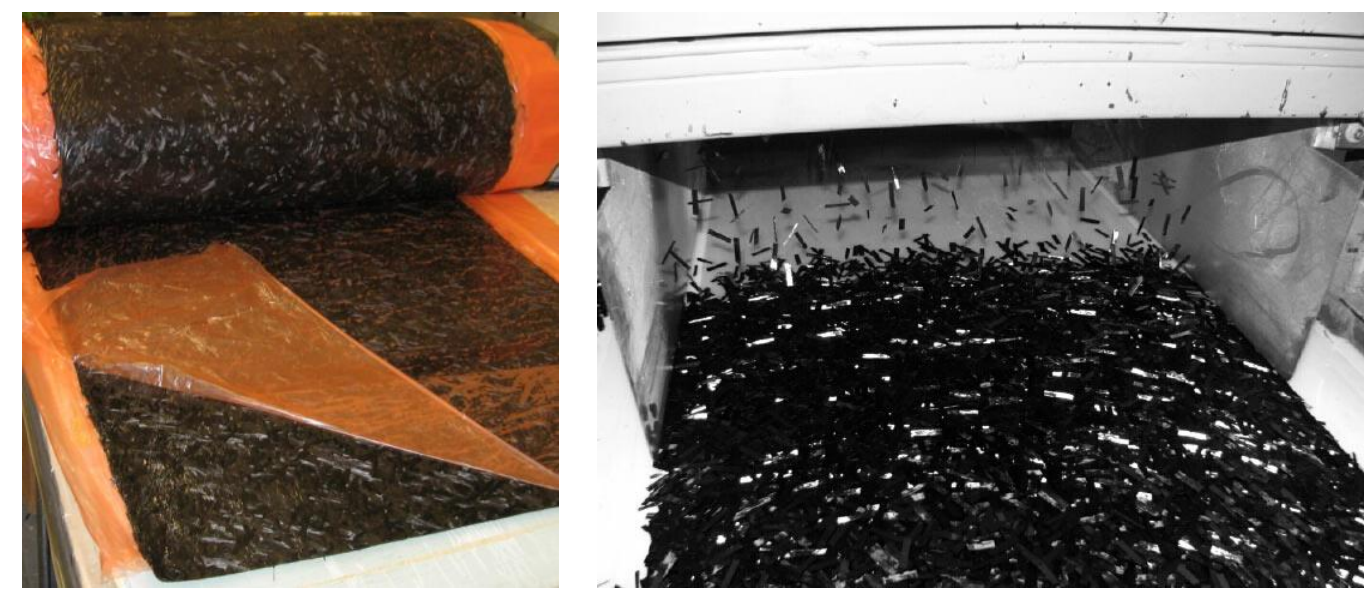

Figure 1.2. SMC (left) and BMC (right) material forms used for compression molding [6]. 
Compression molding is a matched mold manufacturing process in which heated molds are used to apply pressure to a charge of material in order to form the material. In the case of compression molding thermoset epoxy resin, the heated molds also serve to cure the resin. Compression molding of composite materials has been used in industry since the 1940's [7] due to its suitability for high volume production, repeatability, and, more recently, production of superior surface finish [8]. When paired with a chopped fiber form such as SMC or BMC, compression molding is a short cycle time, low-waste production method, unlike continuous fiber manufacture. The compression molding process is shown schematically in Figure 1.3.

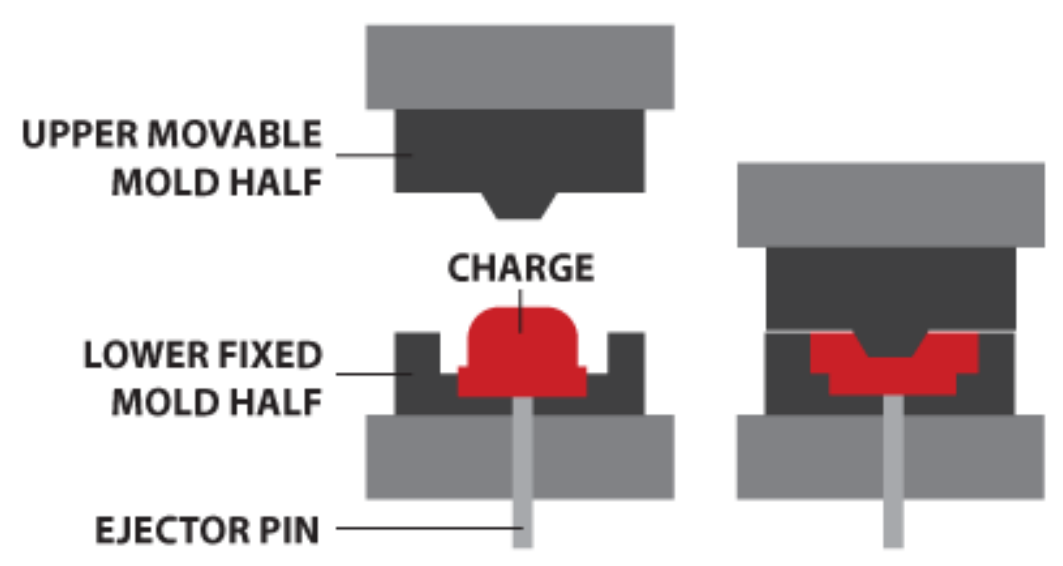

Figure 1.3. Compression molding process [9].

Continuous and chopped fiber prepregs each have distinct advantages and disadvantages which can be used to tailor the characteristics of a component design. A component which required high directional strength and stiffness may be manufactured using continuous fiber prepregs, but the resulting product may produce a large amount of waste and may not respond well to any necessary machining. If chopped fiber was manufactured from the scraps and incorporated into the machined features of the component, waste would be minimized and the component would be optimized for both strength and manufacturability. 
The motivation for this project was to convert the waste produced by prepreg manufacture into usable material in the compression molding process. The scrap left over after cutting out the desired plies could be cut into chopped fibers and used later in another part or it may be used in an area of the part which requires secondary machining or complex geometry. This project strove to develop a process by which to create usable chopped fiber from leftover prepreg scrap which could be integrated into a component design which was functionally graded to meet mechanical, geometric, and machining requirements. This process would result in much higher net material utilization and more highly tuned component characteristics. The compression molding manufacturing method was selected to best take advantage of the molding capabilities of chopped fiber as well as to develop a new process for the ME composites lab which had a much lower cycle time than the traditionally employed autoclave manufacturing method.

The herein presented thesis project was principally experimental in nature. Thus, the events and findings of this project are presented chronologically. 


\section{Chapter 2. Unidirectional Fiber Characterization}

In order to best understand the compression molding manufacturing method, the process was first developed for the more familiar material form of unidirectional prepreg tape in preparation for the compression molding of a hybrid continuous and chopped fiber component. The recent addition of a heated laboratory press to the Cal Poly ME composites lab and a recently finished compression mold manufacturing project provided the means by which to compression mold composite test specimens.

The first material considered for eventual manufacture into a functionally graded component was $\mathrm{P} 35 / \mathrm{Z} 03$, a carbon fiber composite. With this material, processes were developed for manufacturing the charges for compression molding, determining the amount of material required to fill the molds, and trimming the specimens to their final dimensions. During this phase of development, it was also discovered that the tensile specimens originally created by the mold would not function and mechanical testing was instead performed in 3-point bending.

When the P35/Z03 proved to be incompatible with the developed compression molding process, M46J/TC250 carbon fiber composite was manufactured and tested using the processes developed for the P35/Z03 material. Limited cure cycle data led to the experimental determination of a truncated cure cycle for the TC250 resin system. This cure cycle served as a starting point for the chopped fiber experimentation described in 0 .

\subsection{Compression Molding Apparatus}

The first step in designing a functionally graded compression molded component was to develop the compression molding process for the Cal Poly ME composites laboratory. While a press was present in the lab, molds and procedures had yet to be developed for its use. These were developed concurrently with test specimens to expand the lab's compression molding capability. 


\subsubsection{Carver Laboratory Press}

A Carver heated laboratory press (Model C) was donated by Quatro Composites for use in Cal Poly's ME composites lab. The press is shown in Figure 2.1.

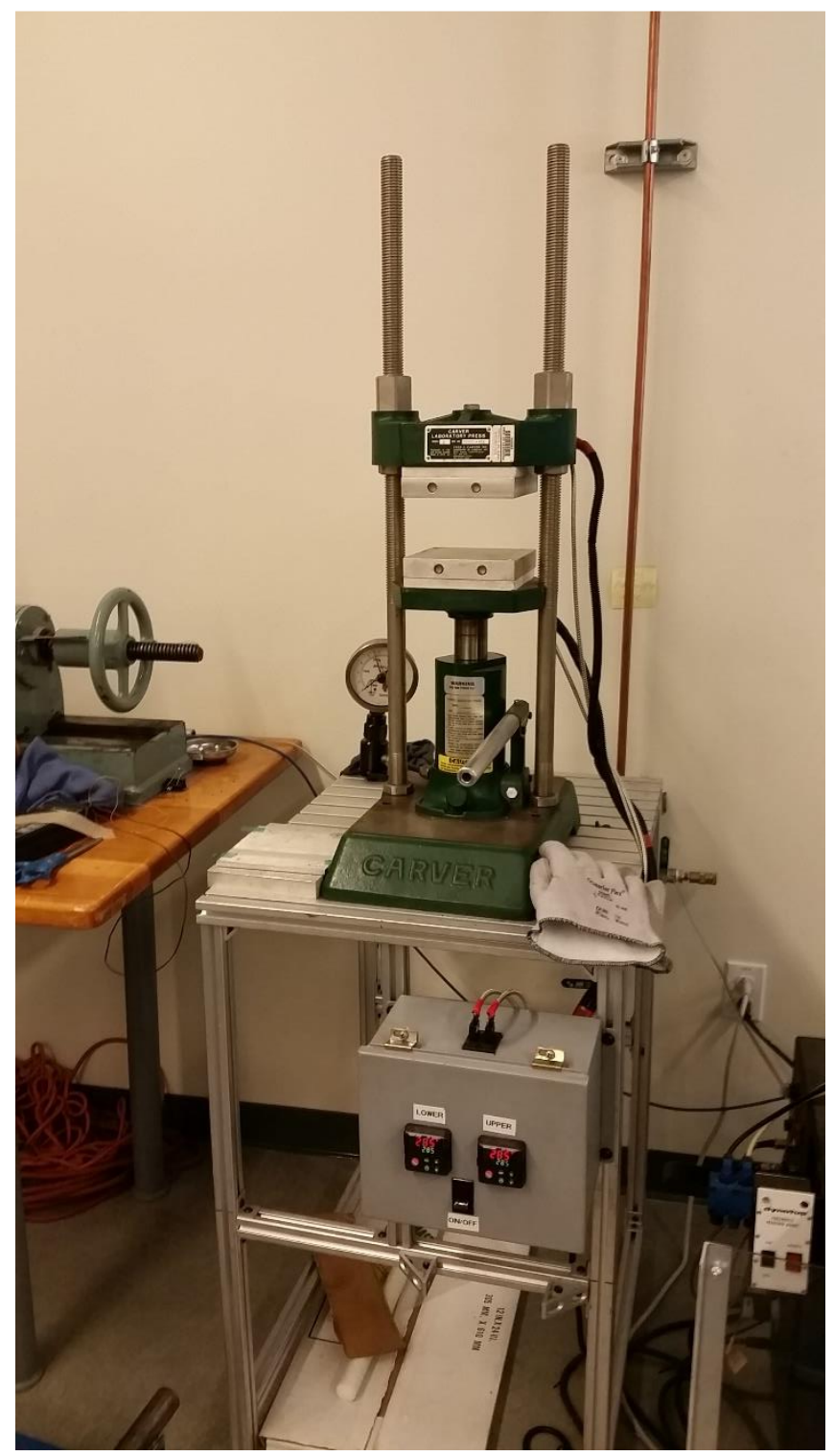

Figure 2.1. Carver press setup used for compression molding.

The press has 6 in $x 6$ in platens heated by two $700 \mathrm{~W}$ heating elements, each, with a maximum temperature of $650{ }^{\circ} \mathrm{F}$. The temperature of each platen is monitored with a J-type thermocouple embedded in the center of the platen which feeds into a control unit with a digital display. The 
press is capable of exerting 12 tons of force between the heated platens via a hand-operated hydraulic unit with a 5.125 in stroke. The daylight opening is adjustable from 0 in to $15 \mathrm{in}$. Pressure is measured with an analog pressure gage in increments of $200 \mathrm{lb}$ [10].

\subsubsection{Press Safety}

The Carver press presents a number of safety hazards which can be easily avoided with the proper personal protective equipment (PPE) and usage policies. First, it is the policy of the Cal Poly ME composites lab to always wear safety glasses when using experimental equipment. Therefore, safety glasses were worn at all times while using the press.

The heated platens of the press, as well as any material heated by the platens, present a thermal hazard. A set of thermally insulated gloves were purchased to allow handling of hot molds. To prevent any injury to other lab users, a "Caution, Hot!" sign was attached to the press whenever it was heating up, actively being used, or cooling down.

The control system of the press presents an electrical hazard. However, the electrical connections for the press are contained inside of the gray control box shown in Figure 2.1. The press was unplugged anytime the electrical box was accessed.

\subsubsection{Tensile Specimen Mold Design and Manufacture}

The first mold for this project was designed and manufactured by Karlos Guzman. The following is a summary of the process which Karlos undertook to create the mold. The design process is documented in greater detail in his own report on mold design [11].

The mold was designed to make two tensile test specimens and two short beam shear specimens. Both sets of parts were designed as well as possible within the dimensions of the press platens. Designs were based on their respective ASTM testing standards: D3039 for tensile properties of 
polymer matrix composite materials [12] and D2344 for short-beam strength of polymer matrix composite materials [13]. For these experiments, only the cavity for the tensile specimen was used. The dimensions for the tensile specimen are shown in Figure 2.2.
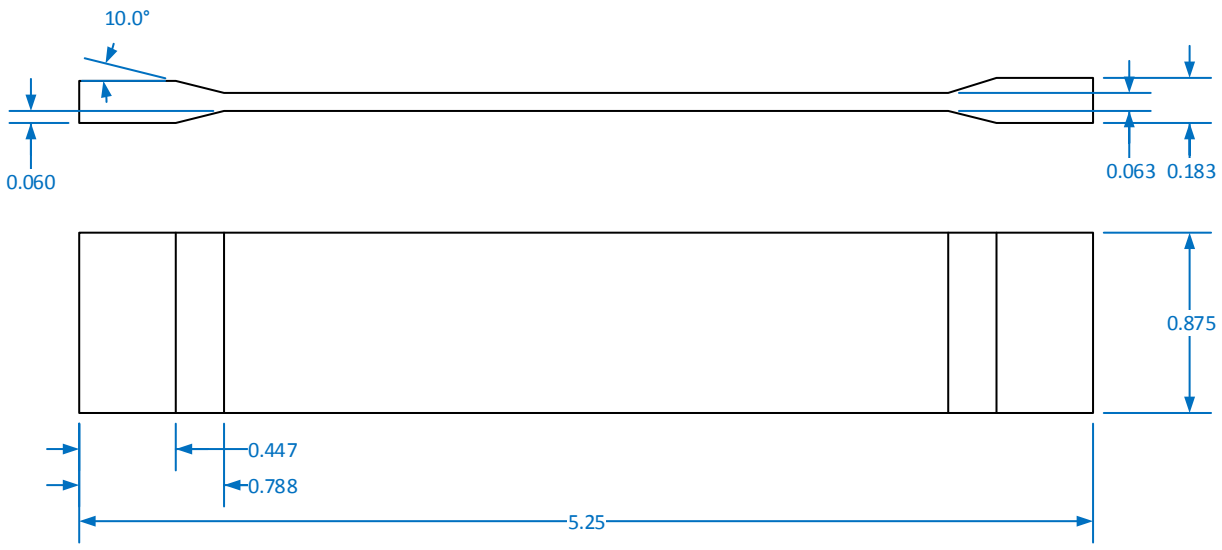

NOT TO SCALE

Figure 2.2. Tensile test specimen dimensions (inches).

With the parts selected, they were designed using SolidWorks 3D modeling software. The modeled part is shown in Figure 2.3. The mold features included in the SolidWorks software provided the tools necessary to complete the mold design.

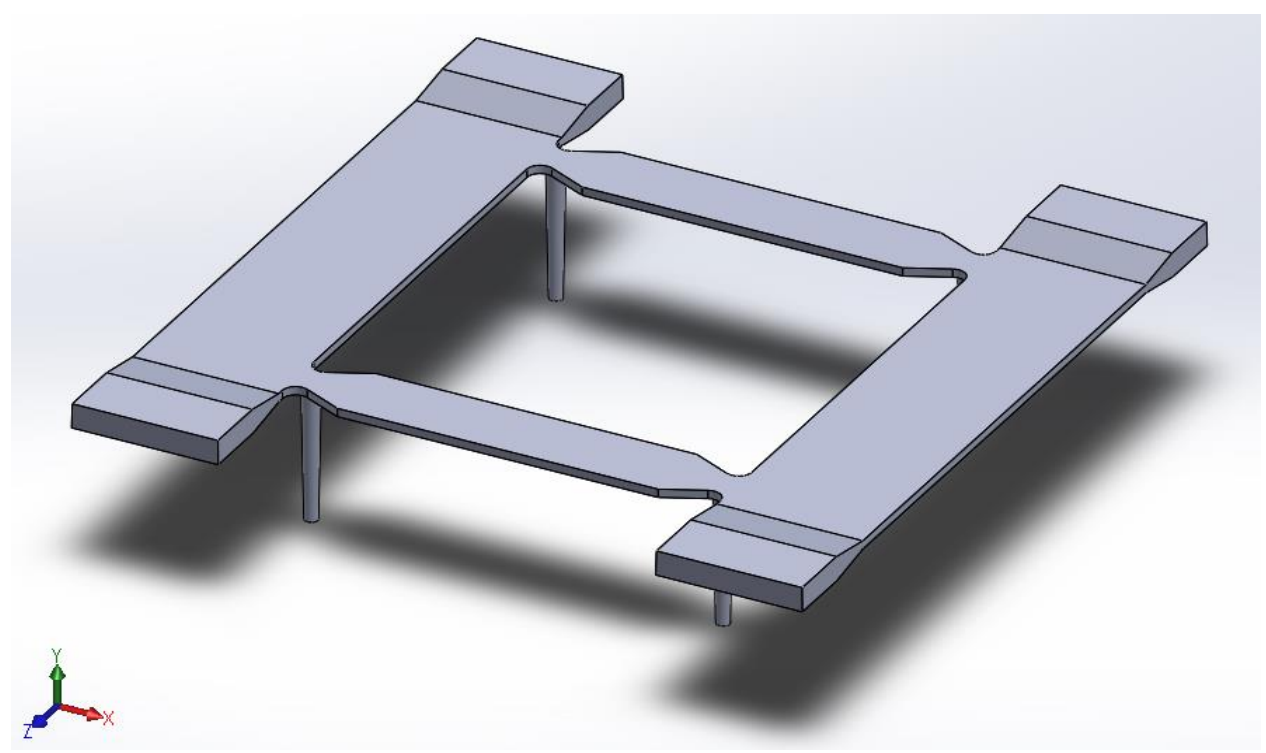

Figure 2.3. Original test specimens as designed with coordinate axes. 
First, a draft angle of $1^{\circ}$ was added to the edges of the molded part to facilitate mold opening and closing and the removal of the parts from the mold. Then the part was scaled for the expansion and contraction of the molding material using the longitudinal and transverse coefficients of thermal expansion for the composite material as well as its bulking factor. The scale factors were assigned based on the fiber direction in the tensile specimens. The factors are shown in Table 2.1.

Table 2.1. Model scale factors to account for thermal expansion of P35/Z03.

\begin{tabular}{|c|c|c|}
\hline Model Axis & Material Direction & Scale Factor \\
\hline $\mathrm{Z}$ & 1 & 0.99991 \\
\hline $\mathrm{X}$ & 2 & 1.00270 \\
\hline $\mathrm{Y}$ & 3 & 1.10000 \\
\hline
\end{tabular}

A parting line was chosen from the designed part and a shutoff plane was constructed around the perimeter of the part. The parting line and shutoff plane provided the dividing surface for the mold halves. The final exploded view of the mold halves and parts being molded, including ejector pins, is shown in Figure 2.4.

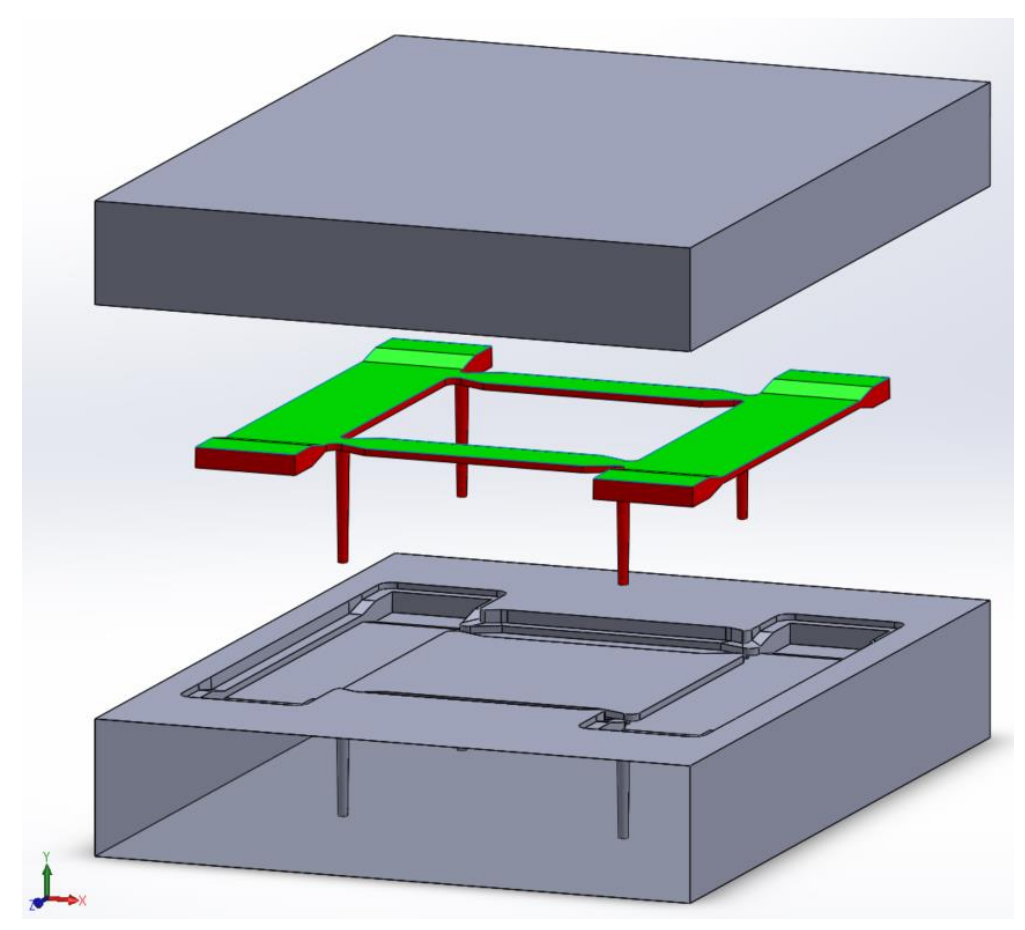

Figure 2.4. Exploded view of mold halves and parts being molded with draft angle check. 
The mold design was updated for manufacturability and G-code was generated for the halves using the HSMWorks computer-aided manufacture (CAM) integrated software for SolidWorks. Then the mold halves were machined from 6061 aluminum stock in a Haas VF-3 vertical machining center in the Mustang ' 60 machine shop. The cavity is shown mid-process in Figure 2.5. The finished mold halves are shown in Figure 2.6.

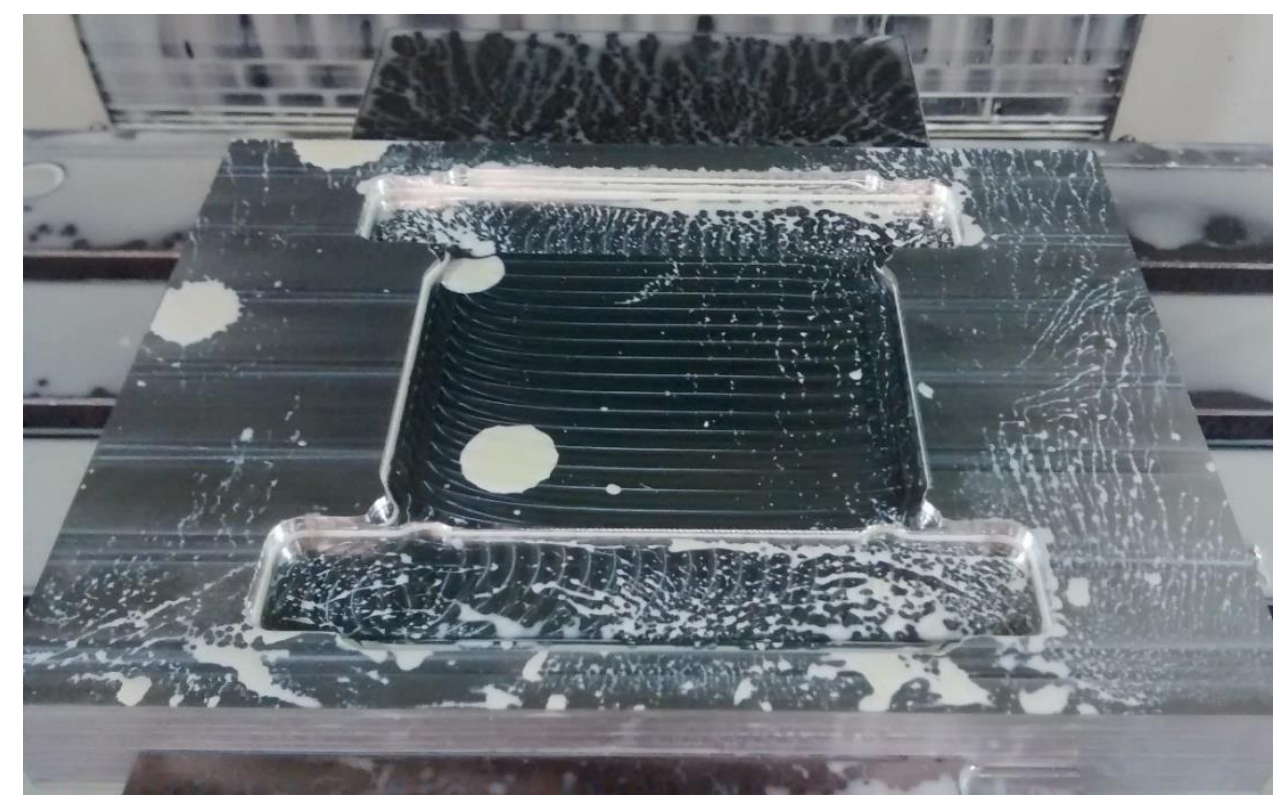

Figure 2.5. Mold cavity during machining process in Haas VF-3.

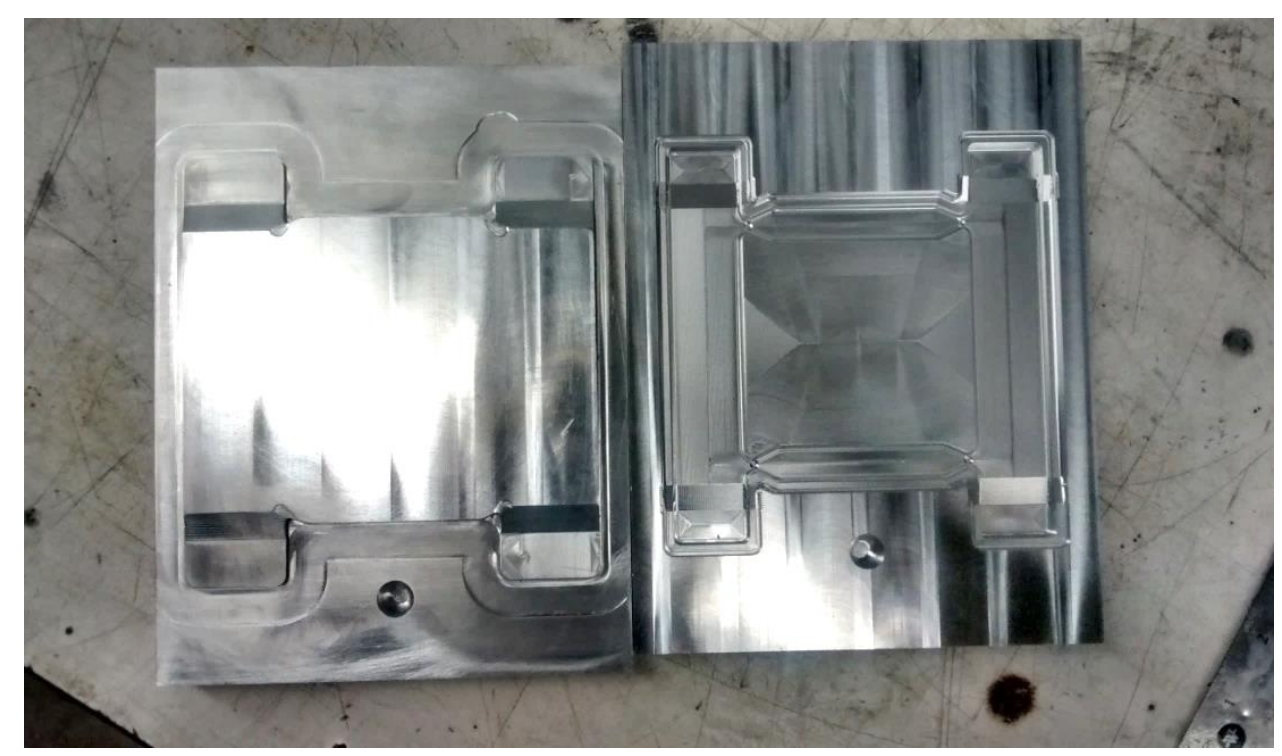

Figure 2.6. Finished mold halves. 


\subsubsection{Seasoning the Mold}

To prevent the molded parts from sticking in the mold after compression, the mold was seasoned to seal the pores in the aluminum. A process developed by Quatro Composites was used to season and seal the molds [14]. The chemicals used to seal the mold are Mavcoat 527 ML, Frekote 700 NC, and Axel F-57NC. In accordance with suggestions from the material safety data sheets (MSDSs) for all three materials [15] [16] [17], mold seasoning was done in a fume hood with safety glasses and nitrile gloves, as shown in Figure 2.7. The procedure for seasoning the molds is detailed in Appendix A.2.

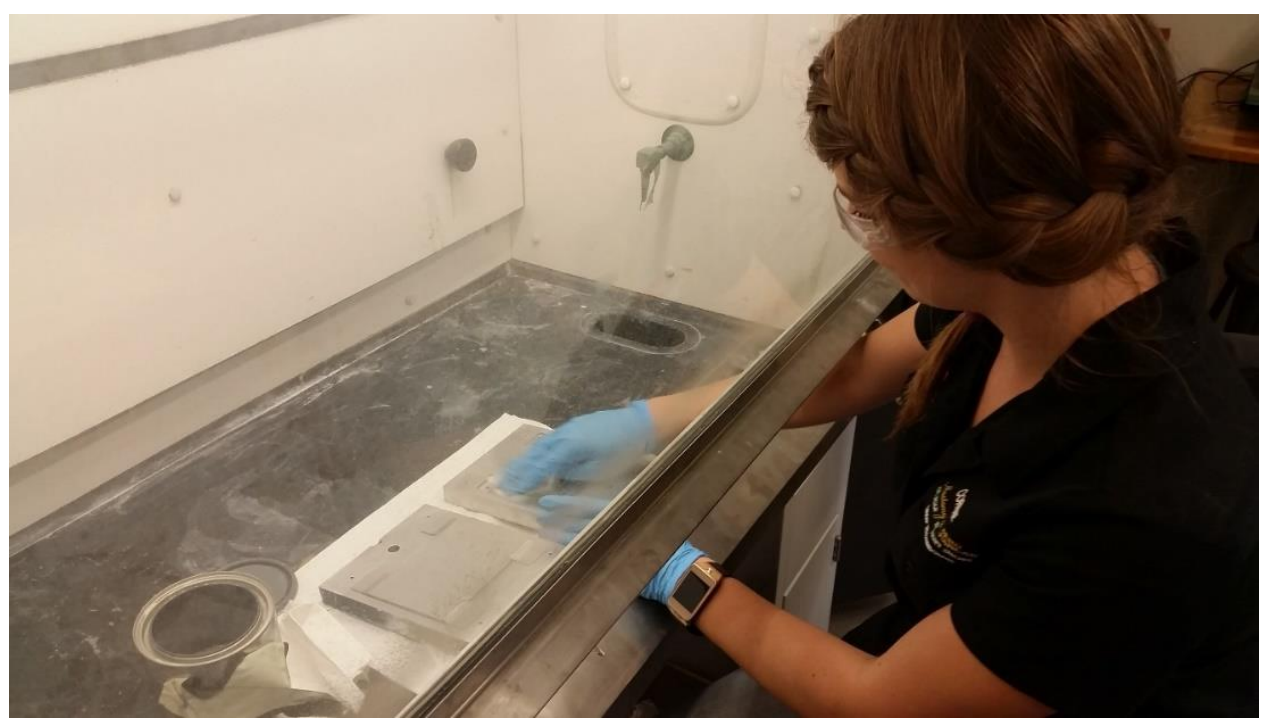

Figure 2.7. Mold seasoning procedure being performed in fume hood.

Sealing the molds in this way lasts at least 20 pulls. A higher cure temperature requires reseasoning of the mold. For the purposes of this project, the mold was seasoned multiple times. However, once a maximum cure temperature of $300^{\circ} \mathrm{F}$ was established, the mold was seasoned to $325^{\circ} \mathrm{F}$. This seasoning was used for the remaining pulls. 


\section{2. $\mathrm{P35} / \mathrm{Z03}$ Material}

The original material selected for molding was a unidirectional composite made from Panex P35 fiber and Zoltek Z03 resin, both manufactured by Zoltek Carbon Fiber. P35/Z03 was used in the lab experiments for Cal Poly's composites class lab and was therefore a familiar material system with existing experimental data. The material characteristics provided by the manufacturer are shown in Table 2.2 [18]. It should be noted that the material used for this study was well past its expiration date and therefore may not reflect the characteristics of newer material.

Table 2.2. P35/Z03 prepreg characteristics.

\begin{tabular}{|c|c|c|}
\hline Property & Value & Units \\
\hline Fiber Areal Weight (FAW) & 150 & $\mathrm{~g} / \mathrm{m}^{2}$ \\
\hline Fiber Density & 1.81 & $\mathrm{~g} / \mathrm{cm}^{3}$ \\
\hline Prepreg Density & 1.54 & $\mathrm{~g} / \mathrm{cm}^{3}$ \\
\hline Fiber Content (by volume) & $65 \%$ & --- \\
\hline
\end{tabular}

$\mathrm{P} 35 / \mathrm{Z} 03$ has a minimum viscosity of approximately $10 \mathrm{~Pa} \cdot \mathrm{s}$, similar to that of honey [19], as shown in Figure 2.8 .

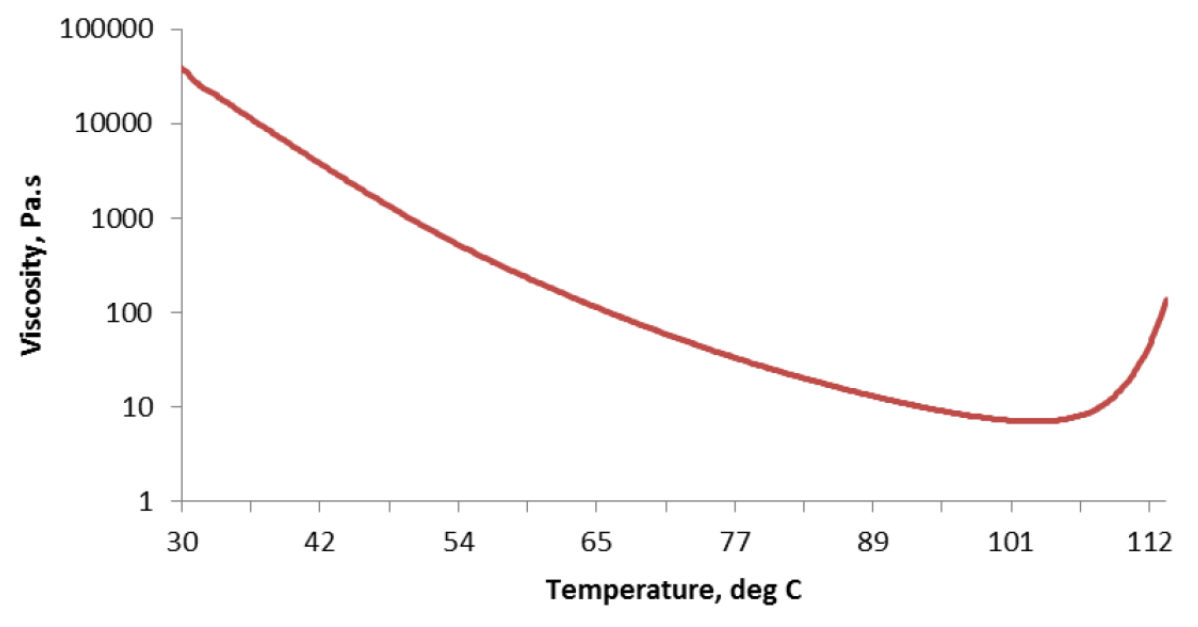

Figure 2.8. Viscosity profile of P35/Z03 [18]. 
The P35/Z03 material was also chosen due to its flexible cure cycle. According to the material manufacturer, the resin reaches $95 \%$ cure after 50 minutes at $270{ }^{\circ} \mathrm{F}$ or after 20 minutes at $300^{\circ} \mathrm{F}$ under only vacuum bag pressure [18]. It was recommended by the material donor, Quatro Composites that 1 hour at $250{ }^{\circ} \mathrm{F}$ or 30 minutes at $270{ }^{\circ} \mathrm{F}$ would fully cure the material if $70-120$ psi was applied to the part during cure [20].

\subsubsection{Number of Plies}

As previously mentioned in Section 2.1.3, the mold was originally designed for a 10-ply layup based on the measured thickness of the uncured material (0.007 in). The measured ply thickness was also used to calculate the dimensions of each ply in the end tabs by calculating the length of the tab at the depth of each ply. A schematic of the ply geometry is shown in Figure 2.9.

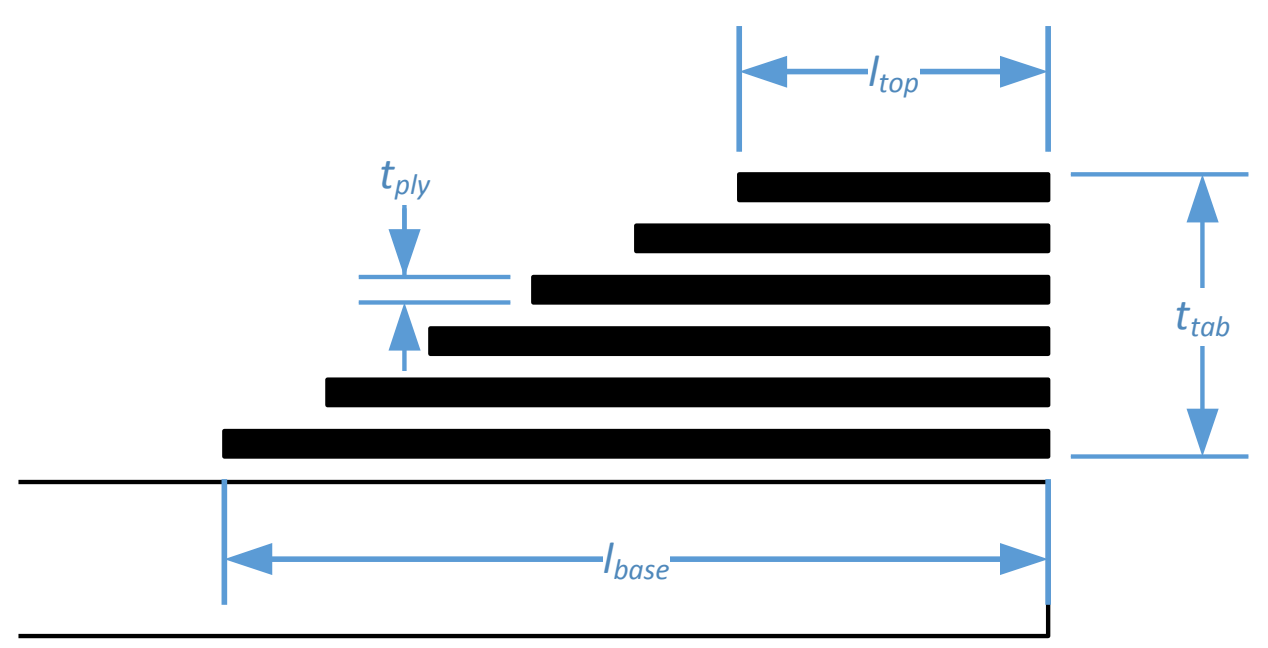

Figure 2.9. Schematic of tensile specimen tab layup.

The number of plies required for one tab was calculated by dividing the total thickness of the tab by the thickness of each ply.

$$
N_{\text {plies }}=\frac{t_{t a b}}{t_{p l y}}
$$


Then, the difference in length between adjacent plies was calculated using the slope of the linear interpolation between the starting and ending lengths of the tab.

$$
\Delta l_{\text {ply }}=\frac{\left(l_{\text {base }}-l_{\text {top }}\right)}{N_{\text {plies }}}
$$

The values used in these calculations are shown in Table 2.3. Tabulated ply length values, rounded to caliper precision, are shown in Table 2.4. These dimensions were used to construct the tabs for each manufactured tensile specimen.

Table 2.3. Tab dimensions used to calculate ply lengths.

\begin{tabular}{|c|c|c|c|c|c|}
\hline Parameter & Value & Units & Parameter & Value & Units \\
\hline $\mathrm{t}_{\text {ply }}$ & 0.007 & in & $1_{\text {base }}$ & 0.4470 & in \\
\hline $\mathrm{t}_{\text {tab }}$ & 0.060 & in & $1_{\text {top }}$ & 0.7875 & in \\
\hline $\mathrm{N}_{\text {plies }}$ & 9 & & $\Delta 1_{\text {ply }}$ & 0.0397 & in \\
\hline
\end{tabular}

Table 2.4. Ply lengths calculated for $\mathrm{t}_{\mathrm{ply}}=0.007 "$.

\begin{tabular}{|c|c|c|c|}
\hline Ply No. & y-position & Length & Units \\
\hline 1 & 0.060 & 0.467 & in \\
\hline 2 & 0.053 & 0.507 & in \\
\hline 3 & 0.046 & 0.546 & in \\
\hline 4 & 0.039 & 0.586 & in \\
\hline 5 & 0.032 & 0.626 & in \\
\hline 6 & 0.025 & 0.665 & in \\
\hline 7 & 0.018 & 0.705 & in \\
\hline 8 & 0.011 & 0.745 & in \\
\hline 9 & 0.004 & 0.788 & \\
\hline
\end{tabular}

\subsubsection{Charge Layup and Initial Parts}

Before molding, the charge for each specimen was cut out of the raw material and laid up. The P35/Z03 material came in a 24-inch wide roll of unidirectional fiber. One 7-inch strip of material cut from the roll was enough material to make two tensile specimens. The plies for one tensile specimen are shown in Figure 2.10. 


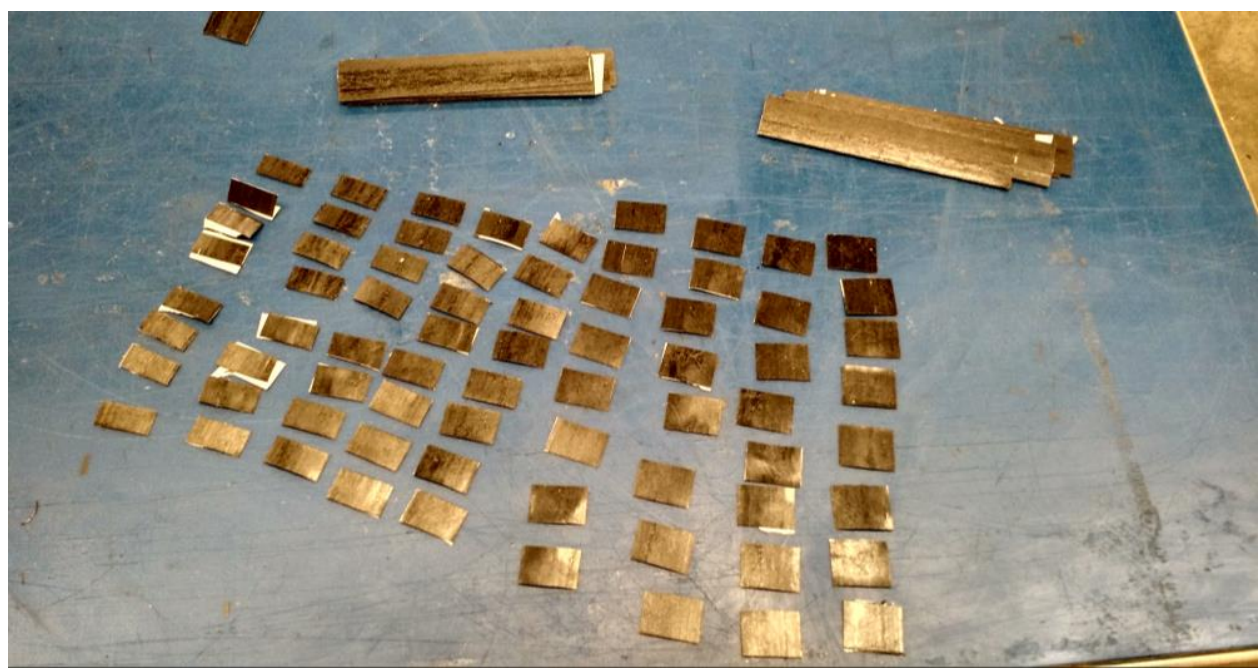

Figure 2.10. Plies for two tensile specimens and tabs.

First, the tabs were laid up then placed into the treated mold, as shown in Figure 2.11. Then the body of the test specimen was placed into the mold over the first tabs, as shown in Figure 2.12 and the second round of tabs were set into place (Figure 2.13). The tab layups were varied to test which method would produce the best lamination between the layers of the tabs. Due to the fillets in the corners of the parts, which were required to make the mold halves machinable, the corners of the material were trimmed to fit into the cavity. Finally, the alignment pins were set into place, and the mold core was placed over the mold cavity (Figure 2.14).

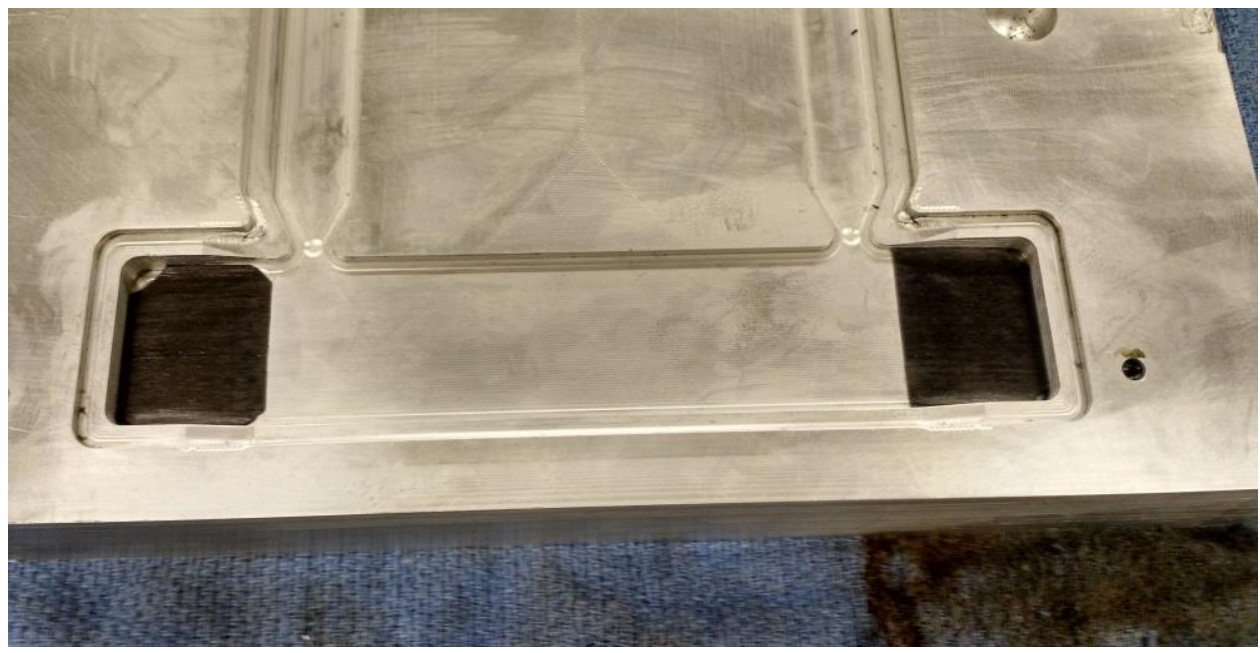

Figure 2.11. Lower tabs in place in the mold cavity for tensile specimens. 


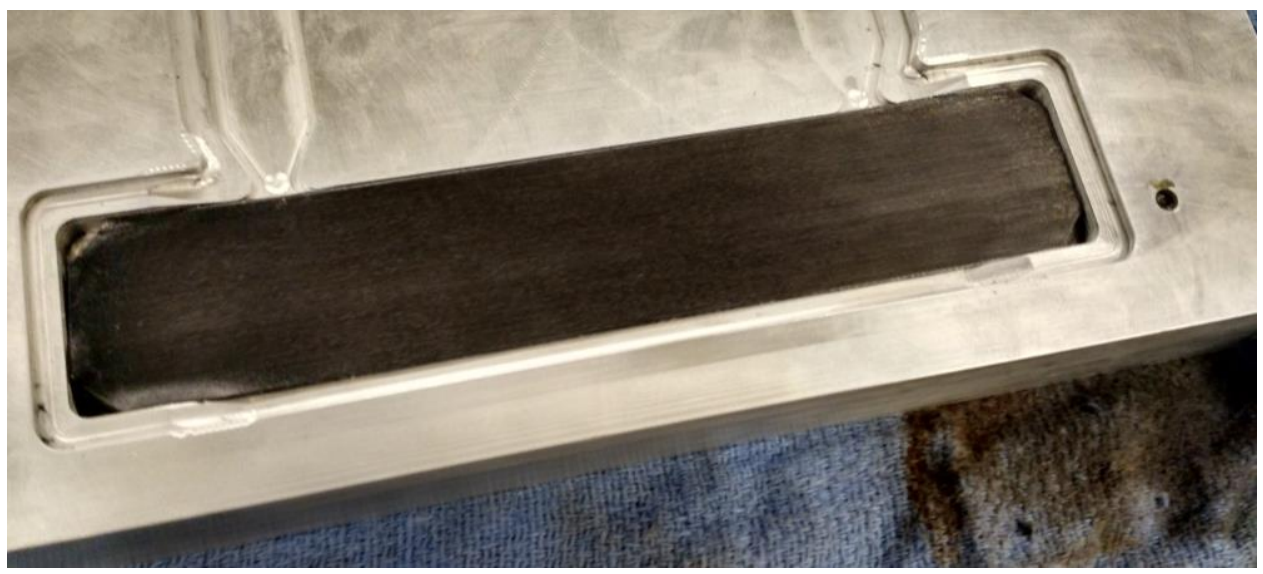

Figure 2.12. Tensile specimen body in place in mold cavity.

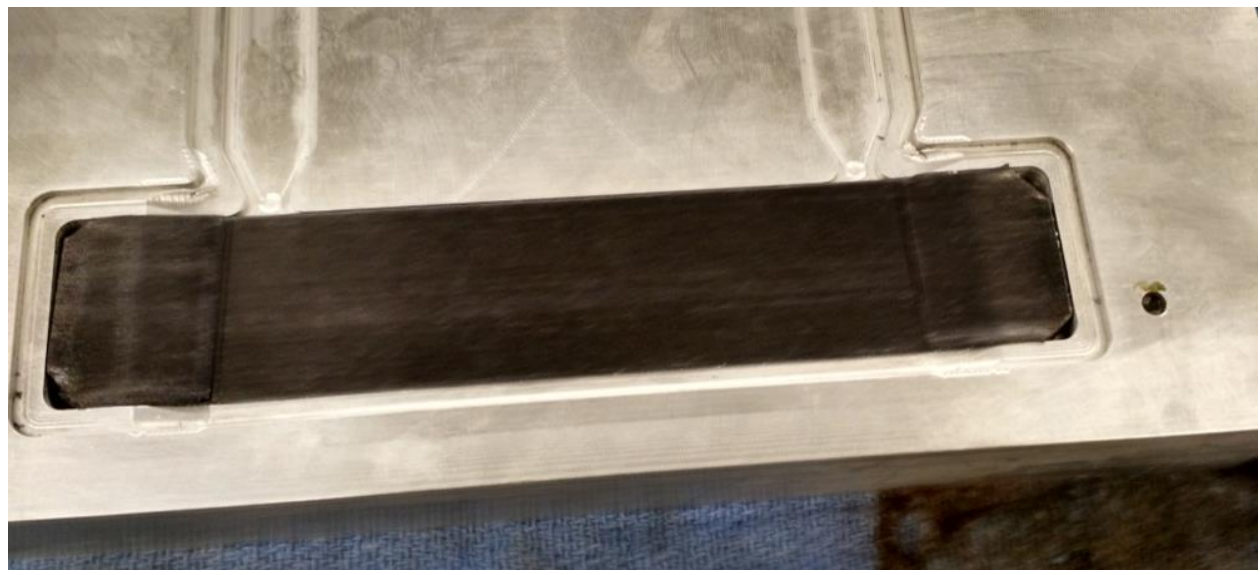

Figure 2.13. Upper tabs in place in the mold cavity for tensile specimens.

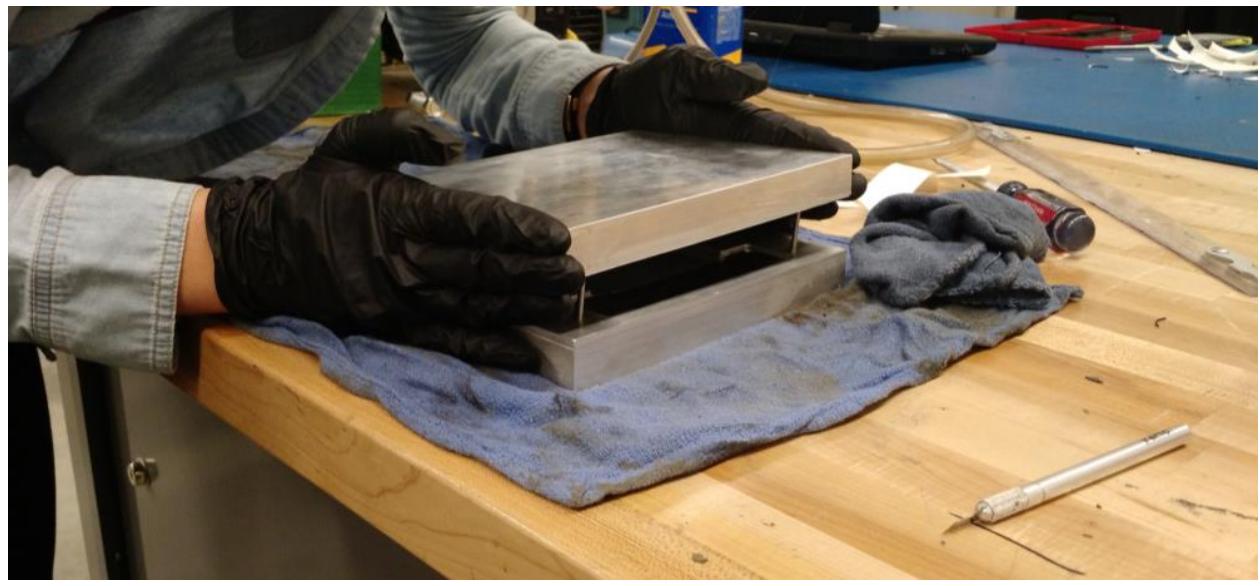

Figure 2.14. Mold core being placed onto mold cavity using alignment pins. 
For the first three lots of parts, the 1 -hour $250{ }^{\circ} \mathrm{F}$ cure was selected to ensure that the parts would cure fully and to ensure that the press would hold the mold at the cure temperature for the entire cure. The press was preheated to $250^{\circ} \mathrm{F}$, then the mold was placed into the press and $70 \mathrm{psi}$ (1.2 tons of force over the 6 in $x 6$ in mold surface) was applied. The press took approximately 8 minutes to heat back up to cure temperature. Once the temperature stabilized, the 1-hour timer for the cure was started. At the end of the cycle, the mold was removed from the press with thermally insulated gloves and allowed to cool slightly before prying the mold halves apart and removing the cured tensile specimens.

As mentioned in Section 2.1.3, the mold was designed for a 10-ply part by measuring the uncured ply thickness of the P35/Z03 material. However, the 10-ply parts appeared uncompacted upon removal and no resin was pressed out of the material. The first parts are shown in Figure 2.15.

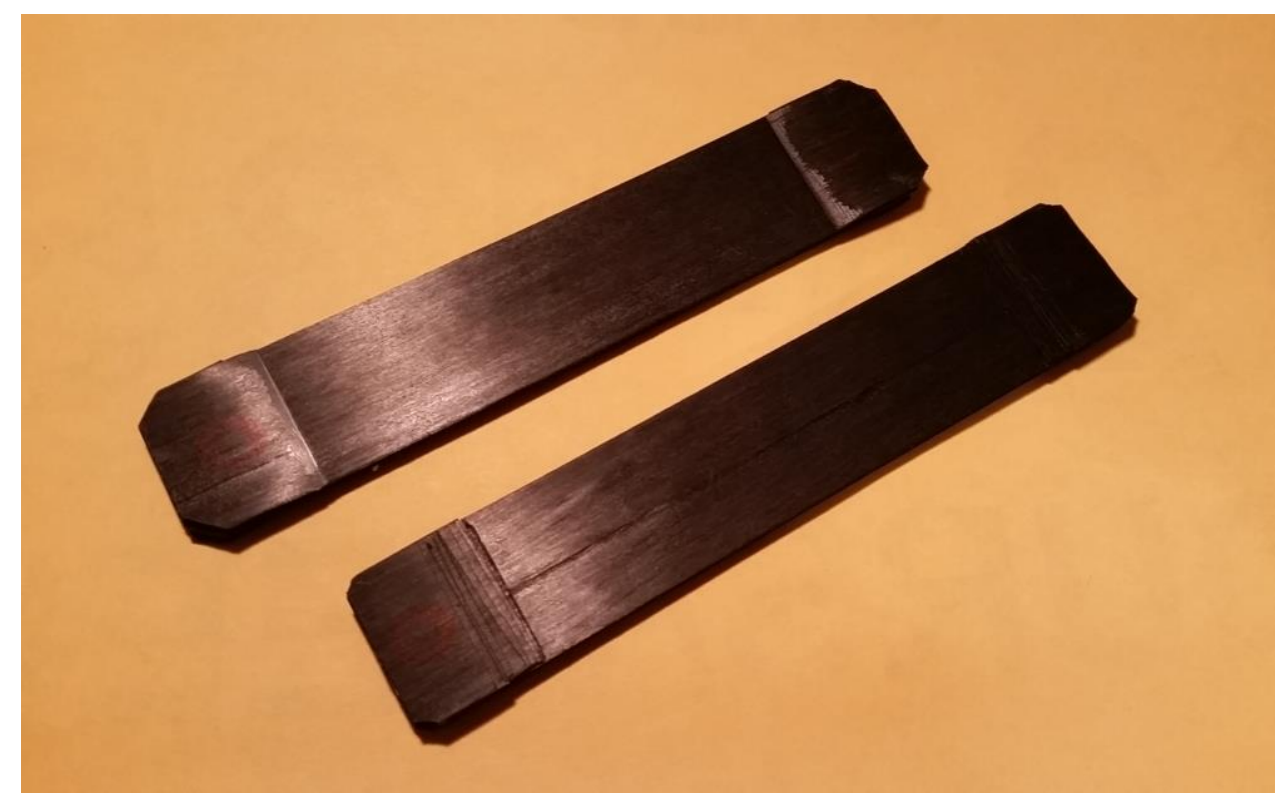

Figure 2.15. First compression molded parts: 10-ply P35/Z03 tensile specimens with tabs.

While the parts in Figure 2.15 appeared to be fully cured, only small parts of the tabs on the upper part showed evidence of contacting the upper mold half. An 11-ply specimen under 100 psi was 
also attempted, but also came up uncompacted. This indicated that the method of determining the number of plies to place into the mold was invalid.

\subsubsection{Ply Thickness Calculation}

The measurement of an uncured ply did not account for the consolidation between layers which occurs during pressure application and therefore did not accurately represent the thickness of a single ply in a larger laminate. Instead of relying on the physical measurement of each ply, the material properties were used to calculate each ply's thickness in a laminate. Per MIL-HDBK-17$3 \mathrm{~F}$ [21], the cured ply thickness $(C P T)$ of a laminate is calculated using

$$
C P T=\frac{F A W}{V_{f} \rho_{f}}
$$

where $V_{f}$ is the fiber volume in the composite material and $\rho_{f}$ is the density of the fiber reinforcement. Table 2.2 gives the properties of P35/Z03 necessary to calculate its cured ply thickness. Using these values, the calculated $C P T$ for the material was 0.00502 in, which means that approximately 13.45 plies were required for the main body and approximately 11.95 plies were required for each tab. A comprehensive spreadsheet-based calculator for cured ply thickness is discussed in Appendix B.1.

In order to achieve full compression and to experiment with different amounts of resin press-out, both 14 and 15-ply parts were molded. As a conservative start, two full-length tab plies were added to each ply layup. The updated tab layup is shown schematically in Figure 2.16. 


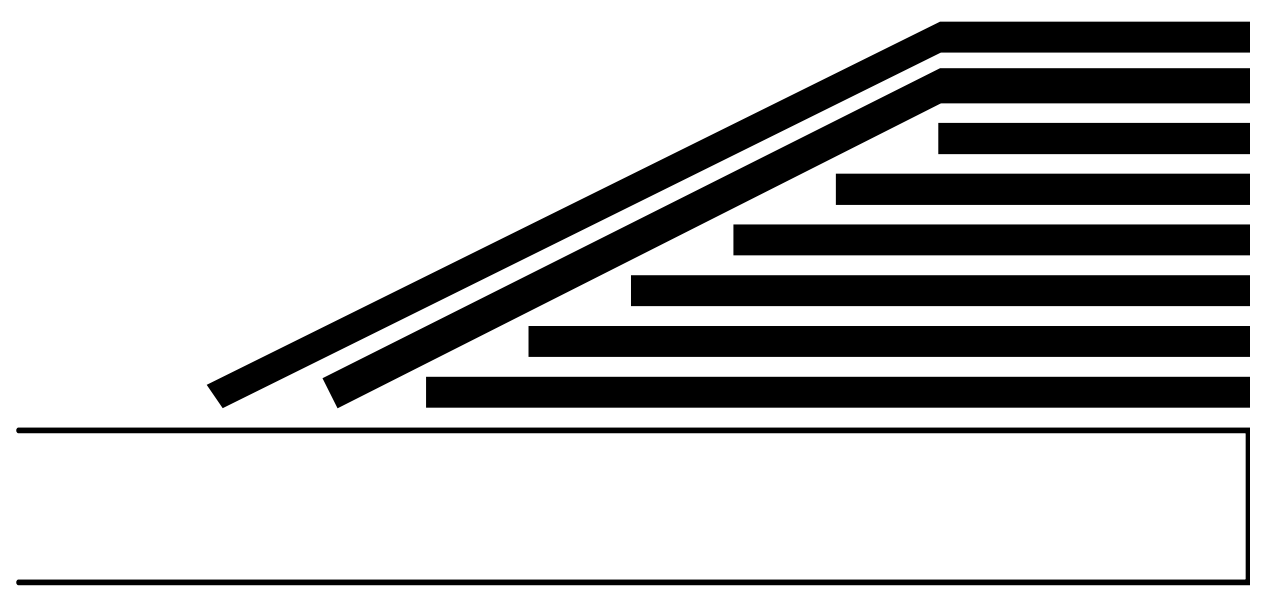

Figure 2.16. Schematic of updated tab layup with positions of additional plies.

The 14 and 15-ply specimens with the 11-ply tabs both laminated together well. Since the 14-ply layup was sufficient to achieve resin press-out and lamination, only the 14-ply layup was pursued further. The 11-ply tabs also appeared to laminate together well and were therefore used for the remaining tensile specimens. The 14 and 15-ply parts are shown in the mold in Figure 2.17.

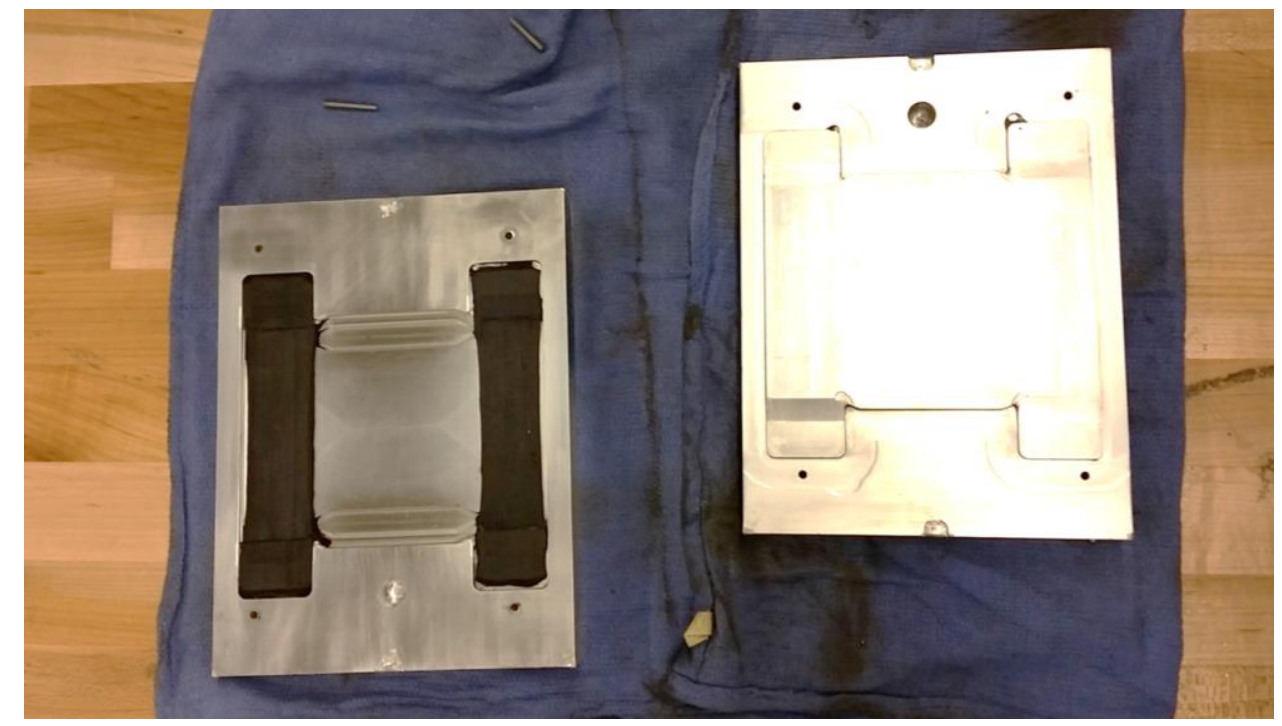

Figure 2.17. Cured 14-ply (right) and 15-ply (left) P35/Z03 specimens before demolding.

It should be noted that, to this point, ejector pins were neither installed nor necessary for demolding parts. However, since the 14 and 15-ply parts completely filled the mold cavity, they could not be removed without machining the ejector pin holes. Therefore, the ejector pin holes 
were machined with the parts in the mold and ejector pins were used to demold all further tensile specimens. The ejector pins were machined into the tab region of the parts, as originally designed. The result of machining the ejector pins with parts in place is shown in Figure 2.18.

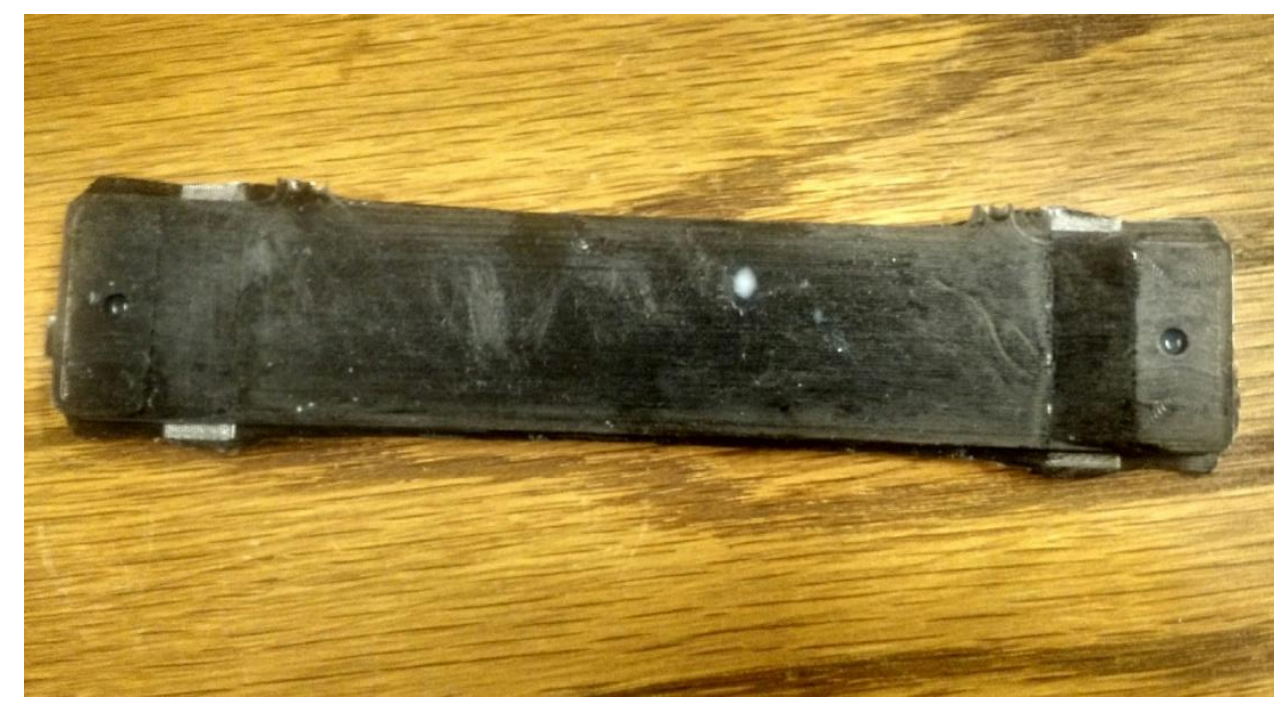

Figure 2.18. 14-ply P35/Z03 part with holes from machining ejector pins.

Machining into the specimens did not appear to affect the tab integrity, nor did it damage the gage section, so the parts were still considered for testing. Two more lots of 14-ply tensile specimens were produced using the same method, giving six total parts for testing: one 15-ply and five 14ply specimens. The specimens all seemed to laminate together and saw full compression, but appeared dry.

Further research revealed that the resin content of P35/Z03 is low compared to composites designed compression molding. Material systems which were specifically designed for compression molding applications have a higher resin content. For example, Hexcel's HexMC sheet molding compound (SMC) has a resin content of $43 \%$ by volume [22]. A material system with a higher resin content allows for better material flow in the mold and typically produces a part with a better surface finish. 
Additionally, resin systems which are specifically developed for compression molding typically have a higher viscosity than traditional resin systems. This prevents resin flow out of the mold [23] and causes the fibers and resin to move as a unit, rather than the resin flowing independently of the fiber [4]. SMCs typically have a minimum viscosity which is at least an order of magnitude higher than that of traditional composite prepregs [24], close to $100 \mathrm{~Pa} \cdot \mathrm{s}$, which is the viscosity of sour cream [19]. The lower viscosity of the Z03 resin could cause the resin to separate from the P35 fibers. While the appearance of the molded parts reflected these potential issues, testing was still required to see the effect of those factors on the mechanical properties of the P35/Z03 parts.

\subsubsection{Specimen Reproducibility}

An important advantage to compression molding is the consistency it provides between every lot of parts with careful process control. To ensure that the molds were performing as anticipated, detailed measurements were taken of each specimen. A schematic of the measurement locations is shown in Figure 2.19.

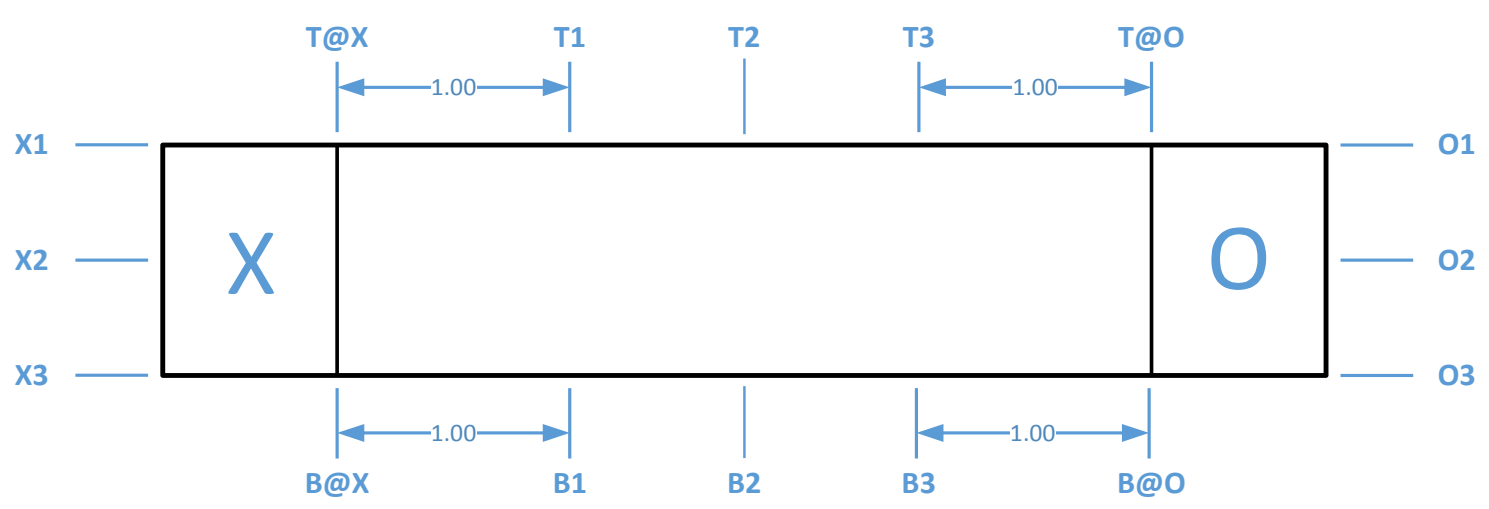

Figure 2.19. Locations for specimen measurement to evaluate mold consistency (inches).

The most critical dimensions were the width and thickness of the gage section as a rectangular prismatic cross section was required per ASTM standards [12], [13]. The width of the gage section was controlled by the flash trimming process discussed in Section 2.2.5, but the thickness 
was dependent upon the machining and fitment of the mold halves. The thickness measurements for the 15-ply and five 14-ply specimens is shown in Table 2.5.

Table 2.5. Thicknesses for gage sections of 14 and 15-ply P35/Z03 tensile specimens.

\begin{tabular}{|c|c|c|c|c|c|c|}
\hline Dimension & $\mathbf{1 4} \mathbf{~ p l y}$ & $\mathbf{1 5} \mathbf{~ p l y}$ & $\mathbf{R ~ 1 ~ L ~}$ & $\mathbf{R ~ 1 ~ R}$ & $\mathbf{R} \mathbf{2}$ L & R 2 R \\
\hline T @ X & 0.094 & 0.094 & 0.095 & 0.094 & 0.094 & 0.095 \\
\hline T1 & 0.095 & 0.094 & 0.095 & 0.094 & 0.095 & 0.094 \\
\hline T2 & 0.095 & 0.094 & 0.095 & 0.094 & 0.095 & 0.094 \\
\hline T3 & 0.095 & 0.094 & 0.095 & 0.093 & 0.095 & 0.094 \\
\hline T @ O & 0.094 & 0.094 & 0.094 & 0.094 & 0.094 & 0.093 \\
\hline B @ X & 0.094 & 0.094 & 0.095 & 0.094 & 0.094 & 0.094 \\
\hline B1 & 0.094 & 0.094 & 0.094 & 0.094 & 0.094 & 0.095 \\
\hline B2 & 0.094 & 0.095 & 0.094 & 0.094 & 0.094 & 0.095 \\
\hline B3 & 0.094 & 0.094 & 0.094 & 0.094 & 0.093 & 0.094 \\
\hline B @ O & 0.095 & 0.093 & 0.094 & 0.094 & 0.094 & 0.094 \\
\hline Average & 0.094 & 0.094 & 0.094 & 0.093 & 0.094 & 0.094 \\
\hline
\end{tabular}

Measurements indicated that the mold produced part thicknesses which were consistent to caliper precision. Even the 15-ply specimen had a similar average thickness to the 14-ply specimens.

Despite its consistency, the mold produced parts which were nearly 0.1 in thick when it was designed to produce parts which were 0.0675 in thick.

After measurement and further inspection, it was discovered that the complex inside corners and the long inside edges of the mold were cut with a 1/16 in ball endmill and were therefore interfering with the matching features on the core half of the mold. The interfering feature is shown in Figure 2.20. These features were filed and sanded down in preparation for future specimens. The modifications reduced, but did not completely close, the gap between the mold halves during compression molding. 


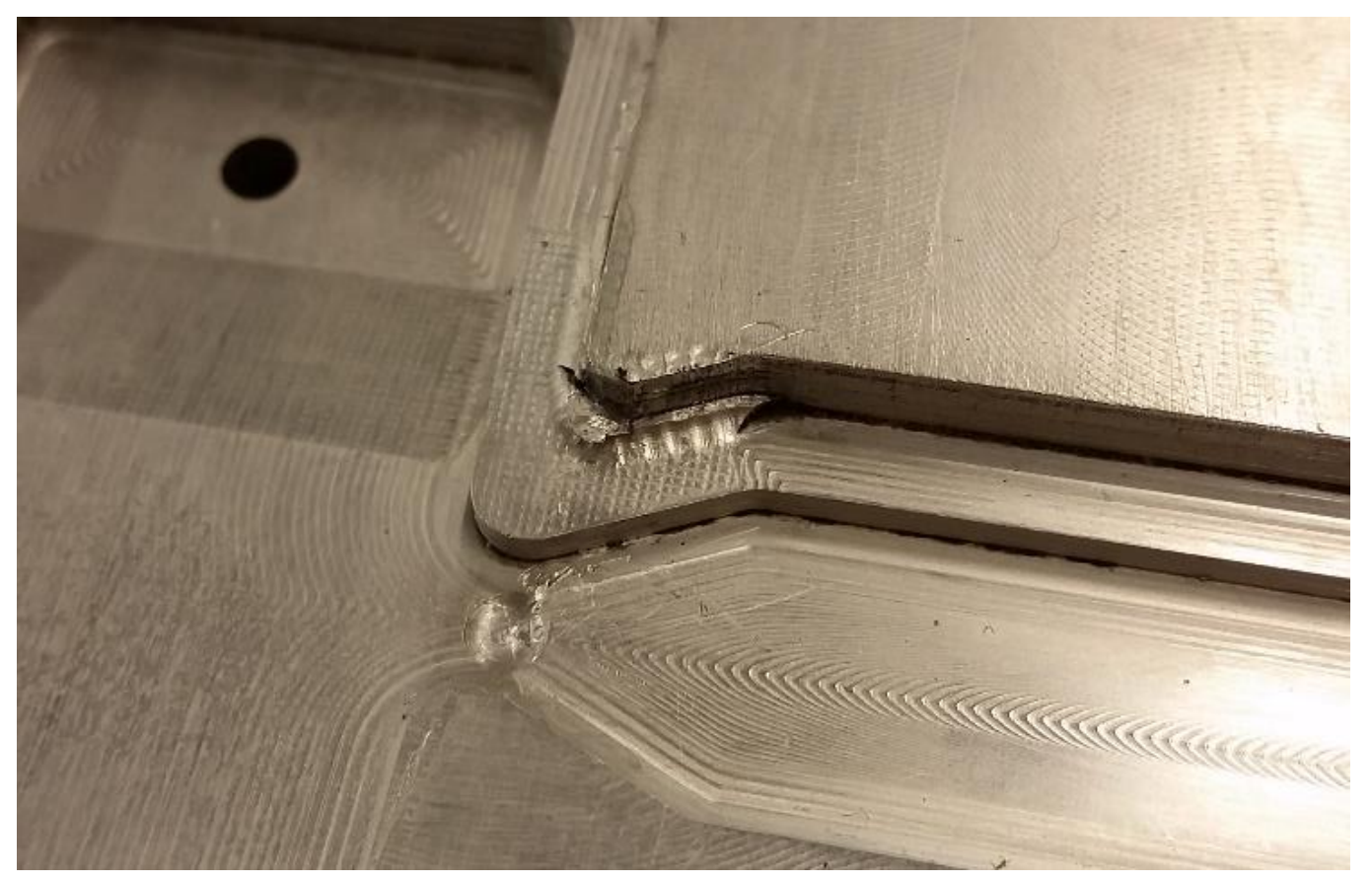

Figure 2.20. Interfering feature in tensile specimen mold cavity.

The thicker parts also revealed a problem with the $C P T$ calculation. According to the calculator, 14 plies should have only produced a well-compacted part which was 0.0675 in thick, but 14 plies instead created well-compacted parts which were closer to 0.094 in thick.

The fiber volume fraction used to calculate the $C P T$ was 0.65 which was calculated by subtracting the resin content from unity. Thorough review of the material data sheets revealed that the resin content was in weight percent, not in volume percent. The handling guide for the prepreg [18] suggested that the fiber volume fraction was 0.60 , not 0.65 . Plugging this value into the calculator confirms that only 12 plies would be necessary to create a 0.0675 in thick part. However, the calculator also showed that closer to 17 plies should have been used for a 0.094 in thick part. Testing would reveal whether the lack of material would affect the mechanical properties of the finished test specimens. 


\subsubsection{Post-Processing Specimens}

Each specimen had a small flash of resin where the mold halves came together. It was necessary to trim this flash in order to produce tensile specimens with rectangular cross sections. A wet diamond saw was selected to trim the flash to achieve a good surface finish and so that the dust formed during trimming would be suppressed. The wet diamond saw is shown in Figure 2.21.

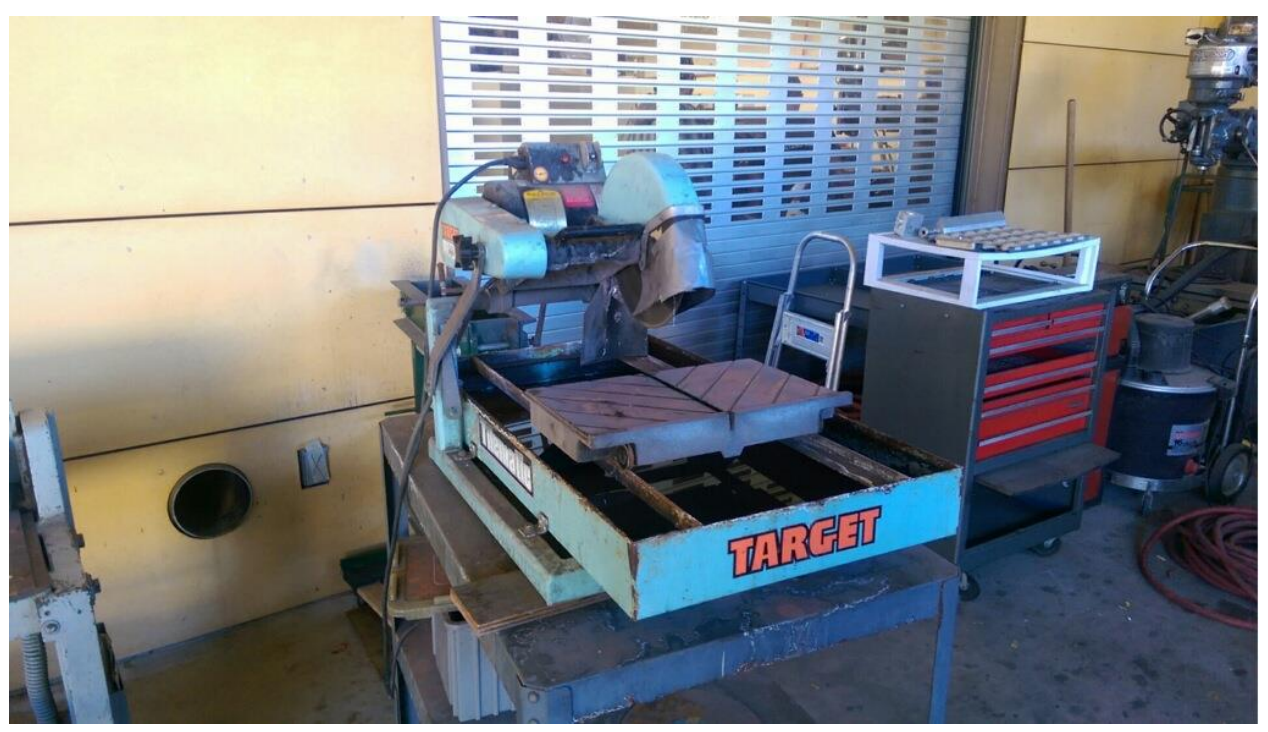

Figure 2.21. Wet diamond saw used to trim and rip specimens.

In the ME 412 composites class, a composite part is typically trimmed on the wet diamond saw by first attaching the specimen to a larger piece of acrylic with double-sided tape, then using the acrylic to control the specimen during the cutting procedure. This method works well for flat specimens, but the co-cured tabs on the tensile specimens did not provide sufficient surface area with which to attach the parts to the acrylic. Therefore, a new jig was designed which would hold the specimens in place during flash trimming. It was also later discovered that the cross section of each specimen was too large to be reasonably tested per ASTM standards, so the jig was modified to also rip the specimens in half length-wise. The finished jig is shown in Figure 2.22. The initial jig is shown clamped to the wet diamond saw in Figure 2.23. 


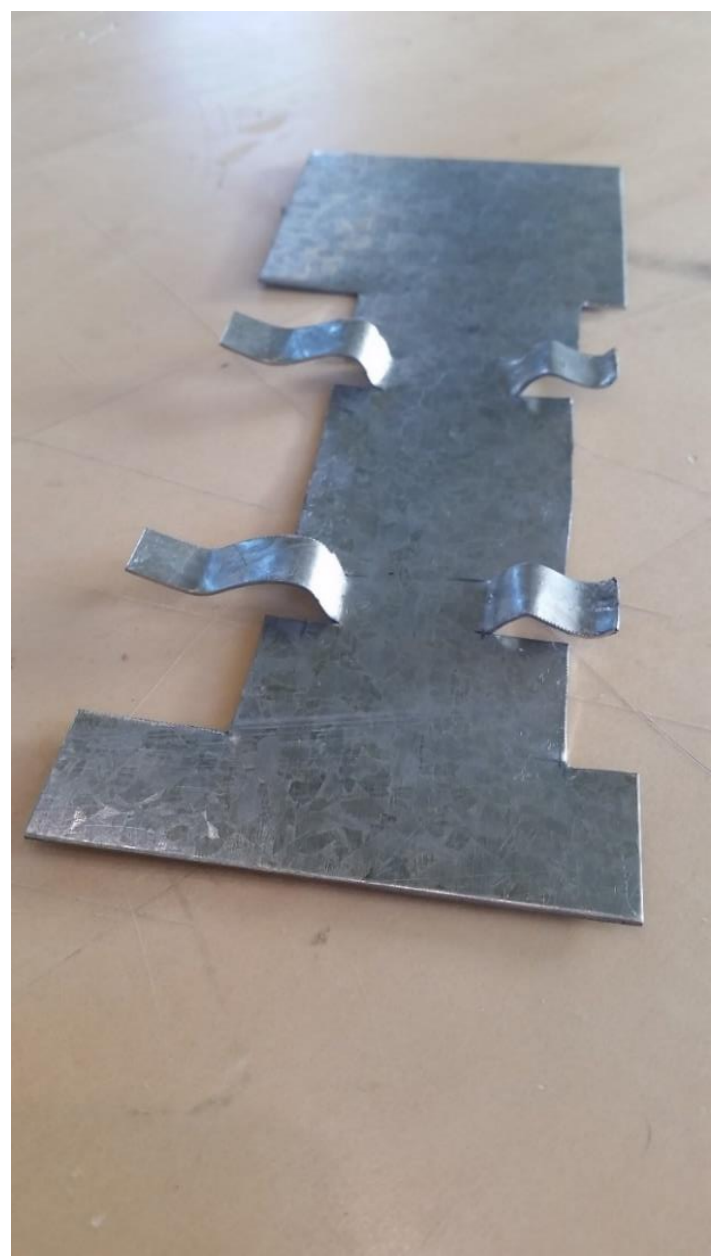

Figure 2.22. Finished flash-trimming and specimen-ripping jig.

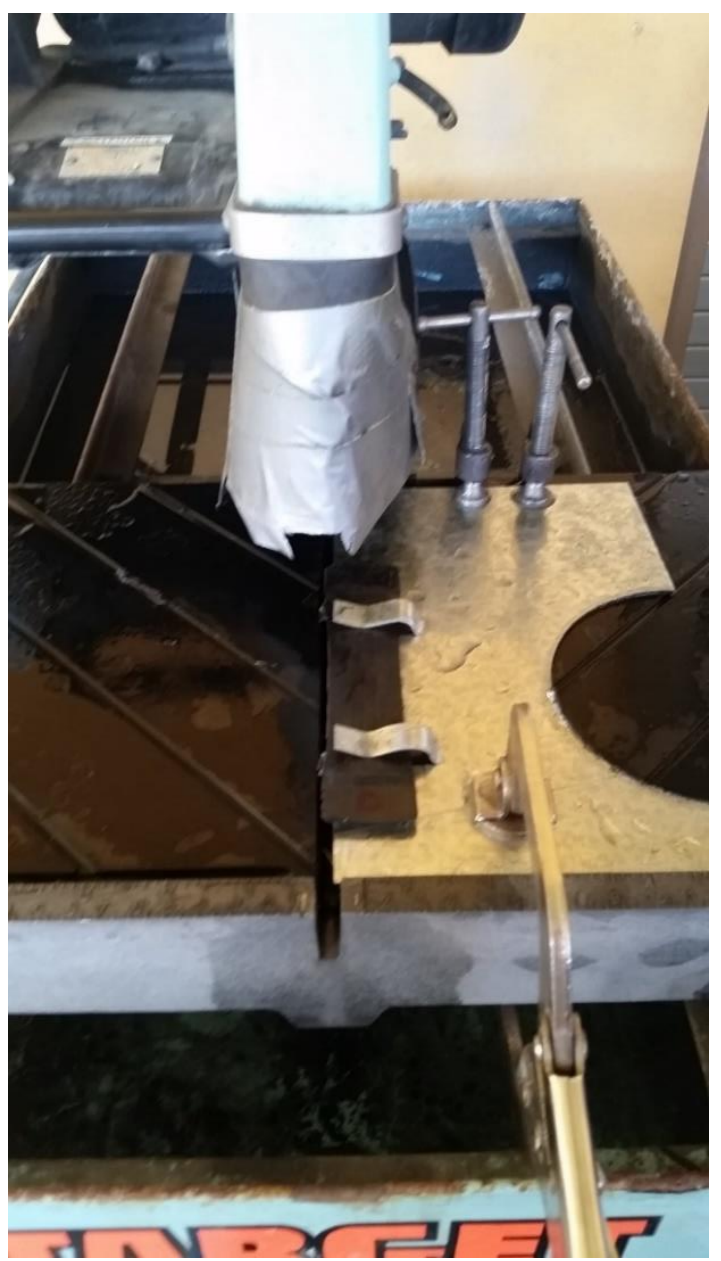

Figure 2.23. Flash-trimming jig clamped to the wet diamond saw with tensile specimen.

The jig was cut from a 0.120 in thick sheet of galvanized steel. Tabs were cut and bent into shape to hold down the material, then the edges of the jig were trimmed to the correct width. In order to place the jig consistently for every cut, shims were cut from the same material. The jig with the placement shims is shown in Figure 2.24. 

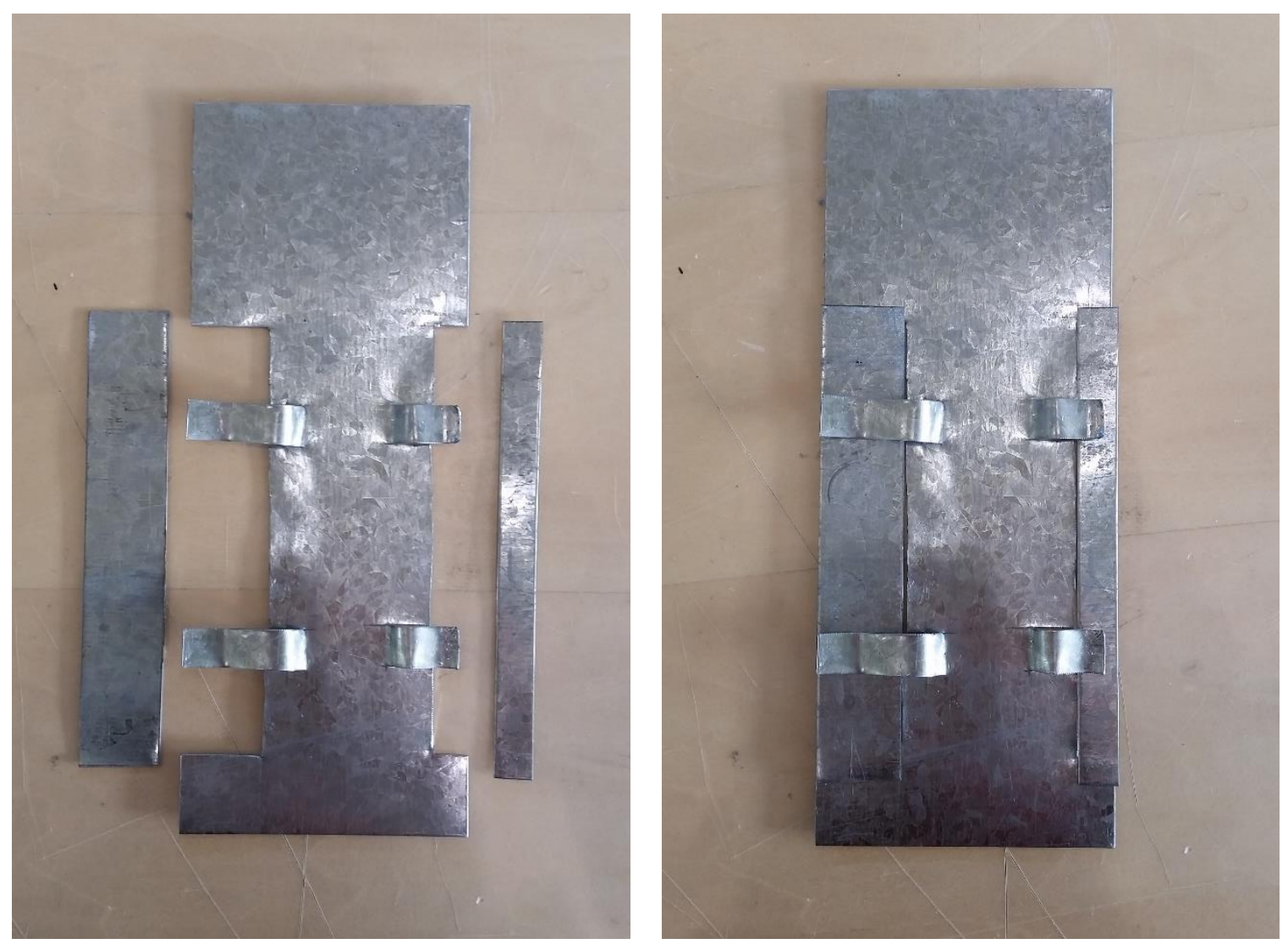

Figure 2.24. Trimming and ripping jig with alignment shims.

\subsection{Material Evaluation}

The goal of this compression molding study was to show that parts produced by the compression molding method had equivalent mechanical properties to those of autoclave specimens. In order to test the mechanical properties, the test specimens were subjected to destructive testing. The manufacturer-provided mechanical properties of the P35/Z03 material were used to predict the ultimate failure in each loading case. These properties are given in Table 2.6.

Table 2.6. P35/Z03 mechanical properties provided by Zoltek [18].

\begin{tabular}{|c|c|c|}
\hline Property & Value (SI) & Value (English) \\
\hline Tensile Strength & $2212 \mathrm{MPa}$ & $320.8 \mathrm{ksi}$ \\
\hline Tensile Modulus & $134 \mathrm{GPa}$ & $19.4 \mathrm{Msi}$ \\
\hline Compressive Strength & $1370 \mathrm{MPa}$ & $198.7 \mathrm{ksi}$ \\
\hline Compressive Modulus & $126 \mathrm{GPa}$ & $18.3 \mathrm{Msi}$ \\
\hline Interlaminar Shear Strength & $85 \mathrm{MPa}$ & $12.3 \mathrm{ksi}$ \\
\hline
\end{tabular}




\subsubsection{Testing Apparatus}

All destructive testing was conducted with an Instron Model 1331 controlled by a Series 8500 Plus control module. The Instron had a 20-kip maximum load and was outfitted with 2718 Series hydraulic wedge grips. The system was powered with a Model 210-5 hydraulic power supply. All data was collected from the controller using a National Instruments data acquisition (DAQ) system. Data was processed using a custom script developed with National Instruments' LabVIEW System Design Software. The entire testing setup is shown in Figure 2.25. The Instron testing machine was prepared for testing using the process outlined in Appendix A.1.

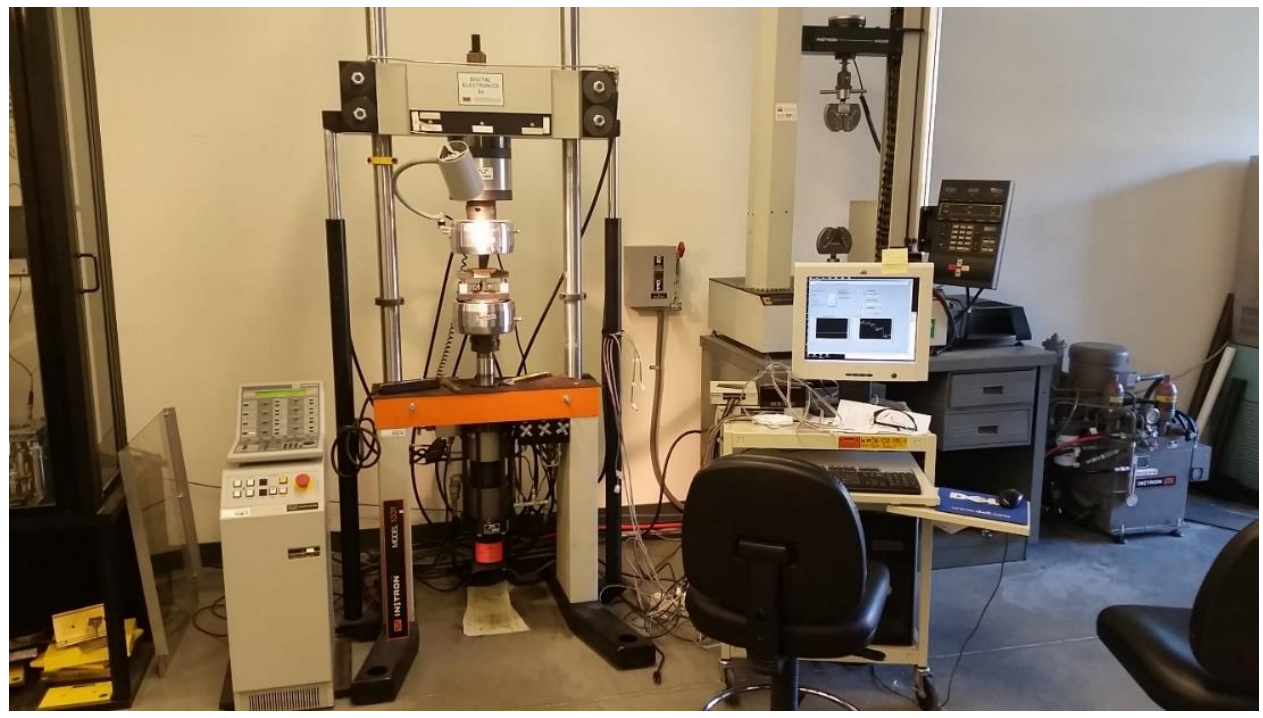

Figure 2.25. Instron test machine setup with National Instruments DAQ system.

\subsubsection{Tensile Testing}

To test the quality of the compression molding manufacturing method, the tensile specimens were to be tested per ASTM D3039 [12]. A satisfactory tensile test result would indicate that the specimens produced by the mold were up to standard and that the compression molding method works as well as the autoclave method of manufacture. A preliminary test was performed on an uncompacted, 10-ply specimen to ensure that the Instron tensile setup was correct. The loading 
program was set to pull the specimen at a constant $0.050 \mathrm{in} / \mathrm{min}$ per ASTM recommendations [12] up to a maximum displacement of 0.5 in to ensure that the test was not ended prematurely. Using the mechanical properties in Table 2.6, the maximum load which the tensile specimen could withstand $\left(P_{\max }\right)$ was predicted using

$$
P_{\text {max }}=\sigma_{t} A
$$

where $\sigma_{t}$ is the ultimate tensile strength of $\mathrm{P} 35 / \mathrm{Z} 03$ and $A$ is the cross sectional area of the gage section of the test specimen. The gage section cross sectional area of the 10-ply specimen was $0.071 \mathrm{in}^{2}$ giving an average expected $P_{\max }$ of $22,720 \mathrm{lbf}$.

Despite the fact that the predicted $P_{\max }$ exceeded the maximum capacity of the Instron load frame, the specimen was to be loaded to $10,000 \mathrm{lbf}$ to obtain preliminary stiffness measurements.

For the first $1500 \mathrm{lbf}$ of force application, an extensometer was used to measure the deflection in the specimen. The load-deflection curve for the initial load case with a linear trendline giving the initial slope of the data is shown in Figure 2.26.

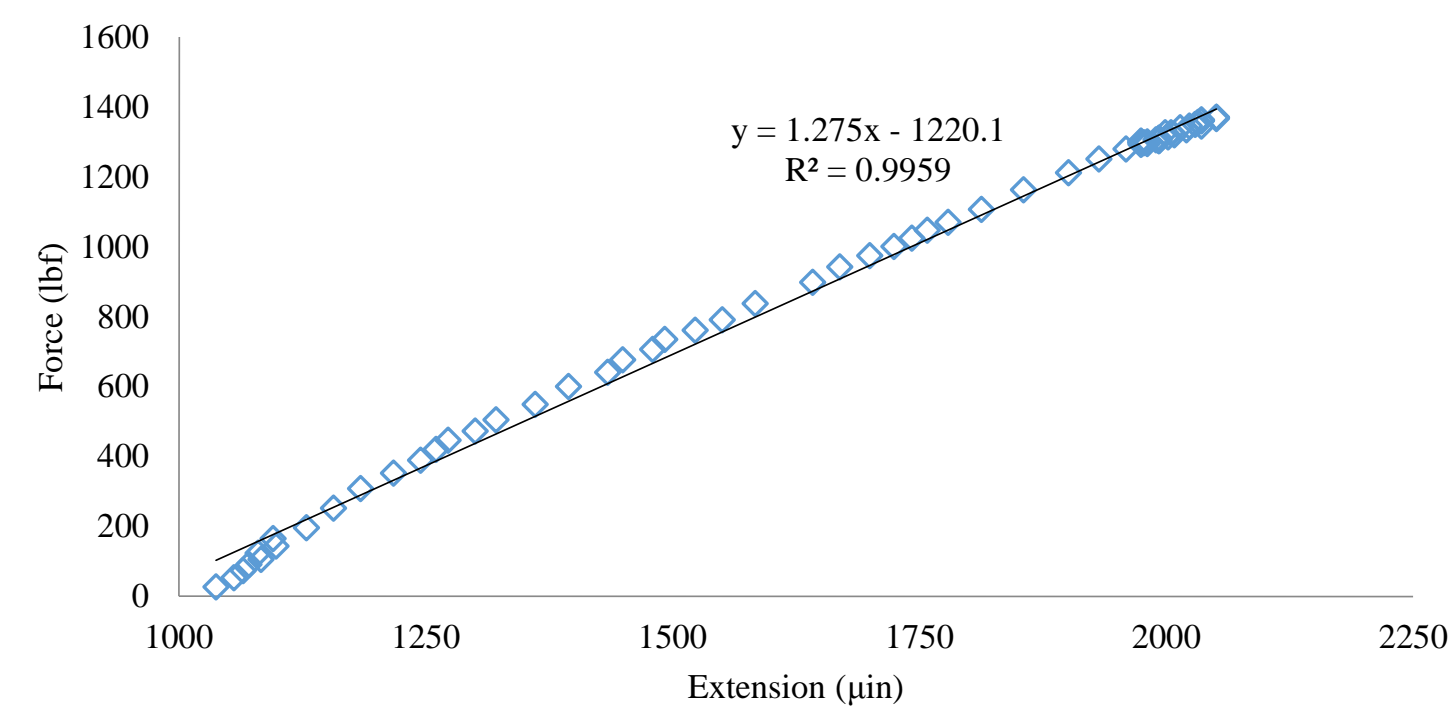

Figure 2.26. Load-deflection curve for a 10-ply P35/Z03 tensile specimen. 
Once approximately $1500 \mathrm{lbf}$ was reached, the specimen was unloaded and the extensometer was removed. Then a Plexiglas shield was installed in case of specimen failure and the load program was restarted to achieve a load of 10,000 lbf. However, the specimen failed unexpectedly at 6713 lbf. The result of the final loading case is shown in Figure 2.27.

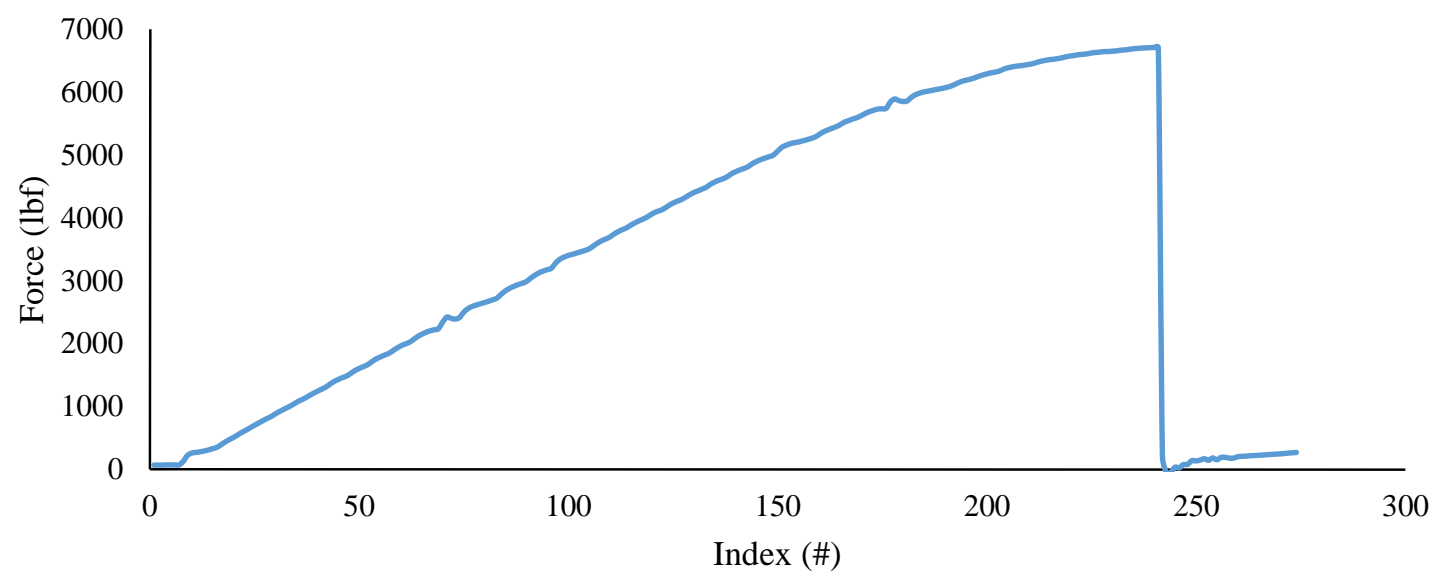

Figure 2.27. Load curve for a 10-ply P35/Z03 tensile specimen loaded to failure.

The specimen experienced a "brooming" failure mode which was not typically seen as a result of ASTM tensile testing [12]. The failure is shown in Figure 2.28.

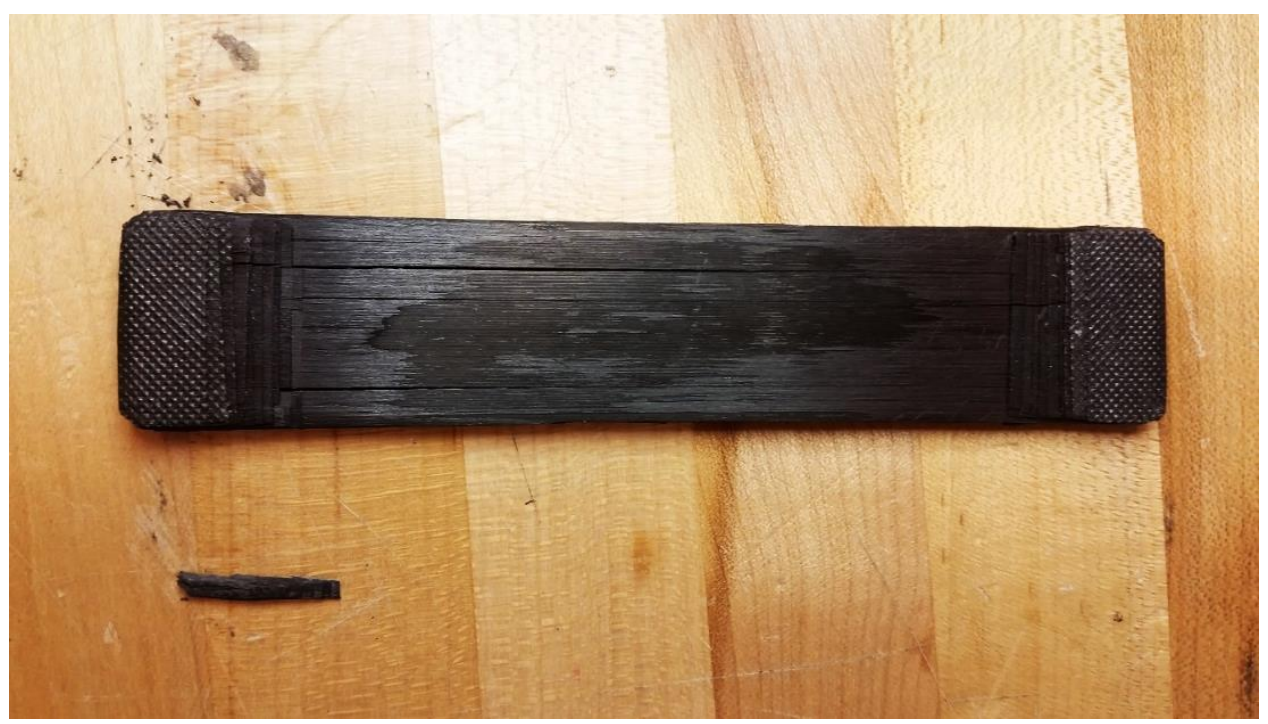

Figure 2.28. "Brooming" failure mode experienced by a 10-ply P35/Z03 tensile specimen. 
To confirm that the apparent "dryness" of the specimen was not the cause of the failure, the 15ply specimen was ripped in half lengthwise on the diamond saw using the ripping jig discussed in Section 2.2.5. Simply clamping the specimen in the Instron's hydraulic grips caused the specimen to fail in a similar manner (Figure 2.29). The atypical failure mode led to an investigation into whether the mold geometry, which had been necessitated by limited platen size, and layup of the specimen were fit for tensile testing.

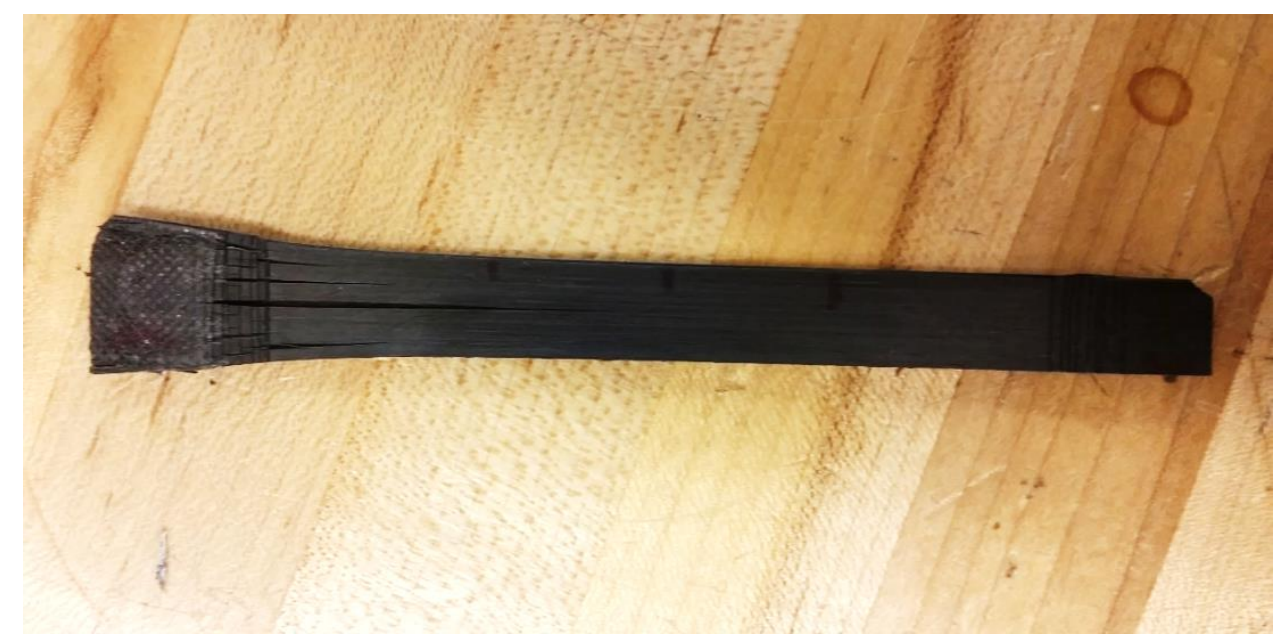

Figure 2.29. 15-ply P35/Z03 tab "brooming" failure from clamping in Instron grips.

\subsubsection{Tensile Specimen Re-Evaluation}

Upon careful review of the ASTM standard for tensile testing [12], the original layup of all [0] plies was not valid for tensile testing as there were no [90] plies to prevent the tabs from splitting in the 1-3 plane as shown in Figure 2.28 and Figure 2.29.

However, even with a $[0 / 90]_{\mathrm{n}}$ layup, the tab length was not sufficient to sustain the ultimate load of the specimen's gage section. Minimum tensile specimen tab length $\left(L_{m i n}\right)$ was calculated [12]

$$
L_{\min }=\frac{F^{t u} h}{2 F^{s u}}
$$


where $F^{t u}$ was the ultimate tensile strength of the composite material, $h$ was the thickness of the gage section, and $F^{s u}$ was the ultimate shear strength of the bond between the tab and the test specimen. In this case, $F^{\text {su }}$ was the interlaminar shear strength (ILSS) of P35/Z03. According to Eq. 2.5, the minimum tab length necessary to sustain the ultimate load of a specimen with an average thickness of 0.094 in was 1.22 in . Detailed calculations for minimum tab length may be found in Appendix C.1. Thus the tensile specimens could not be used for tensile testing.

Mold modification was considered, but was not possible due to the complex shutoff plane. The manufacture of a new mold to create tensile specimens was outside the scope of the project. Plus, a tensile specimen which met ASTM standards would be too large to fit in a mold which fit into the press platens. Instead, the existing tensile specimens were modified to accommodate a different method of destructive mechanical testing.

\subsubsection{3-Point Bend Testing}

As tensile testing was not an option, the remaining specimens were instead tested in 3-point bend per ASTM D790 [25]. For a material with the same tensile and compressive strengths, its flexural strength is the same as its tensile strength. However, for anisotropic materials, the flexural strength is a function of the material's different tensile and compressive strengths. For composite materials, the flexural modulus may be estimated by [26]

$$
E_{f}=\sqrt{E_{t} E_{c}}
$$

Thus, the quality of the specimen could still be evaluated by comparing the experimentally determined flexural modulus to the reported tensile and compressive moduli of the composite.

All specimens were ripped in half and the tabs were removed with the wet diamond saw. The resulting specimens are shown in Figure 2.30. Each was approximately 0.45 in wide in per the ASTM standard which states that 3-point bend specimens thicker than $1.6 \mathrm{~mm}(1 / 16 \mathrm{in})$ and less 
than $3.2 \mathrm{~mm}$ (1/8 in) should be approximately $12.7 \mathrm{~mm}(1 / 2 \mathrm{in})$ wide [25]. The 10-ply specimens were treated in a similar manner and were used to ensure the quality of the initial test setup.

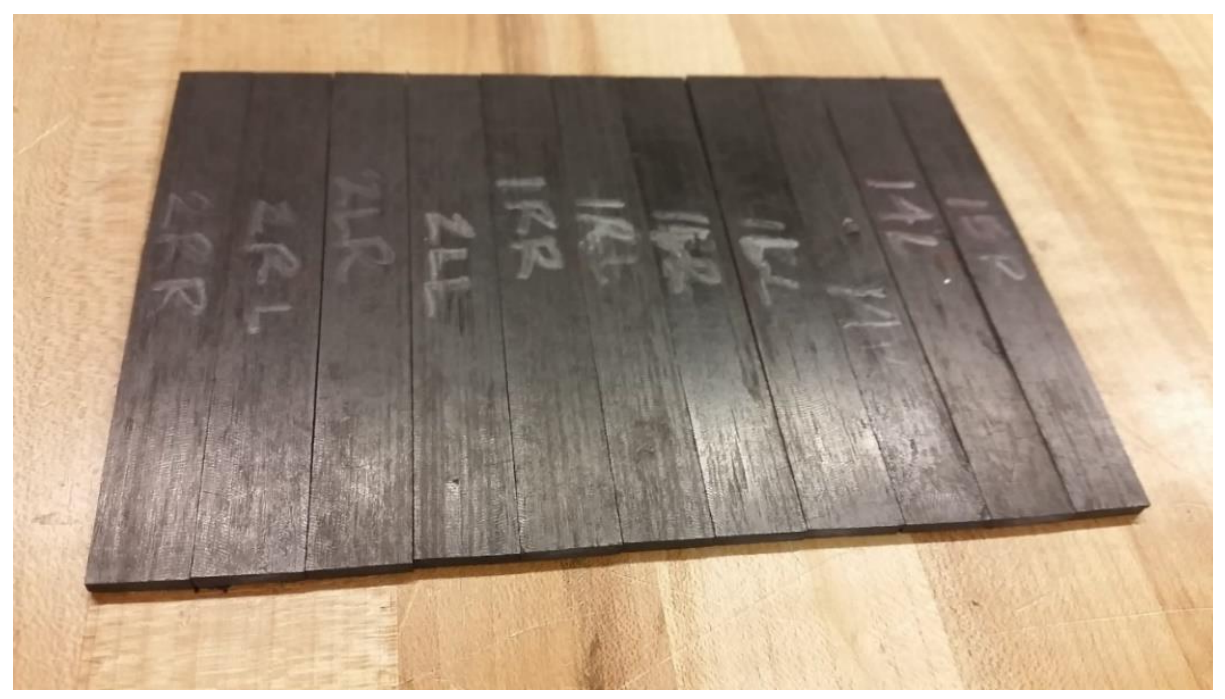

Figure 2.30. Tensile specimens trimmed into 3-point bend specimens.

The 3-point bend apparatus used on the Instron tester was manufactured by Wyoming Test Fixtures. It featured adjustable 0.25 in diameter lower supports and a 0.25 in loading roller. The upper part of the apparatus was constrained by linear bearings at each end. The bearings rode on precision machined shafts pressed into the steel base. The apparatus is shown in Figure 2.31.

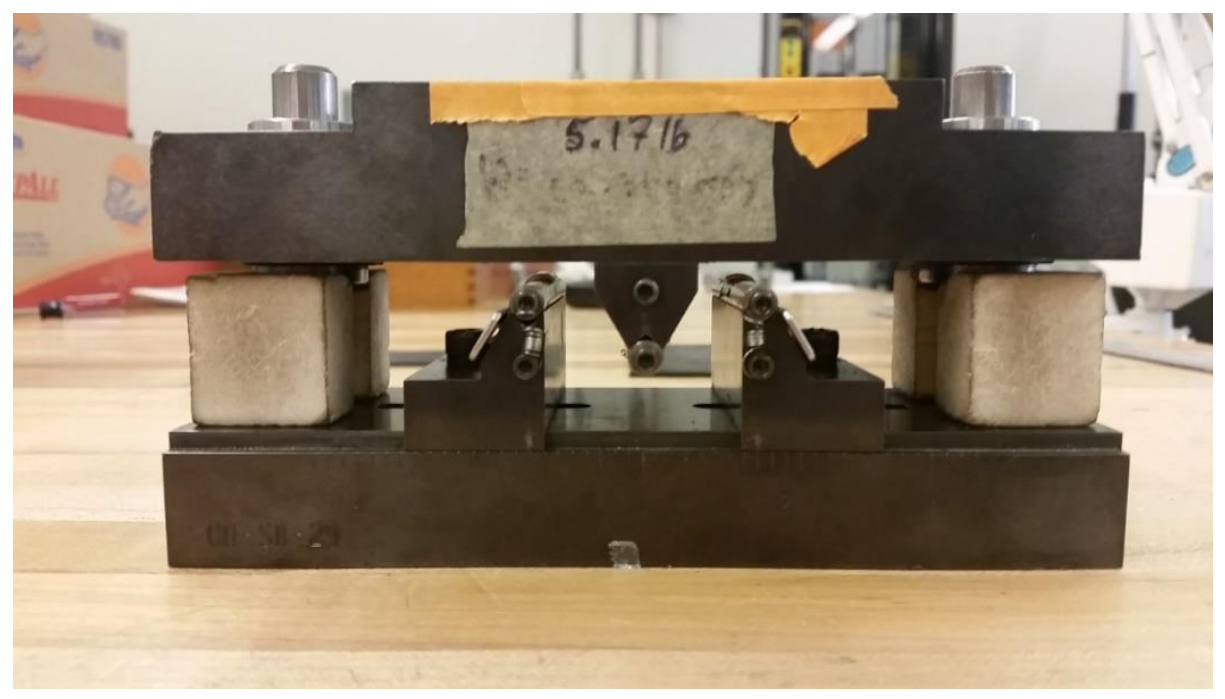

Figure 2.31. 3-point bend apparatus used to test specimens per ASTM D790. 
The span was set to 16 times the thickness of the specimen per the ASTM standard [25]. As the average specimen was 0.094 in thick, the span was set to 1.6 in. It was possible to check the span by measuring the outside of the rollers, as shown in Figure 2.32 .

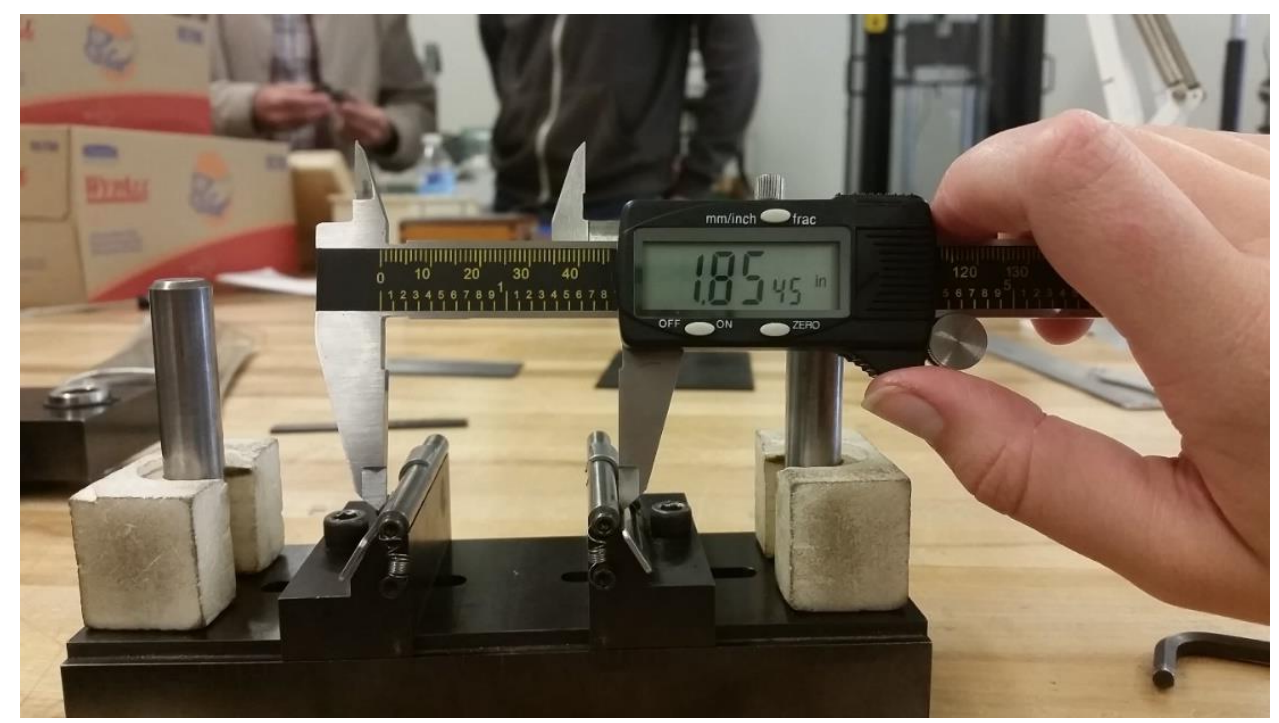

Figure 2.32. Span of 3-point bend apparatus checked with calipers.

Specimens were loaded into the 3-point bend apparatus by removing the apparatus from the Instron, removing the upper half, and placing the specimen against the alignment tabs and centering the specimen on the span as shown in Figure 2.33.

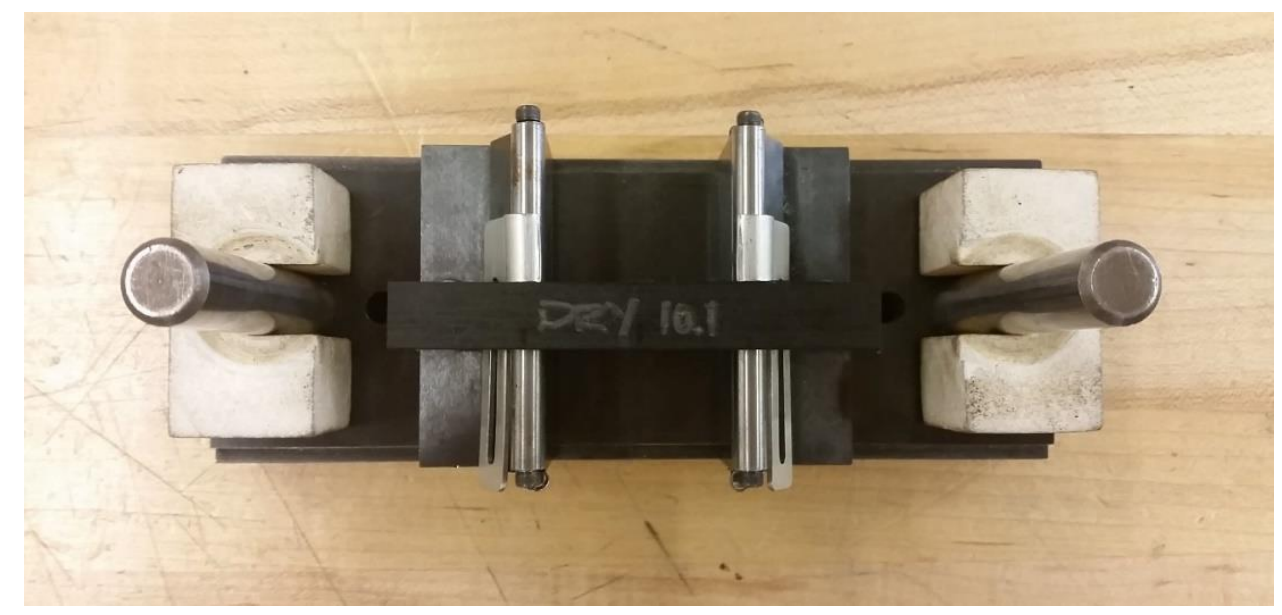

Figure 2.33. Specimen placement in lower half of 3-point bend apparatus. 
The 3-point bend apparatus was operated by pressing the upper and lower halves together between the lower jaw of the Instron and a plunger clamped into the upper jaw. Proper alignment was achieved by placing the apparatus onto the lower jaw, bringing the apparatus up close to the upper jaw, placing the plunger on top of the apparatus, and clamping the plunger in the upper jaw. A level base plate could optionally be used to press against the lower half of the test apparatus. The fully aligned apparatus is shown in Figure 2.34.

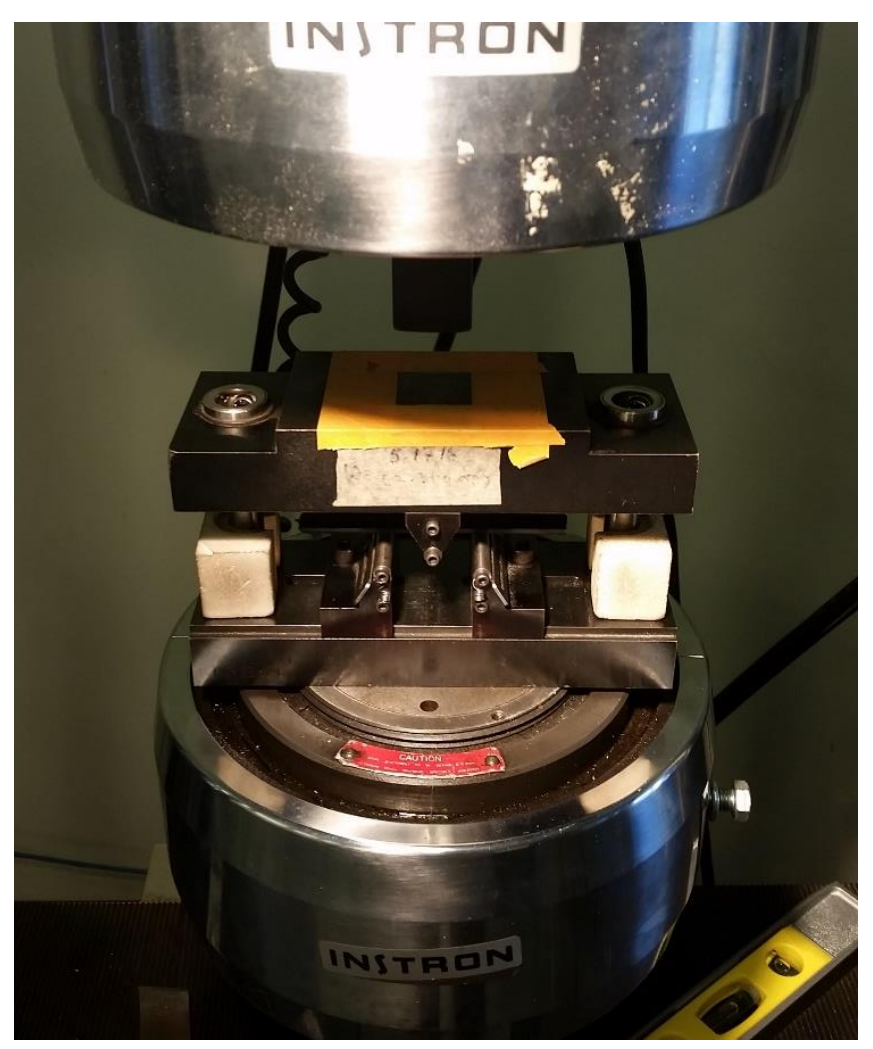

Figure 2.34. 3-point bend apparatus set up on Instron load frame.

The position waveform on the Instron was set to load the apparatus in compression up to 0.5 in.

The rate of loading $(R)$ was calculated with [25]

$$
R=\frac{Z L^{2}}{6 d}
$$


where $Z$ was the rate of straining the outer fiber (set to $0.01 \mathrm{in} / \mathrm{in} / \mathrm{min}$ ), $L$ was the support span, and $d$ was the depth of the beam being tested. From this calculation, $R=0.043 \mathrm{in} / \mathrm{min}$. Each specimen was tested using this waveform. The test was stopped when a 30\% drop in load was observed or when the specimen failed completely.

\subsubsection{3-Point Bend Results}

All specimens resisted load application linearly until initial yield. A representative loaddisplacement curve is shown in Figure 2.35.

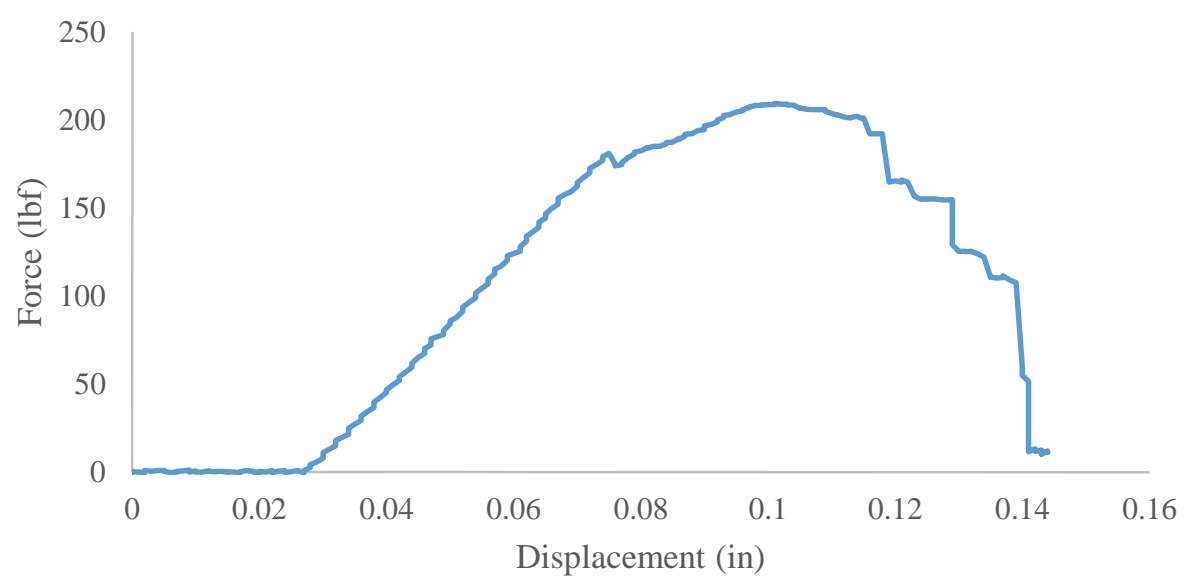

Figure 2.35. Typical load-displacement curve for 3-point bend test of P35/Z03 specimens.

The majority of the 14-ply specimens failed in microbuckling of the top layers of the composite beam. Two experienced complete fiber fracture. Representative samples of each failure mode are shown in Figure 2.36 and Figure 2.37. 


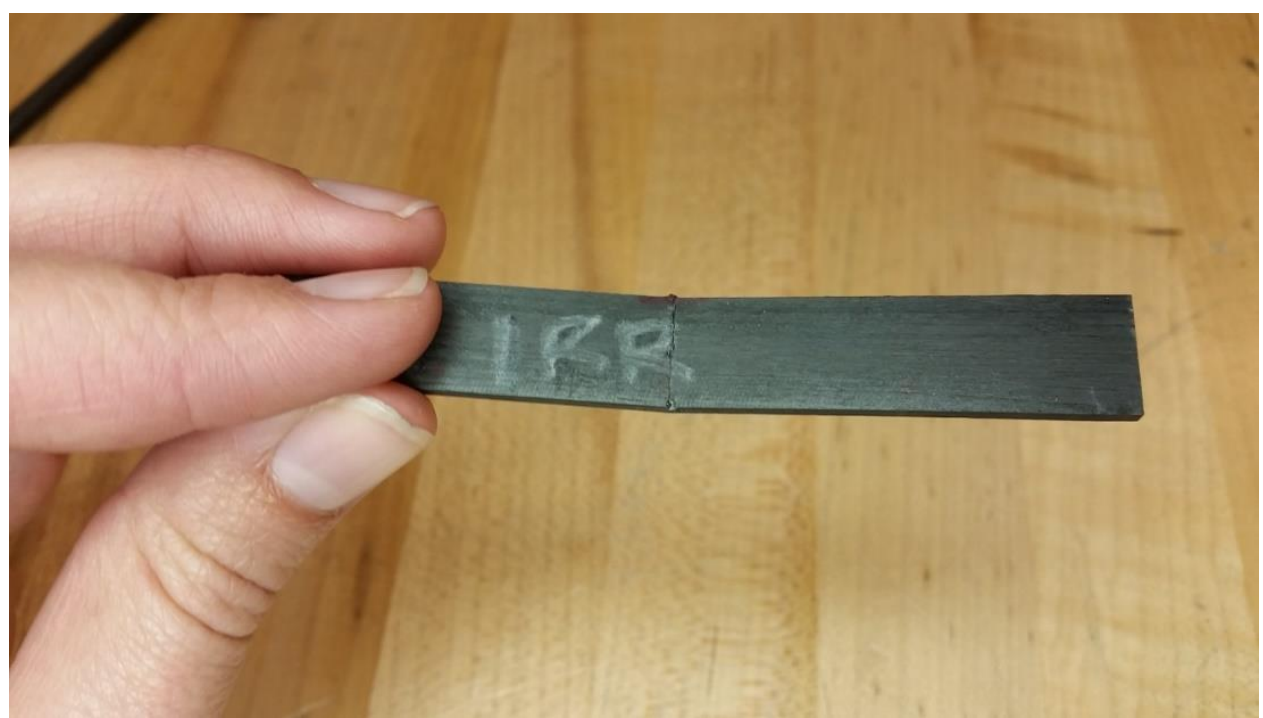

Figure 2.36. Microbuckling failure mode of 3-point bend specimens.

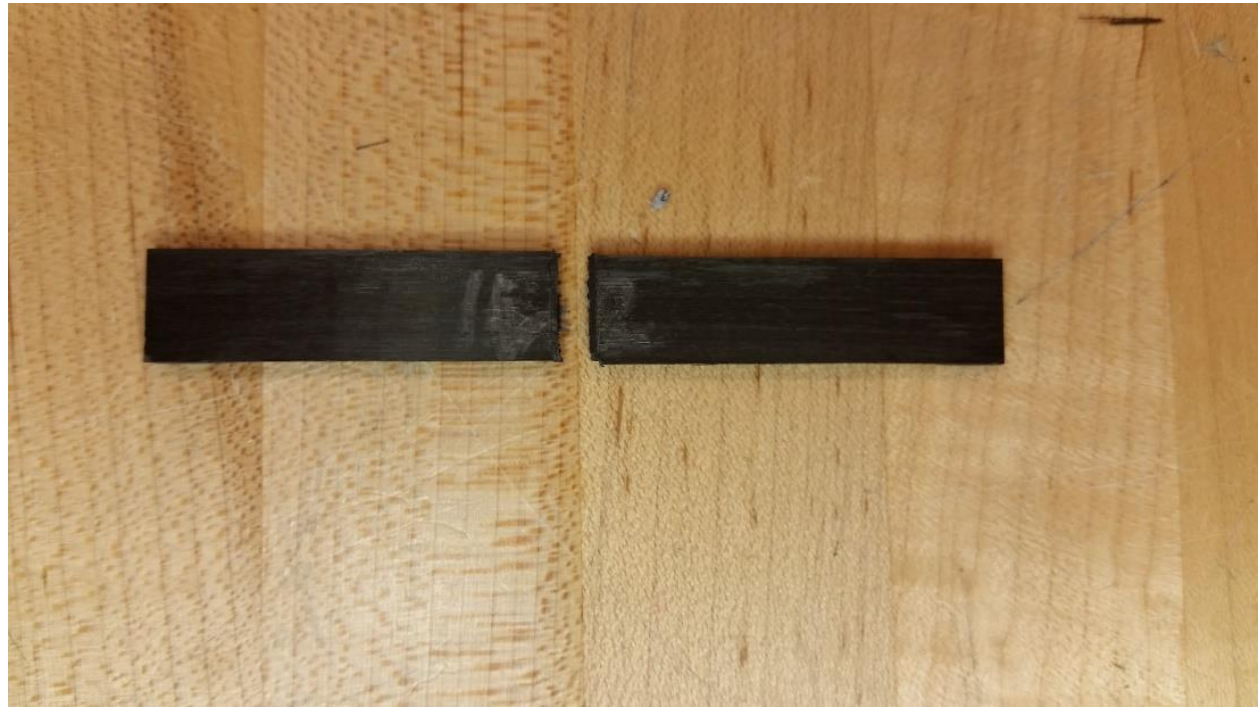

Figure 2.37. Complete fiber failure of 3-point bend specimens.

The failure modes of the 3-point bend specimens indicated that they failed in pure bending rather than in shear. According to classical lamination theory, a specimen which failed in shear would have experienced delamination rather than outer ply failure.

The flexural strength $\left(\sigma_{f}\right)$, ultimate flexural strain $\left(\varepsilon_{f}\right)$, and tangent modulus $\left(E_{B}\right)$ of each specimen were calculated per ASTM D790 using [25] 


$$
\begin{gathered}
\sigma_{f}=\frac{3 P L}{2 b d^{2}} \\
\varepsilon_{f}=\frac{6 D d}{L^{2}} \\
E_{B}=\frac{L^{3} m}{4 b d^{3}}
\end{gathered}
$$

where $P$ is the load at initial failure, $L$ is the span, $b$ is the width of the specimen, $d$ is the depth of the specimen, $D$ is the deflection at initial failure, and $m$ is the slope of the linear portion of the load-displacement curve for the specimen. The results of these calculations are shown in Table 2.7. Detailed calculations can be found in Appendix C.2.

Table 2.7. Flexural strength, strain, and tangent modulus of P35/Z03 specimens.

\begin{tabular}{|c|c|c|c|}
\hline Specimen ID & $\begin{array}{c}\text { Flexural Strength } \\
(\mathbf{k s i})\end{array}$ & $\begin{array}{c}\text { Flexural Strain } \\
\text { (in/in) }\end{array}$ & $\begin{array}{c}\text { Tangent Modulus } \\
\text { (Msi) }\end{array}$ \\
\hline 14L & 9.67 & 0.0229 & 8.41 \\
\hline $14 \mathrm{R}$ & 110 & 0.0176 & 9.86 \\
\hline 1LL & 106 & 0.0223 & 10.0 \\
\hline 1LR & 115 & 0.0194 & 10.8 \\
\hline 1RL & 114 & 0.0183 & 11.0 \\
\hline 1RR & 112 & 0.0178 & 10.7 \\
\hline 2LL & 95.7 & 0.0169 & 8.85 \\
\hline 2LR & 125 & 0.0176 & 10.3 \\
\hline 2RL & 105 & 0.0183 & 10.3 \\
\hline 2RR & 109 & 0.0178 & 9.09 \\
\hline
\end{tabular}

For P35/Z03, the estimated flexural modulus, according to the material properties provided by Zoltek and Eq. 2.6, was approximately 18.84 Msi. The average flexural modulus of the specimens was 9.96 Msi, about $47 \%$ lower than the flexural modulus predicted by Eq. 2.6. Additionally, although these specimens were made using the same cure cycle, their strengths were inconsistent.

From this calculation and the overall difficulty of working with the material, it was clear that the P35/Z03 material was not compatible with the molding processes being employed. This fact, in 
conjunction with the already low resin content of the material and a timely donation from Space Exploration Technologies Corp. (SpaceX), led to the investigation of a new material system.

\subsection{M46J/TC250 Material}

The new material system consisted of $12 \mathrm{~K}$ bundles of M46J carbon fibers manufactured by Toray Carbon Fibers America, Inc. and TC250 resin manufactured by TenCate Advanced Composites in a unidirectional prepreg. The material properties provided by the donor, SpaceX, and the material manufacturers are shown in Table 2.8.

Table 2.8. M46J/TC250 prepreg characteristics.

\begin{tabular}{|c|c|c|}
\hline Property & Value & Units \\
\hline Fiber Areal Weight (FAW) & 200 & $\mathrm{~g} / \mathrm{m}^{2}$ \\
\hline Fiber Density & 1.84 & $\mathrm{~g} / \mathrm{cm}^{3}$ \\
\hline Resin Density & 1.21 & $\mathrm{~g} / \mathrm{cm}^{3}$ \\
\hline Resin Content (by weight) & $38 \% \pm 3 \%$ & --- \\
\hline
\end{tabular}

In order to calculate the cured ply thickness of M46J/TC250, the composite density $\left(\rho_{c}\right)$ was calculated using [1]

$$
\rho_{c}=V_{f} \rho_{f}+\left(1-V_{f}\right) \rho_{r}
$$

where $\rho_{r}$ was the resin density. The fiber volume fraction $\left(V_{f}\right)$ was calculated using [27]

$$
V_{f}=\frac{1}{1+\frac{\rho_{f}}{\rho_{r}}\left(\frac{1}{W_{f}}-1\right)}
$$

Using the calculated composite density and Eq. 2.3, the cured ply thickness was calculated to be 0.009 in. For a mold cavity estimated to be 0.090 in, 10 plies would fill the mold.

The slightly higher resin content of the prepreg lent itself more to compression molding than the P35/Z03 material. However, the rheology of the material indicated the potential for a lower 
minimum viscosity than P35/Z03 as shown in Figure 2.38. According to this plot, TC250 could reach a minimum viscosity of approximately $1.4 \mathrm{~Pa} \cdot \mathrm{s}$, similar to the viscosity of light corn syrup. Its lower viscosity could cause the resin to flow independently of the fibers during molding.

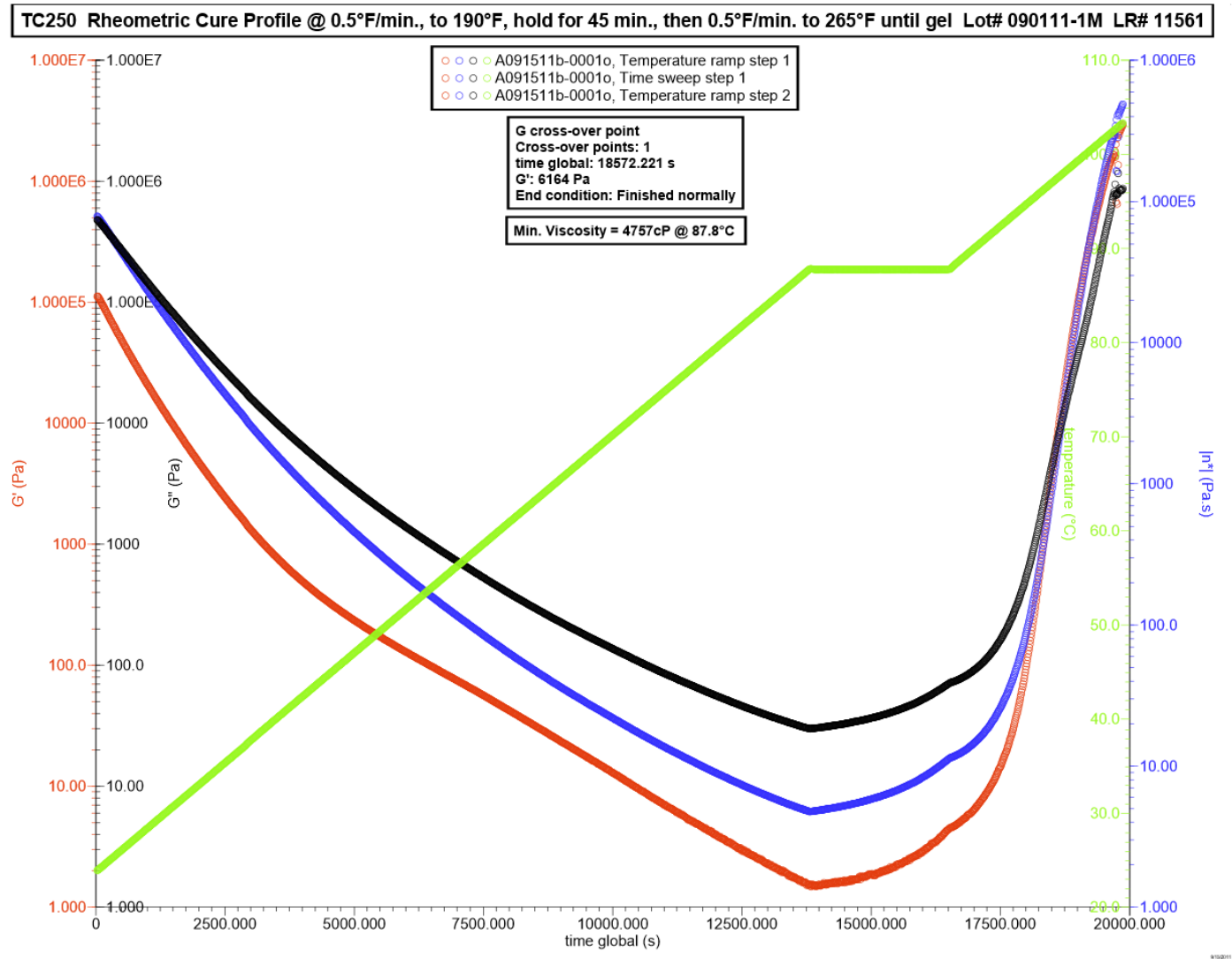

Figure 2.38. Rheometry of TC250 resin system subjected to a 5F/min ramp [28].

Unlike the P35/Z03 material, M46J/TC250 had one singular recommended cure cycle, shown in Figure 2.39. The NCAMP data for TC250 suggested that the initial isothermal hold was optional, so the equivalent compression molding cycle was a $265^{\circ} \mathrm{F}$ isothermal hold for 120 minutes. 


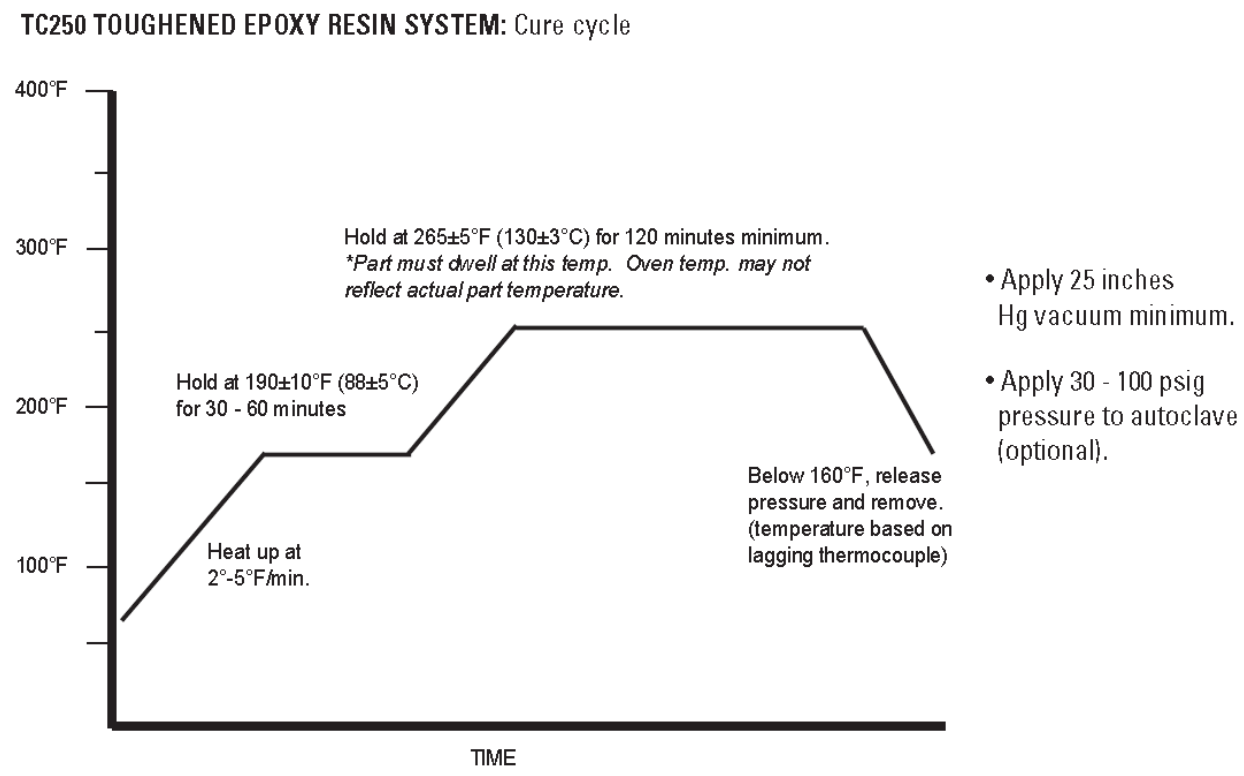

Figure 2.39. Manufacturer recommended cure cycle for TC250 resin.

The mechanical properties of M46J/TC250 were not directly available; properties for the TC250 resin system with a different fiber reinforcement and properties for M46J were available with a different resin matrix. It was expected that the fiber-dominated properties would be closer to those reported for M46J/TC250, but that the resin-dominated properties would be closer to those for the TC250 material. Therefore, the flexural strength from the M46J datasheet was averaged with the calculated (Eq. 2.6) flexural strength of the TC250 composite, and that average was used as a comparison to the experimental flexural strength of these components. Since interlaminar shear strength is a matrix-dominated property, the interlaminar shear strength (ILSS) of TC250 was used as a comparison to the experimental short-beam strength discussed in Section 2.4.4.

The TC250 resin system underwent testing by the National Center for Advanced Materials Performance (NCAMP) and was in the process of being NCAMP-Qualified in 2015. The mechanical properties reported by NCAMP for a unidirectional prepreg system with a Toho Tenax HTS carbon fiber reinforcement are shown in Table 2.9. The reported properties for M46J preimpregnated with a Toray $250^{\circ} \mathrm{F}$ cure resin system are shown in Table 2.10. 
Table 2.9. NCAMP certification properties for HTS/TC250 [29].

\begin{tabular}{|c|c|c|}
\hline Property & Value & Units \\
\hline Tensile Strength & 305.39 & $\mathrm{ksi}$ \\
\hline Tensile Modulus & 20.26 & Msi \\
\hline Compressive Strength & 218.95 & $\mathrm{ksi}$ \\
\hline Compressive Modulus & 19.27 & Msi \\
\hline Interlaminar Shear Strength & 11.20 & $\mathrm{ksi}$ \\
\hline
\end{tabular}

Table 2.10. Composite properties for M46J fibers with a Toray resin system [30].

\begin{tabular}{|c|c|c|}
\hline Property & Value & Units \\
\hline Tensile Strength & 320 & $\mathrm{ksi}$ \\
\hline Tensile Modulus & 38.5 & Msi \\
\hline Compressive Strength & 155 & $\mathrm{ksi}$ \\
\hline Flexural Strength & 210 & $\mathrm{ksi}$ \\
\hline Flexural Modulus & 32.0 & Msi \\
\hline Interlaminar Shear Strength & 11.5 & $\mathrm{ksi}$ \\
\hline
\end{tabular}

\subsubsection{Cure Cycle Selection}

In an effort to shorten the cure cycle time of the TC250 resin, a study was conducted to determine the effects of cure temperature and time on the mechanical properties of the material. Three cure cycles were desired for investigation in order to paint a more complete picture of the effects of cure temperature on the material.

Barry Meyers at TenCate Composites suggested that the shortest cure cycle which would fully cure the TC250 was a $300{ }^{\circ} \mathrm{F}$ isothermal hold for 30 minutes [31]. By plotting the recommended cure cycles for P35/Z03 (Figure 2.40), it was clear that a linear interpolation between the two recommended cure cycles for TC250 would be a conservative method of selecting a third cure cycle for evaluation. A $285^{\circ} \mathrm{F}$ isothermal hold for 70 minutes was selected from the linear interpolation shown in Figure 2.41. 


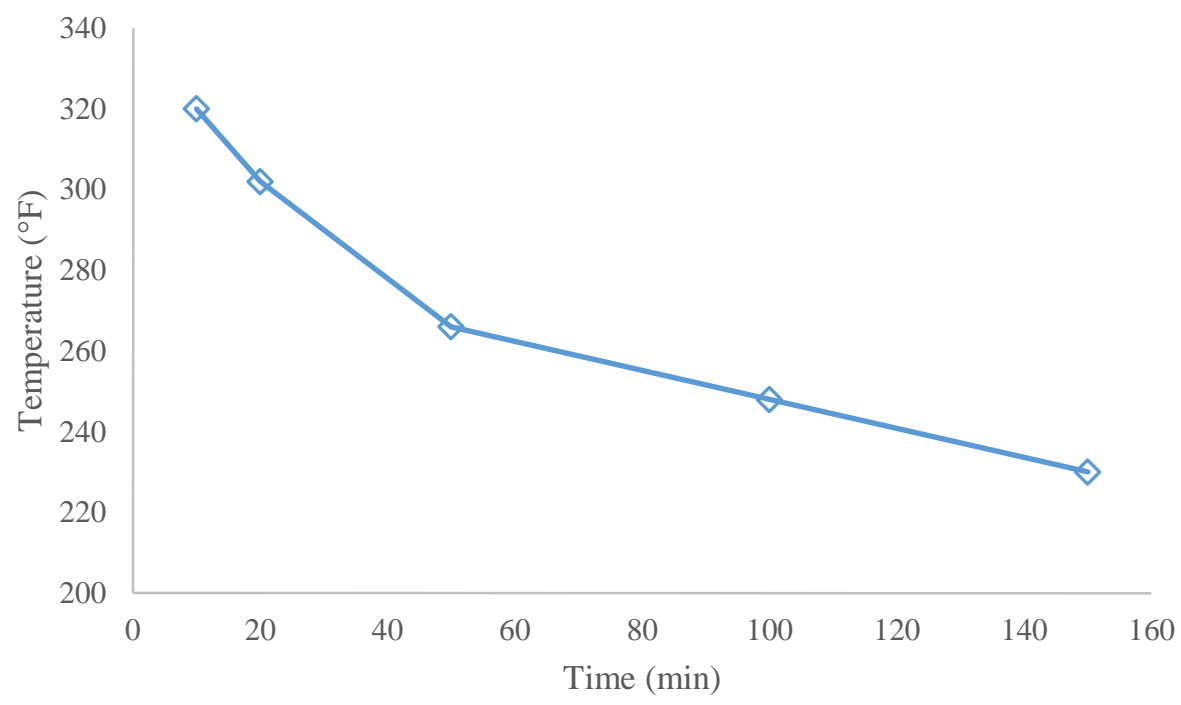

Figure 2.40. Cure temperatures and times for P35/Z03 cure cycles.

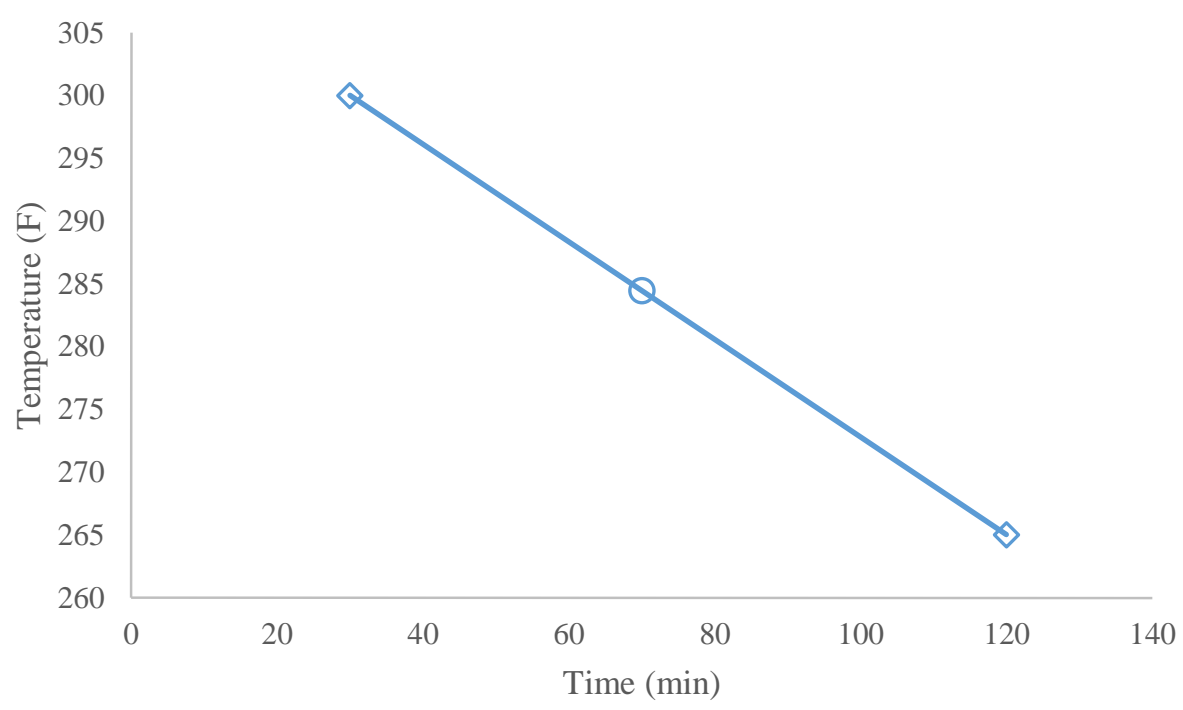

Figure 2.41. Projected cure temperatures and times for M46J/TC250 cure cycles.

Each of the three cure cycles was tested at full time and at half time to test whether a high degree of cure could be achieved with half of the allotted time. All resulting cure cycles were administered to both a 10-ply layup and a 12-ply layup to test the effect of lower resin content on the specimens' mechanical properties. The full test matrix is shown in Table 2.11. Each of the resulting specimens were tested in 3-point bend to compare the quality of each tested cure cycle. 
Table 2.11. Factors and levels for the M64J/TC250 cure cycle experiment.

\begin{tabular}{|c|c|c|}
\hline Temperature $\left({ }^{\circ} \mathbf{F}\right)$ & Time (min) & Plies \\
\hline \multirow{4}{*}{265} & \multirow{2}{*}{120 (full) } & 10 \\
\hline & & 12 \\
\hline & \multirow{2}{*}{60 (half) } & 10 \\
\hline & & 12 \\
\hline \multirow{4}{*}{285} & \multirow{2}{*}{70 (full) } & 10 \\
\hline & & 12 \\
\hline & \multirow{2}{*}{35 (half) } & 10 \\
\hline & & 12 \\
\hline \multirow{4}{*}{300} & \multirow{2}{*}{30 (full) } & 10 \\
\hline & & 12 \\
\hline & \multirow{2}{*}{15 (half) } & 10 \\
\hline & & 12 \\
\hline
\end{tabular}

\subsubsection{Specimen Fabrication}

As the tabs for tensile testing were no longer required for making 3-point bend specimens, dam tape (typically used in vacuum bag cure procedures) was used to block the material from the tab region of the mold, as shown in Figure 2.42. The resulting mold area was 1 in by 3.7 in.

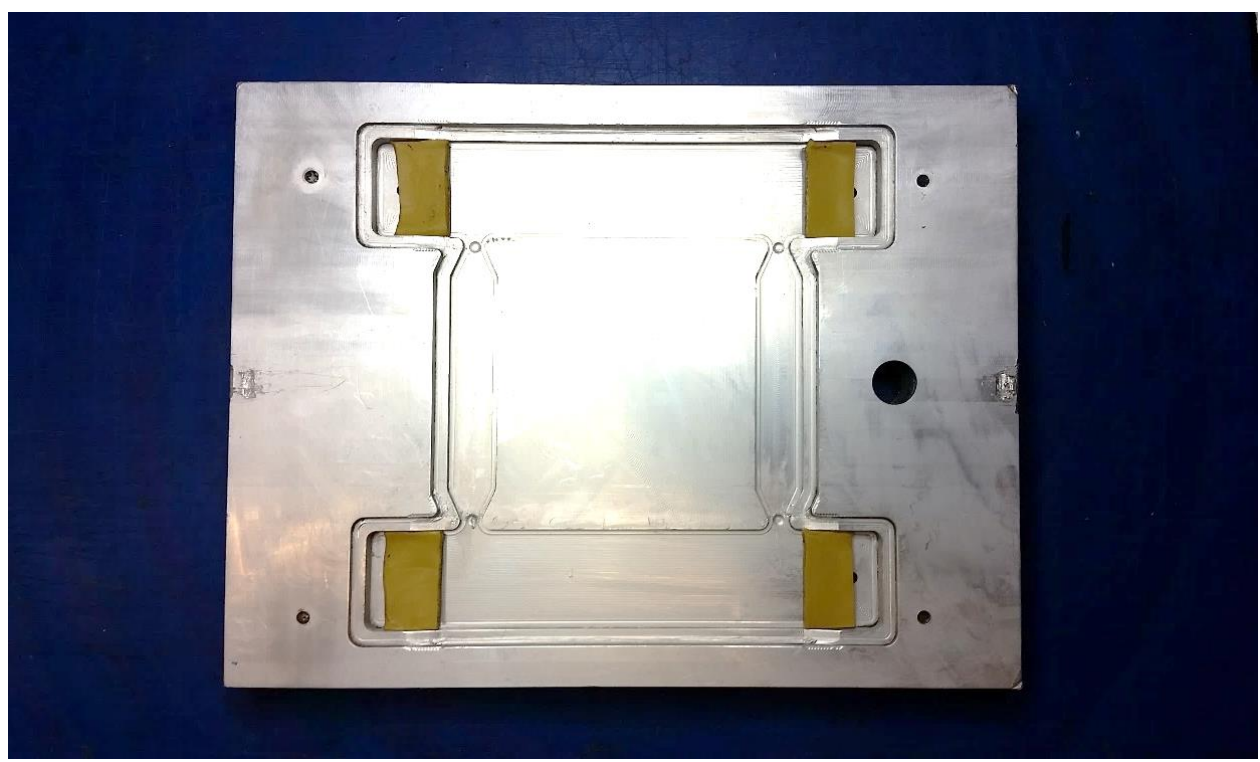

Figure 2.42. Dam tape shutoffs for tab region of mold. 
For each lot, 10 and 12-ply charges were cut to fill the mold area. Parts were cured using the procedure outlined in Section 2.2.2. A representative lot is shown in Figure 2.43.
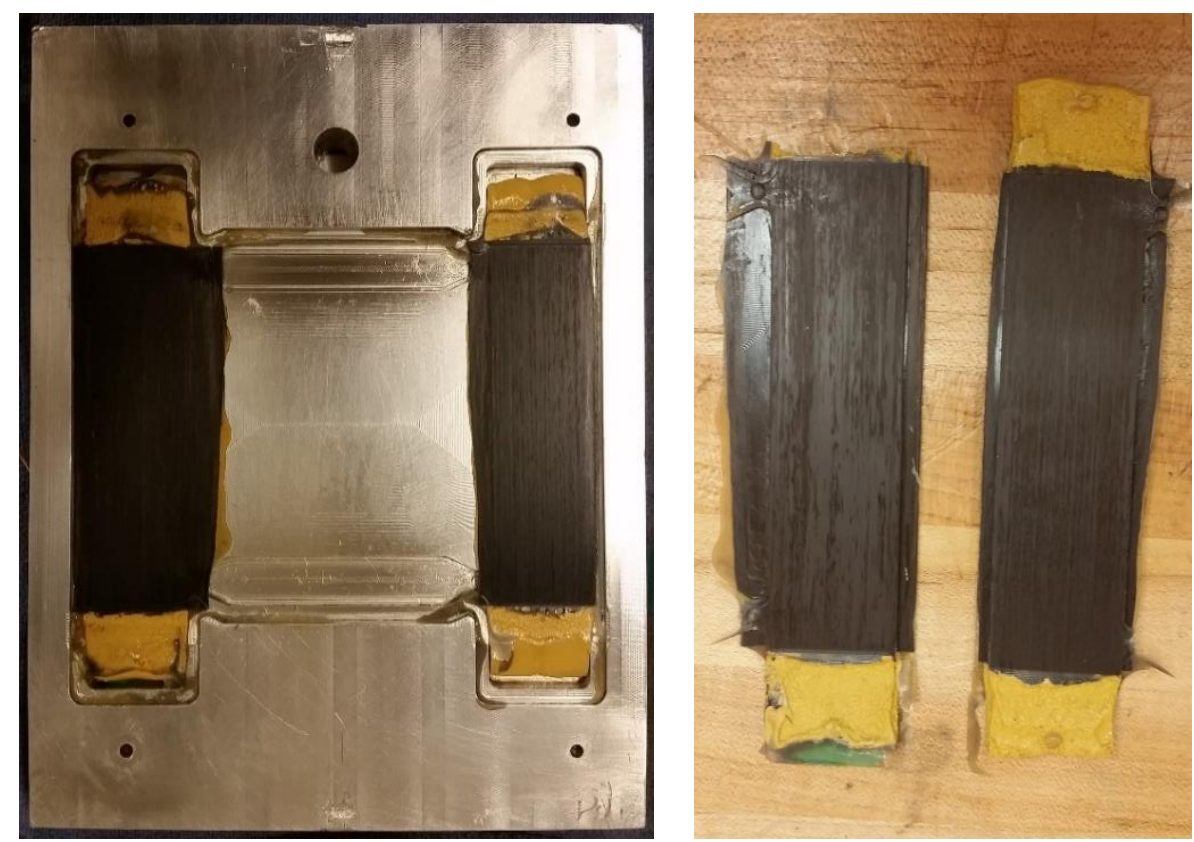

Figure 2.43. Representative lot of M46J/TC250 unidirectional specimens.

Without the tabs, the specimen trimming jig was no longer functional. Instead, the trimming procedure from Cal Poly's ME 412 lab was utilized to trim the specimens and to rip them to their final shape. The specimens were attached to a piece of acrylic with double-sided tape, then trimmed using the wet diamond saw, as shown in Figure 2.44.

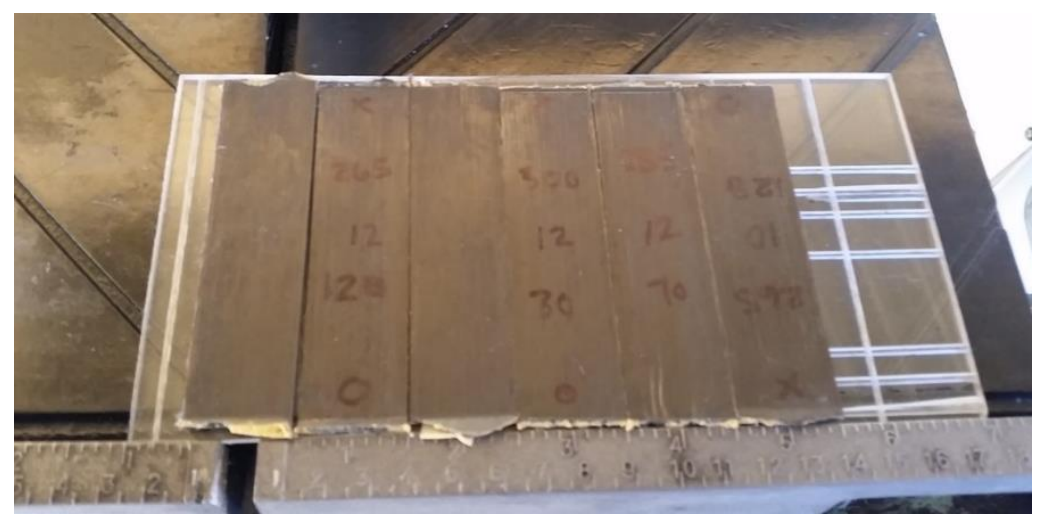

Figure 2.44. M46J/TC250 3-point bend specimens prepared for ripping. 
The thicknesses of the parts produced by the molds were measured in three places along their length after being ripped in half. The results of those measurements are shown in Table 2.12.

Table 2.12. M46J/TC250 specimen thickness measurements.

\begin{tabular}{|c|c|c|c|c|c|c|c|}
\hline Specimen ID & TX & TM & TO & Specimen ID & TX & TM & TO \\
\hline 265-10-L-120 & 0.084 & 0.082 & 0.080 & $265-12-L-120$ & 0.087 & 0.087 & 0.085 \\
\hline 265-10-R-120 & 0.084 & 0.082 & 0.080 & $265-12-R-120$ & 0.088 & 0.088 & 0.086 \\
\hline 265-10-L-60 & 0.083 & 0.082 & 0.079 & $265-12-L-60$ & 0.086 & 0.086 & 0.083 \\
\hline 265-10-R-60 & 0.083 & 0.083 & 0.080 & $265-12-R-60$ & 0.087 & 0.087 & 0.084 \\
\hline 285-10-L-70 & 0.084 & 0.082 & 0.080 & $285-12-L-70$ & 0.087 & 0.087 & 0.086 \\
\hline 285-10-R-70 & 0.084 & 0.083 & 0.080 & $285-12-R-70$ & 0.086 & 0.087 & 0.086 \\
\hline 285-10-L-35 & 0.083 & 0.082 & 0.079 & $285-12-L-35$ & 0.088 & 0.087 & 0.084 \\
\hline 285-10-R-35 & 0.083 & 0.083 & 0.081 & $285-12-R-35$ & 0.087 & 0.088 & 0.086 \\
\hline $300-10-L-30$ & 0.085 & 0.082 & 0.080 & $300-12-L-30$ & 0.088 & 0.088 & 0.086 \\
\hline $300-10-R-30$ & 0.083 & 0.082 & 0.080 & $300-12-R-30$ & 0.088 & 0.088 & 0.086 \\
\hline $300-10-L-15$ & 0.083 & 0.082 & 0.079 & $300-12-L-15$ & 0.087 & 0.087 & 0.087 \\
\hline $300-10-R-15$ & 0.084 & 0.083 & 0.079 & $300-12-R-15$ & 0.088 & 0.088 & 0.085 \\
\hline
\end{tabular}

As discussed in Section 2.2.4, the modifications to the mold decreased the gap between the mold halves, resulting in thinner overall and still consistent parts. However, the imprecise method of modifying the molds resulted in slightly uneven pressure application which caused the $T X$ end to be slightly thicker than the $T O$ end. Additionally, the 12-ply parts were approximately 0.005 in thicker than the 10-ply parts. This could be due to the fact that the 10-ply and 12-ply parts were always manufactured on the same sides, or to the extra material in the 12-ply parts. Regardless, all calculated properties were normalized by the central cross section of the specimen.

\subsubsection{3-Point Bend Results}

Each specimen was tested in 3-point bend per the procedure outlined in Section 2.3.4. The rate of load application was set to $R=0.050 \mathrm{in} / \mathrm{min}$ per Eq. 2.7 and the span was set to $1.35 \mathrm{in}$, about 16 times the average part thickness of 0.084 in. All of the test specimens failed exclusively in microbuckling on the top surface, limiting the damaged region to the point of force application. A lot of tested samples is shown in Figure 2.45. A typical specimen load-displacement curve is 
shown in Figure 2.46. The saw tooth pattern in the elastic portion of the load displacement curve was caused by the sampling rate of the testing apparatus which was set to record 3 data points per second, which was not sufficient to fully capture the high stiffness of the M46J/TC250 material.

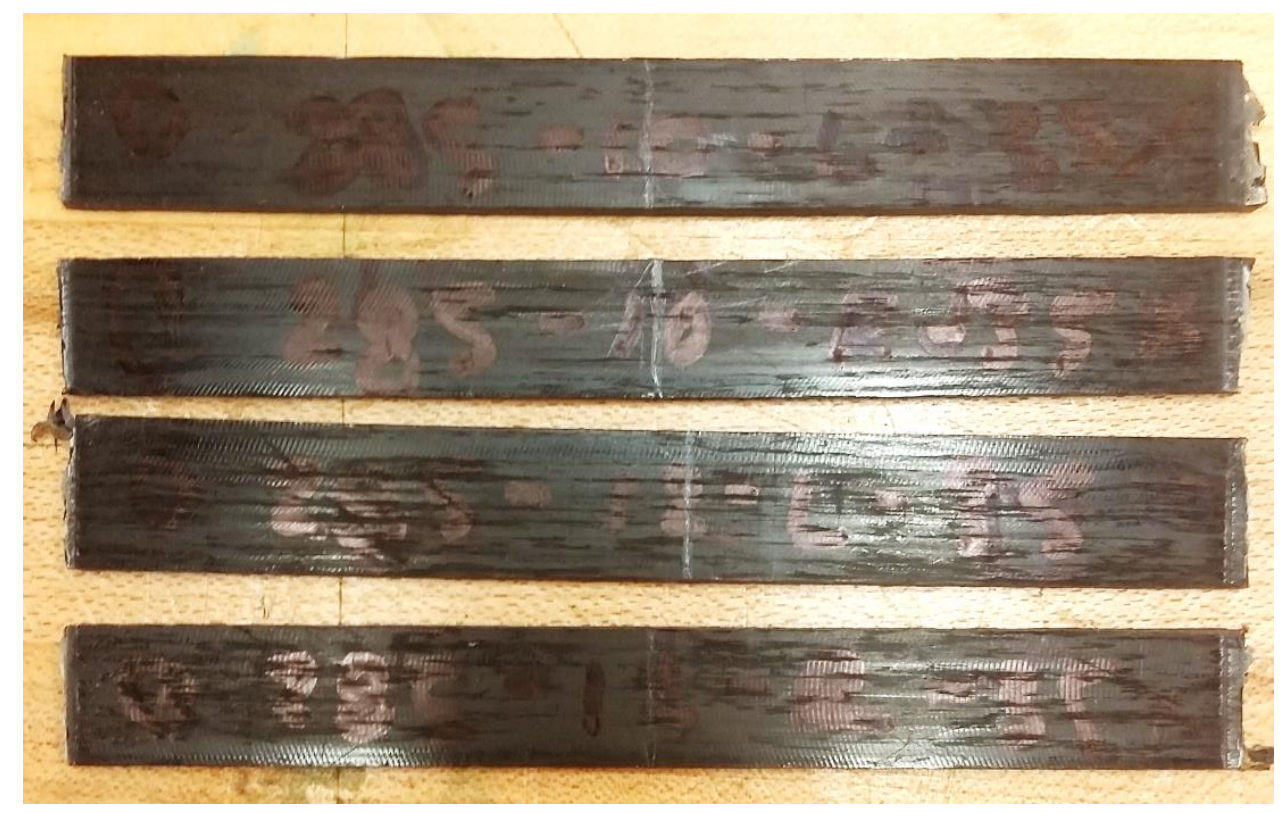

Figure 2.45. Representative tested M46J/TC250 3-point bend specimens.

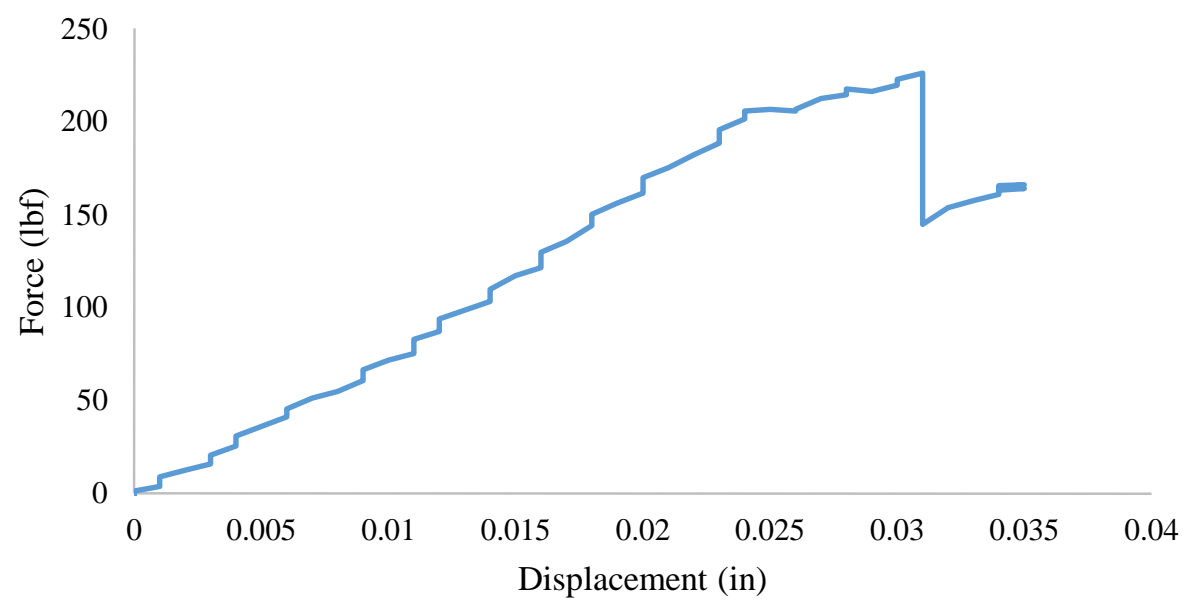

Figure 2.46. Typical load-displacement curve for 3-point bend M46J/TC250 specimen.

The calculated flexural strength, strain, and tangent modulus were calculated using Eq. 2.8 - Eq. 2.10. These values for each specimen are shown in Table 2.13. 
Table 2.13. Flexural strength, strain, and tangent modulus of M46J/TC250 specimens.

\begin{tabular}{|c|c|c|c|}
\hline Specimen ID & $\begin{array}{c}\text { Flexural Strength } \\
(\text { ksi) }\end{array}$ & $\begin{array}{c}\text { Flexural Strain } \\
\text { (in/in) }\end{array}$ & $\begin{array}{c}\text { Tangent Modulus } \\
\text { (Msi) }\end{array}$ \\
\hline 265-10-L-120 & 129 & 0.00729 & 17.3 \\
\hline $265-10-R-120$ & 137 & 0.01053 & 14.6 \\
\hline 265-12-L-120 & 121 & 0.00680 & 17.5 \\
\hline 265-12-R-120 & 118 & 0.00687 & 17.5 \\
\hline 265-10-L-60 & 111 & 0.00773 & 13.9 \\
\hline $265-10-\mathrm{R}-60$ & 108 & 0.00810 & 12.5 \\
\hline 265-12-L-60 & 128 & 0.00784 & 16.6 \\
\hline 265-12-R-60 & 129 & 0.00821 & 15.9 \\
\hline 285-10-L-70 & 115 & 0.00675 & 17.2 \\
\hline $285-10-\mathrm{R}-70$ & 118 & 0.00783 & 14.7 \\
\hline 285-12-L-70 & 129 & 0.00802 & 16.3 \\
\hline 285-12-R-70 & 143 & 0.00878 & 17.3 \\
\hline 285-10-L-35 & 130 & 0.00773 & 16.8 \\
\hline $285-10-R-35$ & 108 & 0.00810 & 12.5 \\
\hline 285-12-L-35 & 132 & 0.00849 & 16.3 \\
\hline 285-12-R-35 & 117 & 0.00773 & 15.2 \\
\hline 300-10-L-30 & 119 & 0.00864 & 16.3 \\
\hline $300-10-R-30$ & 126 & 0.00810 & 15.5 \\
\hline $300-12-\mathrm{L}-30$ & 129 & 0.00831 & 16.1 \\
\hline $300-12-R-30$ & 149 & 0.01031 & 15.7 \\
\hline 300-10-L-15 & 138 & 0.01067 & 14.5 \\
\hline $300-10-R-15$ & 126 & 0.00783 & 16.3 \\
\hline 300-12-L-15 & 128 & 0.00888 & 15.1 \\
\hline 300-12-R-15 & 127 & 0.00802 & 16.8 \\
\hline
\end{tabular}

For comparison, the flexural modulus of M46J/TC250 was estimated by calculating the predicted flexural modulus of HTS/TC250 with Eq. 2.6 and averaging that with the flexural modulus of M46J/Toray 250. This process yielded a predicted flexural modulus of 25.8 Msi.

While the average flexural modulus of the test specimens 15.8 Msi was 39\% lower than the predicted flexural modulus, the M46J/TC250 material was still an improvement on the P35/Z03 material in terms of both mechanical properties and workability. However, to completely evaluate the M46J/TC250 material, short beam shear testing was also performed. 


\subsubsection{Short-Beam Shear Testing and Results}

The short-beam strength of a composite beam is a matrix-driven mechanical property. Thus, testing the specimens in short beam shear provides better insight into the degree of cure of the resin system and also a useful metric for evaluating the quality of the applied cure cycle. It also allows the calculation of the short-beam strength, which may be directly compared to the reported interlaminar shear strength for the TC250 composite. The procedure for conducting a short-beam shear test is provided in ASTM D2344 [13].

Since all of the 3-point bend specimens failed exclusively in the very middle, the ends were left undamaged. Therefore, short-beam shear specimens were created by trimming 1.0 in off of each end of each specimen, giving 48 total specimens.

The 3-point bend test apparatus was used for short-beam shear testing. The test setup for shortbeam shear is very similar to that of the 3-point bend setup (Section 2.3.4), except the rate of load application is fixed at $0.05 \mathrm{in} / \mathrm{min}$ and the span-to-depth ratio is $4: 1$. A typical load-displacement curve is shown in Figure 2.47.

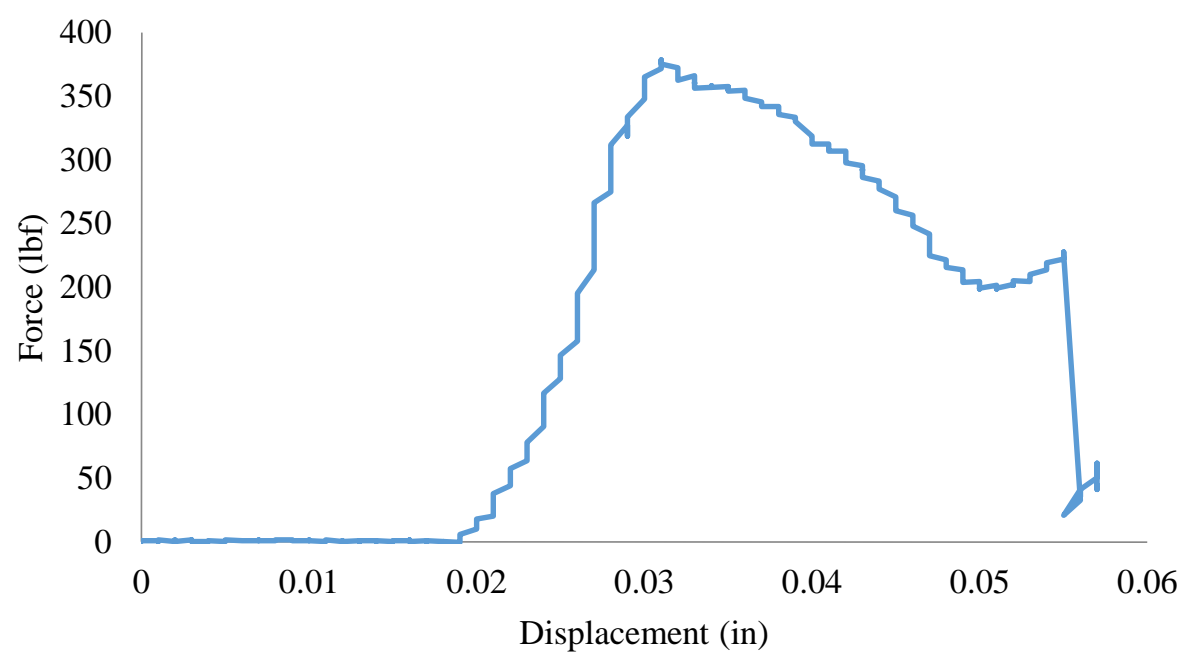

Figure 2.47. Typical load-displacement curve for short-beam shear M46J/TC250 specimen. 
The majority of specimens failed in inelastic deformation. According to a recent study [32], composite laminates with low porosity tend to fail in inelastic deformation. This indicates that, for all cure cycles, good compaction and substantial devolatilization were achieved.

The short-beam shear strength $\left(F_{s b s}\right)$ was calculated using [13]

$$
F_{s b s}=0.75\left(\frac{P_{\max }}{b h}\right)
$$

The calculated short-beam strength for each test specimen is shown in Table 2.14. Detailed calculations may be found in Appendix C.3.

Table 2.14. Short-beam strength of M46J/TC250 specimens.

\begin{tabular}{|c|c|c|c|}
\hline Specimen ID & $\begin{array}{c}\text { Short-Beam } \\
\text { Strength (ksi) }\end{array}$ & Specimen ID & $\begin{array}{c}\text { Short-Beam } \\
\text { Strength (ksi) }\end{array}$ \\
\hline 265-10-L-120-A & 7.93 & $265-10-\mathrm{L}-120-\mathrm{B}$ & 7.67 \\
\hline 265-10-R-120-A & 7.85 & $265-10-\mathrm{R}-120-\mathrm{B}$ & 8.39 \\
\hline $265-12-\mathrm{L}-120-\mathrm{A}$ & 8.51 & $265-12-\mathrm{L}-120-\mathrm{B}$ & 8.82 \\
\hline $265-12-\mathrm{R}-120-\mathrm{A}$ & 8.33 & $265-12-\mathrm{R}-120-\mathrm{B}$ & 8.76 \\
\hline $265-10-\mathrm{L}-60-\mathrm{A}$ & 7.52 & $265-10-\mathrm{L}-60-\mathrm{B}$ & 7.62 \\
\hline $265-10-\mathrm{R}-60-\mathrm{A}$ & 7.51 & $265-10-\mathrm{R}-60-\mathrm{B}$ & 7.91 \\
\hline $265-12-\mathrm{L}-60-\mathrm{A}$ & 8.63 & $265-12-\mathrm{L}-60-\mathrm{B}$ & 8.69 \\
\hline $265-12-\mathrm{R}-60-\mathrm{A}$ & 8.93 & $265-12-\mathrm{R}-60-\mathrm{B}$ & 8.73 \\
\hline $285-10-\mathrm{L}-70-\mathrm{A}$ & 7.82 & $285-10-\mathrm{L}-70-\mathrm{B}$ & 8.40 \\
\hline $285-10-\mathrm{R}-70-\mathrm{A}$ & 7.80 & $285-10-\mathrm{R}-70-\mathrm{B}$ & 8.27 \\
\hline $285-12-\mathrm{L}-70-\mathrm{A}$ & 8.84 & $285-12-\mathrm{L}-70-\mathrm{B}$ & 8.95 \\
\hline $285-12-\mathrm{R}-70-\mathrm{A}$ & 9.03 & $285-12-\mathrm{R}-70-\mathrm{B}$ & 8.68 \\
\hline $285-10-\mathrm{L}-35-\mathrm{A}$ & 7.72 & $285-10-\mathrm{L}-35-\mathrm{B}$ & 7.50 \\
\hline $285-10-\mathrm{R}-35-\mathrm{A}$ & 7.94 & $285-10-\mathrm{R}-35-\mathrm{B}$ & 7.79 \\
\hline $285-12-\mathrm{L}-35-\mathrm{A}$ & 8.97 & $285-12-\mathrm{L}-35-\mathrm{B}$ & 8.14 \\
\hline $285-12-\mathrm{R}-35-\mathrm{A}$ & 8.66 & $285-12-\mathrm{R}-35-\mathrm{B}$ & 8.51 \\
\hline $300-10-\mathrm{L}-30-\mathrm{A}$ & 8.06 & $300-10-\mathrm{L}-30-\mathrm{B}$ & 7.75 \\
\hline $300-10-\mathrm{R}-30-\mathrm{A}$ & 8.31 & $300-10-\mathrm{R}-30-\mathrm{B}$ & 8.15 \\
\hline $300-12-\mathrm{L}-30-\mathrm{A}$ & 8.85 & $300-12-\mathrm{L}-30-\mathrm{B}$ & 8.42 \\
\hline $300-12-\mathrm{R}-30-\mathrm{A}$ & 9.06 & $300-12-\mathrm{R}-30-\mathrm{B}$ & 8.79 \\
\hline $300-10-\mathrm{L}-15-\mathrm{A}$ & 8.05 & $300-10-\mathrm{L}-15-\mathrm{B}$ & 7.95 \\
\hline $300-10-\mathrm{R}-15-\mathrm{A}$ & 7.85 & $300-10-\mathrm{R}-15-\mathrm{B}$ & 7.80 \\
\hline $300-12-\mathrm{L}-15-\mathrm{A}$ & 8.31 & $300-12-\mathrm{L}-15-\mathrm{B}$ & 8.05 \\
\hline $300-12-\mathrm{R}-15-\mathrm{A}$ & 8.70 & $300-12-\mathrm{R}-15-\mathrm{B}$ & 8.37 \\
\hline
\end{tabular}


The average short-beam strength of the M46J/TC250 specimens was $8.28 \mathrm{ksi}$, approximately $26 \%$ lower than the reported interlaminar shear strength of $11.2 \mathrm{ksi}$ for a TC250 composite system. However, the calculated values for short-beam strength appear to be consistent for all cure cycles, indicating that a similar degree of cure was reached as a result of each. To more closely examine any differences between each cure cycle, a design of experiments approach was utilized to determine the effect that each cure cycle had on the parts it produced.

\subsubsection{Cure Cycle Factor Effects Study}

While the flexural and short-beam strengths of each specimen appear to be consistent, hidden trends may be present which indicate the quality of one cure cycle over another. Response surface methodology is defined as "a collection of mathematical and statistical techniques useful for the modeling and analysis of problems in which a response of interest is influenced by several variables and the objective is to optimize this response." [33]

Response surface methodology was used to determine the effects of each facet of the cure cycle on the mechanical properties of the M46J/TC250 material. This study was documented in a report for Cal Poly's IME 427 [34]. A full data reduction for the analysis may be found in Appendix D.

The factors and levels for the experiment were given in Table 2.11. The responses were flexural strength, tangent modulus, and short-beam strength. For simplicity, the short-beam strengths for any two samples from the same specimen were averaged in this analysis. All data were analyzed in Minitab 16 Statistical Software using a response surface analysis.

The analysis revealed that none of the cure cycle factors had a statistically significant effect on the mechanical properties of the specimens, which means that all of the cure cycles produced statistically similar specimens. However, the main factor effects were the most significant and showed clear trends for each response. The 12-ply layups were stronger overall than the 10-ply 
layups, even in short-beam shear, which is a matrix-driven property; perhaps due to better consolidation. The specimens which were subjected to a full-time cure were also stronger. In general, the temperature of the cure was not a significant factor, but a slight drop-off in shortbeam strength for the $300{ }^{\circ} \mathrm{F}$ cure suggested that the $285^{\circ} \mathrm{F}$ cure for 70 minutes would produce the strongest M46J/TC250 specimens of the tested cure cycles.

\subsection{Comparison to Autoclave}

As a final quality check for the new manufacturing method and cure cycle, comparable specimens were manufactured using the traditional vacuum bag and autoclave method. The autoclave specimens were tested under the same conditions as the compression molded specimens to ensure that compression molding did not compromise the material.

\subsubsection{Autoclave Specimen Manufacture}

The specimens were cut from the same M46J/TC250 material to the same dimensions as the adjusted 3-point bend parts produced by the mold. Specimens were laid up on brown Teflon release film over a thick aluminum caul plate, separated by foam dam tape (Figure 2.48). The specimens were then covered with another layer of release and individual caul plates were attached to the top of each (Figure 2.49). Finally, the assembly was covered in breather and sealed in a vacuum bag with a vacuum valve (Figure 2.50 ). 


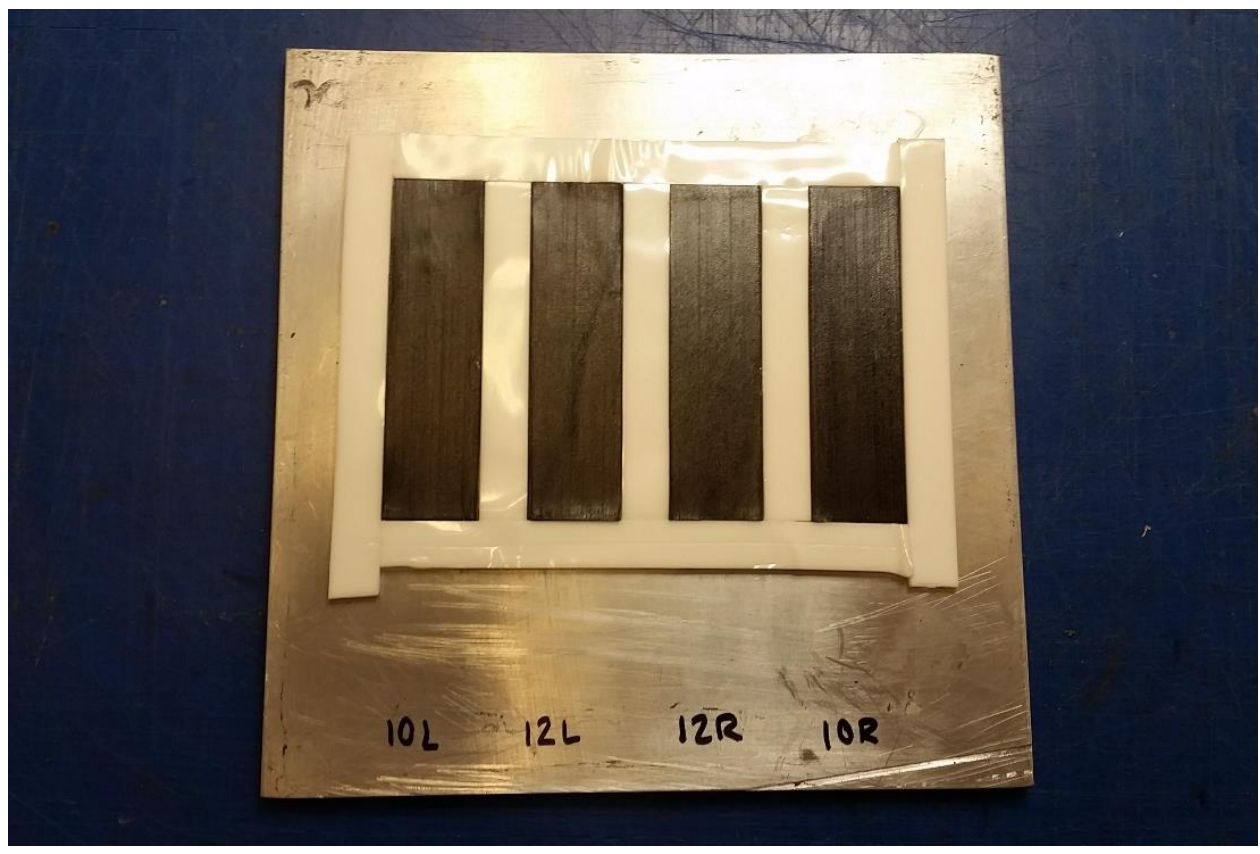

Figure 2.48. Autoclave specimens on caul plate, separated by dam tape.

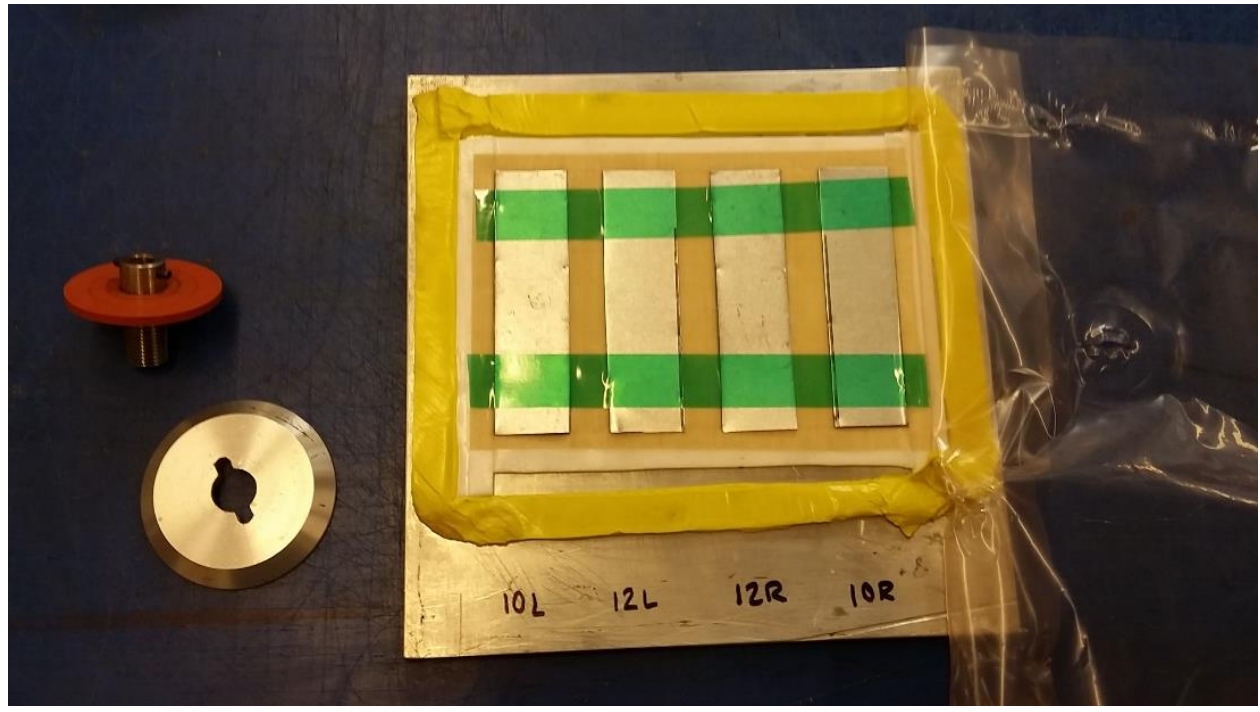

Figure 2.49. Individual caul plates for each autoclave specimen. 


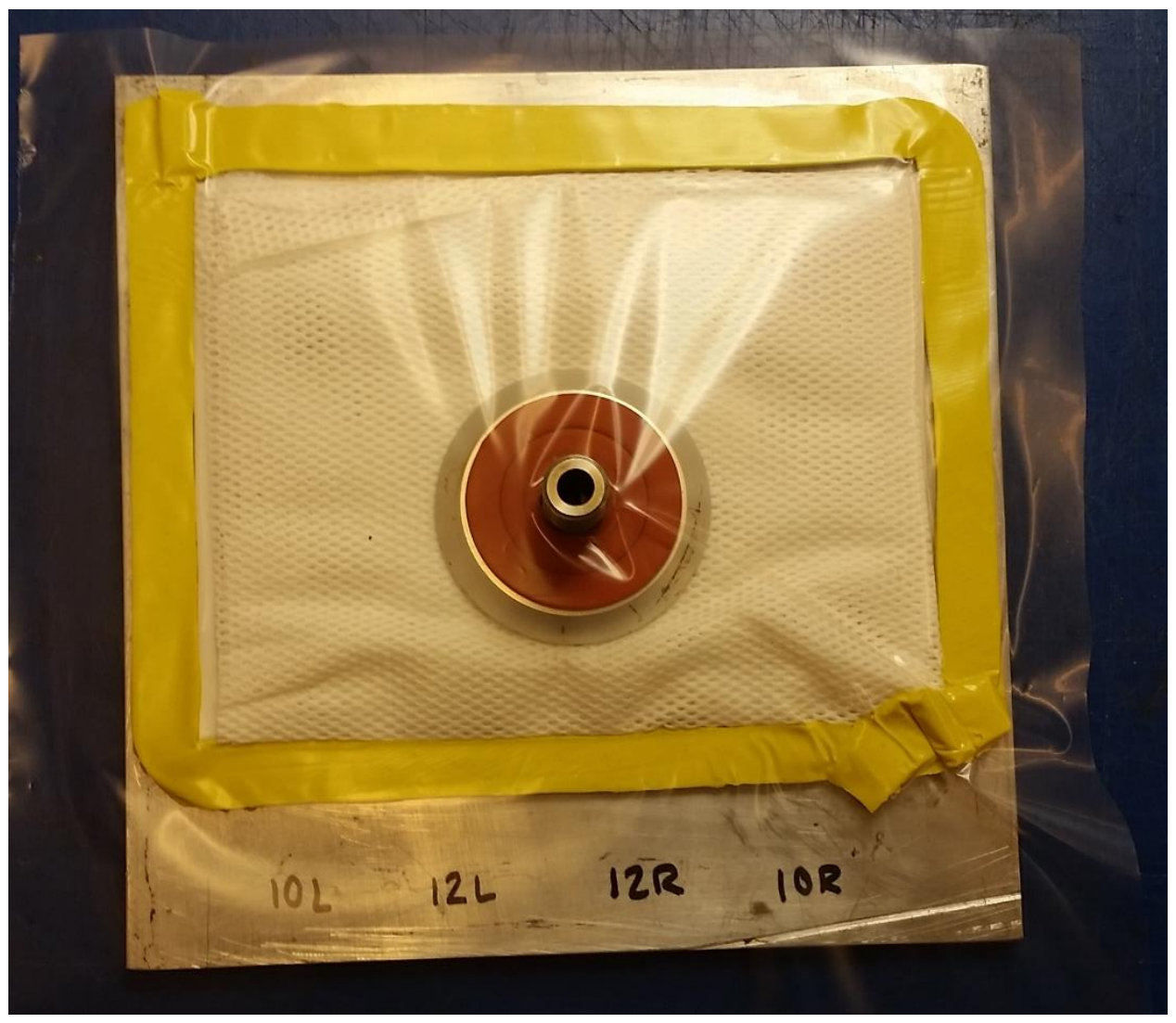

Figure 2.50. Completed vacuum bag ready for vacuum fitting and autoclave cure.

The autoclave used to cure the specimens was a $2 \times 4 \mathrm{ft}$ Econoclave manufactured by ASC Process Systems. It was equipped with automatic cooling, pressurizing, and pressure relief systems as well as a safety relief valve [35]. The specimens were cured using the manufacturer recommended cure cycle shown in Figure 2.39. The specimens and bagging material required to manufacture the specimens are shown in Figure 2.51. Once debagged, the parts were trimmed and ripped using the procedure outlined in Section 2.4.2. 


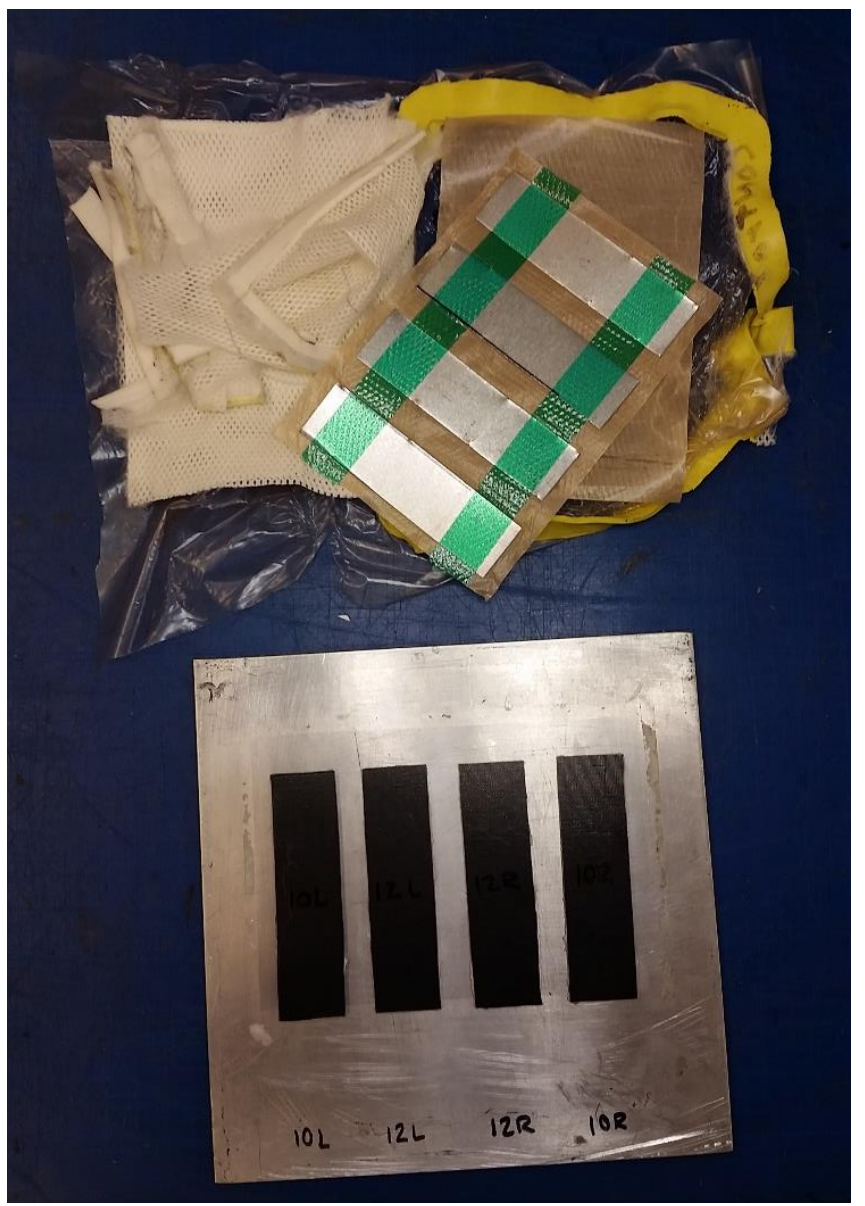

Figure 2.51. Fully cured autoclave specimens and used bagging material.

To compare the dimensional stability of autoclave parts to that of the compression molded parts, the thickness of each specimen was measured in the same locations. The measurements are shown in Table 2.15 .

Table 2.15. Thickness dimensions for 10 and 12-ply M46J/TC250 autoclave specimens.

\begin{tabular}{|c|c|c|c|c|}
\hline Dimension & $\mathbf{1 0 L}$ & $\mathbf{1 2 L}$ & $\mathbf{1 2 R}$ & $\mathbf{1 0 R}$ \\
\hline $\mathrm{T} 1$ & 0.085 & 0.108 & 0.103 & 0.086 \\
\hline $\mathrm{T} 2$ & 0.090 & 0.108 & 0.095 & 0.086 \\
\hline $\mathrm{T} 3$ & 0.082 & 0.102 & 0.099 & 0.084 \\
\hline $\mathrm{B} 1$ & 0.083 & 0.105 & 0.103 & 0.087 \\
\hline B2 & 0.085 & 0.104 & 0.100 & 0.086 \\
\hline B3 & 0.081 & 0.102 & 0.100 & 0.086 \\
\hline Average & 0.084 & 0.105 & 0.100 & 0.086 \\
\hline
\end{tabular}


In the case of the autoclave specimens, the number of plies makes a significant difference in their thickness. The specimens are also less consistent, likely due to the quality of the caul plates used to distribute the vacuum during cure. These dimensions could not be directly compared to the compression molded specimens, but gave a good idea of the compaction achieved for the 12-ply specimens since the 10 and 12-ply compression molded specimens have similar thicknesses.

\subsubsection{3-Point Bend Testing and Comparison}

The autoclave specimens were tested using the same procedure as the compression molded specimens, as outlined in Section 2.3.4. The mechanical properties are shown in Table 2.16.

Table 2.16. Flexural strength, strain, and tangent modulus of autoclave specimens.

\begin{tabular}{|c|c|c|c|}
\hline Specimen ID & $\begin{array}{c}\text { Flexural Strength } \\
\text { (ksi) }\end{array}$ & $\begin{array}{c}\text { Flexural Strain } \\
\text { (in/in) }\end{array}$ & $\begin{array}{c}\text { Tangent Modulus } \\
\text { (Msi) }\end{array}$ \\
\hline AC10L-L & 123 & 0.00769 & 16.7 \\
\hline AC10L-R & 140 & 0.00882 & 16.3 \\
\hline AC10R-L & 134 & 0.00873 & 16.8 \\
\hline AC10R-R & 135 & 0.00975 & 17.0 \\
\hline AC12L-L & 117 & 0.00784 & 16.6 \\
\hline AC12L-R & 109 & 0.00696 & 15.2 \\
\hline AC12R-L & 143 & 0.01172 & 14.2 \\
\hline AC12R-R & 125 & 0.00895 & 15.8 \\
\hline
\end{tabular}

The average tangent modulus of the autoclave specimens, $16.1 \mathrm{Msi}$, was only slightly higher than that of the compression molded specimens (15.8 Msi), which indicates that the specimen quality is comparable in flexure.

\subsubsection{Short-Beam Shear Testing and Comparison}

For completeness, the autoclave specimens were also tested in short-beam shear. Comparable short beam shear strengths would indicate a similar degree of cure for both the compression 
molded specimens and autoclave specimens. The short-beam strength of the autoclave specimens is shown in Table 2.17 .

Table 2.17. Short-beam strength of autoclave M46J/TC250 specimens.

\begin{tabular}{|c|c|c|c|}
\hline Specimen ID & $\begin{array}{c}\text { Short-Beam } \\
\text { Strength (ksi) }\end{array}$ & Specimen ID & $\begin{array}{c}\text { Short-Beam } \\
\text { Strength (ksi) }\end{array}$ \\
\hline AC10-LLA & 8.83 & AC12-LLA & 8.69 \\
\hline AC10-LLB & 9.76 & AC12-LLB & 10.0 \\
\hline AC10-LRA & 8.85 & AC12-LRA & 8.67 \\
\hline AC10-LRB & 9.85 & AC12-LRB & 9.58 \\
\hline AC10-RLA & 8.47 & AC12-RLA & 8.33 \\
\hline AC10-RLB & 10.9 & AC12-RLB & 9.83 \\
\hline AC10-RRA & 9.06 & AC12-RRA & 9.17 \\
\hline AC10-RRB & 9.13 & AC12-RRB & 9.47 \\
\hline
\end{tabular}

The average short-beam strength of the autoclave specimens was $9.2 \mathrm{ksi}$, approximately $12.4 \%$ higher than that of the compression molded specimens. The autoclave short-beam specimens tended to fail more progressively than the compression molded specimens. They cracked continuously until ultimate failure whereas, in general, the compression molded parts failed all at once. However, the compression molded specimens had a more consistent shear strength.

\subsubsection{Manufacturing Time Comparison}

Designing a mold suitable for compression molding of carbon fiber was a long and thorough process. Careful consideration was given to geometric constraints, machining limitations, and material properties in order to produce the mold used for these experiments. The procedure that Karlos Guzman used to manufacture the molds took approximately ?? from design to machined and seasoned mold.

However, the compression molding manufacturing method is well-suited to the production of multiple repeatable specimens with properties similar to those of autoclave specimens. The compression molded specimens were mechanically similar to the autoclave specimens, as shown 
in Sections 2.5.2 and 2.5.3. Compression molded specimens also had superior dimensional stability, as shown in Section 2.5.1. However, the autoclave specimens took much longer to manufacture than the compression molded specimens. A manufacturing time breakdown for a single specimen fabricated using each method is shown in Table 2.18.

Table 2.18. Manufacturing time for compression molded and autoclave specimens.

\begin{tabular}{|c|c|c|}
\hline Procedure & Compression Molding & Autoclave \\
\hline Preparation for layup & $\begin{array}{l}\text { - Apply F57-NC to mold } \\
\text { Time: } 10 \text { min }\end{array}$ & $\begin{array}{l}\text { - Program autoclave cycle } \\
\text { Time: } 10 \text { min }\end{array}$ \\
\hline Ply cutting and layup & $\begin{array}{l}\text { - Cut plies } \\
\text { - Form charges } \\
\text { - Place into mold } \\
\text { Time: } \mathbf{2 0 ~} \mathbf{~ m i n}\end{array}$ & $\begin{array}{l}\text { - Cut plies } \\
\text { - Form charges } \\
\text { - Form vacuum bag } \\
\text { - Check and repair bag leaks } \\
\text { Time: } \mathbf{4 0} \text { min }\end{array}$ \\
\hline Cure & $\begin{array}{l}\text { - Pre-heat platens } \\
\text { - Place mold, apply pressure } \\
\text { - Start timer when cure } \\
\text { temperature is reached } \\
\text { - Remove mold } \\
\text { Time: } \mathbf{8 0} \text { min }\end{array}$ & $\begin{array}{l}\text { - Apply vacuum to parts } \\
\text { - } \text { Lock autoclave door } \\
\text { - } \text { Start program } \\
\text { - Allow program to run } \\
\text { - depressurize } \\
\text { - Unlock autoclave door } \\
\text { - Remove parts } \\
\text { Time: } \mathbf{2 3 0} \text { min }\end{array}$ \\
\hline Demolding/debagging & $\begin{array}{l}\text { - Press parts out with ejector } \\
\text { pin plate } \\
\text { Time: } \mathbf{5} \text { min }\end{array}$ & $\begin{array}{l}\text { - Remove vacuum bag } \\
\text { - Peel parts off of release } \\
\text { - Peel dam material off of parts } \\
\text { Time: } 10 \text { min }\end{array}$ \\
\hline Post-processing & $\begin{array}{l}\text { - } \text { Trim flash } \\
\text { - Rip in half } \\
\text { Time: } 20 \text { min } \\
\end{array}$ & $\begin{array}{l}\text { - } \text { Trim edges } \\
\text { - Rip in half } \\
\text { Time: } 20 \text { min }\end{array}$ \\
\hline Total & Time: 135 min & Time: 310 min \\
\hline
\end{tabular}




\section{Chapter 3. Chopped Fiber Integration}

Before integrating chopped fiber into a functional design, it was necessary to fully characterize and understand the new material form. Multiple methods of creating the chopped fiber material from M46J/TC250 prepreg were attempted. An initial chopped fiber lot produced parts which were sufficiently random, but revealed that the tensile specimen mold was not well-suited to the compression molding of chopped fibers.

A new mold was designed and manufactured which would create simple 3-point bend specimens. It was analyzed using SolidWorks thermal simulation to ensure that the mold would reach the cure temperature at the anticipated time. The previously determined cure cycle for M46J/TC250 was used to cure the material, but adjustments were made to pressure application time to account for the low viscosity of the TC250 resin system. Layup and molding techniques were evaluated by producing continuous fiber parts in the new mold in addition to chopped fiber parts.

Both specimen types were tested in 3-point bend. Inconclusive 3-point bend test results for the chopped fiber specimens led to experimentation with 4-point bend loading instead. The findings from 4-point bend testing drove the development of a MATLAB script which predicted the strength of a sandwich structure composed of continuous fibers and chopped fibers using composite laminate theory (CLT) and a simplified Tsai-Wu failure criterion. The results from this code were evaluated experimentally using 4-point bend testing.

\subsection{Chopped Fiber Manufacture}

Creating a functionally graded component from unidirectional scrap involves first choosing a chopped fiber length, then chopping those fibers. Longer chopped fibers tend to yield parts which are stronger in tension where shorter-fiber parts had lower flexure strength, but higher flexural stiffness [36]. Common sheet molding and bulk molding compound fiber lengths range from 0.25 
in to 1 in [22] [24] [37]. For the small test specimens manufactured for this experiment, 1 in fibers would likely not achieve sufficient randomization within the space of the mold cavity. Considering the possibility of using the smaller short-beam specimen mold cavity, a fiber length of 0.25 in was selected. Relative to the scale of the specimens being manufactured, a 0.25 in fiber length was still large, but was also not so small that it was infeasible to manufacture.

\subsubsection{Chopped Prepreg Manufacture}

A number of methods were attempted for creating chopped fibers. A satisfactory chopping method would create randomly-oriented, consistently-sized fibers with minimal effort in a short amount of time. Method \#1 involved attempting to cut the prepreg into 0.25 in square chips. Initially, the prepreg was cut transversely into 0.25 in strips with a sliding blade, but the blade dulled quickly, as shown in Figure 3.1.
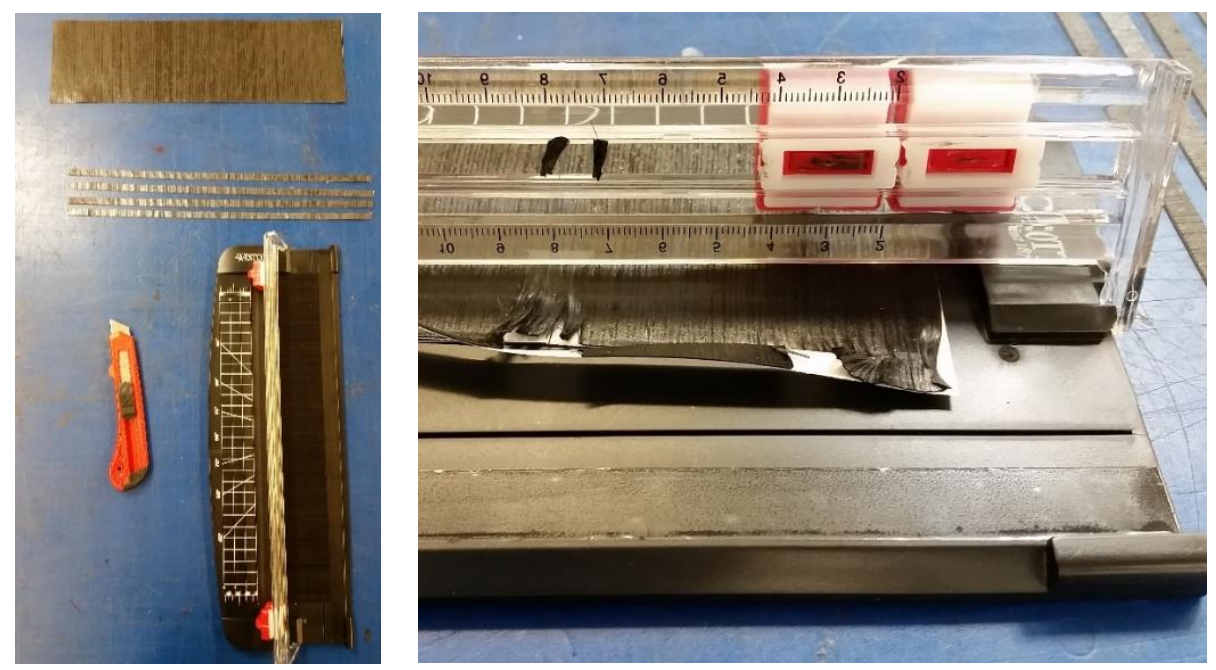

Figure 3.1. Method \#1: sliding blade cutter used to cut transverse 0.25 in strips.

Additionally, cutting the strips into squares required careful removal of the backing paper from each square. Removing the backing from the strips deformed the strip, preventing the controlled trimming into squares. Removing the paper backing before trimming the material into strips also resulted in excessively deformed square. 
The next attempt also aimed to cut the plies into squares to be dropped into the mold to achieve a random orientation. While removing the backing paper from the entire sheet was unsuccessful, leaving reinforcement at the ends of the fibers to be cut seemed to prevent the squares from deforming while being cut. The center of the backing paper was removed by outlining the working section with a laser cutter. The working section was then cut along the fibers in 0.25 in increments and trimmed across the fibers with a rolling cutter. The general process is shown in Figure 3.2. The resulting squares are shown in Figure 3.3.
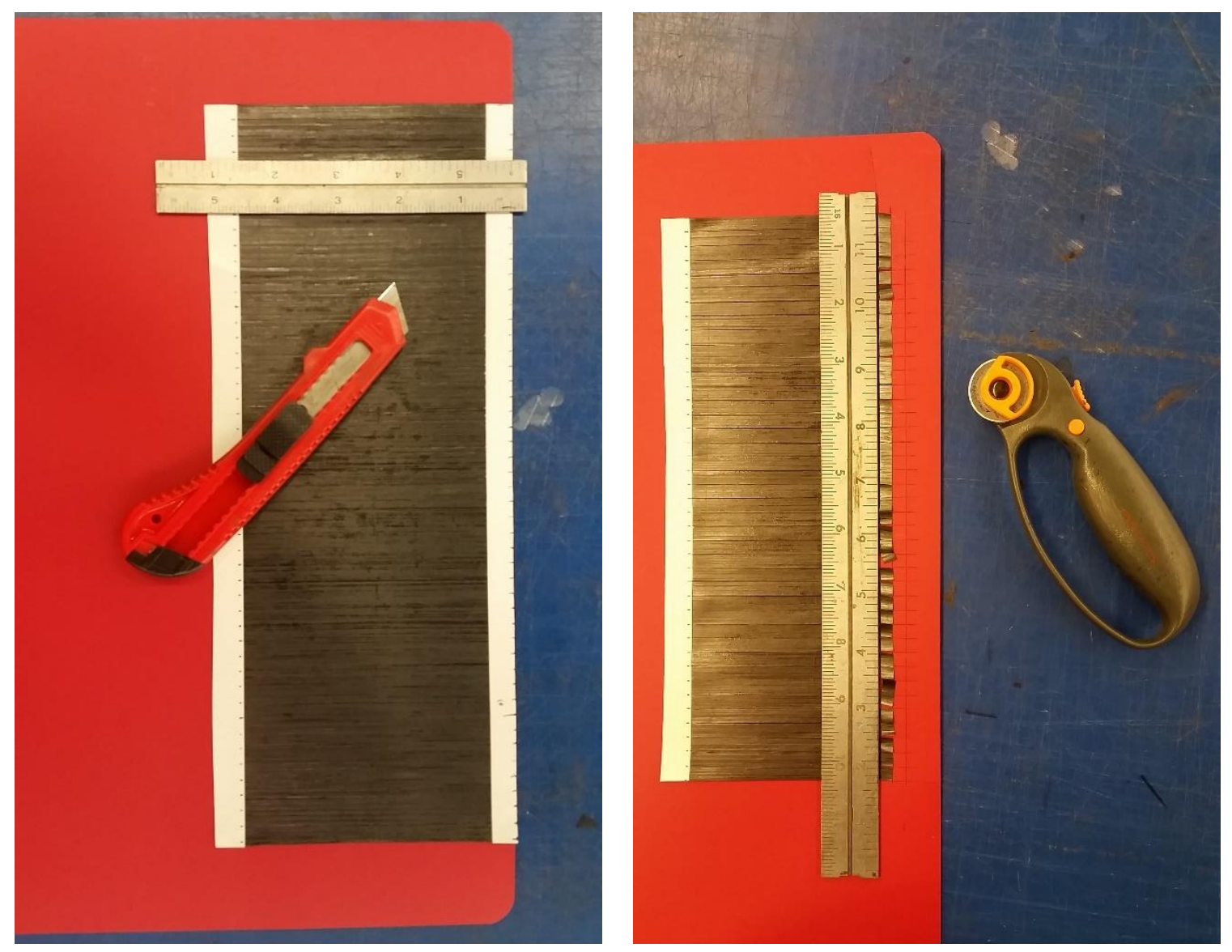

Figure 3.2. Process for cutting 0.25 in squares using Method \#2. 


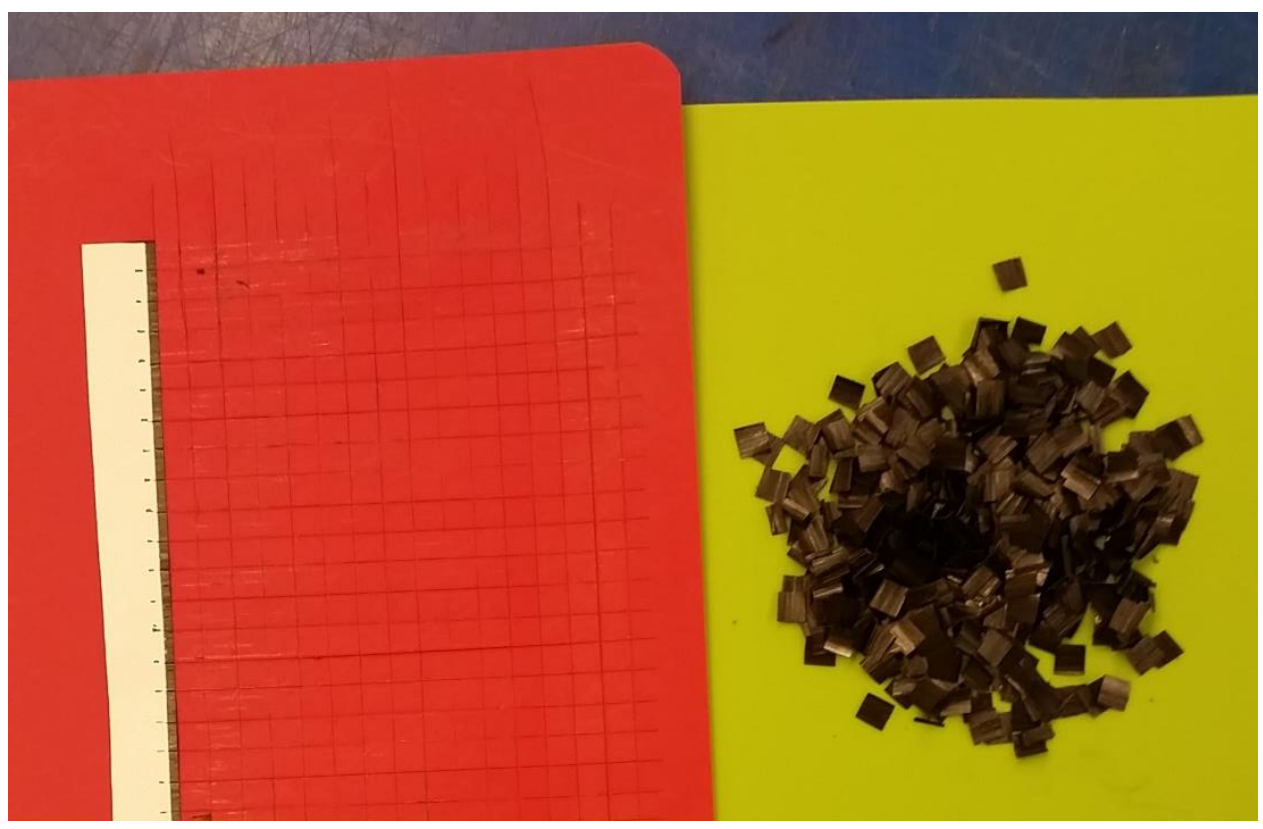

Figure 3.3. Resulting equipment and material from Method \#2.

While Method \#2 successfully created 0.25 in squares from the prepreg material, the procedure to create the equivalent of a 10-ply part took approximately 2 hours. It also required the use of a laser, which is not a universally available piece of equipment, and destroyed the cutting boards used to keep the material clean. Additionally, the squares which were produced by Method \#2 were still very tacky and were therefore difficult to distribute.

Research into the commercial manufacture of SMC and BMC revealed that prepregs are subjected to an additional aging process before chopping to prevent the prepreg from sticking to the cutting apparatus. An attempt was made to artificially age the prepreg using a heat gun. The heat gun method was not effective, but the material became more workable after approximately 3 days of room temperature exposure. Method \#2 still took a long time and consumed multiple cutting boards, but the experimentation yielded enough material to produce two test specimens. 


\subsubsection{Layup and Cure}

Before molding, the disarrayed squares of prepreg were placed into a preform in the shape of the mold to ensure that all of the material would be pressed into the mold cavity. The material in the preform was then transferred into the mold, as shown in Figure 3.4.
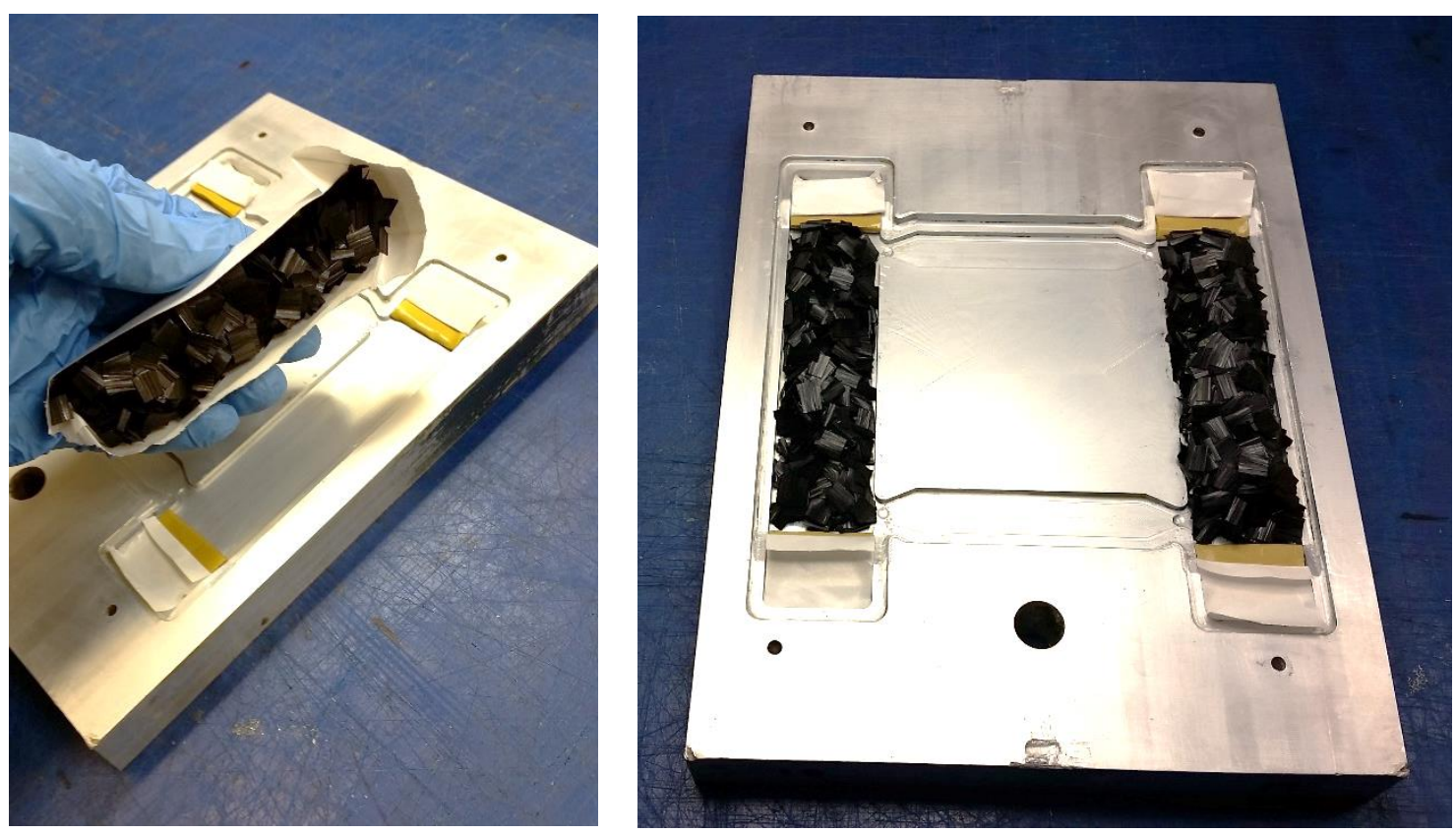

Figure 3.4. Chopped prepreg preforms placed into mold cavity.

In the mold, the charges were shaped into hemispherical prisms in an attempt to keep all of the material inside the mold cavity during compression. Initially, the mold halves did not completely press together due to the bulky nature of the chopped prepreg. It took 4.5 tons of force (about 1000 psi over the surface of the parts) to press the mold halves together. During cure, the force decayed to 2 tons (500 psi) and the mold halves meshed together and closed after about two minutes. The same $285^{\circ} \mathrm{F}$ cure cycle for 70 minutes was used to cure the chopped fiber parts in the press.

The resulting chopped fiber specimens appeared random, but a significant amount of material was pressed out of the cavity portion of the mold, resulting in cavities in the surface of the parts. Resin 
leaked out of the fibers in both parts, likely due to the low viscosity of the resin, as discussed in Section 2.4. The dam tape was also less effective at constraining the material to the gage section of the mold. The parts are shown in Figure 3.5 with the 12-ply equivalent on the left and the 10ply equivalent on the right.
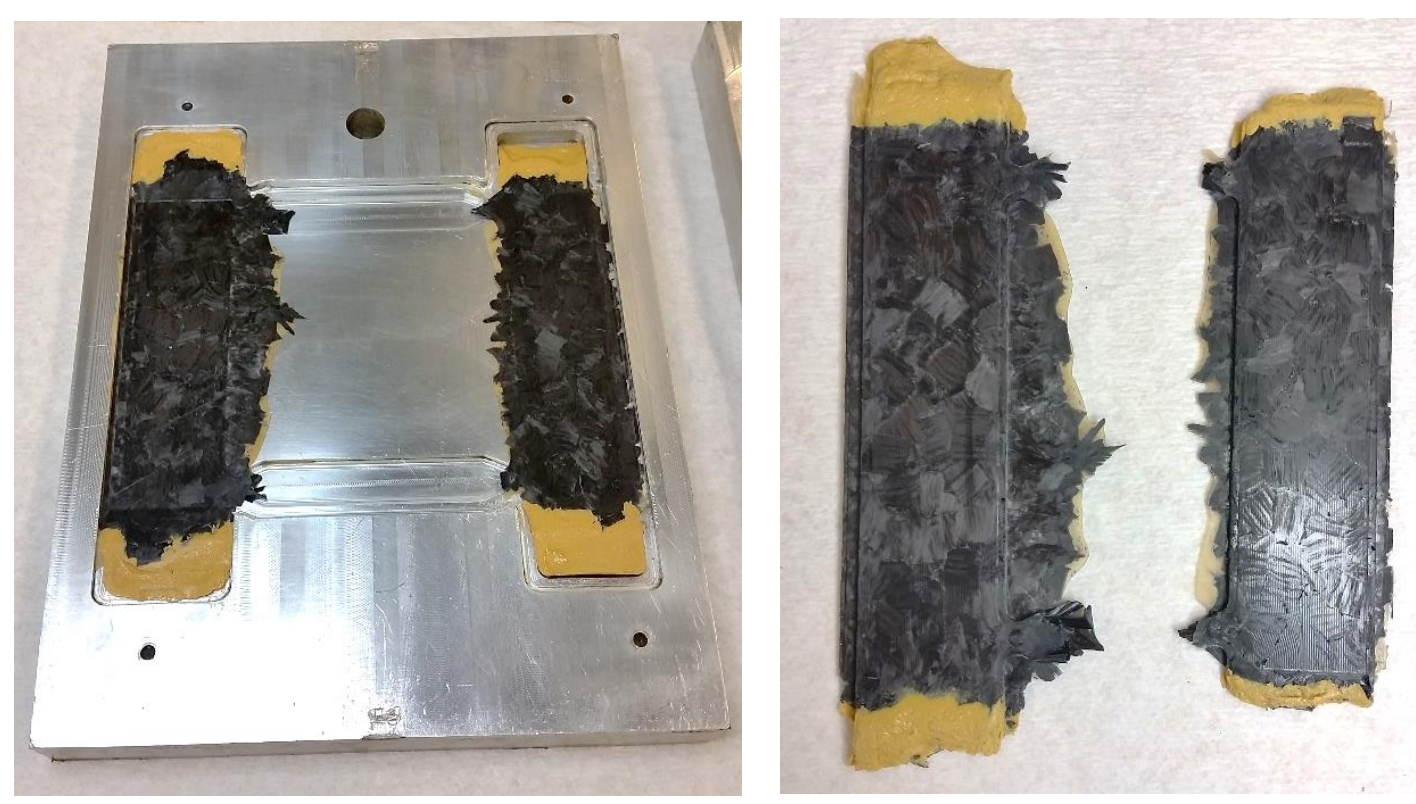

Figure 3.5. First compression molded chopped fiber parts.

A second attempt was made to create random, chopped fiber parts in the tensile specimen mold using a different method of chopping the fibers (Method \#3). Instead of cutting the prepreg into squares, it was cut into 0.25 in strips across the fiber direction. Then those strips were twisted and pressed into the preform. Method \#3 was significantly faster than Methods \#1 or \#2 and still yielded randomly oriented charges. The preform before and after pressing is shown in Figure 3.6. 

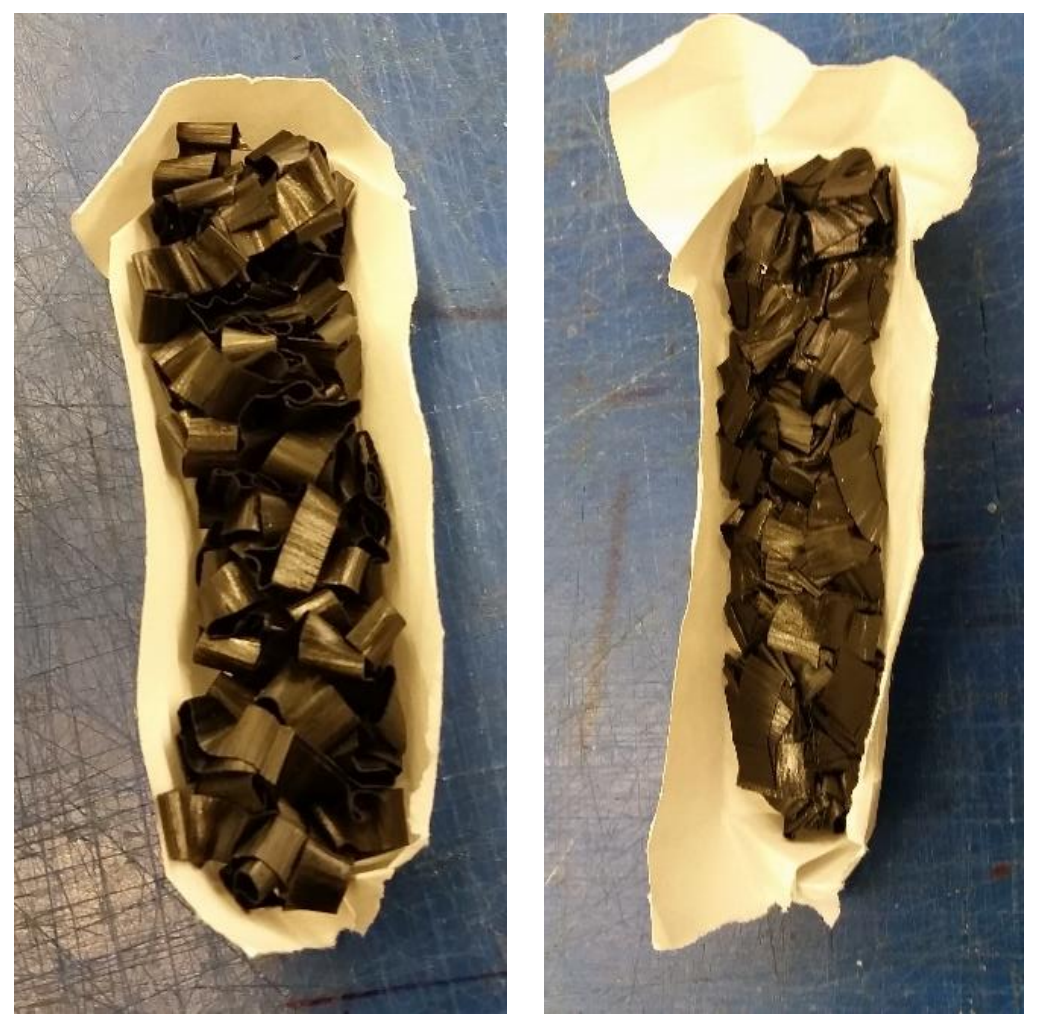

Figure 3.6. Preformed 0.25 in strips formed by Method \#3.

The charges were further preformed by pressing them in the mold cold and re-shaping them as necessary. This process caused the charges to expand outside the mold cavity much like the cured parts in Figure 3.5, indicating that the tensile specimen mold may not be well suited for molding chopped fiber specimens.

\subsection{3-Point Bend Specimen Mold}

From the experiments with chopped fiber discussed in Section 3.1.2, it was clear that a new mold was necessary to progress with the chopped fiber study. The main problem with the tensile specimen mold was its inability to contain the chopped fibers during compression. The mold also did not contain the resin in the area of the part as there were too many avenues available for the resin to flow through. Both of these problems could be addressed with a deeper, simpler mold cavity which better contained the chopped prepreg. 


\subsubsection{Mold Design and Manufacture}

The new mold was designed to create 3-point bend specimens based on the requirements in ASTM D790 [25]. It was initially intended to be a proof of concept mold which demonstrated that a deeper mold cavity would better contain the prepreg material, so the coefficient of thermal expansion (CTE) of the aluminum and the scale factors for the prepreg material were not factored into the design.

The mold cavity was designed to produce a part which was long enough to be cut in half to create two 3-point bend specimens. In order to fit within the confines of the press platens, the mold cavity was designed to be 5 in long. This would produce two approximately 2.4 in specimens after cutting. From the ASTM standard, the support span should be set to 16 times the thickness of the specimen and the specimen should overhang the supports by at least $10 \%$. This would allow for a 0.125 in thick specimen, but to ensure that all specifications were comfortably met and to allow for radii at the end of the part for machinability, the specimen was designed to be 0.1 in thick. ASTM D790 suggests making a specimen which is 0.5 in wide. Thus the final dimensions for the specimen were 5 in by 0.5 in by 0.1 in.

Instead of designing the shutoff plane in line with the plane of the part, it was designed above the plane to create a deep cavity. The shutoff plane was made to be 0.2 in above the top of the part, which would allow for an uncompacted charge which was twice the compacted thickness of the finished part. To expedite the machining process, the cavity and core were designed with vertical walls rather than tapered ones. To prevent tool breakage, the cavity and core were designed with 0.3 in radii in each corner to allow the use of a 0.25 in endmill.

The mold halves were machined from 0.75 in thick 6061-T6 aluminum on a Haas VF-3. The CAM programming and CNC machining were performed by Nathan Harry. Both mold halves after machining are shown in Figure 3.7. The halves were machined until a slip fit was achieved. 

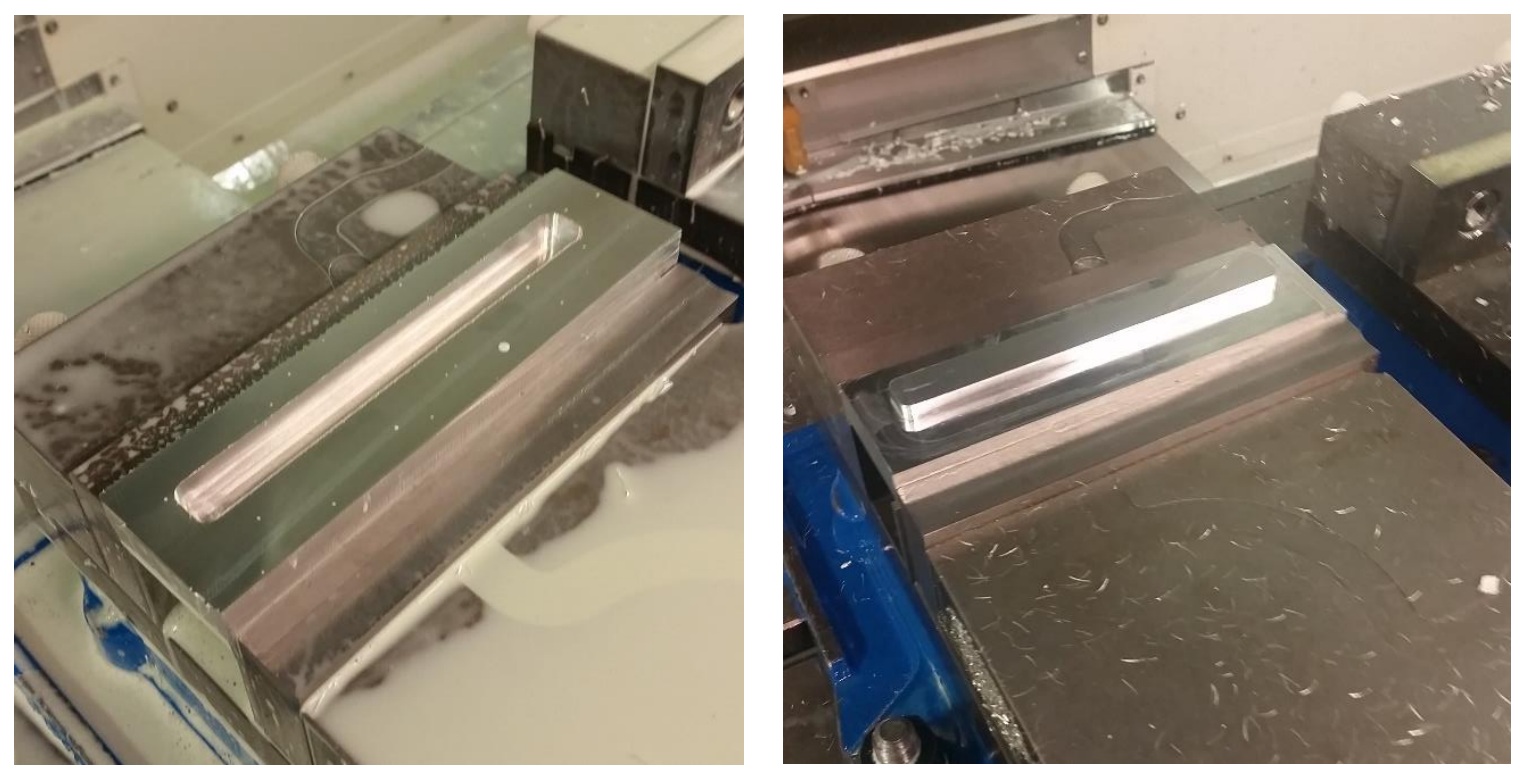

Figure 3.7. Machined 3-point bend specimen molds fixtured in a Haas VF-3.

The mold was originally machined with one 0.11 in diameter ejector pin in one end of the mold cavity, but that later proved to be insufficient as it broke a specimen during demolding. In the final mold, three 0.375 in ejector pins were used to remove the part from the mold cavity. The final mold cavity with ejector pins and ejector pin plate are shown in Figure 3.8.

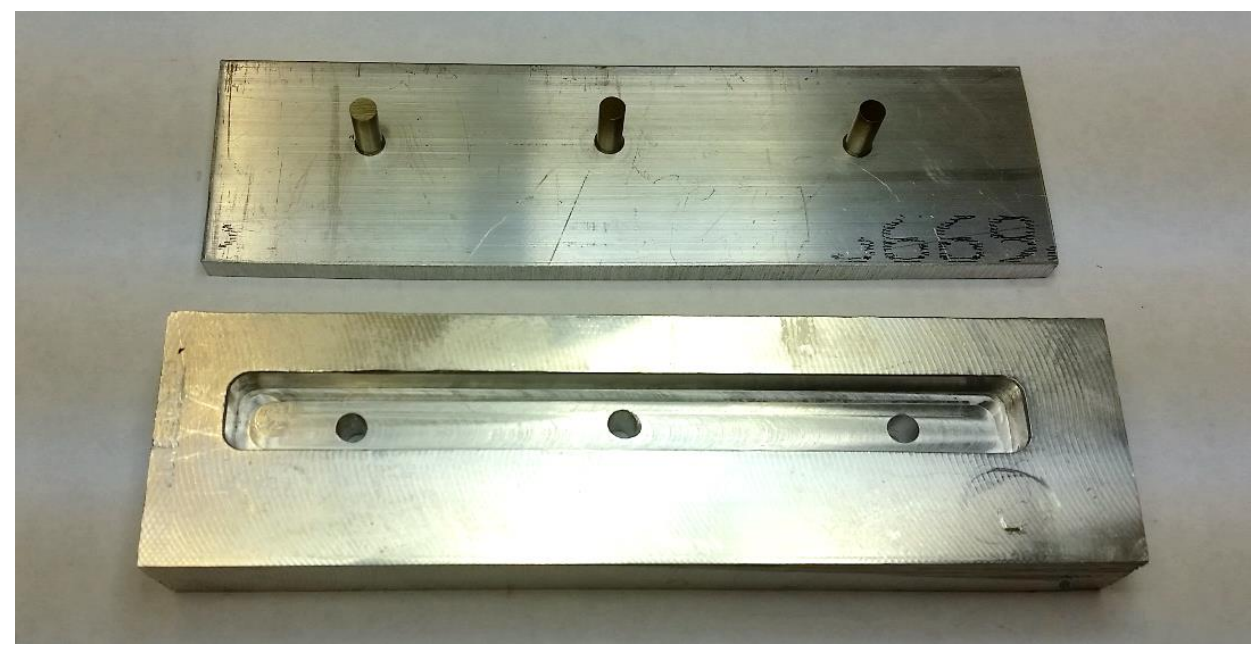

Figure 3.8. Finished mold cavity with ejector pin plate. 


\subsubsection{Thermal Analysis}

To ensure that the material inside the mold saw the full cure temperature for the allotted amount of time, a thermal analysis was performed on the 3D model of the mold in SolidWorks. The model was placed into an assembly with a model of the heated platens. The process of creating a thermal simulation in SolidWorks is detailed in Appendix A.3.

The platens were modeled with the thermostat feature in SolidWorks. The heating element power (700 W per platen) was applied to the model of the heating elements and the thermocouple location was modeled with a point. The thermostat feature then monitored the temperature of that point and controlled the power output of the heating elements to keep that point within a specified range. In this case, the range was set to keep the thermocouple between $275^{\circ} \mathrm{F}$ and $295^{\circ} \mathrm{F}$.

To model heat loss due to natural convection with the surrounding air, it was necessary to calculate the convective heat transfer coefficient of the system. The following taken from a previous report for Cal Poly's ME 554 class on flow around a similar mold and platen assembly [38]. The parameters used for the calculation are shown in Table 3.1.

Table 3.1. Material properties used for convective heat transfer coefficient calculation.

\begin{tabular}{|c|c|c|c|c|c|}
\hline Material & $\boldsymbol{\rho ( \mathbf { k g } / \mathbf { m } ^ { \mathbf { 3 } } )}$ & $\mathbf{c}_{\mathbf{p}}(\mathbf{J} / \mathbf{k g}-\mathbf{K})$ & $\mathbf{k}(\mathbf{W} / \mathbf{m}-\mathbf{K})$ & $\mathbf{v}(\mathbf{k g} / \mathbf{m}-\mathbf{s})$ & $\boldsymbol{\beta}(\mathbf{1} / \mathbf{K})$ \\
\hline Air & $0.719^{*}$ & 1006 & 0.0258 & $1.54 \mathrm{e}-05$ & $3.36 \mathrm{e}-03$ \\
\hline
\end{tabular}

The flow in this problem was the natural convection of air around the heated mold. For natural convection, the important parameters were the Rayleigh and Grashof numbers. These numbers gave the ratio of buoyancy to viscous forces. This ratio indicated whether to use a laminar or a viscous model for natural convection. The Prandtl, Rayleigh, and Grashof numbers were calculated using: 


$$
\begin{gathered}
G r_{x}=\frac{\rho^{2} g \beta}{\mu^{2}}\left(T_{S}-T_{\infty}\right) L^{3} \\
\operatorname{Pr}=\frac{\vartheta}{k / \rho c_{p}} \\
R a_{x}=G r P r
\end{gathered}
$$

where $\mu=v \rho$. For steady state temperature in the mold and platens, the Grashof number calculated to approximately $9.06 \times 10^{6}$. Since this number was below $10^{9}$, the natural convection was modeled as laminar. The Rayleigh number calculated to $3.92 \times 10^{6}$ since the Prandtl number was about 0.43 , which confirmed accurate use of the laminar model $R a_{x}<10^{9}$.

The Nusselt number was also important as it was used to calculate the convection heat transfer coefficient. It was defined for free convection using:

$$
N u_{L}=0.68+\frac{0.61 R a_{x}{ }^{1 / 4}}{\left[1+(0.492 / P r)^{9 / 16}\right]^{4 / 9}} \text { for } R a_{x} \leq 10^{9}
$$

The Nusselt number calculated to a value of 0.84 . Then, the heat transfer coefficient was calculated using:

$$
N u_{L}=\frac{h L}{k}
$$

The heat transfer coefficient calculated to $0.26 \mathrm{~W} / \mathrm{m}^{2}-\mathrm{K}$. Such a relatively low heat transfer coefficient indicates low heat loss to the environment. However, a convection boundary condition was applied to all exposed surfaces of the mold with this heat transfer coefficient. Detailed calculations may be found in Appendix C.4. 
In order to accurately model contact between the mold halves and between the mold and platens, it is necessary to calculate the contact resistance at each interface. The contact resistance parameter is the inverse of contact conductance $\left(h_{c}\right)$, which is dependent on a number of different factors [39]. One such factor is the effective thermal conductivity $\left(k_{s}\right)$ between the two contacting materials, which is given by

$$
k_{s}=\frac{2 k_{1} k_{2}}{k_{1}+k_{2}}
$$

where $k_{1}$ and $k_{2}$ correspond to the thermal conductivities of each material.

Contact conductance is also dependent upon the root mean squared (RMS) roughness of the two surfaces $\left(R_{q}\right)$ which is calculated with [40]

$$
R_{q}=\sqrt{\frac{1}{l} \int_{0}^{l} Z^{2}(x) d x}
$$

where $l$ is the sampling length and $Z(x)$ is the height of the roughness profile along the sampling length. Another common surface roughness parameter is average roughness $\left(R_{a}\right)$ which is the arithmetic mean of the heights measured along the sampling length. A graphic representation of $R_{q}$ and $R_{a}$ is shown in Figure 3.9.

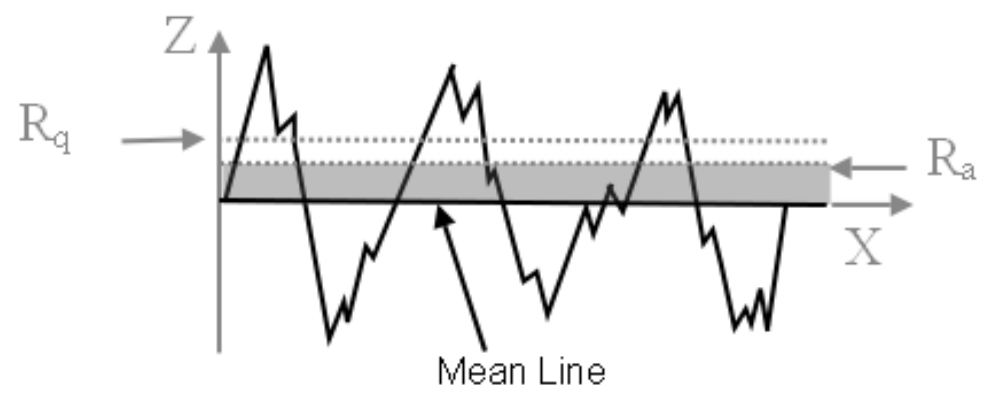

Figure 3.9. Common roughness parameters $R_{q}$ and $R_{a}$ [41]. 
RMS roughness for a standard machining process can be estimated using the average roughness of the surface using the relationship [42]

$$
\frac{R_{q}}{R_{a}}=\frac{\pi}{2 \sqrt{2}}=1.11
$$

The average roughness of a material can be estimated by the machining process employed to achieve the surface. Some values of $R_{a}$ for various machining processes are shown in Figure 3.10.

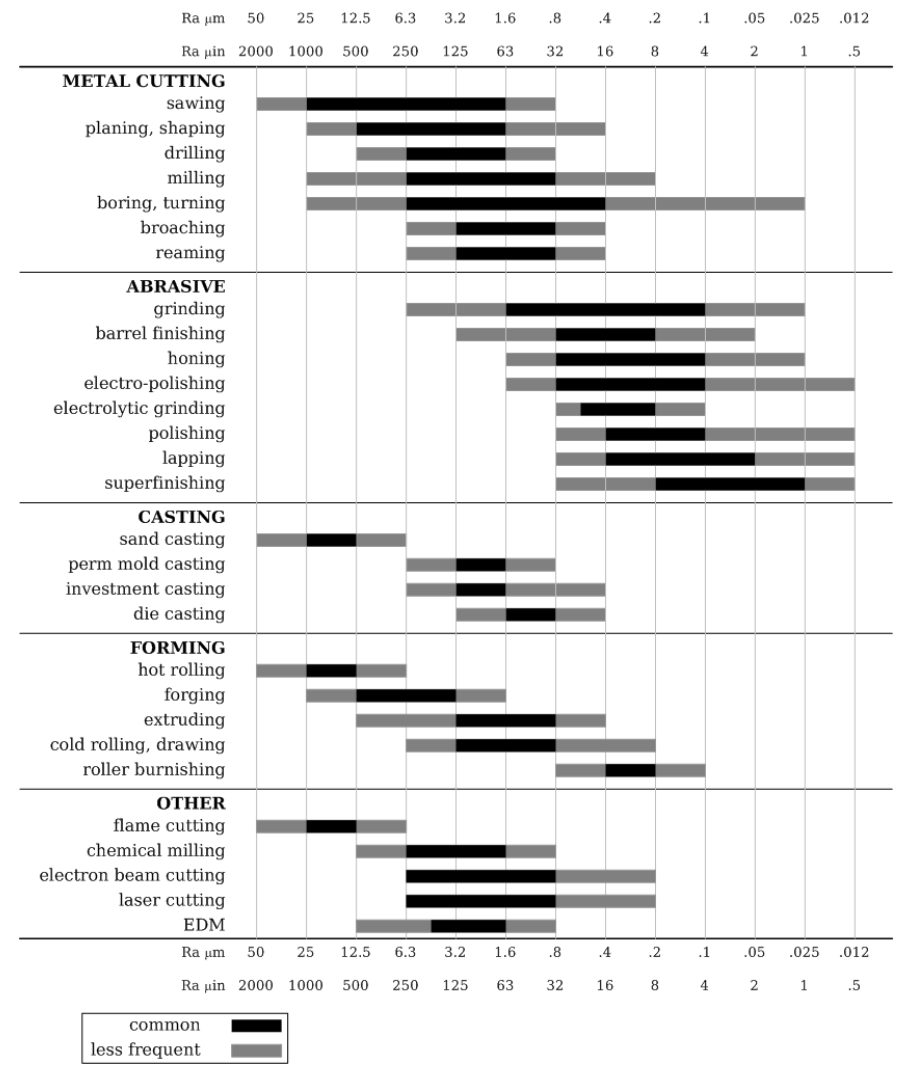

Figure 3.10. Typical average roughness parameters for different machining processes [43].

The surface roughness between two surfaces is typically determined by the root mean square of the values for each material. If the surfaces were machined using the same process, a single roughness parameter can be used in calculations. 
The recommended method for calculating the contact conductance between two elastically deforming surfaces [39] was developed by Mikic (1974) and is given by

$$
h_{c}=1.9 \frac{k_{s}}{R_{q}}\left(\frac{P}{E^{\prime}}\right)^{0.94}
$$

in which $P$ is the pressure between the two surfaces and $E^{\prime}$ is calculated from the materials' moduli of elasticity and Poisson's ratios using [39]

$$
E^{\prime}=\frac{E_{1} E_{2}}{E_{2}\left(1-v_{1}^{2}\right)+E_{1}\left(1-v_{2}^{2}\right)}
$$

Calculations for this system can be found in Appendix C.5. The temperatures of the top platen (red triangles), bottom platen (blue squares), and inside of the mold (green diamonds) are plotted in Figure 3.11 with respect to time.

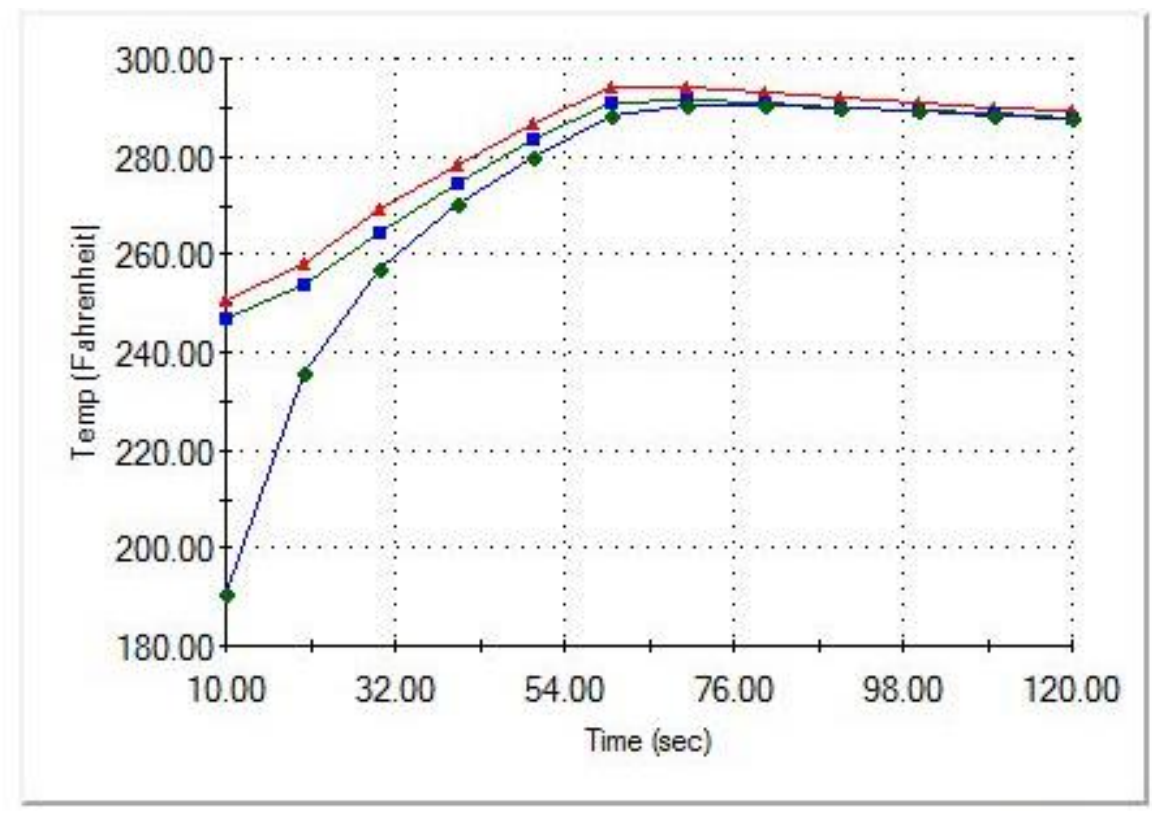

Figure 3.11. Temperatures of top platen, bottom platen, and inside mold, with respect to time.

This simulation revealed that the inside of the mold reached cure temperature at a comparable rate to the rest of the mold and that the cure timing method used for the tensile specimen mold 
was still valid. With the mold's thermal behavior confirmed, it was seasoned as described in Section 2.1.4.

\subsection{3-Point Bend Specimen Manufacture and Evaluation}

With the 3-point bend mold manufactured and seasoned, a new procedure was developed for creating chopped fiber components in the mold. The new mold featured a much smaller and much deeper mold cavity, which necessitated a much more precise method of preforming the chopped fiber material.

\subsubsection{Specimen Layup}

A preform for the chopped fiber material was cut on the laser to facilitate charge formation for the completed molds. The preform is shown in Figure 3.12.

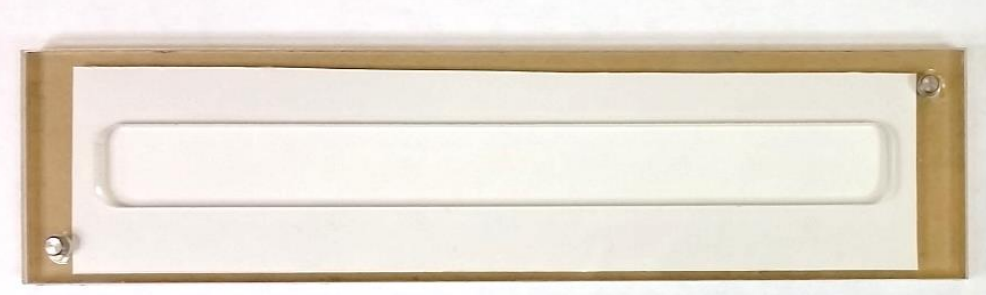

Figure 3.12. Acrylic preform for 3-point bend specimen mold.

It was made from two layers of acrylic held together by locating pins. The separable halves held a piece of prepreg backing paper in place to prevent the chopped fibers from sticking to the preform. A preform filled with a charge ready to be molded is shown in Figure 3.13. 


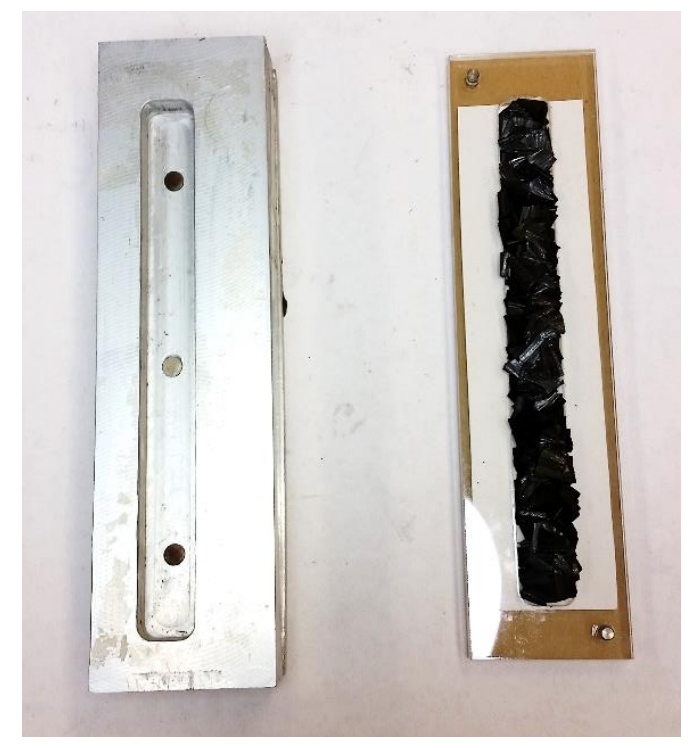

Figure 3.13. Filled preform with 3-point bend specimen mold cavity.

With a charge prepared for molding, the preform halves were separated and the backing paper strip was removed. The tacky material remained stuck in the top half of the preform, which was then placed on top of the mold cavity. Then the material was pressed down into the mold cavity and the mold core was installed.

The chopped fiber specimens were initially cured in the same way as those in the tensile specimen mold: by curing at $285^{\circ} \mathrm{F}$ for 70 minutes with 70 psi applied to the mold once the platens reached cure temperature. Pressure application caused the resin in the charge to leak out of the mold, as shown in Figure 3.14. To try to eliminate resin press-out, three additional chopped fiber parts were manufactured which were subjected to only 30 psi. Pressure was applied at the time cure temperature was reached, two minutes after, and four minutes after for each part respectively. In all three cases, resin still pressed out of the mold. 


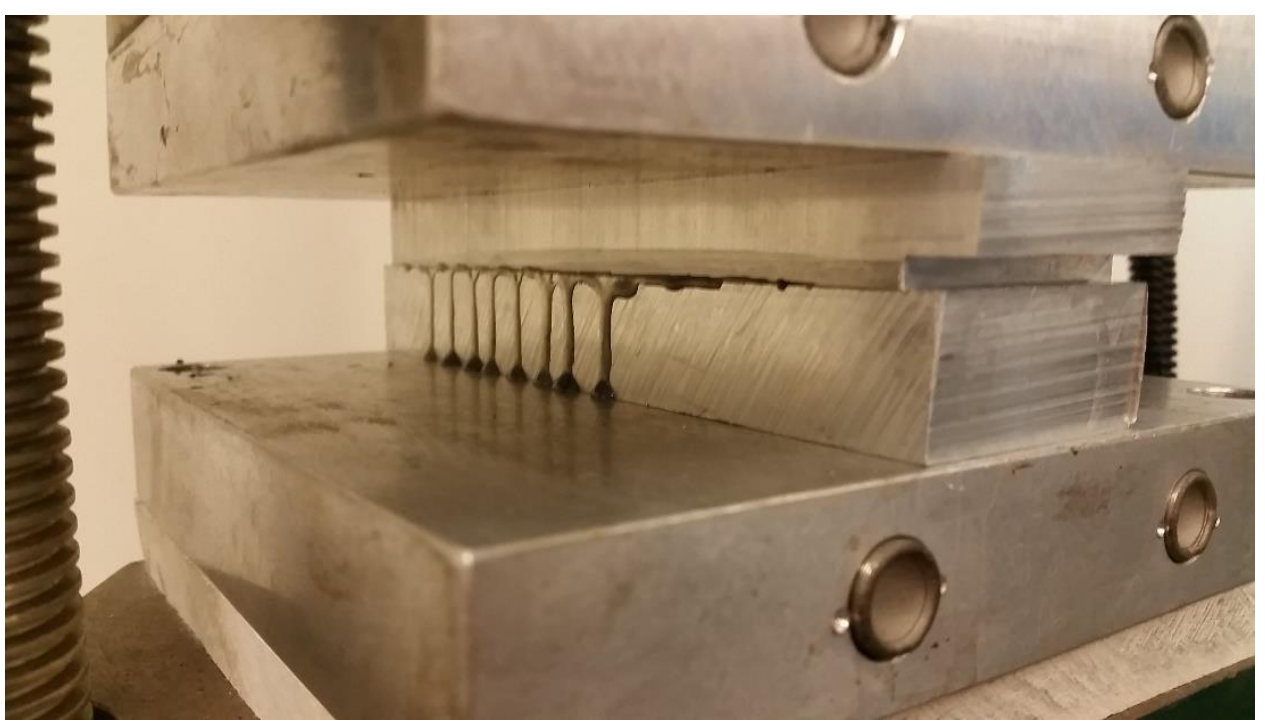

Figure 3.14. Resin leaking out of 3-point bend specimen mold upon pressure application.

The finished part was removed by removing the ejector pin plate placing 0.125 in shims over the mold cavity and using the press to force the ejector pins up to eject the part. Light pressure on one end of the specimen levered the specimen completely out of the mold cavity after ejection. A freshly ejected specimen is shown in Figure 3.15.

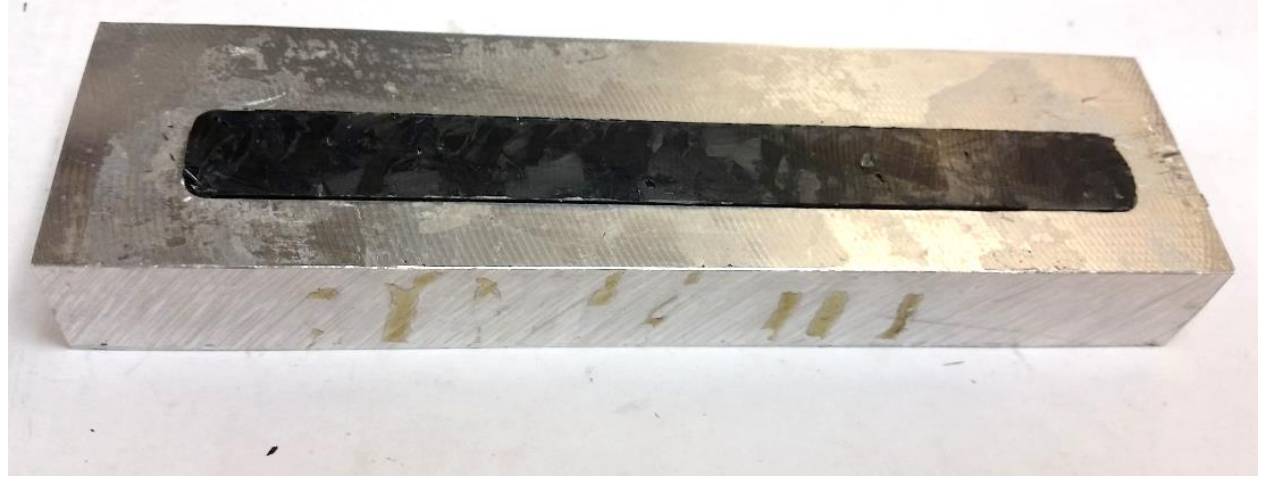

Figure 3.15. Chopped fiber 3-point bend specimen ejected from mold cavity.

All of the parts produced by the mold had a cross section of 0.1 in by $0.5 \mathrm{in}$, as designed. Overall, the 3-point bend specimen mold did well to mold and contain the chopped fiber material, but the 
low minimum viscosity of the M46J/TC250 material caused the resulting chopped fiber parts to have an apparently lower resin content with a moderate quality surface finish.

To test whether the resin leakage was caused by the amount of material in the mold, the viscosity profile of the M46J/TC250, the chopped fiber material type, or by the mold itself, continuous fiber parts were also manufactured in the 3-point bend specimen mold. According to the $C P T$ calculator, the 0.1 in mold cavity would accommodate 10.9 plies of material, so 10,12 , and 14 -

ply layups were attempted to determine whether the resin press-out was significantly affected by the amount of material in the mold. For each specimen, pressure was applied at 2 minutes past reaching cure temperature instead of at the moment cure temperature was reached.

The 14-ply specimen leaked a significant amount of resin and had a good surface finish when demolded. The 12-ply specimen, which most closely represented the amount of material used for the chopped fiber parts, leaked much less and had a similar surface finish. The 10-ply specimen did not leak at all and did not appear compressed when demolded. Thus the amount of material in the mold had a significant effect on the amount of resin which was pressed out of the part. The additional 2 minutes of preheating before pressure application also appeared to decrease the amount of resin pressed out of the parts.

\subsubsection{3-Point Bend Testing}

The effect of resin press-out was evaluated by testing the manufactured chopped fiber and unidirectional parts in 3-point bend. First, each specimen was cut in half to yield two specimens per cure cycle. Each specimen was tested using the same procedure outlined in Section 2.3.4.

The continuous fiber parts failed in the same way as previous continuous fiber parts, in microbuckling at the point of load application. As with previous specimens, more plies caused 
stiffer, stronger parts. In general, the parts had equivalent mechanical properties to those exhibited by previous parts, indicating that the mold did not adversely affect those properties.

The chopped fiber parts all broke in half at the point of load application almost instantly, as shown in Figure 3.16.

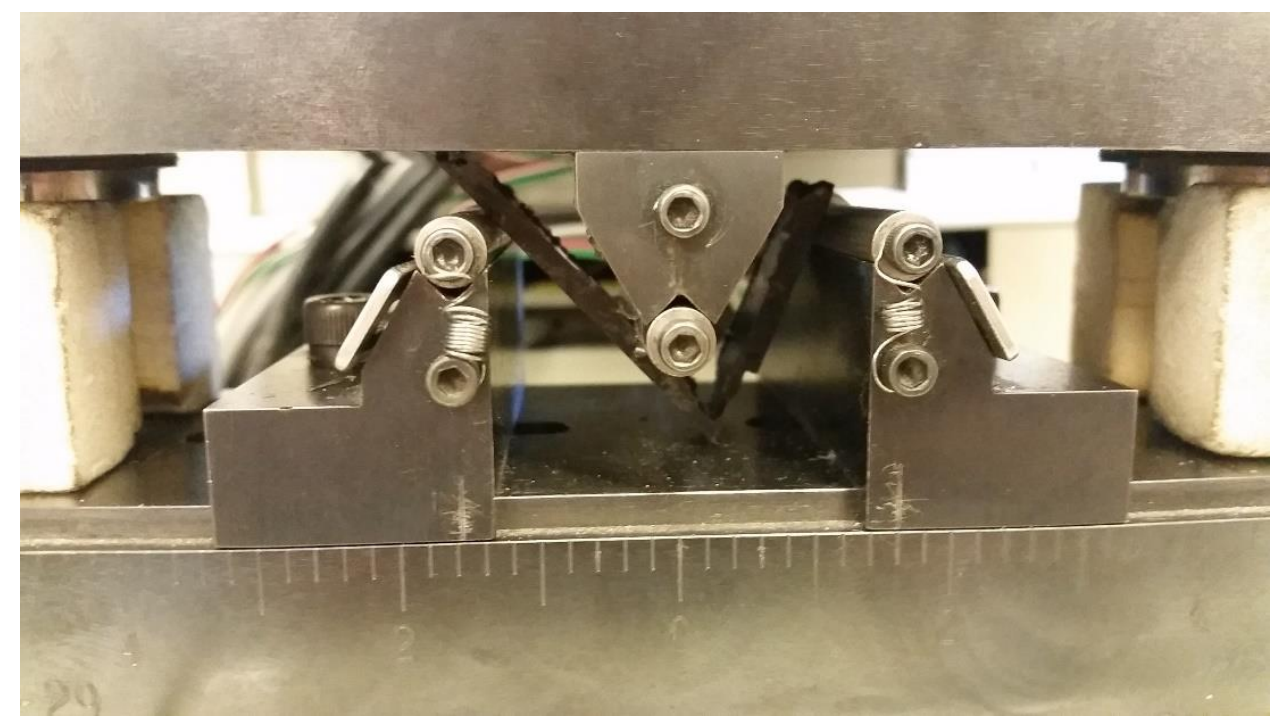

Figure 3.16. Chopped fiber 3-point bend specimen failure mode.

The flexural strengths and moduli of the chopped fiber specimens were inconsistent between lots, but followed no clear trend related to processing parameters. The flexural strength, strain, and modulus of each chopped fiber specimen is shown in Table 3.2.

Table 3.2. Flexural strength, strain, and tangent modulus of initial 3-point bend specimens.

\begin{tabular}{|c|c|c|c|}
\hline Specimen ID & $\begin{array}{c}\text { Flexural Strength } \\
\text { (ksi) }\end{array}$ & $\begin{array}{c}\text { Flexural Strain } \\
\text { (in/in) }\end{array}$ & $\begin{array}{c}\text { Tangent Modulus } \\
\text { (Msi) }\end{array}$ \\
\hline $200-0-1 B$ & 12.1 & 0.0101 & 1.58 \\
\hline $200-0-1 \mathrm{U}$ & 15.0 & 0.0070 & 2.23 \\
\hline $200-2-1 \mathrm{~B}$ & 12.4 & 0.0077 & 1.64 \\
\hline $200-2-1 \mathrm{U}$ & 7.16 & 0.0091 & 1.51 \\
\hline $200-4-1 \mathrm{~B}$ & 19.4 & 0.0122 & 3.11 \\
\hline $200-4-1 \mathrm{U}$ & 13.0 & 0.0096 & 1.60 \\
\hline $4000-1$ & 19.4 & 0.0110 & 2.22 \\
\hline
\end{tabular}


After inspection of the specimens, it appeared that each failed at a different discontinuity between the chopped fibers. While these discontinuities were part of the nature of chopped fiber, it was possible that the single point of load application of the 3-point bend apparatus may have hastened the failure of the chopped fiber material by exaggerating the stress concentrations at those points. It was also possible that the relatively large chopped fiber length used in the smaller mold resulted in discontinuities which could easily span the width of the specimen, resulting in a natural point of failure. More specimens and further testing were required to evaluate whether a different method would yield more consistent results.

\subsubsection{Pressure Application Timing}

Following the unidirectional parts, it was clear that resin press-out was likely unavoidable. Thus, more chopped fiber parts were manufactured with 3 and 4-minute preheating cycles before pressure application to decrease press-out as much as possible. Each preheating cycle was tested in both a cold mold and a preheated mold. In general, more preheating time caused less resin to press out in terms of initial mold temperature and time before pressure application.

The additional time likely allowed the resin to progress past its minimum viscosity point and gradually increase in viscosity as preheating time increased. To confirm this suspicion, an additional chopped fiber part was manufactured with a 6-minute preheating time. After 6 minutes, even 5 tons of force (4000 psi) would not close the mold as the resin had already crosslinked and begun to set. Thus, the specimen experienced almost no lamination.

\subsubsection{4-Point Bend Testing}

After the abrupt failure of the chopped fiber parts during 3-point bend testing, an alternate method of flexural testing seemed pertinent. 4-point bend testing offered a similar flexural test, but distributed the load between two points instead of exerting all of the load in one central location. 
4-point bend testing also caused an area of constant moment between the load span. The procedure for 4-point bend testing is outlined in ASTM D6272 [44]. A comparison of the shear and moment diagrams for 3-point and 4-point bending are shown in Figure 3.17.

The shear force applied to the test specimen was the same for both test cases and the applied moment was smaller for the 4-point bend test. However, for 3-point bend, the shear force was applied at a single point where the applied moment also reached its maximum. In the case of the chopped fiber material, the properties of which were unknown, it was difficult to tell whether the failure was caused by the large moment or by the large shear force at that point. Testing in 4point bend instead of 3-point bend may have clarified the failure mode of the material. The distributed loading may also have allowed the material more time to undergo linear deflection before ultimate failure.
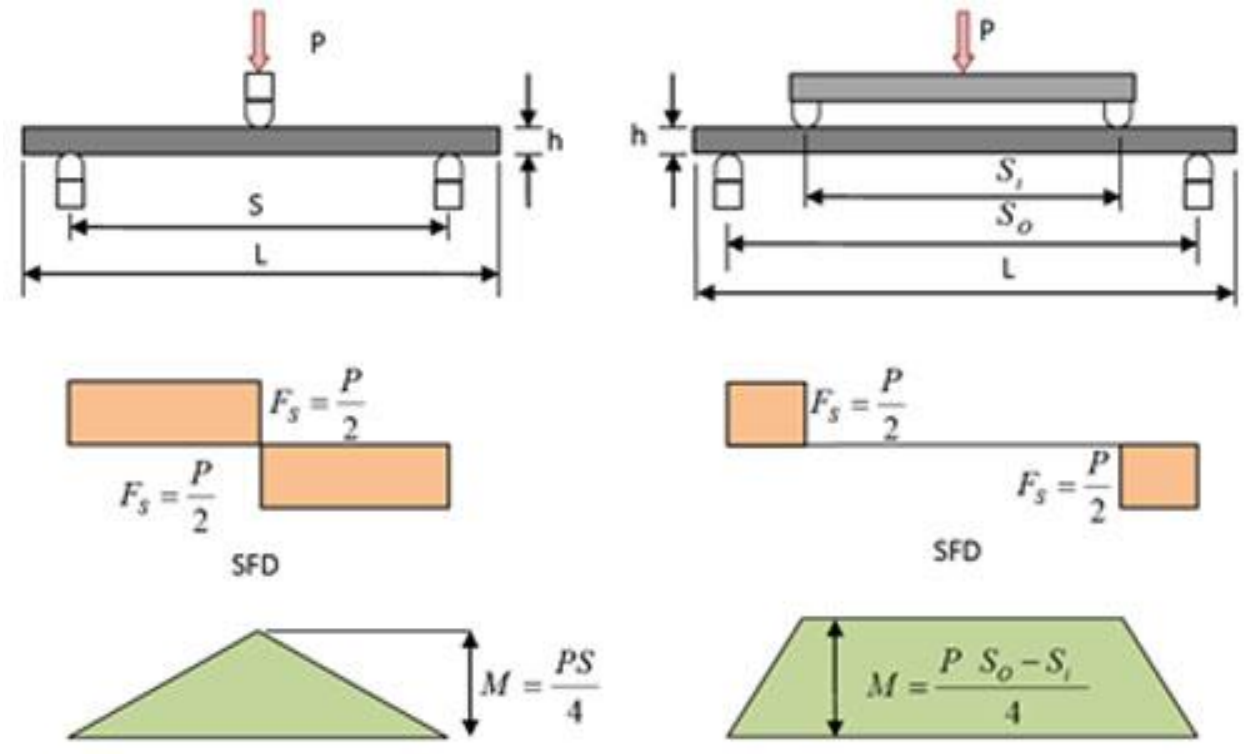

Figure 3.17. Shear and moment diagrams for 3-point and 4-point bend testing [45].

A 4-point bend apparatus was discovered which was compatible with the base of the 3-point bend apparatus. This upper fixture was machined by Josh Smith in September of 2013 [46]. It featured two adjustable loading rollers and linear bearings which fit onto the shafts of the 3-point bend 
apparatus base. The fixture was machined from A-36 hot rolled steel to minimize compliance in the apparatus during testing. It is shown in Figure 3.18 set up in the Instron load frame with a chopped fiber specimen.

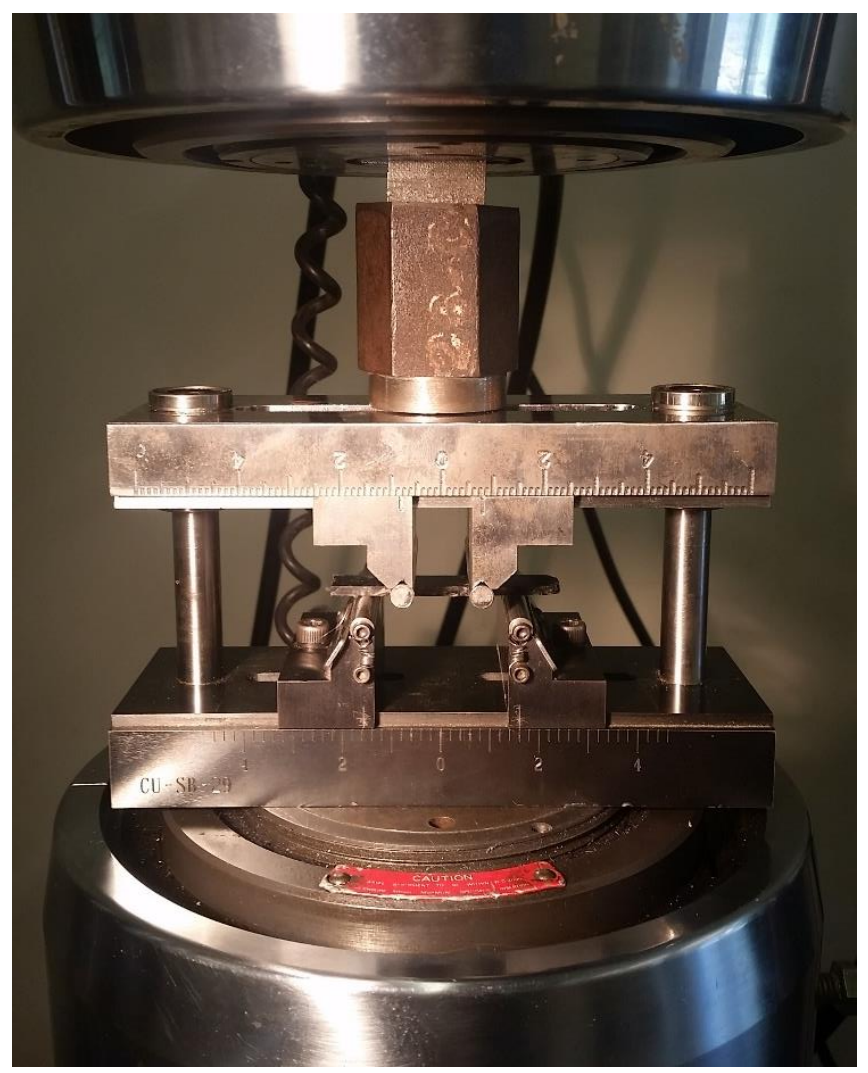

Figure 3.18. 4-point bend apparatus set up in Instron load frame.

A load span of one half of the support span was selected for testing due to its more common use in industry [47]. A support span of 16 times the thickness of the part (as with 3-point bend testing) gave a span of 1.6 in with a load span of 0.8 in. The rate of crosshead motion was calculated using

$$
R=\frac{0.167 Z L^{2}}{d}
$$

where $Z$ was set to $0.01 \mathrm{in} / \mathrm{in} / \mathrm{min}$. This calculation gave a crosshead rate of $0.0427 \mathrm{in} / \mathrm{min}$. This value was reduced to $90 \%$ of the total when failure still initiated too quickly. 
The chopped fiber specimens failed in the constant moment region close to the load rollers. A typical failure mode is shown in Figure 3.19. A typical load displacement curve for the chopped fiber specimens is shown in Figure 3.20.

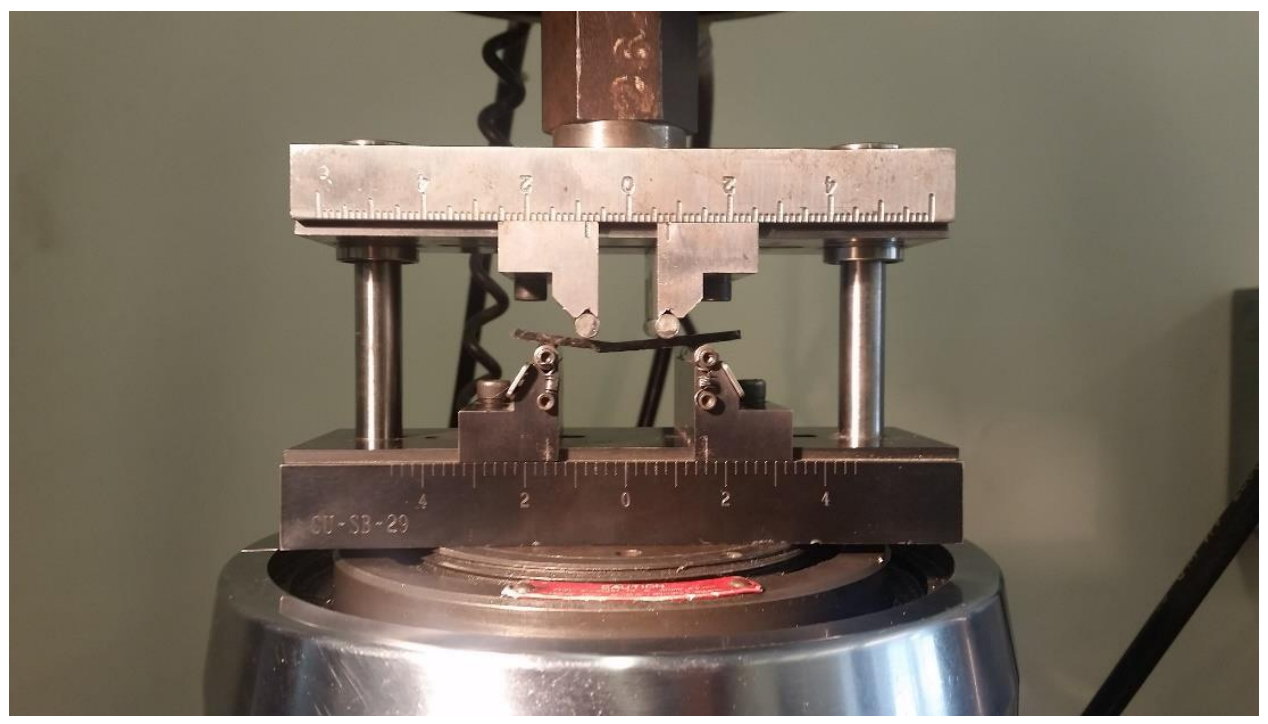

Figure 3.19. Typical chopped fiber specimen failure mode in 4-point bend.

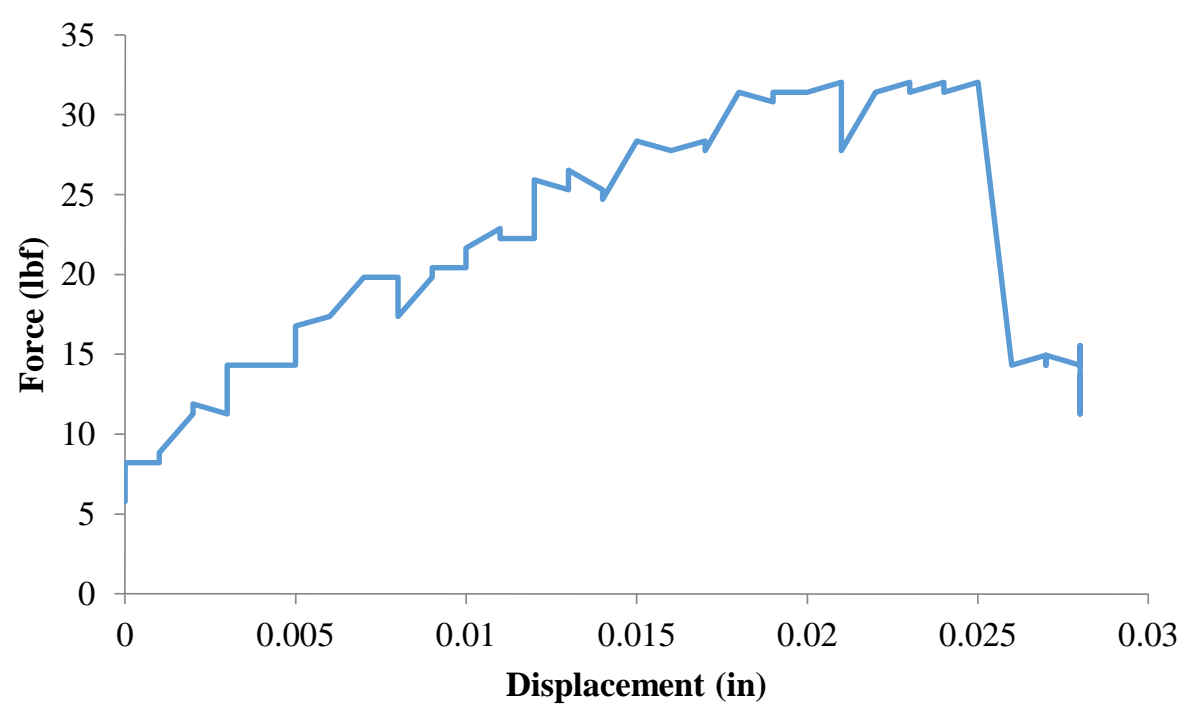

Figure 3.20. Typical load displacement curve for chopped fiber specimen in 4-point bend. 
For 4-point bend loading, the flexural strength, flexural strain, and bending modulus differ slightly from those of 3-point bending discussed in Section 2.3.5. The calculated mechanical properties for the chopped fiber specimens are shown in Table 3.3. They are calculated using [44]

$$
\begin{gathered}
\sigma_{f}=\frac{3 P L}{4 b d^{2}} \\
\varepsilon_{f}=4.36 \frac{D d}{L^{2}} \\
E_{B}=0.17 \frac{L^{3} m}{b d^{3}}
\end{gathered}
$$

Table 3.3. Flexural strength, strain, and tangent modulus of 4-point bend specimens.

\begin{tabular}{|c|c|c|c|}
\hline Specimen ID & $\begin{array}{c}\text { Flexural Strength } \\
(\mathbf{k s i})\end{array}$ & $\begin{array}{c}\text { Flexural Strain } \\
\text { (in/in) }\end{array}$ & $\begin{array}{c}\text { Tangent Modulus } \\
(\mathbf{M s i})\end{array}$ \\
\hline 1B & 13.1 & 0.006 & 1.97 \\
\hline 1U & 6.66 & 0.002 & 2.26 \\
\hline 2B & 9.59 & 0.003 & 2.64 \\
\hline 2U & 6.80 & 0.003 & 1.98 \\
\hline 3B & 7.68 & 0.004 & 1.72 \\
\hline 3U & 11.6 & 0.004 & 2.42 \\
\hline 4B & 6.22 & 0.002 & 2.26 \\
\hline 4U & 10.3 & 0.003 & 2.48 \\
\hline
\end{tabular}

Testing the chopped fiber specimens in 4-point bend yielded slightly more consistent results, but with no apparent trends to explain discrepancies between the mechanical properties of each lot. The resulting average flexural strength from 4-point bend testing was $9.00 \mathrm{ksi}$ and the average flexural modulus was 2.22 Msi. Since chopped fiber specimens tend to have isotropic mechanical properties, the tensile and compressive moduli were assumed to be equal to the flexural modulus of the material. 


\subsection{Chopped Fiber Sandwich Structures}

As a means of applying the results of testing both modes of material, a sandwich structure was designed with continuous unidirectional fiber face sheets and a chopped fiber core. These specimens served as a way to test the compatibility of the chopped and continuous fibers in a compression molding environment and to validate mechanical testing results. Specimens with 1, 2, and 3-ply face skins were modeled and manufactured. The geometry of the sandwich structure and locations of stress analysis are shown in Figure 3.21.

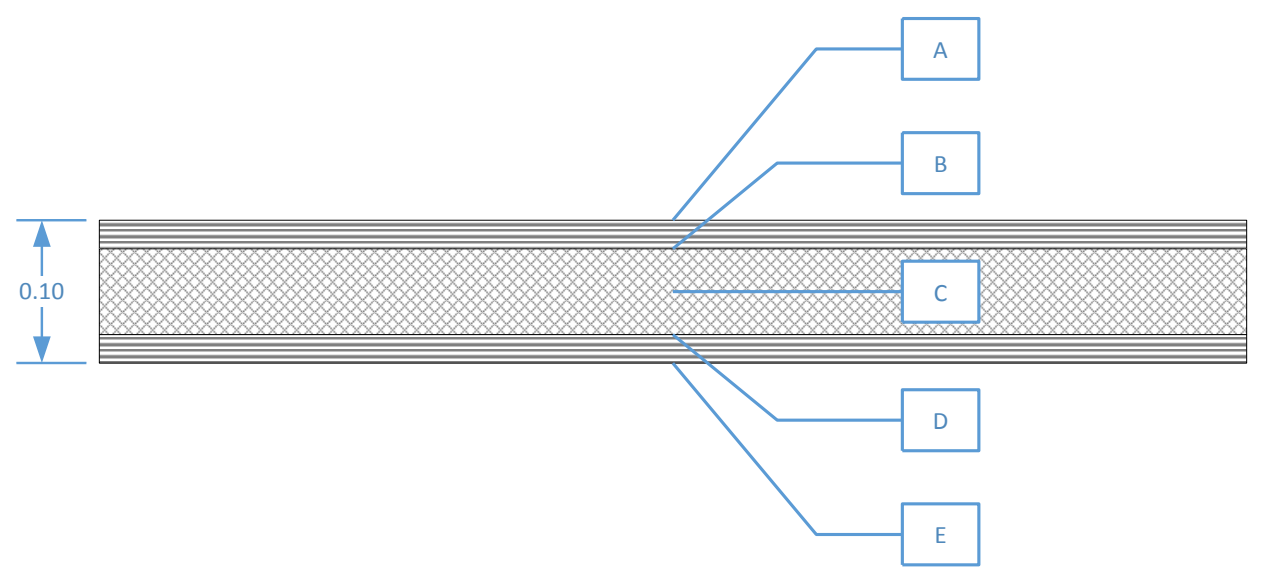

Figure 3.21. Sandwich structure schematic with failure analysis locations.

\subsubsection{CLT Flexural Strength Prediction}

To predict the strength of the sandwich structures, a MATLAB function and wrapper were generated which used CLT to analyze the stresses and strains produced by 4-point bend loading. A simplified, 1-dimensional Tsai-Wu failure theory was used to predict the location of failure in the constant moment section of 4-point bend loading due to its simplicity.

The MATLAB function (sandwich.m) was a coded version of a first ply failure (FPF) determination procedure outlined by Daniel and Ishai [2]. Using the four basic material properties for each material $\left(E_{1}, E_{2}, v_{12}, \& G_{12}\right)$, it calculated the layer stiffnesses with [1] 


$$
Q=\left[\begin{array}{ccc}
\frac{E_{1}}{1-\vartheta_{12} \vartheta_{21}} & \frac{\vartheta_{12} E_{2}}{1-\vartheta_{12} \vartheta_{21}} & 0 \\
\frac{\vartheta_{21} E_{1}}{1-\vartheta_{12} \vartheta_{21}} & \frac{E_{2}}{1-\vartheta_{12} \vartheta_{21}} & 0 \\
0 & 0 & G_{12}
\end{array}\right]
$$

Since all of the continuous plies were oriented along the length of the specimen, it was not necessary to transform the layer stiffnesses. From the location and stiffness of each layer, the laminate stiffness was calculated using

$$
K=\left[\begin{array}{ll}
A & B \\
B & D
\end{array}\right]
$$

where, for $i, j=1,2,3$

$$
\begin{gathered}
A_{i j}=\sum_{k=1}^{n}\left(\bar{Q}_{i j}\right)_{k}\left(h_{k}-h_{k-1}\right) \\
B_{i j}=\frac{1}{2} \sum_{k=1}^{n}\left(\bar{Q}_{i j}\right)_{k}\left({h_{k}}^{2}-{h_{k-1}}^{2}\right) \\
D_{i j}=\frac{1}{3} \sum_{k=1}^{n}\left(\bar{Q}_{i j}\right)_{k}\left(h_{k}{ }^{3}-h_{k-1}{ }^{3}\right)
\end{gathered}
$$

From the laminate stiffness, the laminate compliance $\left(C=K^{-1}\right)$ was calculated and mechanical load was used to calculate plane strains and curvatures for each layer using

$$
\left\{\begin{array}{c}
\epsilon^{0} \\
k
\end{array}\right\}=[C]\left\{\begin{array}{l}
N \\
M
\end{array}\right\}
$$

In the case of 4-point bend loading, only the center section with constant moment was calculated. This moment was modeled as a line moment and converted into an equivalent force using the 
wrapper function. The layer strains calculated from the mechanical loading were converted to stresses using the relationship

$$
\left\{\begin{array}{c}
\sigma_{1} \\
\sigma_{2} \\
\tau_{12}
\end{array}\right\}=[Q]\left\{\begin{array}{c}
\varepsilon_{1} \\
\varepsilon_{2} \\
\gamma_{12}
\end{array}\right\}
$$

The stress at the top and bottom of each layer of the laminate were calculated in order to determine the Tsai-Wu criterion and coefficients at each outer and interfacial location. The TsaiWu criterion is calculated for a two-dimensional state of stress using [2]

$$
f_{1} \sigma_{1}+f_{2} \sigma_{2}+f_{11} \sigma_{1}^{2}+f_{22} \sigma_{2}^{2}+f_{66} \tau_{6}^{2}+2 f_{12} \sigma_{1} \sigma_{2}<1
$$

where

$$
\begin{gathered}
f_{1}=\frac{1}{F_{1 t}}-\frac{1}{F_{1 c}} \text { and } f_{11}=\frac{1}{F_{1 t} F_{1 c}} \\
f_{2}=\frac{1}{F_{2 t}}-\frac{1}{F_{2 c}} \text { and } f_{22}=\frac{1}{F_{2 t} F_{2 c}} \\
f_{66}=\frac{1}{F_{6}{ }^{2}}
\end{gathered}
$$

in which $F_{1 t}$ is the ultimate strength of the layer in tension in the 1-direction, $F_{2 c}$ is the ultimate strength of the layer in compression in the 2-direction, etc.

The wrapper for the FPF code (mtof . m) determined the maximum line moment $\left(M_{x}\right)$ which each sandwich structure could withstand by increasing the load incrementally until one of the Tsai-Wu criteria reached unity, indicating failure at that location. It then converted the line moment to an equivalent applied load on the entire sandwich structure in a 4-point half-span configuration using 


$$
F_{\text {max }}=\frac{4 M_{x} b}{L_{\text {span }}}
$$

where $L_{\text {span }}$ is the load span length.

The material properties required for each calculation were estimated based on the flexural testing performed on both modes of material. The results of the analysis for 1,2, and 3-ply skinned sandwich structures are shown in

Table 3.4. Predicted first ply failure locations for sandwich structures.

\begin{tabular}{|c|c|c|}
\hline Face Skin Plies & Failure Location and Ply & Maximum Force (lbf) \\
\hline 1 & D, chopped fiber & 132 \\
\hline 2 & D, chopped fiber & 250 \\
\hline 3 & E, continuous fiber & 300 \\
\hline
\end{tabular}

The code for sandwich.m and mtof. $m$ can be found in Appendix B.2.

\subsubsection{Manufacture}

The sandwich structures were constructed by cutting the appropriate number of unidirectional plies from a sheet of prepreg which was large enough to fill the mold in chopped form, then chopping the remaining fibers. One face sheet was laid into the mold, then the mold was filled with the preformed chopped fiber. Then the top face sheet was placed on top of the chopped fiber. The manufacture of the 1-ply face sheet sandwich is shown in Figure 3.22. 


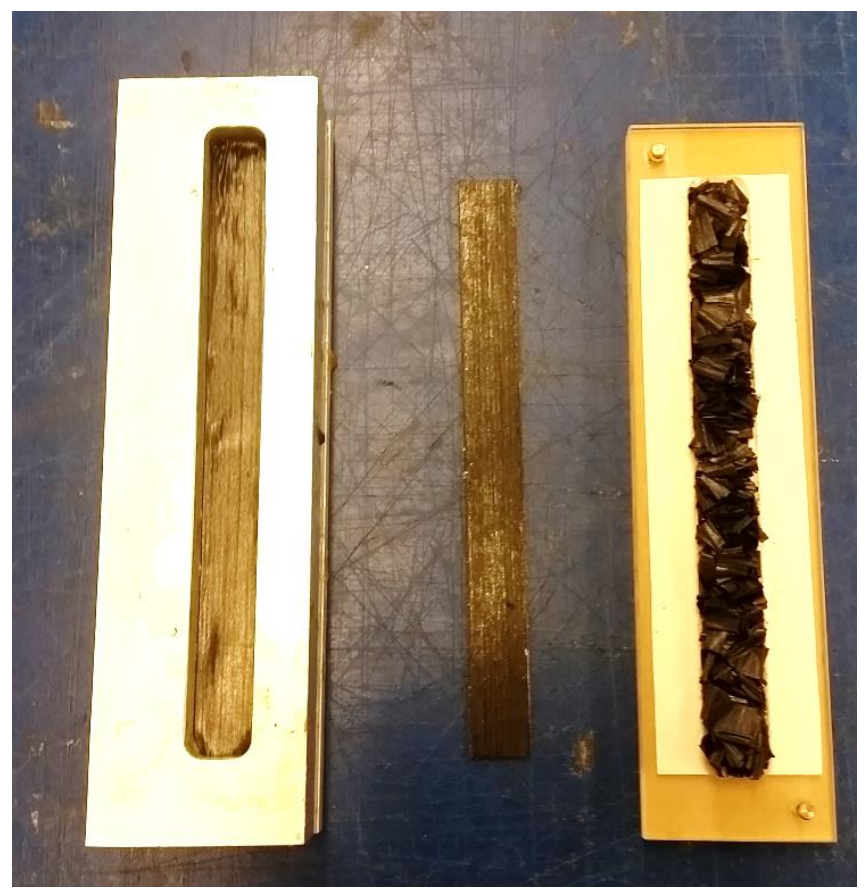

Figure 3.22. 1-ply face sheet sandwich structure layup.

Each specimen was cured using the $285^{\circ} \mathrm{F}$ cure for 70 minutes with latent pressure application.

The specimens all pressed out a similar amount of resin and maintained a mold surface finish.

\subsubsection{4-Point Bend Testing}

The same testing process was employed for the sandwich structures as was for the chopped fiber specimens as discussed in Section 3.3.4. The specimens experienced either complete fracture at one of the load rollers (Figure 3.23) or delamination at the interface between the continuous and chopped fibers (Figure 3.24). The sandwich structures also failed quickly under loading. 


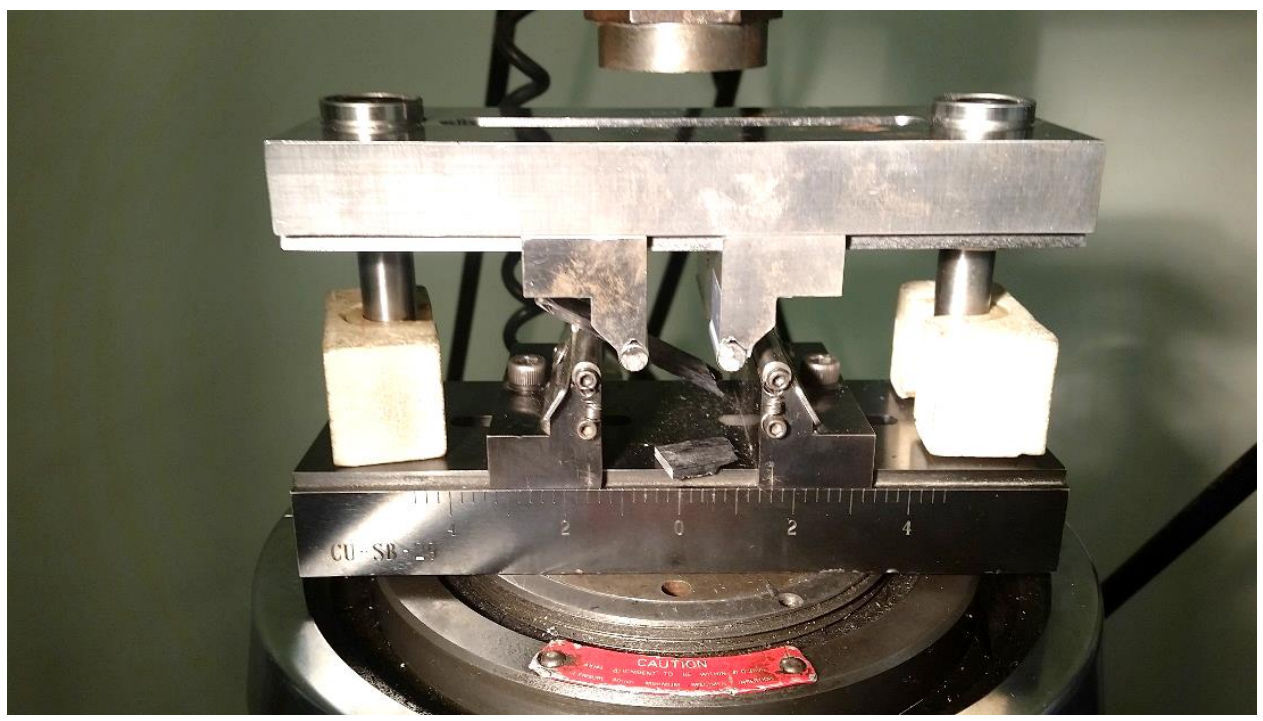

Figure 3.23. Complete fracture failure of sandwich specimen.

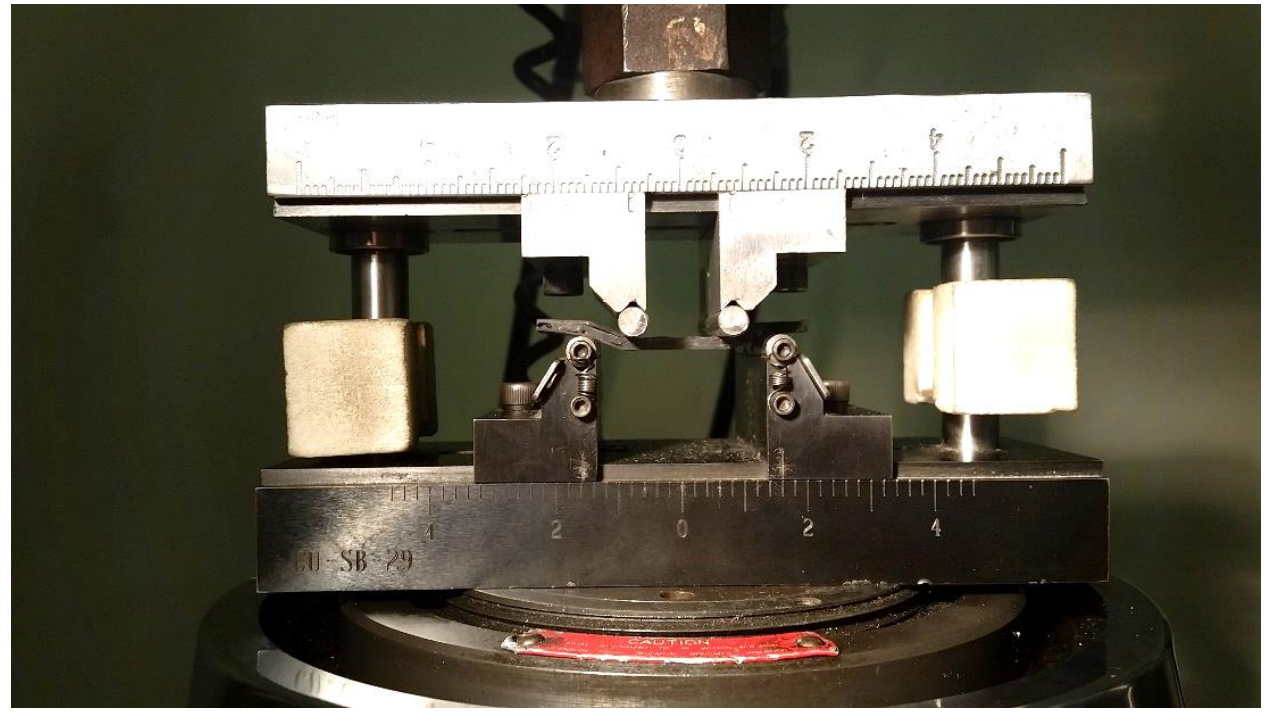

Figure 3.24. Delamination failure of sandwich specimen.

It was discovered during these tests that part of the reasoning behind the quick failure of the specimens in this section was due to erroneous programming of the Instron load frame position waveform. Instead of setting the rate of crosshead motion in units of in/min, it was set in in/s. For example, the calculated load rate for 4-point bend testing was $0.0427 \mathrm{in} / \mathrm{min}$, but the Instron was instead set to displace the crosshead at $0.0427 \mathrm{in} / \mathrm{s}$, or $2.562 \mathrm{in} / \mathrm{min}$. Rearranging Eq. 3.11, this is equivalent to a strain rate $(Z)$ of $0.6 \mathrm{in} / \mathrm{in} / \mathrm{min}$ rather than the specified $0.01 \mathrm{in} / \mathrm{in} / \mathrm{min}$ [44]. 
According to studies on the strain rate dependence of the flexural properties of composite materials [48] [49], the increased loading rate would yield strength values significantly higher than a true quasi-static test. Therefore, the sandwich structures should withstand a much higher load than predicted by the CLT model, thus invalidating the model for this load case. The flexural properties of the sandwich structures are shown in Table 3.5. For reference, the ultimate failure load of each specimen, compared to the predicted value, is shown in Table 3.6.

Table 3.5. Flexural strength, strain, and tangent modulus of sandwich structures.

\begin{tabular}{|c|c|c|c|}
\hline Specimen ID & $\begin{array}{c}\text { Flexural Strength } \\
(\mathbf{k s i})\end{array}$ & $\begin{array}{c}\text { Flexural Strain } \\
(\mathbf{i n} / \mathbf{i n})\end{array}$ & $\begin{array}{c}\text { Tangent Modulus } \\
(\mathbf{M s i})\end{array}$ \\
\hline 1AB & 93.9 & 0.0083 & 16.8 \\
\hline $1 \mathrm{AU}$ & 103 & 0.0061 & 20.6 \\
\hline 1BB & 93.3 & 0.0068 & 27.5 \\
\hline 1BU & 79.6 & 0.0099 & 16.8 \\
\hline $2 \mathrm{AB}$ & 109 & 0.0119 & 34.0 \\
\hline $2 \mathrm{AU}$ & 149 & 0.0092 & 35.2 \\
\hline 2BB & 131 & 0.0095 & 39.8 \\
\hline 2BU & 111 & 0.0083 & 34.3 \\
\hline 3AU & 117 & 0.0065 & 30.1 \\
\hline 3AB & 120 & 0.0099 & 30.4 \\
\hline 3BB & 133 & 0.0094 & 32.4 \\
\hline 3BU & 143 & 0.0077 & 45.6 \\
\hline
\end{tabular}

Table 3.6. Experimental and predicted ultimate load for sandwich structures.

\begin{tabular}{|c|c|c|c|}
\hline Specimen ID & $\begin{array}{c}\text { Ultimate Load } \\
\text { (lbf) }\end{array}$ & $\begin{array}{c}\text { Predicted Load } \\
(\mathbf{l b f})\end{array}$ & $\begin{array}{c}\text { Difference } \\
(\boldsymbol{\%})\end{array}$ \\
\hline 1AB & 392 & 132 & 196 \\
\hline 1AU & 432 & 132 & 227 \\
\hline 1BB & 389 & 132 & 194 \\
\hline 1BU & 332 & 132 & 151 \\
\hline $2 \mathrm{AB}$ & 457 & 250 & 83.0 \\
\hline $2 \mathrm{AU}$ & 622 & 250 & 148 \\
\hline 2BB & 549 & 250 & 119 \\
\hline 2BU & 467 & 250 & 86.6 \\
\hline $3 \mathrm{AU}$ & 491 & 300 & 63.7 \\
\hline $3 \mathrm{AB}$ & 503 & 300 & 67.5 \\
\hline $3 \mathrm{BB}$ & 558 & 300 & 85.8 \\
\hline 3BU & 599 & 300 & 99.7 \\
\hline
\end{tabular}


Interestingly, despite exhibiting an apparently higher strength, the sandwich specimens tended to fail in the locations predicted by the CLT scripts described in Section 3.4.1. Thus, in future research, the theory may still accurately model the behavior of the structure when tested in a truly quasi-static mode. The failed specimens are shown in Figure 3.25.

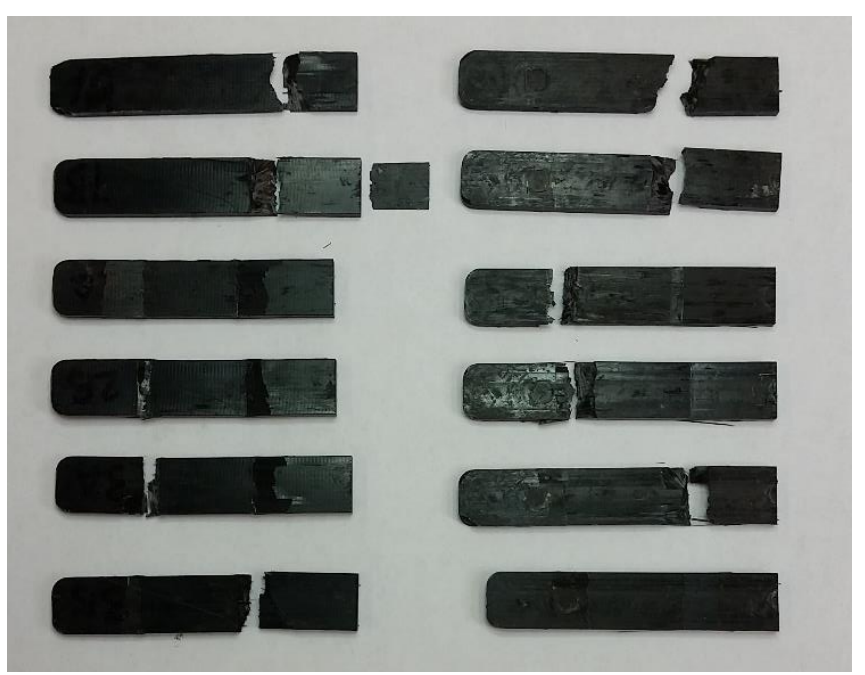

Figure 3.25. Tested sandwich specimens. 


\section{Chapter 4. Hybrid Continuous-Chopped Fiber Component Design}

With both unidirectional and chopped M46J/TC250 experimentally characterized in terms of manufacturability and mechanical performance, it was possible to incorporate the properties of both into a functional part design. A pin-loaded tensile specimen was selected for design due to the extensive available literature on composite lug design. A large cloth composite lug, which failed in net-tension, is shown in Figure 4.1.

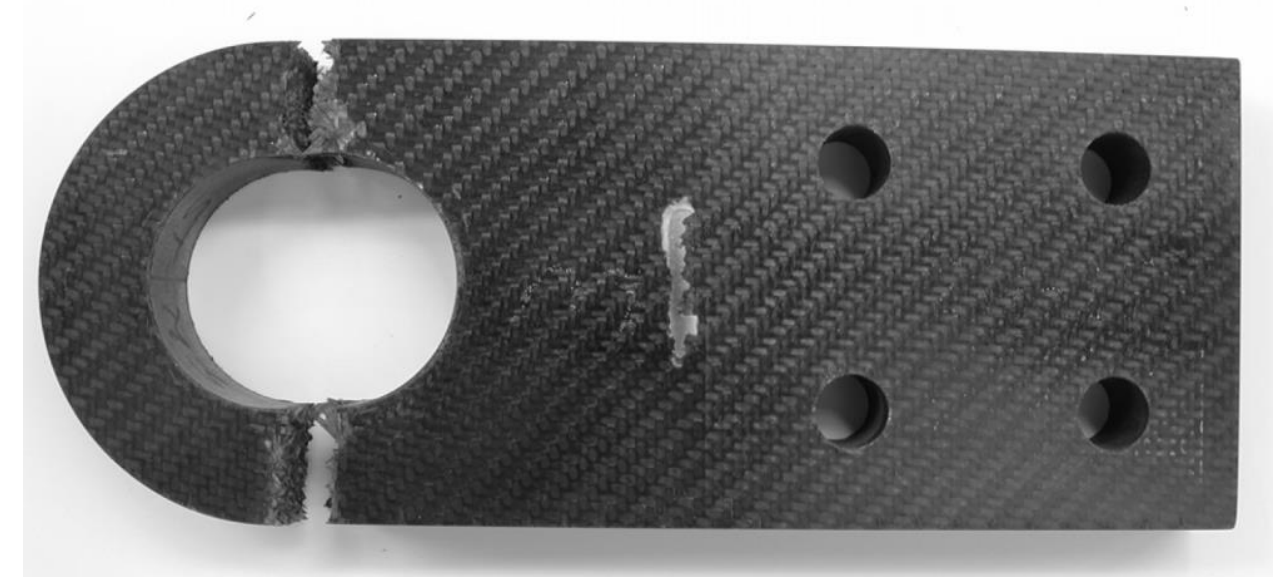

Figure 4.1. Example of a composite lug which has failed in net-tension [50].

The specimen was designed with two lugs at either end of a smaller gage section. Continuous fibers were used to increase the strength of the specimen while chopped fibers were used as filler to simplify part geometry and as a means of improving the manufacturability of the lug.

The lug portion of the specimen was designed to fail in bearing by modeling the component with a lug design parameter calculator script in MATLAB. The geometry and layup of the final specimen were both driven by this code. A 3-part mold was designed to mold the specimen to satisfy its geometric constraints. During manufacture, different charge sizes were molded to further experiment with pressure application timing and resin press-out. The lug holes were machined on a mill for accuracy. 
A test method was developed with which to load the specimens through the lugs in tension. Specimens were evaluated based on their ultimate tensile load as it compared to the predicted value from the lug design script.

\subsection{Functional Part Design}

To demonstrate the possibility of combining continuous and chopped fibers from the same prepreg material, a pin-loaded tensile specimen was designed and manufactured. The specimen consisted of a reinforced gage section with lugs at each end to accept the pins for tensile testing.

\subsubsection{Composite Lug Design Concepts}

A composite joint can experience a number of different failure modes, but the most common are net-tension, shear-out, and bearing failure [51]. The three failure modes are illustrated in Figure 4.2. Of the three primary failure modes, it is desirable to design a lug to fail in bearing as it is the least catastrophic failure mode of the three [51].
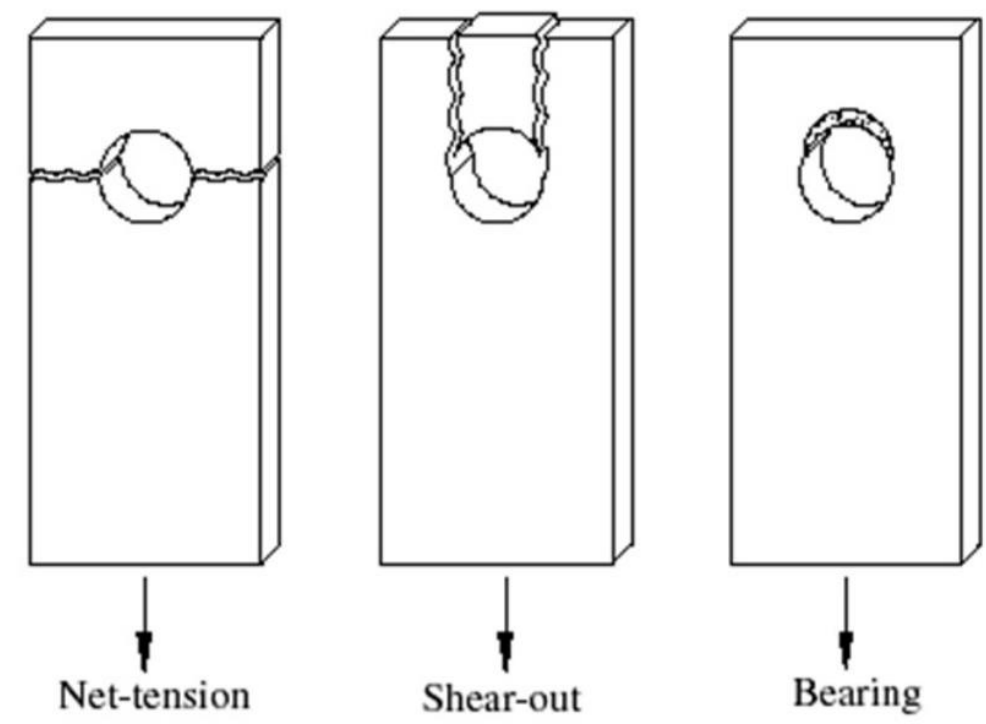

Figure 4.2. Common failure modes for bolted composite joints [52]. 


\subsubsection{MATLAB Lug Strength Prediction}

The ultimate strength in net-tension, shear-out, and bearing were summarized by Heslehurst [53] in terms of lug geometry and laminate properties. These relationships were developed empirically for composite lugs based on empirical development of similar empirically-developed relationships for metallic lugs. These relationships were then coded into a MATLAB script (lug.m) which evaluated the applied and ultimate stress of a lug based on the force applied at the pin. The input parameters required for calculation were:

\begin{tabular}{|c|c|}
\hline$P:$ Force exerted on lug (lbf) & $P_{0}$ : Percentage of 0 degree fibers \\
\hline$D$ : Diameter of bolt (in) & $P_{45}$ : Percentage of 45 degree fibers \\
\hline$R$ : Edge distance from bolt center (in) & $X$ : Tensile strength of continuous fibers (psi) \\
\hline$t$ : Lug thickness (in) & $\tau$ : Shear strength of continuous fibers (psi) \\
\hline
\end{tabular}

Applied net-tension stress for a composite lug were calculated using

$$
\sigma_{N T}=\frac{P}{K_{t c}(2 R-D) t}
$$

where

$$
\begin{gathered}
K_{t c}=\left[\frac{P_{0}}{100}\left(k_{t e}-1\right)+1\right]^{-1} \\
k_{t e}=2+(\alpha-1)-\left[\frac{3}{2} \frac{(\alpha-1)}{(\alpha+1)}\right] \Theta \\
\Theta=\frac{(R-3 D)}{2(R-D)} \text { and } \alpha=\frac{2 R}{D}
\end{gathered}
$$


If the net-tension stress exceeded the ultimate strength of the continuous plies used in the lug, then the lug would fail in net-tension. To prevent a net-tension failure, an additional face ply was added exclusively to the lug portion of the specimen.

Shear-out stress in the composite lug was calculated using

$$
\tau_{S O}=\frac{P}{t \sqrt{(2 R)^{2}-D^{2}}}
$$

The ultimate shear strength of the composite lug was dependent on the equivalent percentage of 45 degree plies in the lug. Thus $\tau_{u l t}$ was estimated using

$$
\tau_{u l t}=\frac{X}{2000}\left(4.5 P_{45}+1\right)
$$

The bearing stress experienced by the lug was calculated using

$$
\sigma_{B R}=\frac{P}{K_{b r c} D t}
$$

where

$$
K_{b r c}=\left[\frac{\frac{P_{0}}{100}\left(k_{t e}-1\right)+1}{(\alpha-1)}\right]^{-1}
$$

The ultimate bearing strength is estimated at three times the magnitude of the ultimate shear strength of the continuous fibers $(\tau)$ [54]. The code for lug . m can be found in Appendix B.3.

In order for the lug to fail in bearing, the bearing stress must exceed the bearing strength before any other strength is exceeded. Geometric parameters were modified in the code until this requirement was satisfied. 


\subsubsection{Lug Geometry}

According to lug design guidelines from industry [55], many of the lug design decisions are based on the diameter of the pin used to load the lug. Thus, a standard bolt size of 0.25 in was selected as the pin, since 0.25 in is the smallest bolt size certified by ASTM standards. Based on the aforementioned guidelines, the lug thickness was initially chosen to be $0.25 \mathrm{in}$. This would also allow for the chopped fiber in the center of the gage section to flow and press against the strap around the perimeter of the lug, as mentioned in Section 4.1.

A total lug width of 0.75 in was selected as a starting point and, from evaluating that geometry using the code mentioned in Section 4.1.2, the lug section thickness was increased to 0.35 in from 0.25 in. The percentage of 0 degree plies was set to $20 \%$ and assuming that, of the remaining $80 \%$ chopped fibers, about half were in the 45 -degree orientation gave a percentage of 45 degree plies equivalent to $40 \%$. the code suggested that the lug would fail at just over $1000 \mathrm{lbf}$ of applied load through the pins. The final lug geometry is shown in Figure 4.3.

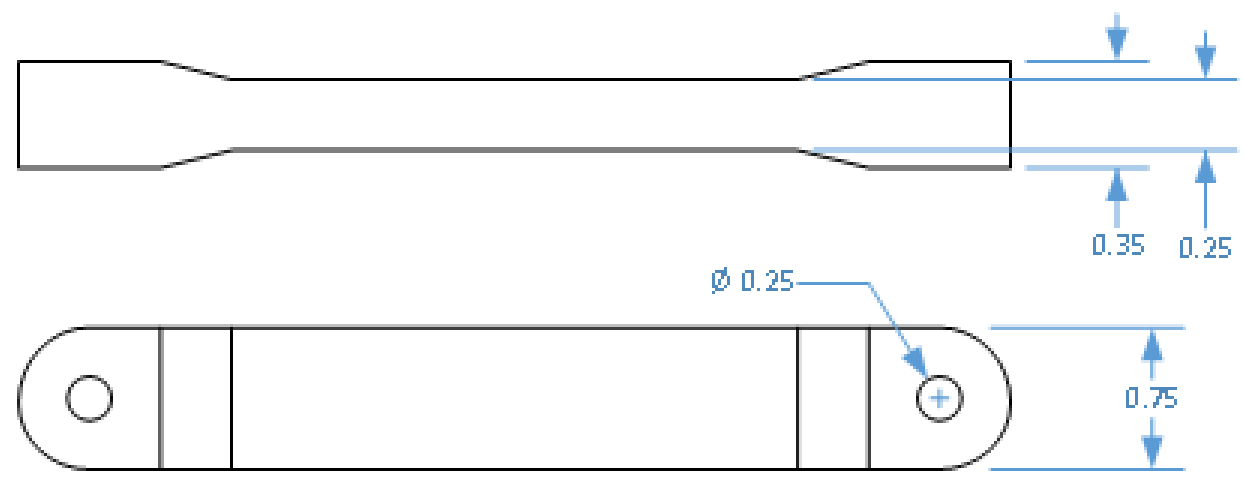

Figure 4.3. Final pin-loaded tensile specimen dimensions.

The specimen was designed with continuous fiber reinforcement plies on either face as well as a continuous fiber strap around the outside of the specimen to better distribute the tensile load to the stronger gage section. The remaining volume of the specimen was made up of chopped fiber. 
The chopped fiber filled in the lug portion of the specimen in order to improve the machinability in the lug and to provide more isotropic properties with which to distribute the stress concentration at the pin. In the center of the specimen, the chopped fibers served to redirect the vertical pressure exerted by the press to the outside of the mold to ensure that the surrounding strap would achieve full compression and cure.

\subsection{Specimen Manufacture and Evaluation}

With the tensile specimen geometry and layup iteratively determined by the lug design script discussed in Section 4.1.2, a method of manufacturing and testing the tensile specimens was developed. A mold which would adequately compact the chopped fiber while laminating together the perimeter strap and face plies of the lug was designed. However, since the specimen geometry was not defined by a testing standard, a new testing method was developed in order to find the ultimate strength of each lug.

\subsubsection{Lug Mold Design and Manufacture}

In order for the strap around the lug to effectively distribute load, it needed to be parallel to the pin through which load was being transferred. This required designing a mold with no draft. Due to the complex 3D surface created by the transition from its lug surface to its gage section, the tensile specimen was an ideal candidate for a 3-part mold. A 3-part mold would allow for sharp corners all around the edge of the tensile specimen which would facilitate layup and allow for specimen symmetry about its midplane.

The mold was designed with a similar mindset to the 3-point bend specimen mold discussed in Section 3.2.1. The deep cavity and thick core of the 3-point bend specimen mold served well to compress charges of material and to contain the material inside the volume of the molded section. The lug mold was similarly designed, with thick cores on the top and bottom of the part which 
defined the lug cross section. To accelerate the mold design and manufacture process, the thermal properties of the mold and charge materials were not considered. The cavity portion of the mold was a simple slot in thick aluminum stock. The exploded view of the mold is shown in Figure 4.4.

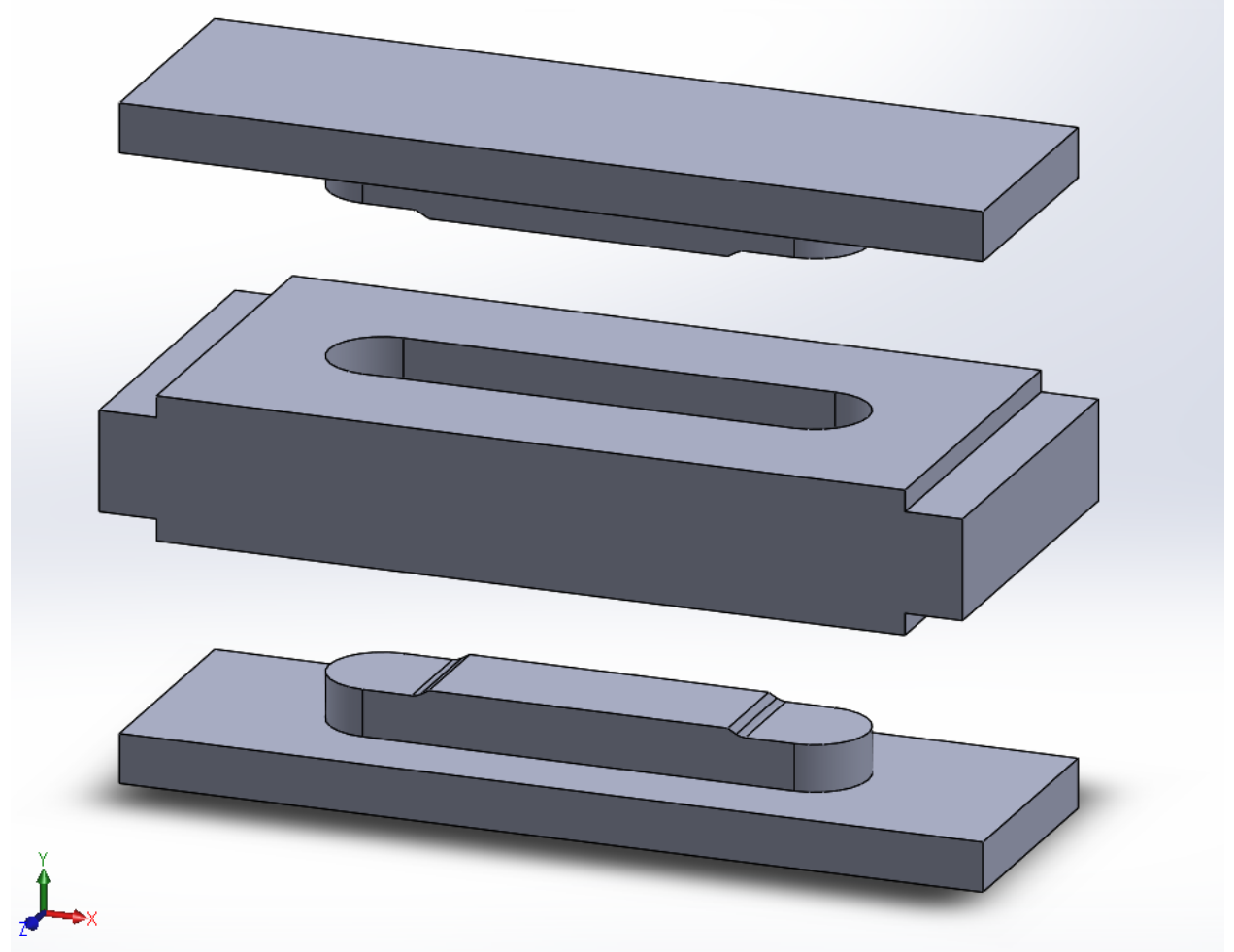

Figure 4.4. Exploded view of 3-part lug mold.

The mold was machined from 6061-T6 aluminum billet on a Haas SMINIMILL2. The CAM and $\mathrm{CNC}$ for this project were performed by Alec Bialek. Due to the complex geometry of the transition between the gage section and lug section of the tensile specimen, a 3D surface program was created and utilized to machine that geometry. The finished mold is shown in Figure 4.5. The lug mold was prepared for use the seasoning procedure outlined in Section 2.1.4. 


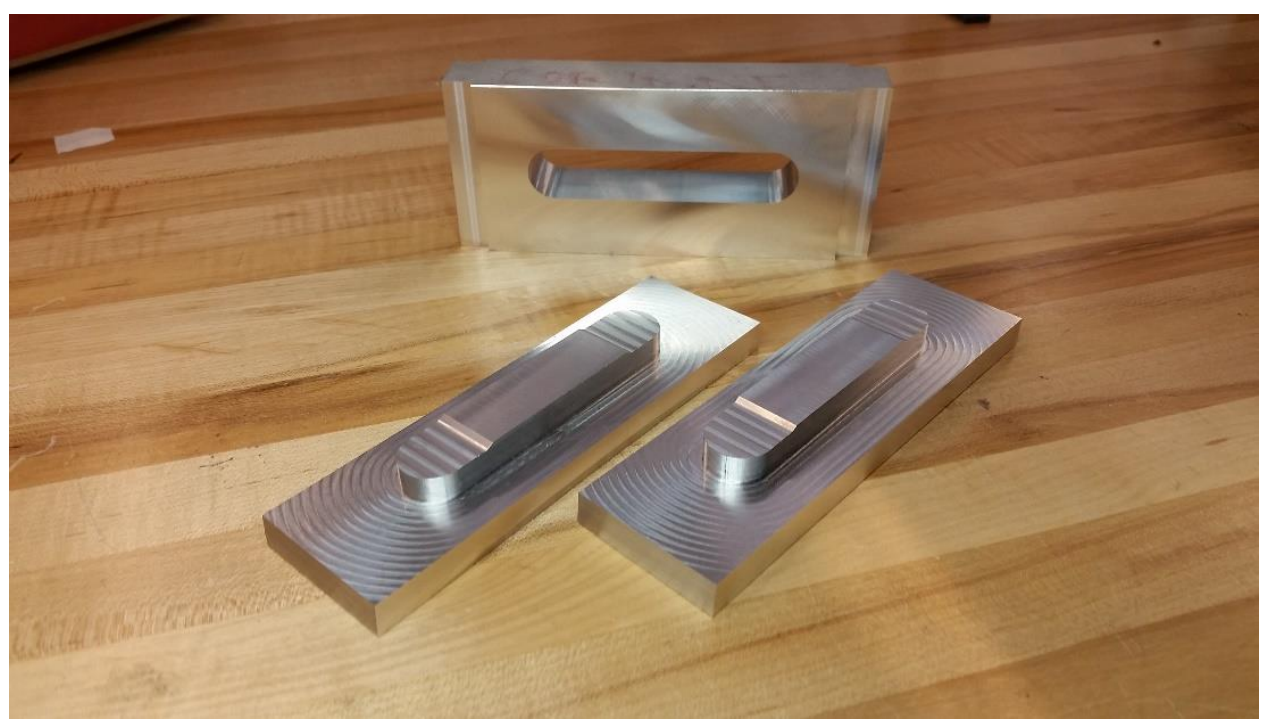

Figure 4.5. Finished 3-part lug mold.

\subsubsection{Layup and Manufacture}

To completely fill the lug and gage sections of the specimen, the $C P T$ calculator was modified to calculate the required length of a 24 in wide strip to be cut from the roll of M46J/TC250 which would completely fill the mold. The layup determined with the lug . m program required $20 \%$ of the cross section of the lug to be made up of 0 degree plies. It also defined the cross sectional dimensions of the lug to be 0.75 in wide by 0.35 in tall.

To satisfy the requirements from the lug program, a 2-ply-thick strap was selected to encase the perimeter of the lug. 2-ply face sheets were used to completely enclose the lug and a third ply was added exclusively in the lug section. These parameters were varied slightly to experiment with the effect of a higher percentage of 0 degree plies. These effects are discussed in Section 4.2.3

The total amount of material required for one tensile specimen was cut from the roll of M46J/TC250 and the required continuous plies were cut from the strip. The trimmings from cutting the plies to shape were preserved for use in the chopped fiber specimen core. Then, the 
remaining material was cut into 0.25 in strips and used to make the core of the specimen. The cut plies and material for one lug are shown in Figure 4.6.

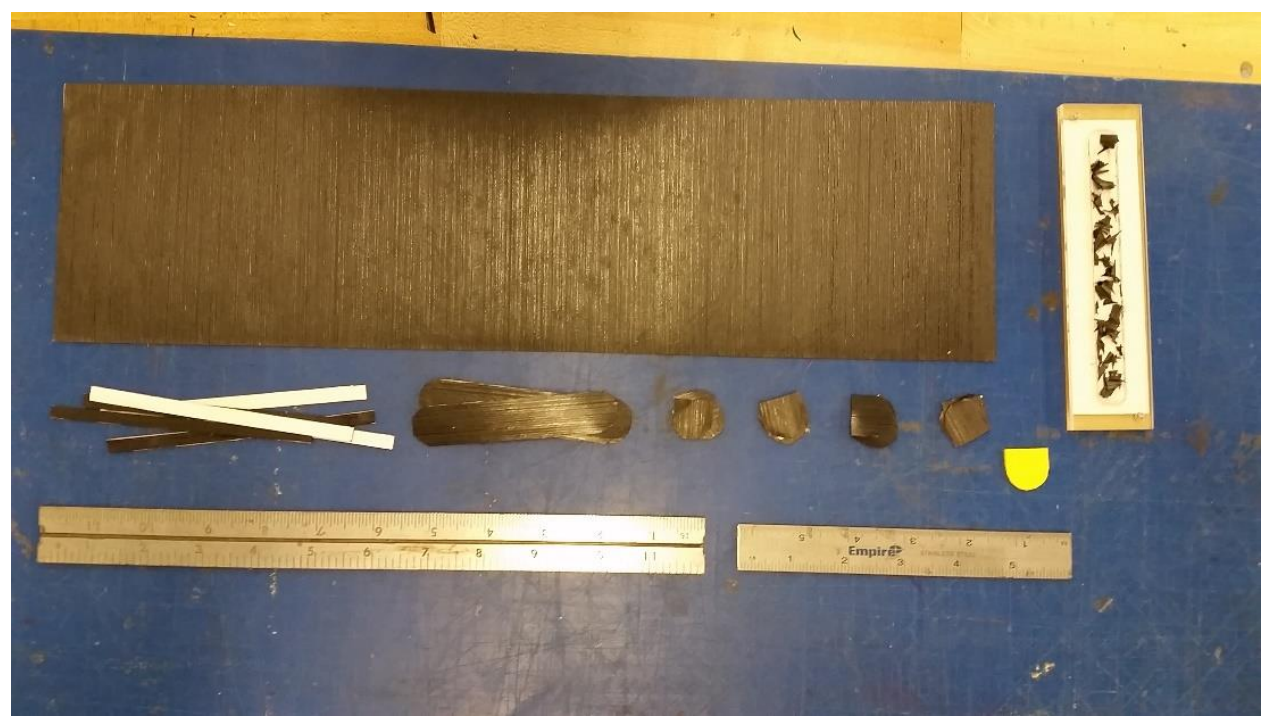

Figure 4.6. Required material for one pin-loaded tensile specimen.

The specimens were manufactured by first assembling one mold core into the cavity. Then the first face skin was laid up and placed on the face of the assembled core, as shown in Figure 4.7.

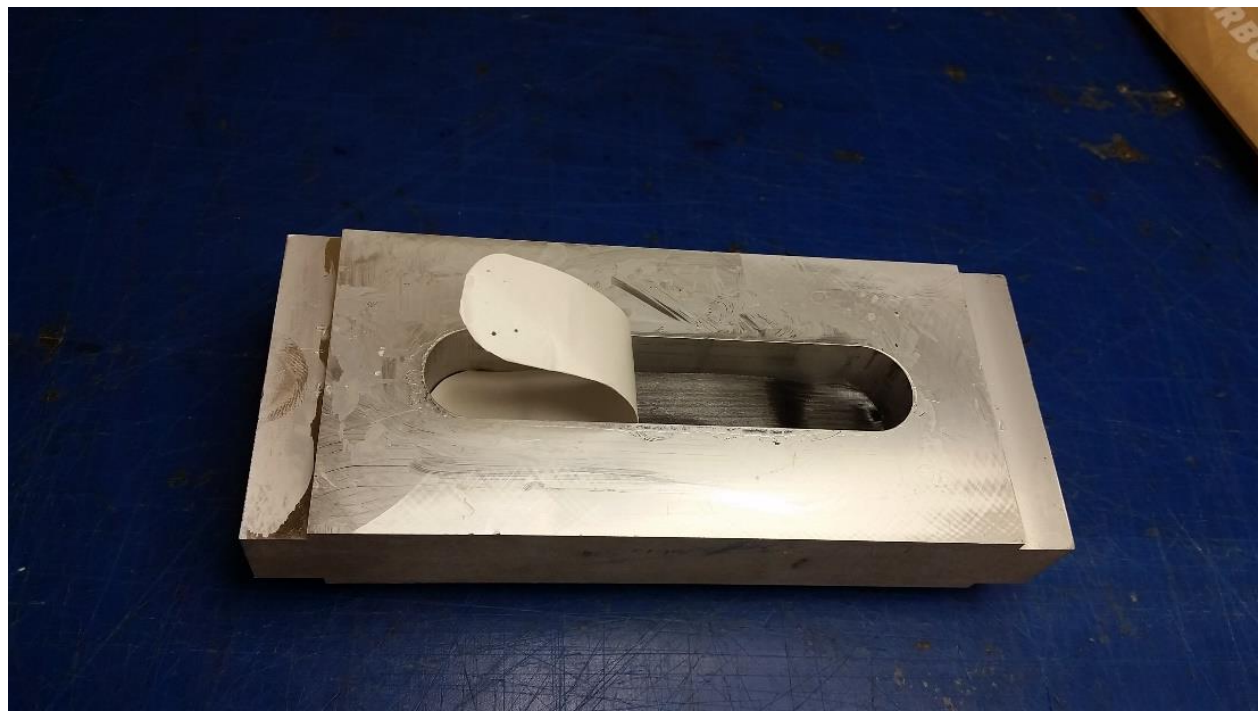

Figure 4.7. First face sheet placed into pin-loaded tensile specimen mold. 
The straps were installed by laying 0.25 in unidirectional strips from the center of the gage section and along the lug portion of the specimen so that each strap intersected the next in the gage section of the specimen. The chopped fibers, including the trimmings pictured in Figure 4.6, were then added to the mold cavity using Method \#3 described in Section 3.1.2. Finally, the second face skin was affixed to the top core and pressed flat to ensure a good surface finish on the top of the lug and the core was installed into the cavity. All specimens were cured at $285^{\circ} \mathrm{F}$ for 70 minutes.

The specimens were demolded by using the mold cores to suspend the cavity in the press and using two 0.75 in diameter Delrin ${ }^{\circledR}$ rods to press the specimen out of the cavity. The process is shown in Figure 4.8.

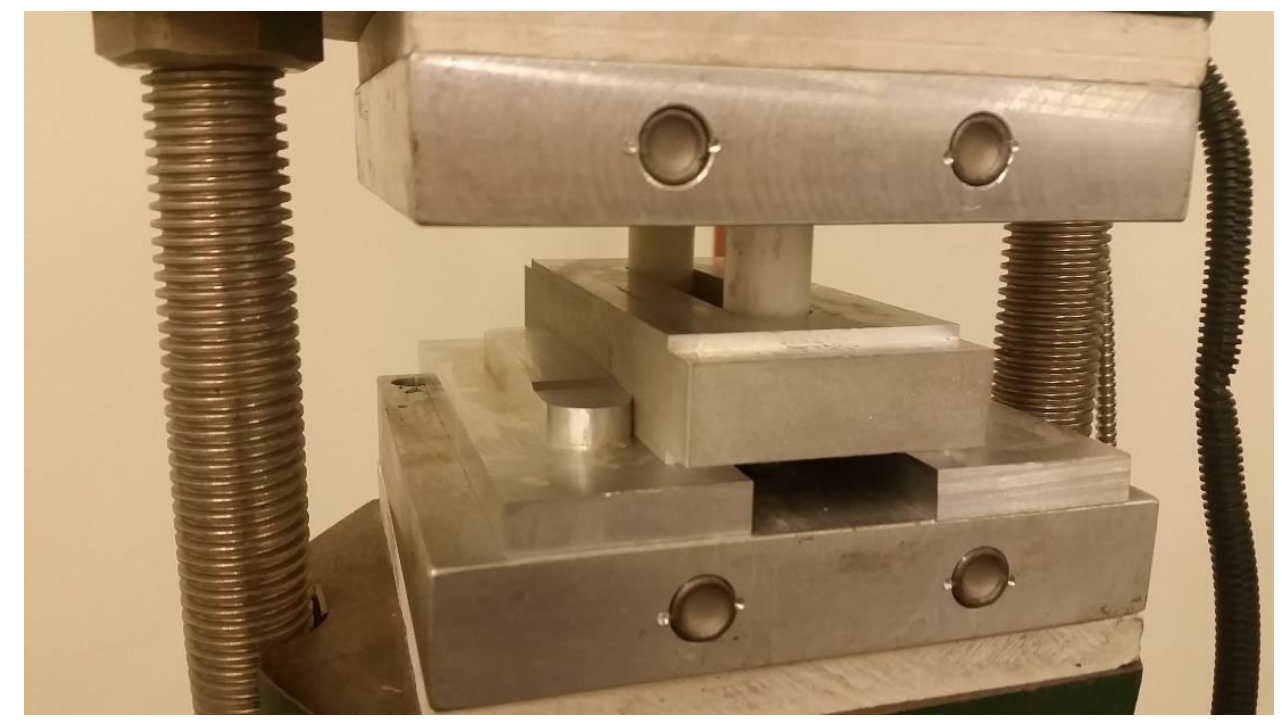

Figure 4.8. Demolding process for pin-loaded tensile specimens.

The holes for pin-loading of the lugs were machined on a Bridgeport Series 1 manual milling machine using a 0.25 in 4 -flute ball endmill. A mill was used to ensure perpendicularity between the face of each lug and the centerline of the drilled hole. A digital read out (DRO) was used to accurately place each hole in the center of the lug. Water was used as a cooling element and a dust suppressant. The setup for the hole drilling procedure is shown in Figure 4.9. The continuous 
fibers on the outside of the lug tended to break and delaminate at the endmill exit location.

However, the chopped fiber region of the lug responded well to machining, resulting in a smooth bearing surface for testing.

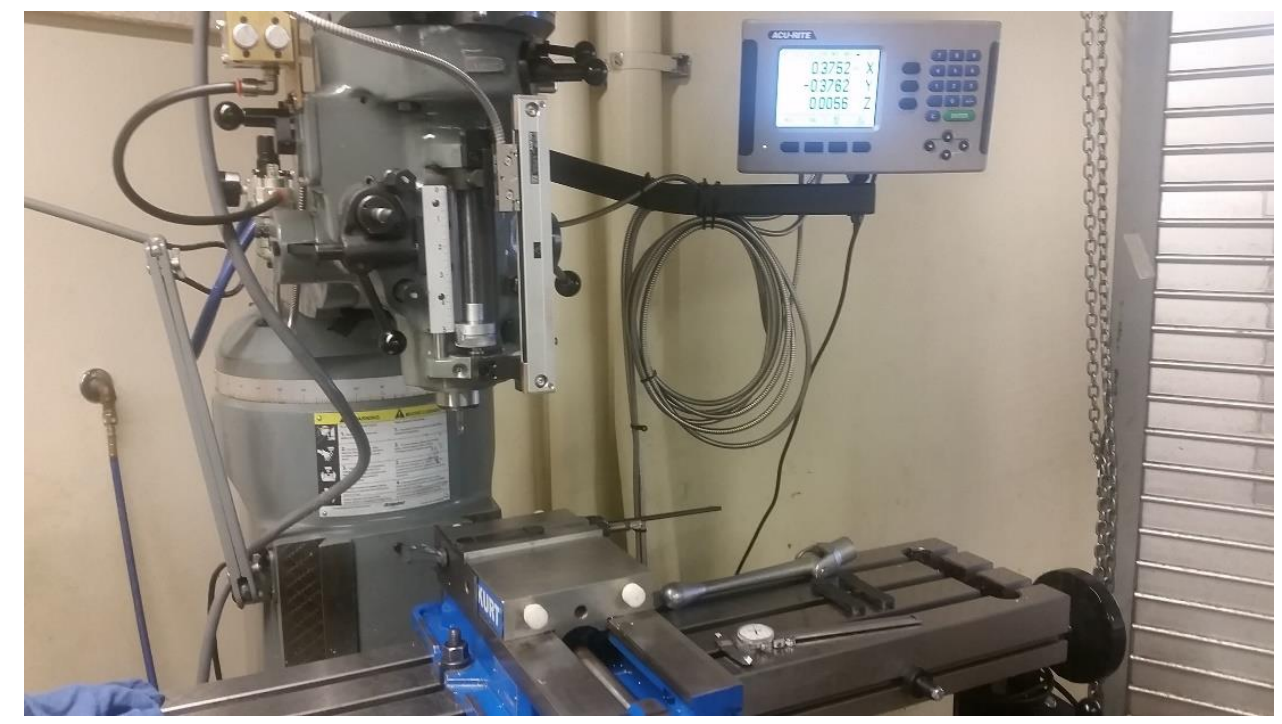

Figure 4.9. Mill setup for lug hole drilling procedure.

\subsubsection{Specimen Variation}

Further experimentation with resin press-out was conducted by varying the amount of material in the charge and the time of pressure application. For this experiment, charges which would create a gage thickness of 0.25 in, 0.27 in, and 0.3 in were considered. The charge information and processing parameters for each specimen are shown in Table 4.1.

Table 4.1. Processing parameters and finished thickness of each pin-loaded tensile specimen.

\begin{tabular}{|c|c|c|c|}
\hline Lug ID & $\begin{array}{c}\text { Equivalent Charge } \\
\text { (in) }\end{array}$ & $\begin{array}{c}\text { Pressure } \\
\text { Application (min) }\end{array}$ & $\begin{array}{c}\text { Finished Thickness } \\
\text { (in) }\end{array}$ \\
\hline 1 & 0.30 & 4.5 & 0.30 \\
\hline 2 & 0.25 & 2.0 & 0.25 \\
\hline 3 & 0.27 & 3.0 & 0.25 \\
\hline 4 & 0.30 & 4.0 & 0.25 \\
\hline 5 & 0.30 & 5.0 & 0.30 \\
\hline
\end{tabular}


As found in Section 3.3.2, more material caused more resin to press out of the mold. However, the time of pressure application had a more significant effect. In the case of Lug 3 and Lug 4, a larger charge which had pressure applied at less than 5 minutes after cure temperature was reached leaked enough resin to allow the mold to close completely and to have a much smaller cured thickness. In fact, Lug \#3, despite having a smaller charge than Lug \#4, leaked the most resin. However, a large charge which had pressure applied at 5 minutes (Lug 1 and Lug 5) did not allow the mold to close completely, but still achieved good compaction and good surface finish with overall larger finished dimensions. Although Lug 3 and Lug 4 leaked more resin than Lug 2, they had a much better surface finish upon demolding.

\subsubsection{Test Apparatus and Method}

Existing clevis-and-pin apparatus were used with the Instron 1331 load frame to test the tensile specimens. ASTM certified Grade 90.25 in bolts were selected to load the specimens. The test setup is shown in Figure 4.10.

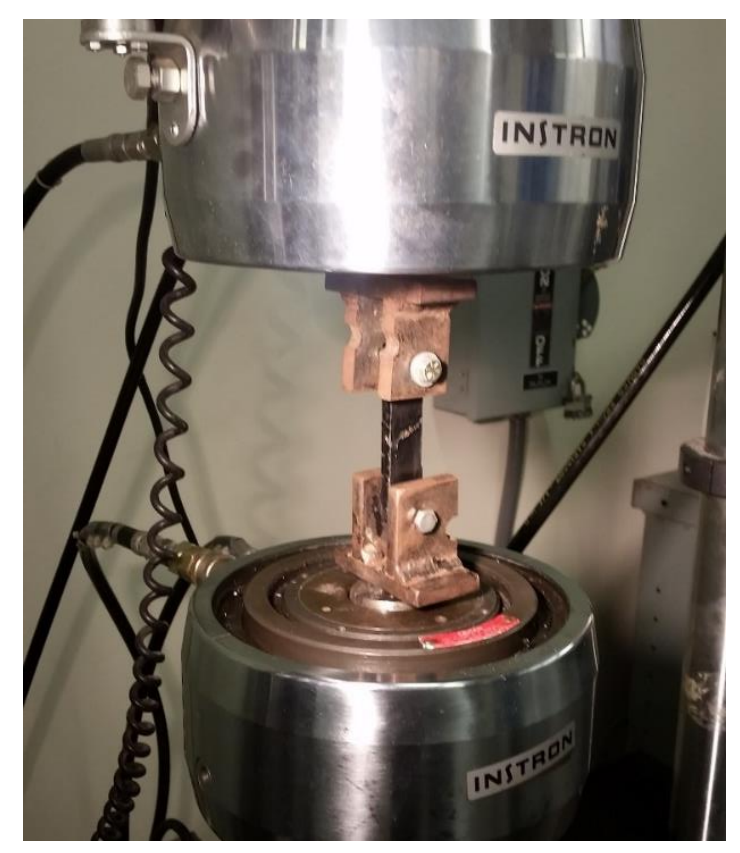

Figure 4.10. Test setup used to evaluate pin-loaded tensile specimens. 
The load rate for the first specimen was set to load the specimen too quickly, so the specimen failed catastrophically in combined cleavage and shear-out. Lug \#1 is shown in Figure 4.11. The remaining specimens were loaded at $0.001 \mathrm{in} / \mathrm{s}$ and failed in bearing, as predicted. A representative lug is shown in Figure 4.12.

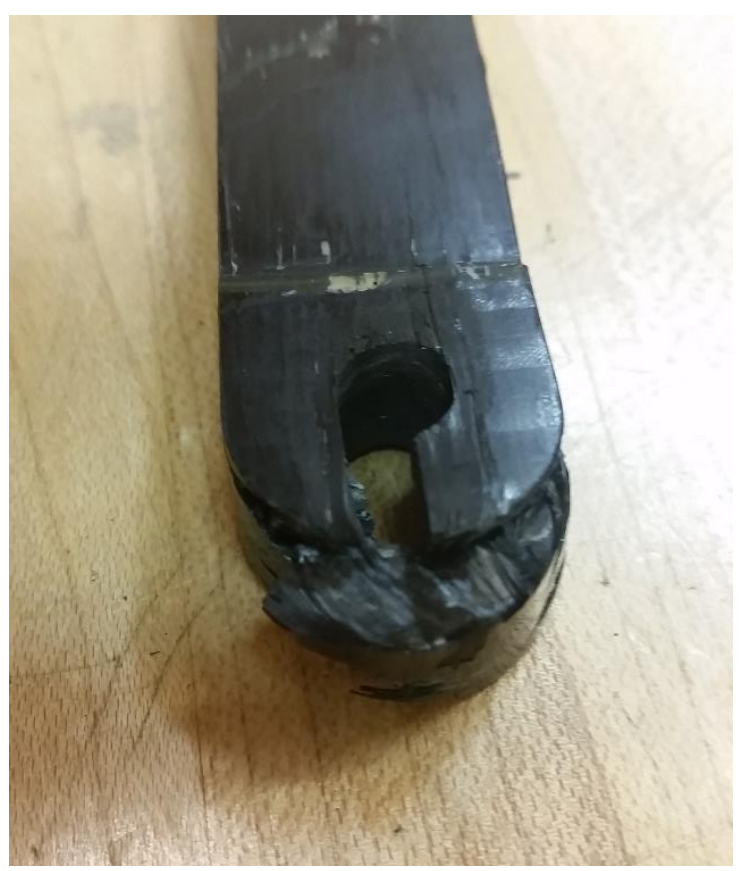

Figure 4.11. Catastrophic cleavage and shearout failure mode.

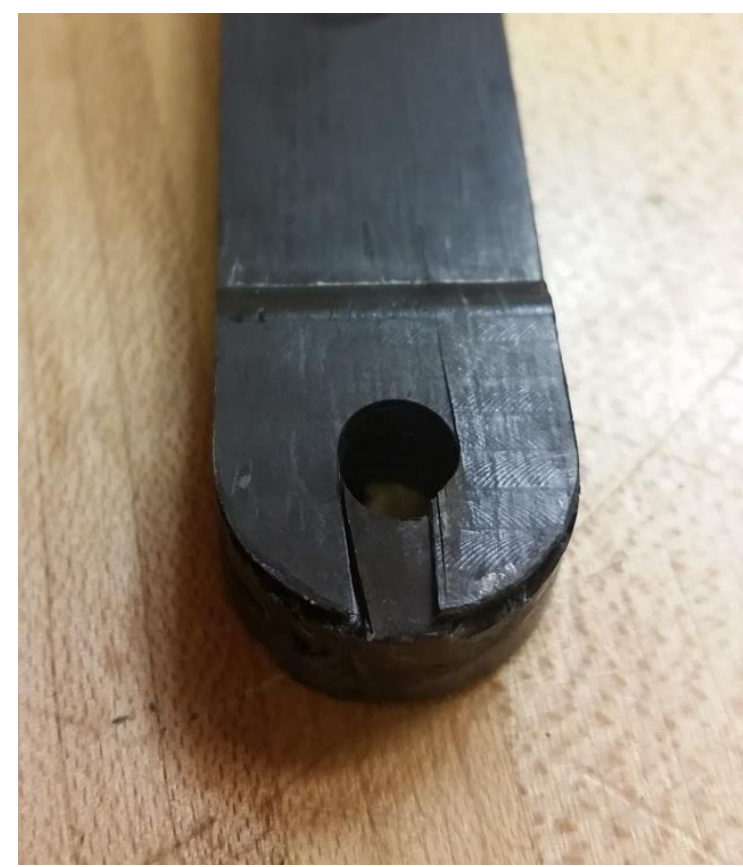

Figure 4.12. Bearing failure mode caused by quasi-static loading.

The layup of each specimen was also varied to determine the effect of layup on the overall specimen quality and strength. The layup of each specimen is shown in Table 4.2. The load rate, failure mode, and ultimate load of each specimen are shown in Table 4.3. The predicted ultimate load in Table 4.3 was calculated using lug.m. Ultimate load for specimens which experienced more compaction was calculated with a higher percentage of 45 degree plies. 
Table 4.2. Layup for each pin-loaded tensile specimen.

\begin{tabular}{|c|c|c|c|c|}
\hline Lug ID & $\begin{array}{c}\text { Equivalent } \\
\text { Charge (in) }\end{array}$ & $\begin{array}{c}\text { Continuous } \\
\text { Face Plies }\end{array}$ & $\begin{array}{c}\text { Additional } \\
\text { Lug Plies }\end{array}$ & Strap Plies \\
\hline 1 & 0.30 & 3 & 3 & 3 \\
\hline 2 & 0.25 & 2 & 2 & 2 \\
\hline 3 & 0.27 & 2 & 1 & 2 \\
\hline 4 & 0.30 & 2 & 1 & 2 \\
\hline 5 & 0.30 & 2 & 1 & 2 \\
\hline
\end{tabular}

Table 4.3. Failure mode and ultimate load for each pin-loaded tensile specimen.

\begin{tabular}{|c|c|c|c|c|c|}
\hline Lug ID & $\begin{array}{c}\text { Load Rate } \\
\text { (in/min) }\end{array}$ & $\begin{array}{c}\text { Failure } \\
\text { Mode }\end{array}$ & $\begin{array}{c}\text { Ultimate } \\
\text { Load (lbf) }\end{array}$ & $\begin{array}{c}\text { Predicted } \\
\text { Load (lbf) }\end{array}$ & $\begin{array}{c}\text { Difference } \\
(\%)\end{array}$ \\
\hline 1 & 0.040 & $\begin{array}{c}\text { Cleavage/ } \\
\text { Shear-out }\end{array}$ & 1451.4 & 1285 & 12.9 \\
\hline 2 & 0.001 & Bearing & 1404.2 & 1320 & 6.37 \\
\hline 3 & 0.001 & Bearing & 1267.2 & 1480 & 14.3 \\
\hline 4 & 0.001 & Bearing & 1444.0 & 1480 & 2.43 \\
\hline 5 & 0.002 & Bearing & 1291.5 & 1760 & 26.6 \\
\hline
\end{tabular}

Lug \#1 was tested at a high load rate, so its higher ultimate load was likely an artifact of that rate. Lug \#2 and Lug \#4 performed much as expected. The lower ultimate load of Lug \#3 was likely due to the fact that it leaked the most resin of the specimens. This indicated that the minimum viscosity point of the TC250 resin system was reached closest to 3 minutes after the cure temperature was reached. Thus, the application of pressure at that point pressed out more resin, resulting in a specimen which likely had high porosity. Conversely, Lug \#5 had pressure applied at the latest time of the five lugs and leaked the least amount of resin. This latent pressure application could have allowed the resin to cure too much and thus prevent the resin from flowing throughout the part, also causing porosity and a lower ultimate strength than expected.

The pin-loaded tensile specimens served well to demonstrate the possibility of combining continuous and chopped fibers into a functionally graded component. The unidirectional plies in the lug portion of the specimens served to tune the net-tension and bearing strengths of the lug while the amount of chopped fiber was used to estimate the shear-out strength of the lug. The 
chopped fiber also served as a filler in the gage section to simplify the geometry and manufacture of the lug. More importantly, the chopped fiber in the lug section responded well to machining, as predicted, and created a smooth bearing surface for the pin loading of each specimen. 


\section{Chapter 5. Conclusions and Key Findings}

The goal of this project was to investigate the possibility of combining continuous and chopped fiber of the same material system into a functionally graded compression molded component with the intent of recycling normally discarded cut off material to maximize net material usage. The compression molding process was developed at a laboratory level for experimentation with different material systems. The behavior of continuous fiber was characterized with this method and compared to specimens produced with the traditional autoclave manufacturing method. A method for cutting material into a random, chopped fiber compound was developed and implemented in the compression molding system. Continuous and chopped fibers were then combined at a coupon and a component level. Both the coupon and the component created using this method produced no waste material. The resulting components were predictable and repeatable, confirming the possibility of designing and manufacturing a functionally graded hybrid chopped and continuous fiber component with zero composite material waste.

\subsection{Mold Design}

When designing a mold for laboratory-scale composite compression molding, it was important to understand the geometric requirements of both the press and the specimen being manufactured. The tensile specimens in Figure 2.2 required longer tabs (per Eq. 2.5) in order to successfully hold the gage section of the specimen when tested to failure. The specimens were originally designed in that way in order to fit within the bounds of the press platens. However, the satisfaction of both requirements was necessary for a complete design.

The thermal properties of the mold and molding material were also important. A complete mold design should include consideration of the CTEs of both the mold material and the charge material to determine whether each will expand or contract at maximum cure temperature. The 
thermal analysis of the mold-platen assembly was also useful in determining how long the mold took to heat up to cure temperature.

Careful manufacturing was critical to quality part production. A mold should always be modeled as it will be manufactured in order to avoid interfering features such as the tensile specimen mold corner in Figure 2.20. The mold should also be manufactured in a way which fully contains the material, which requires a thorough knowledge of the material being molded. The finished mold should allow demolding of each specimen without damaging the specimen or the mold. It was discovered in Section 3.2.1 that poorly designed ejector mechanisms could damage specimens during the demolding process.

\subsection{Specimen Manufacture and Evaluation}

Compression molding requires the careful calculation of mold volume and corresponding charge size. As shown in Figure 2.15, an insufficient amount of material resulted in a specimen which was uncompacted and had a poor surface finish. The $C P T$ calculator in Appendix B.1. was developed to accurately calculate the amount of composite material which would fit into a specified mold cavity.

Similarly, the amount and type of resin in a composite was an important factor in the quality of each compression molded component. In general, composite material with a higher resin content resulted in superior finished specimens. Additionally, the viscosity profile of the resin systems used was an important factor in timing the application of pressure to the system. Pressure application at a low viscosity point in the resin's viscosity profile caused excessive resin press-out which affected the quality and geometry of the molded component, as shown in Section 3.3.3 and Section 4.2.3. 


\subsection{Chopped Fiber Manufacture and Integration}

A method of quickly and consistently cutting unidirectional composite material into chopped fiber was developed, as shown in Figure 3.6. This method was developed using regularly shaped composite plies, but is easily expandable to irregular scraps produced by traditional manufacturing methods. The resulting compound was easily integrated with continuous fibers using the compression molding manufacturing method, as shown in Section 3.4 and Chapter 4.

The chopped fiber material responded well to compression molding as it flowed to fill the entire mold cavity during pressure application, demonstrating its ability to be molded into complex geometries regardless of charge shape. The quality surface finish produced by milling the lug holes through the chopped fiber also demonstrated its superior machinability.

\subsection{Future Work}

The design and manufacture of the pin-loaded tensile specimen demonstrated that functional grading of a composite material was possible by selectively varying fiber lengths. It is possible to further optimize this design method. Different fiber lengths would produce different mechanical and manufacturing properties than the 0.25 in fibers used throughout this project. However, this design validation shows that it is possible to model and predict a hybrid continuous and chopped fiber structure which opens up the possibility of integration into a structural composite component design.

While the idea behind this manufacturing method is valid, the method of chopping fibers presented in this paper is not suitable for the high-volume production for which compression molded is typically employed. If this method is to be implemented in industry, an easier or completely automated method of chopping leftover fibers must be developed. However, at a 
laboratory or prototyping level, the herein suggested method for converting waste to chopped fibers is feasible.

A more rigorous understanding of the molding material would vastly improve and expedite the manufacturing process optimization for any material system. For example, the ability to experimentally determine the viscosity profile of a material system would provide a more precise way to determine the best point of pressure application. For future research on compression molding of composites, a material system which was specifically designed for this manufacturing method would have a more predictable viscosity profile and a high resin content, which would make specimen manufacture much quicker and simpler.

Additionally, the true machinability and molding versatility of chopped fiber was not exhaustively investigated. Further experimentation with the manufacturability of chopped fibers would further improve the functional grading design process. 


\section{REFERENCES}

[1] B. D. Agarwal, L. J. Broutman and K. Chandrashekhara, "Analysis and Performance of Fiber Composites," John Wiley \& Sons, Inc., Hoboken, 2006.

[2] I. M. Daniel and O. Ishai, Engineering Mechanics of Composite Materials, New York: Oxford University Press, 2006.

[3] P. I. Kattan, "Chapter 2: Linear Elastic Stress-Strain Relations," IHS Engineering360, 2015. [Online]. Available: http://www.globalspec.com/reference/45203/203279/chapter-2linear-elastic-stress-strain-relations.

[4] J. D. Fudge, "Chopped Prepregs - A Compelling Performance and Cost Alternative Material Form," Tencate Advanced Composites - CCS Composites, LLC, Fairfield, 2009.

[5] P. Feraboli, E. Peisto, F. Deleo and T. Cleveland, "Characterization of Prepreg-Based Discontinuous Carbon Fiber/Epoxy Systems," Journal of Reinforced Plastics and Composites, vol. 28, no. 10, pp. 1191-1214, 2009.

[6] Quantum Composites, "Products: AMC," Quantum Composites, 2015. [Online]. Available: http://www.quantumcomposites.com/products/amc/.

[7] Mar-Bal Incorporated, "History of Composites," Mar-Bal Incorporated, 2015. [Online]. Available: http://www.mar-bal.com/language/en/applications/history-of-composites/.

[8] K. Mason, "Compression molding press technology adapts to meet new composite material processing requirements," CompositesWorld, 1 June 2004. [Online]. Available: 
http://www.compositesworld.com/articles/compression-molding-press-technology-adaptsto-meet-new-composite-material-processing-requirements.

[9] Core Molding Technologies, "Compression Molding," Core Molding Technologies, 2015. [Online]. Available: http://www.coremt.com/processes/compression-molding/.

[10] Carver Inc., Laboratory Presses and Accessories, Wabash: Carver, Inc., 2015.

[11] K. Guzman, "Manufacturing Methods for Composites," Working Paper, Cal Poly, San Luis Obispo, 2014.

[12] American Society for Testing and Materials, Standard Test Method for Tensile Properties of Polymer Matrix Composites, West Conshohocken: ASTM International, 2014.

[13] American Society for Testing and Materials, Standard Test Method for Short-Beam Strength of Polymer Matrix Composite Materials and Their Laminates, West Conshohocken: ASTM International, 2013.

[14] M. Allen, Interviewee, Mold Seasoning Procedure. [Interview]. 2014.

[15] Maverix Solutions, Inc., "Mavcoat(R) 527 ML Semi-Permanent Mandrel Lubricant and Mold Release Coating," Maverix Solutions, Inc., Irvine, 2012.

[16] Henkel Australia Pty Ltd, "Loctite Frekote 700 NC known as Frekote 700 NC," Henkel Australia Pty Ltd, Kilsyth, 2014.

[17] Axel Mold Releases \& Process Aid Additives, "F-57NC," Axel Plastics Research Laboratories, Inc., Woodside, 2014. 
[18] Zoltek, Panex P35 Handling Guide \& Instructions, St. Louis: Zoltek North America.

[19] Graco Inc., "Viscosity," 2010. [Online]. Available: http://www.vpscientific.com/pdfs/www.liquidcontrol.com_eToolbox_viscosity.pdf. [Accessed 22 November 2015].

[20] K. Gamble, Interviewee, Process Development Manager. [Interview]. 3 May 2013.

[21] United States Department of Defense, "Chapter 2: Materials and Processes - The Effects of Variability on Composite Properties," in Military Handbook 17, vol. 3F, United States Department of Defense, 2002.

[22] Hexcel, HexMC(R) Moulding Concept Product Data, Hexcel Corporation, 2012.

[23] P. Malnati, "Prepreg compression molding makes its commercial debut," CompositesWorld, 1 June 2015. [Online]. Available: http://www.compositesworld.com/articles/prepreg-compression-molding-makes-itscommercial-debut. [Accessed 22 November 2015].

[24] K. Akiyama, "Development of PCM (Prepreg Compression Molding) Technology," Mitsubishi Rayon Co., Ltd., Toyohashi, 2011.

[25] American Society for Testing and Materials, "Standard Test Methods for Flexural Properties of Unreinforced and Reinforced Plastics and Electrical Insulating Materials," ASTM International, West Conshohocken, 2010. 
[26] C. C. Chamis, "Analysis of the Three-Point-Bend Test for Materials With Unequal Tension and Compression Properties," National Aeronautics and Space Administration, Washington, D.C., 1974.

[27] D. Cripps, "Formulae," NetComposites Ltd, 2015. [Online]. Available: http://www.netcomposites.com/guide-tools/guide/formulae/. [Accessed 28 Nov 2015].

[28] TenCate Advanced Composites, "LR\# 11561".

[29] TenCate Advanced Composites USA, Inc., HTS 150 gsm/TC250 UD Tape Prepreg NCAMP Pre-Qualification Data, Morgan Hill, 2008.

[30] Torayca, "M46J Data Sheet," Toray Carbon Fibers America, Inc., Santa Ana, 2008.

[31] B. Meyers, Interviewee, Vice President of Technical Services. [Interview]. 19 May 2015.

[32] A. Siver, "Mechanistic Effects of Porosity on Structural Composite Materials," University of California, Los Angeles, Los Angeles, 2014.

[33] D. C. Montgomery, Design and Analysis of Experiments, Hoboken: John Wiley \& Sons, Inc., 2013.

[34] C. Warnock, K. Maupin and M. McEwan, "Carbon Fiber Compression Molding: Material Property Verification Study," Working Paper, Cal Poly, San Luis Obispo, 2015.

[35] Mechanical Engineering Department, "Procedural Guideline for the Operation of the ASC Autoclave in Bldg. 192 Rm. 135," California Polytechnic State University, San Luis Obispo. 
[36] G. C. Jacob, M. J. Starbuck, J. F. Fellers and S. Simumovic, "Effect of Fiber Volume Fraction, Fiber Length, and Fiber Tow Size on the Energy Absorption of Chopped Carbon Fiber-Polymer Composites," Society of Plastics Engineers, 2005.

[37] Hexcel, "HexTow Chopped Fiber Product Data," Hexcel Corporation, 2009.

[38] C. Warnock, "Heat Distribution Validation of a Compression Molding System," Working Paper, Cal Poly, San Luis Obispo, 2015.

[39] A. K. J. Hasselstrom and U. E. Nilsson, "Thermal Contact Conductance in Bolted Joints," Chalmers University of Technology, Gothenburg, 2012.

[40] Olympus Corporation, "Roughness (2D) Parameter," [Online]. Available: http://www.olympus-ims.com/en/knowledge/metrology/roughness/2d_parameter/. [Accessed 13 October 2015].

[41] Rubert \& Co Ltd, "Roughness Parameters," Rubert, [Online]. Available: http://www.rubert.co.uk/faqs/roughness-parameters/. [Accessed 13 October 2015].

[42] S. R. Schmid, B. J. Hamrock and O. J. Bo., "Surface Parameters," in Fundamentals of Machine Elements, Boca Raton, CRC Press, 2013, p. 197.

[43] Emok, "Surface Finish Tolerances in Manufacturing," Wikipedia, 20 March 2008. [Online]. Available: https://commons.wikimedia.org/wiki/File:Surface_Finish_Tolerances_In_Manfacturing.pn g. [Accessed 13 October 2015]. 
[44] American Society for Testing and Materials, "Standard Test Method for Flexural Properties of Unreinforced and Reinforced Plastics and Electrical Insulating Materials by Four-Point Bending," ASTM International, West Conshohocken, 2010.

[45] P. M. Mohite, "Lecture 39: Shear and Flexural Testing," Indian Institutes of Technology, [Online]. Available: http://nptel.ac.in/courses/101104010/lecture39/39_6.htm.

[46] J. Smith, "Mode I Fracture of Eight-Harness-Satin Carbon Cloth Weaves for Co-Cured and Post-Bonded Laminates," Cal Poly, San Luis Obispo, 2013.

[47] D. Adams, "Flexure test methods," CompositesWorld, 1 November 2005. [Online]. Available: http://www.compositesworld.com/articles/flexure-test-methods.

[48] T. Matsuo, J. Takashi, K. Uzawa, M. Tamaru, T. Asakawa and K. Kiriyama, "Investigation about Strain-Rate Dependenceof the Flexural Behavior of Carbon Fiber Reinforced Polypropylene," JISSE12 Conference, Tokyo, 2015.

[49] G. C. Jacob, J. M. Starbuck, J. F. Fellers, S. Simunovic and R. G. Boeman, "Strain Rate Effects on the Mechanical Properties of Polymer Composite Materials," Wiley Periodicals, Inc., Online, 2004.

[50] M. Wallin, O. Saarela and F. Pento, "Load Response and Failure of Thick RTM Composite Lugs," in 23rd Congress of International Council of the Aeronautical Sciences, Toronto, 2002. 
[51] X. Qing, H.-T. Sun, L. Dagba and F.-K. Chang, "Damage-Tolerance-Based Design of Bolted Composite Joints," Composite Structures: Theory and Practice, vol. ASTM STP, no. 1383, pp. 243-272, 2000.

[52] I. Ilic, Z. Petrovic, M. Maksimovic, S. Stupar and D. Stamenkovic, "Computation Method in Failure Analysis of Mechanically Fastened Joints at Layered Composites," Journal of Mechanical Engineering, vol. 58, no. 9, pp. 553-559, 2012.

[53] R. B. Heslehurst, "Lug Joints," in Design and Analysis of Structural Joints with Composite Materials, Lancaster, DEStech Publications, Inc., 2013, pp. 297-315.

[54] R. Heslehurst, "Estimating Composite Bearing Strength," September 2009. [Online]. Available: http://www.compositesaustralia.com.au/wp-content/uploads/2011/12/16Estimating-Composite-Bearing-Strength.pdf.

[55] Structural Mechanics Corporation, "Composite Joint Design Guidelines," Structural Mechanics Corporation, [Online]. Available:

http://structuralmechanics.com/about/resources/newsletter/articles/composite-joint-designguidelines/. 


\section{APPENDICES}

\section{Appendix A. Test and Analysis Procedures}

\section{A.1. Instron Setup and Calibration}

The following is the procedure for preparing the Instron 1331 and 8500 Series controller for specimen testing. Always wear safety glasses when observing or executing testing. Proper safety training and express permission from the lab owner are required before use. Review and understand the safety documentation available from the Mechanical Engineering Department. Never operate the Instron load frame alone. The controller is shown in Figure A.1 for reference.

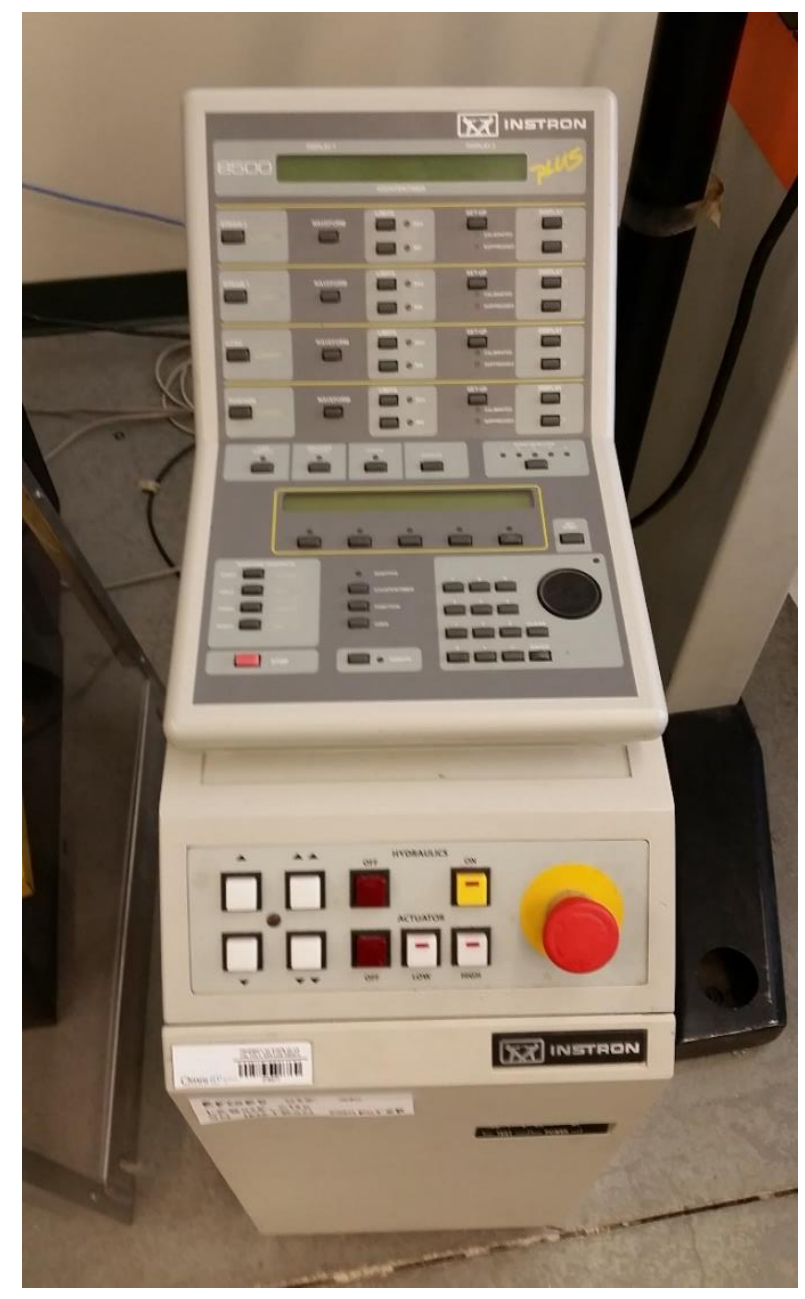

Figure A.1. Instron 8500 Series controller. 
1. Turn on the Instron control panel, hydraulic system, and hydraulic actuator. Ensure that water is flowing through the cooling system on the hydraulic pump. Wait for the controller to finish self-calibration checks.

2. Calibrate the load cell from the control panel using LOAD SET UP > CAL > cal. > AUTO > GO. Calibration is finished when the "CALIBRATED" light stops flashing.

3. Ensure that the wedge grips are free of debris. If desired, use the steel alignment bar to line up the wedge grips by clamping the bar in the upper grip, moving the lower actuator within clamping range, and clamping the bar in the lower grip. Remove bar.

4. Open the appropriate LabVIEW file and set the load and position scale factors to match the load and position outputs on the control panel.

5. Set the loading program as appropriate using the POSITION WAVEFORM menu.

6. Verify accurate data recording by executing a compliance test for higher loads. A compliance test may consist of testing the steel alignment bar in tension or compression to the maximum load anticipated during testing, provided that load does not exceed the yield strength of the steel bar.

Once the Instron is set up, a program can be run with data collection with the following steps:

1. Start data acquisition on LabVIEW by pressing the white arrow in the toolbar.

2. Press the START button on the Instron. Allow the sample to reach the appropriate load or displacement end condition.

3. Press HOLD on the Instron controller.

4. Stop data collection on LabVIEW with the red stop sign button in the toolbar.

5. Press FINISH on the Instron controller.

6. Manually unload the sample by moving the lower grip in the direction opposite of load application using the control box. 


\section{A.2. Mold Seasoning Procedure}

The following is a procedure developed by Quatro Composites for preventing composite parts from sticking into a mold. This process lasts at least 20 pulls. All steps should be executed inside of a fume hood while wearing safety glasses and nitrile gloves. Read and understand the material safety data sheets for MavCoat 527 ML, Frekote 700 NC, and Axel F-57NC before seasoning.

1. Clean the mold with acetone. Make sure it is clear of debris.

2. Apply MavCoat 527 ML mold sealer to all surfaces which could encounter resin.

3. Heat mold to $25^{\circ} \mathrm{F}$ above cure temperature to be used on the press.

4. Repeat steps 2 and 3 three more times.

5. Apply Frekote $700 \mathrm{NC}$ to the mold surface and heat as in step 3.

6. Repeat step 6 two to three more times.

7. Then, right before laying up in the tool, apply two coats of Axel F-57NC. Allow to dry before laying up in mold. Repeat this step for every layup. 


\section{A.3. Thermal Simulation in SolidWorks}

The thermal simulation package in SolidWorks was used to determine the transient thermal behavior of the 3-point bend mold as it was heated by the upper and lower Carver press platens. The following is a summary of the steps necessary to set up a transient thermal analysis study in SolidWorks. (Note that the images used to illustrate these steps were taken from a different thermal analysis. The steps remain the same.)

Before beginning a thermal analysis study, all of the parts being analyzed should be modeled and assembled, including the heating elements inside of the press platens. All parts should have materials already assigned. Ensure that contact between two parts should be represented by a "Coincident" mate in the assembly.

1. Open the assembly and ensure that the SolidWorks Simulation Add-In is active. Under "Simulation" in the Simulation ribbon, select "New Study".

2. Select "Thermal" as the study type and give the study a name. The results of that study will be saved in a new folder with that name. The folder will be created in the same location as the assembly being analyzed.

3. Right-click the study name in the Feature Manager and select "Properties".

a. Set the simulation type to "Transient" by selecting that radio button.

b. Set the total time and time step for this simulation. For the 3-point bend mold simulation, the total time was $120 \mathrm{~s}$ with a $10 \mathrm{~s}$ time step.

c. From this menu, it is also possible to change the simulation results destination folder.

d. When finished, close the "Properties" dialog box.

4. Expand "Connections" in the Feature Manager and delete the global contact set under "Component Contacts". This will allow the definition of a contact resistance between the contacting surfaces in the model. 
5. Define thermal contact resistance at all points of contact in the model. Note that for this simulation, the thermal contact resistance was the same for all points of contact. Thermal contact resistance can also be defined individually for each point of contact.

a. Right-click "Connections" and select "Contact Set". The "Contact Sets" menu is shown in Error! Reference source not found.

b. Select "Automatically find contact sets". Make sure "Touching faces" is selected.

c. Click inside the "Components" box and highlight the entire assembly in the assembly viewing window. The selected components will turn pink.

d. Click "Find contact sets". This will find all of the places in the assembly where different components are touching. Check that this produces many results in the "Results" window.

e. Check the "Thermal Resistance" box and set the thermal resistance to the correct total or distributed value. In this simulation, a distributed value of $0.3 \mathrm{~K}-\mathrm{m}^{2} / \mathrm{W}$ was appropriate.

6. Select all tentative contact sets in the "Results" window and click the "Create contact sets" button (top button to the left of the "Results" window, not pictured). This will create a contact set for each of the points of contact.

7. Define the thermal loads in the system. For this simulation, the thermal loads were an initial temperature, a convection boundary condition, and a heat power thermal load. To define a new thermal load, right-click the "Thermal Loads" item in the Feature Manager and select the appropriate thermal load type.

a. Define the initial temperature for the system by selecting the "Initial Temperature" type. Select the components which should have this initial temperature in the assembly viewing window, then define the correct temperature (Error! Reference source not found.). 
b. Define a convection boundary condition by making a new "Convection" thermal load and select all outside faces. In the case of this simulation, the top face of the upper platen and bottom face of the lower platen were insulated, so all exposed faces excepting those were selected.

c. Define the correct convection coefficient and bulk ambient temperature (Error!

Reference source not found.). A method for calculating the convection coefficient for such a system is outlined in Section 3.2.2.

d. Define a "Heat Power" thermal load to model the heating elements. Note that this requires that the heating elements be modeled as their own solid bodies in the moldplaten assembly and that a point be modeled where the thermocouple is in the system. For this simulation, each platen was modeled as a separate "Heat Power" thermal load as each platen had an independent driving thermocouple. Select the "Selected Entities" box and select the outer faces of the heating elements. For this simulation, the heating elements output a total of $700 \mathrm{~W}$ per platen, so the "Total" radio button was selected and the heat power was input as $700 \mathrm{~W}$. To model the control loop driven by the thermocouple, click the "Thermostat" checkbox and select the appropriate thermocouple point. Input the appropriate "Cut off details" in terms of allowable temperature at the point of the thermocouple. The "Heat Power" menu and an example of a heat power load in the assembly viewing window are shown in Figure A.5.

8. Apply a mesh to the system and run the study. 


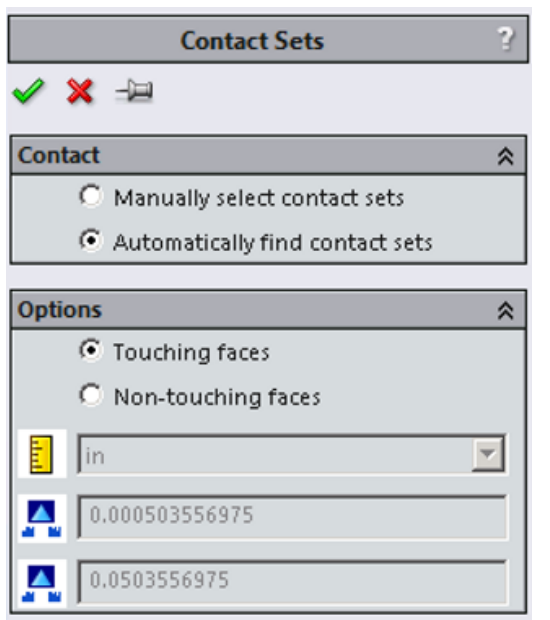

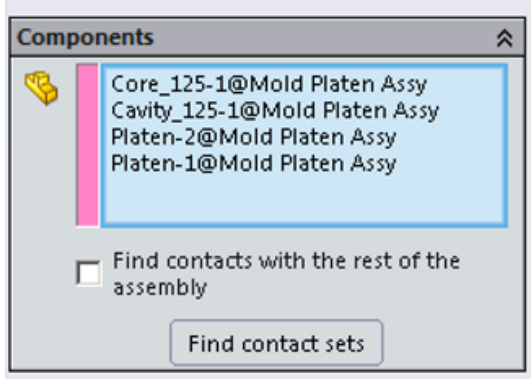

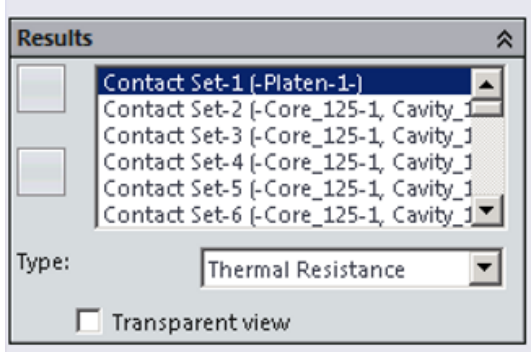

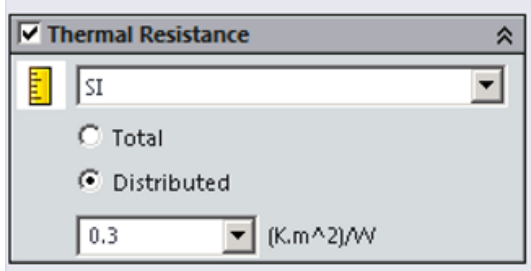

Tdvanced

Figure A.2. Contact Sets dialog.

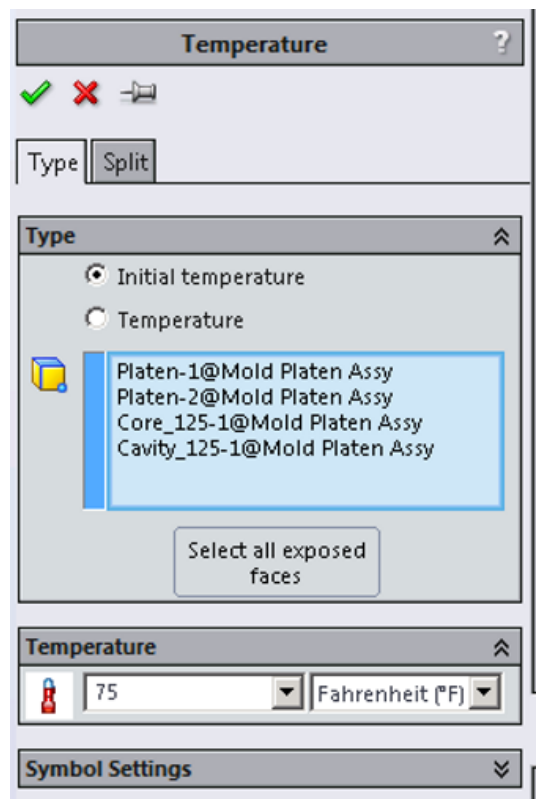

Figure A.3. Temperature thermal load dialog.
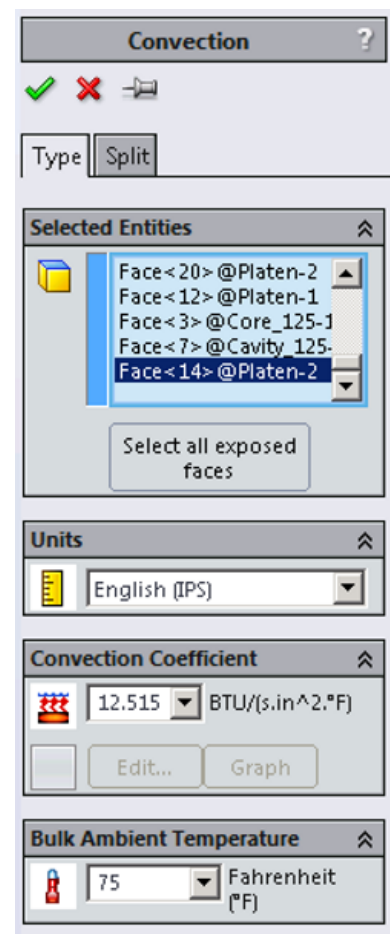

Symbol Settings $\forall$

Figure A.4. Convection thermal load dialog. 


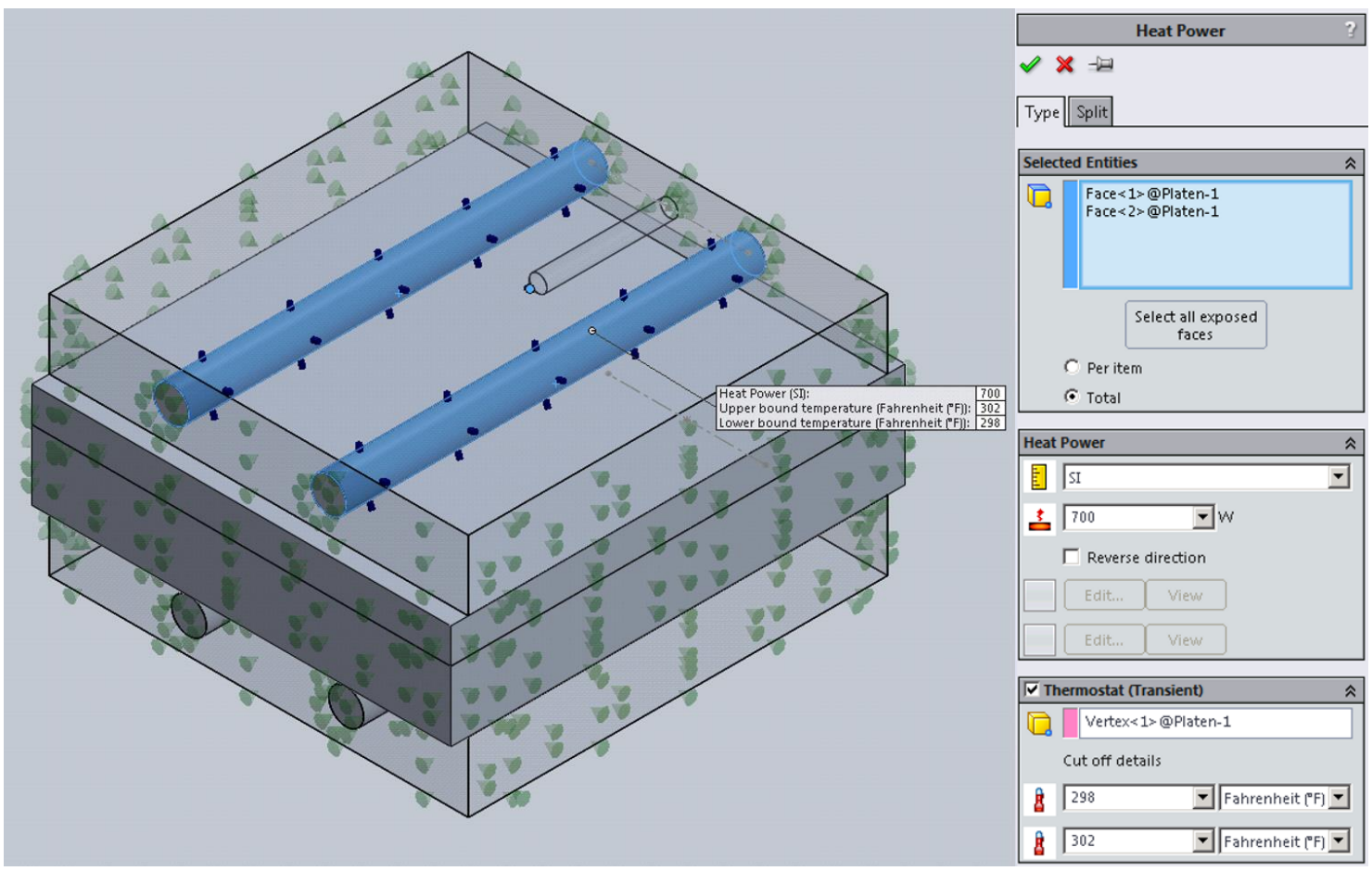

Figure A.5. Heat Power dialog box and heat power setup example. 


\section{Appendix B. Calculators and Scripts}

\section{B.1. Cured Ply Thickness Calculator}

The $C P T$ calculator used throughout this study was a Microsoft Excel document originally developed by Dr. Joseph Mello to calculate important parameters related to the design and manufacture of composites. The calculator is shown in Figure B.1.

\begin{tabular}{|c|c|}
\hline \multicolumn{2}{|c|}{ Cured Ply Thickness } \\
\hline Material Type & UNI \\
\hline Material Designation & TC250-M46J $-200-38 \pm 3-24$ \\
\hline Vf (fiber vol. fraction) & 0.470 \\
\hline FAW (g/m2) & 200 \\
\hline Fiber Density $(\mathrm{g} / \mathrm{m} 3)$ & 1840000 \\
\hline Resin Density (g/m3) & 1210000 \\
\hline Rho Composite (g/m3) & 1506100 \\
\hline Wf (fiber wt. fraction) & 0.574 \\
\hline Wm (resin wt. fraction) & 0.426 \\
\hline $\mathrm{CPT}(\mathrm{m})$ & 0.00023 \\
\hline$t(\mathrm{~mm})$ & 0.23127 \\
\hline$t$ (in) & 0.00911 \\
\hline \multicolumn{2}{|c|}{$\begin{array}{l}\left.\text { Cured Ply Thickness = FAW/(fiber density }{ }^{*} \mathrm{Vf}\right) \\
\text { per MIL-HDBK-17-1F pg 2-73 and some algebra }\end{array}$} \\
\hline Mold Thickness (in) & 0.1000 \\
\hline Mold Thickness (mm) & 2.5400 \\
\hline \# Layers for Mold & 10.9830 \\
\hline Input & Calculated Value \\
\hline
\end{tabular}

Figure B.1. CPT calculator interface.

The calculator took as input the fiber volume $\left(V_{f}\right)$ and fiber areal weight $(F A W)$ of the composite as well as the fiber density $\left(\rho_{f}\right)$ and resin density $\left(\rho_{r}\right)$. It then calculated the composite density $\left(\rho_{c}\right)$, fiber and resin weight fractions ( $W_{f}$ and $\left.W_{r}\right)$, and $C P T$ using

$$
\rho_{c}=V_{f} \rho_{f}+\left(1-V_{f}\right) \rho_{r}
$$




$$
\begin{gathered}
W_{f}=\frac{V_{f} \rho_{f}}{\rho_{c}} \text { and } W_{r}=\frac{V_{r} \rho_{r}}{\rho_{c}} \\
C P T=\frac{F A W}{V_{f} \rho_{f}}
\end{gathered}
$$

The required inputs for the $C P T$ calculator are typically provided by the material vendor or manufacturer. In the case of the M46J/TC250 material, the fiber volume fraction was not available and was therefore calculated using

$$
V_{f}=\frac{1}{1+\frac{\rho_{f}}{\rho_{r}}\left(\frac{1}{W_{f}}-1\right)}
$$




\section{B.2. Sandwich Beam CLT Scripts}

The CLT script sandwich.m was designed to calculate the stresses and strains induced by a line moment on the sandwich specimens discussed in Section 3.4. The script took as inputs the number of unidirectional plies in each face sheet and the magnitude of the line moment and output the Tsai-Wu factor at each of five locations produced by those inputs. The script assumes a sandwich which is 0.1 in thick.

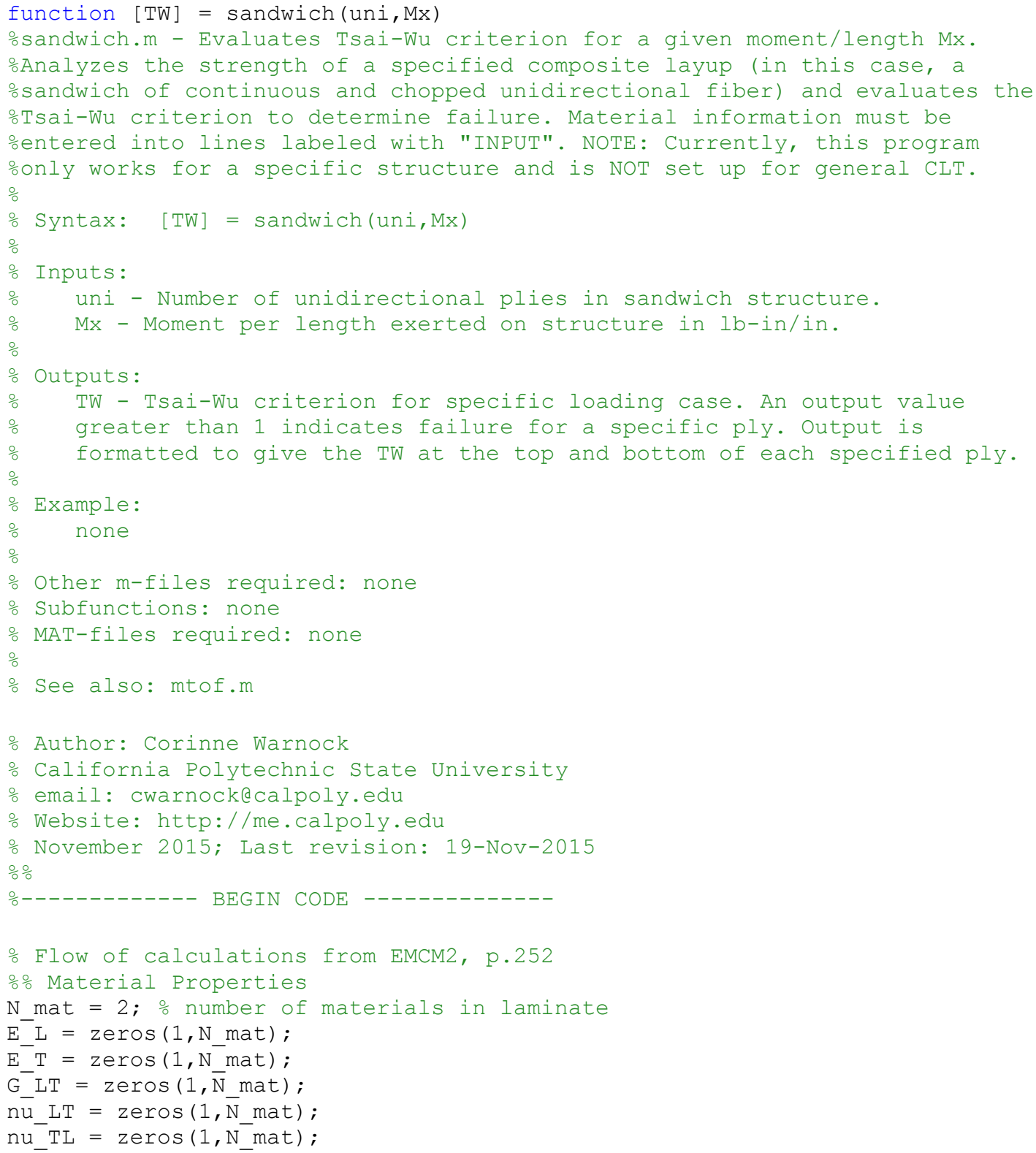




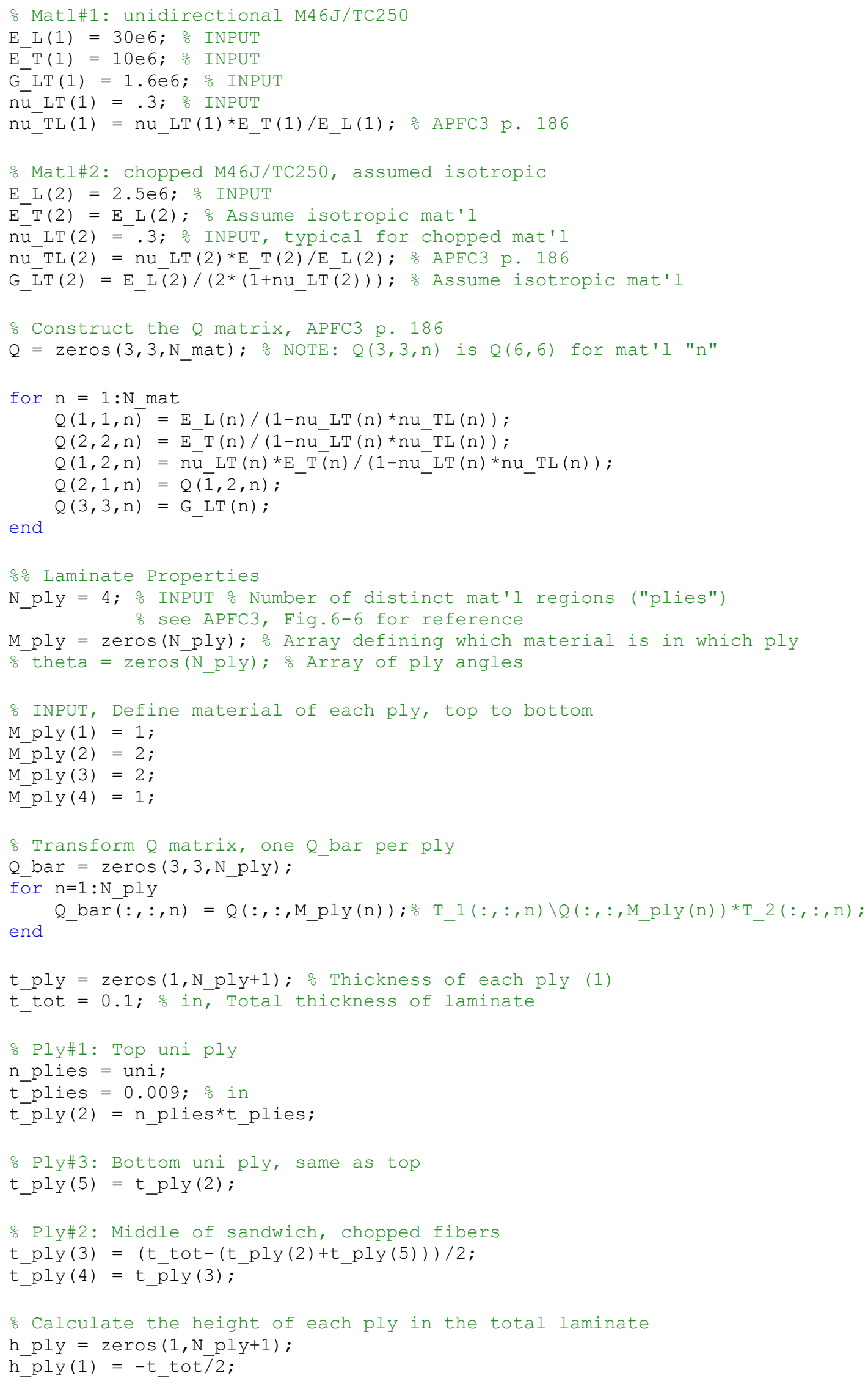




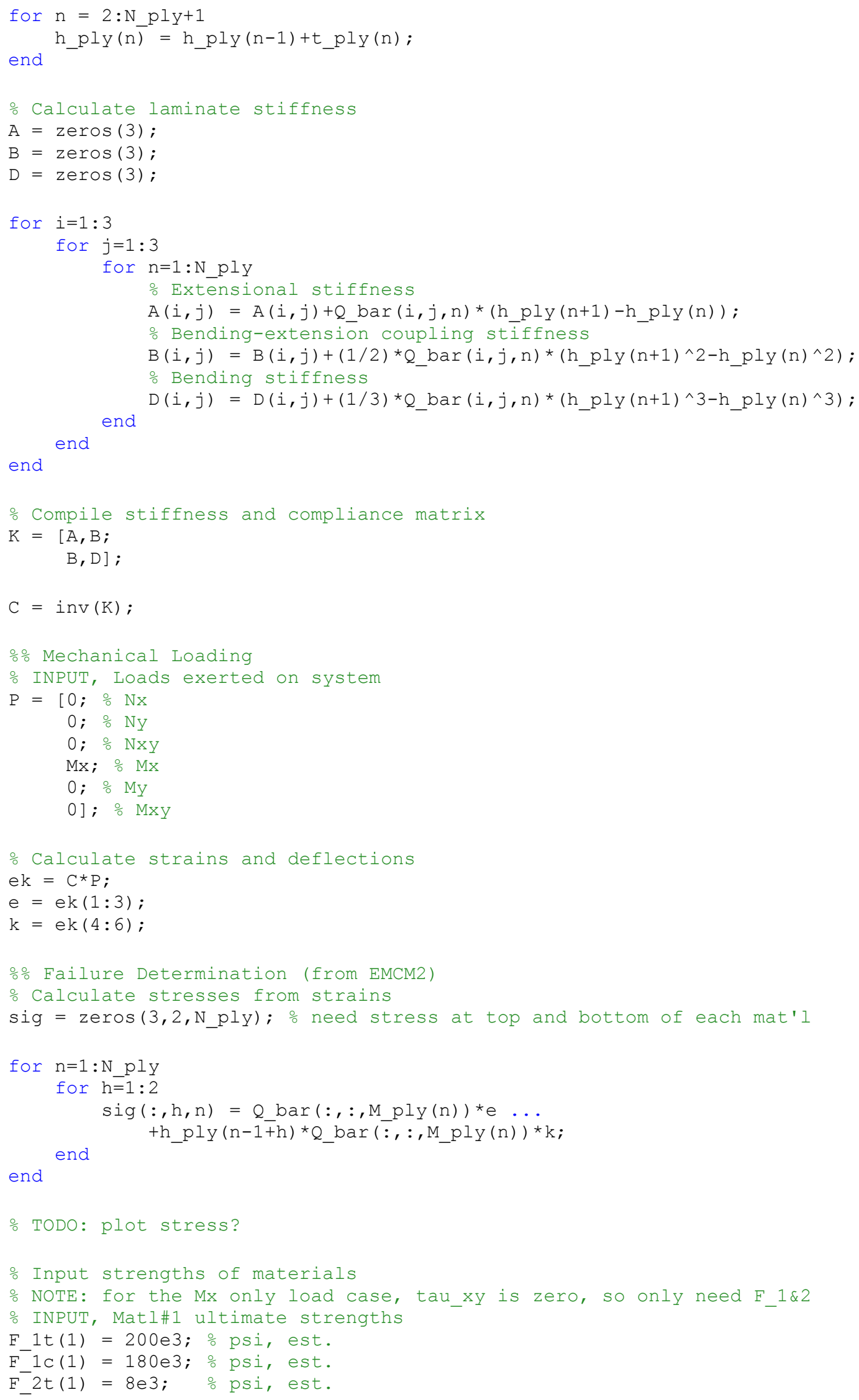




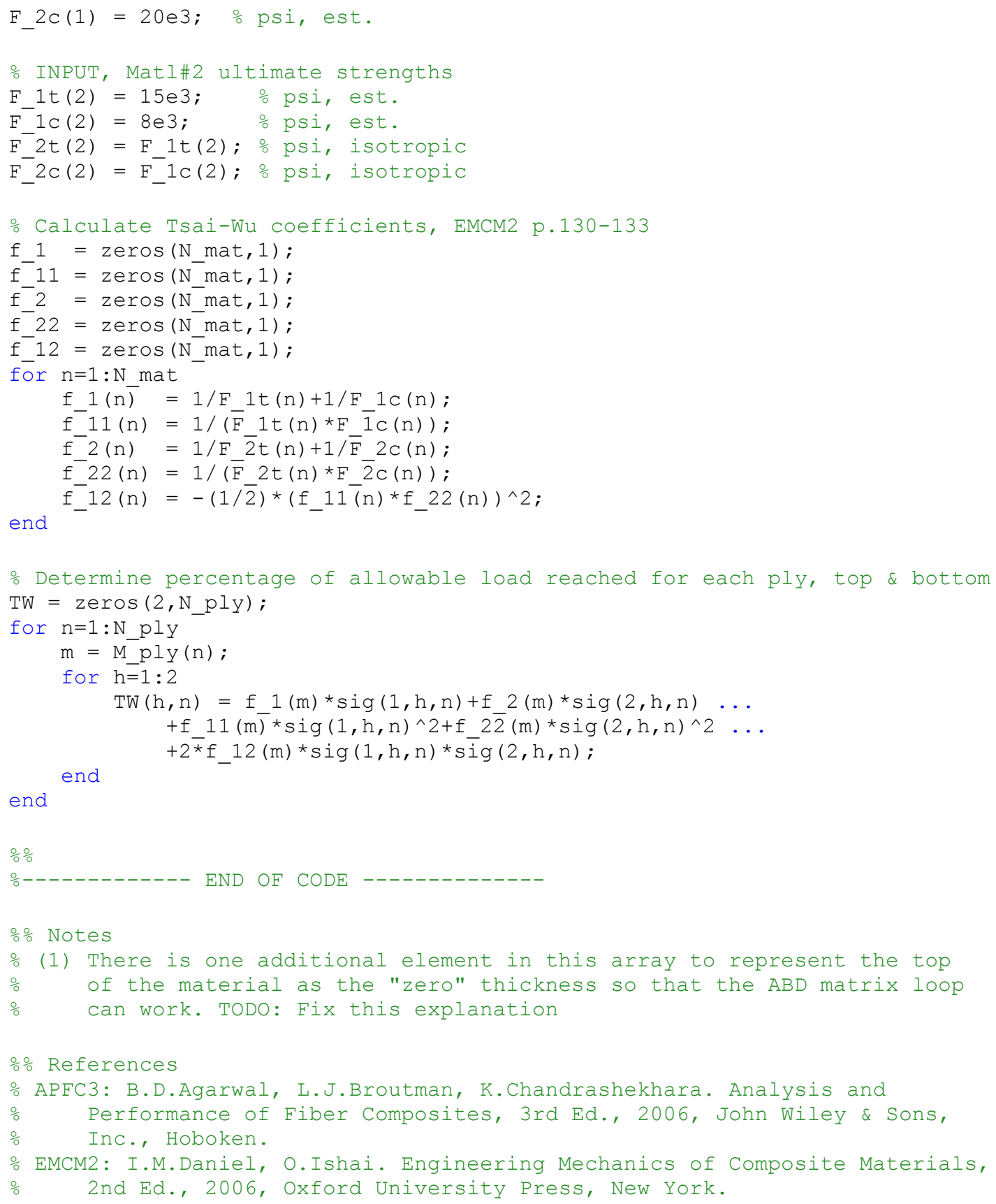


The wrapper script mtof.m was designed to find the maximum moment which sandwiches with

\section{1, 2, and 3-ply face sheets could withstand before failure. It then converted that moment into a}

maximum load in 4-point bend and printed the maximum load and Tsai-Wu factor matrix for

each of the three cases.

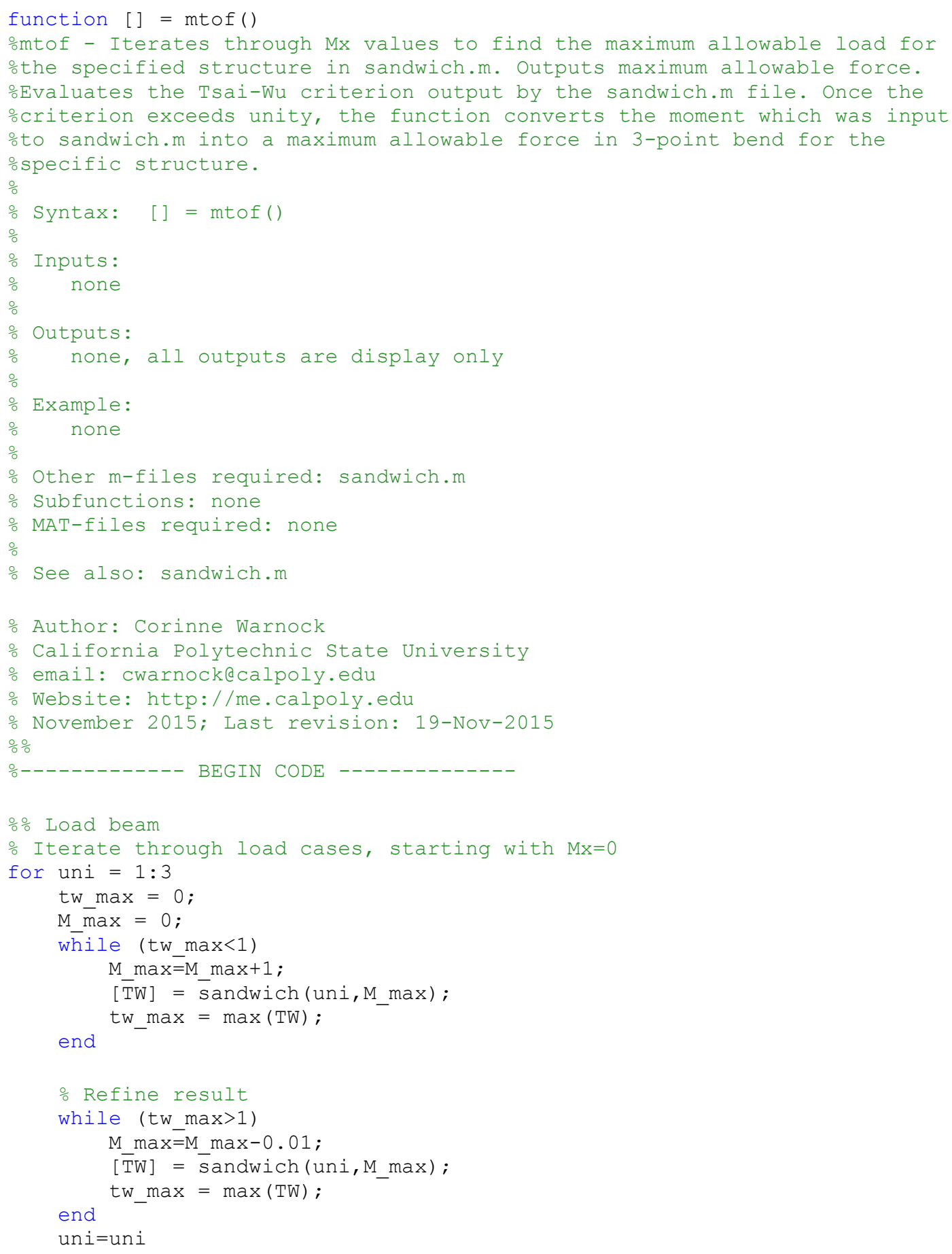


$T W=T W \%$ Display $T W$, for reference

\% Convert $\mathrm{Mx}$ into $\mathrm{F}$ max in 4-point bend

$\div \mathrm{F}=4 * \mathrm{M}^{*} \mathrm{~W} / \mathrm{L}_{\text {_lload; }}$;

$\mathrm{F} \max =4{ }^{*} \mathrm{M} \max { }^{*} .5 / .8$

end

응응

ㄴ---------- END OF CODE ------------

$\%$ Notes

\% none

$\because$ References

\% none 


\section{B.3. Lug Design Script}

The lug design script lug.m was designed to calculate the stresses induces at the lug of the pinloaded tensile specimens discussed in Chapter 4. The induced and ultimate stresses for three different failure modes were evaluated based on the load exerted on the lug and the geometry of the lug.

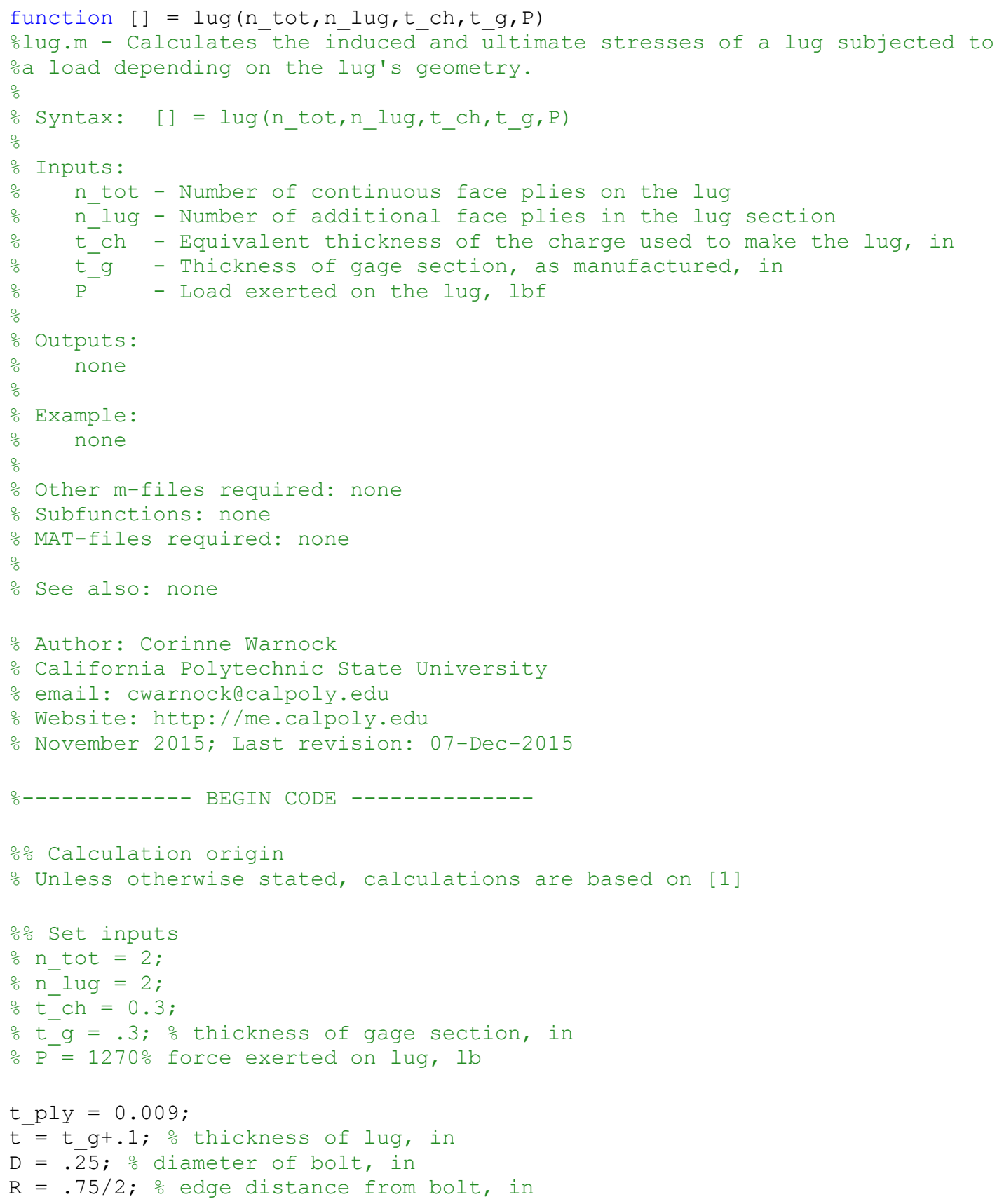




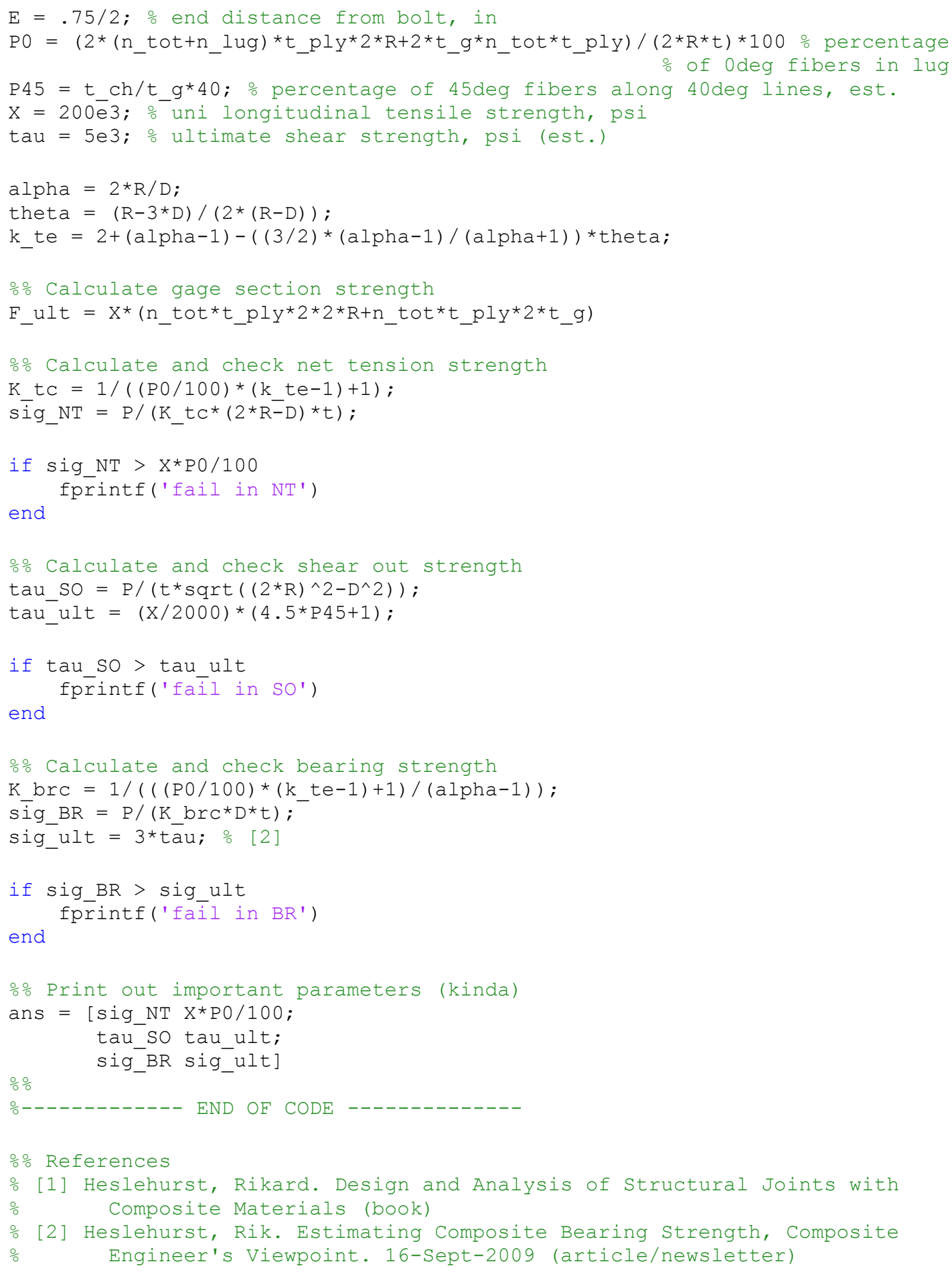




\section{Appendix C. Detailed Calculations}

\section{C.1. Minimum Tab Length}

OBjective: calculate the MINIMUM TAB LENGTH WHICH MUST BE USED TO LOAD A SPELIMEN WITH THE PROPERTIES BELOW. (FROM ASTM D 3039 )

MATERIAL PROPERTIES

$$
\text { P351Z03: } \begin{aligned}
F_{t u} & =320.8 \mathrm{ksl} \\
F_{s u} & =12.3 \mathrm{ksl}(*)
\end{aligned}
$$

COUPON PROPERTIES

$$
h=0.094^{\prime \prime}
$$

(*) NOTE: ILSS FOR P35/ZO3. FOR CO-CURED TABS, ILSS REPRESENTS THE STRENGTH OF THE "ADHESIVE" USED TO "BOND ON TABS"

MINIMUM TAB LENKTH

$$
L_{\text {min }}=\frac{F_{\text {tv }} h}{2 F_{\text {su }}}=\frac{(320.8 \mathrm{ksi})\left(0.094^{\prime \prime}\right)}{2(12.3 \mathrm{ksi})}=1.22^{11}
$$




\section{C.2. Flexural Properties}

objective: calculate tHe fleXURAL PROPERTIES of A SPEMMEN WITH THE PROPERTIES BELOW
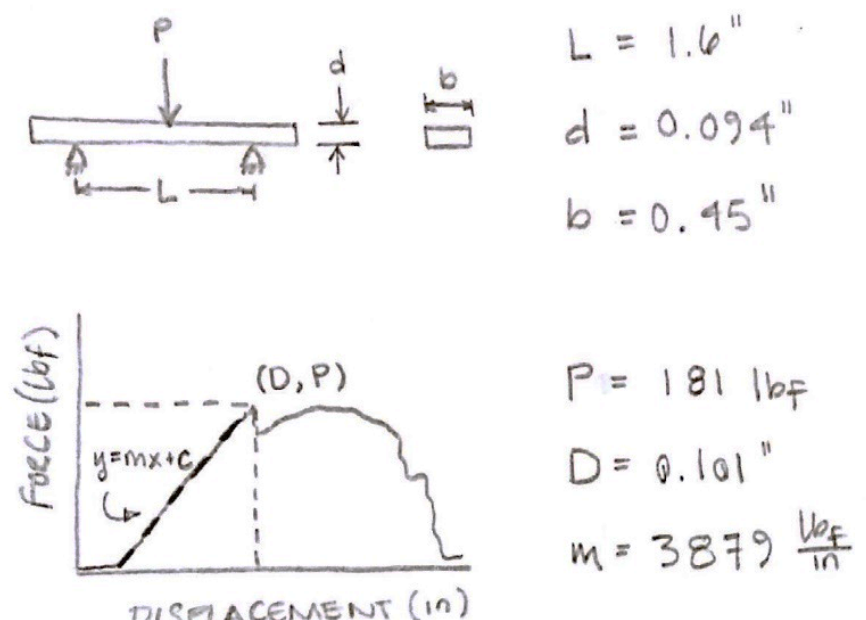

FLEXURAL STRENGTH

$$
\sigma_{f}=\frac{3 P L}{2 b d^{2}}=\frac{3\left(181 U_{f f}\right)\left(1.6^{\prime \prime}\right)}{2\left(0.45^{\prime \prime}\right)\left(0.094^{\prime \prime}\right)^{2}}=1.09 \times 10^{5} \mathrm{ps1}
$$

ULTIMATE FLEXURAL STRAIN

$$
\varepsilon_{F}=\frac{6 D d}{L^{2}}=\frac{6\left(0.101^{\prime \prime}\right)\left(0.094^{\prime \prime}\right)}{\left(1.6^{\prime \prime}\right)^{2}}=0.022 \frac{\mathrm{in}}{\mathrm{ln}}
$$

TANGENT MODUUS

$$
E_{8}=\frac{L^{3} m}{4 b d^{3}}=\frac{\left(1.6^{11}\right)^{3}\left(3879 \frac{\mathrm{lkf}}{10}\right)}{4\left(0.45^{11}\right)\left(0.094^{11}\right)^{3}}=1.06 \times 10^{7} \mathrm{psi}
$$




\section{C.3. Short-Beam Strength}

OBJECTIVE: CALCULATE THE SHORT-BEAM STRENATH OF A SPECIMEN WITH THE PROPERTIES BELOW.
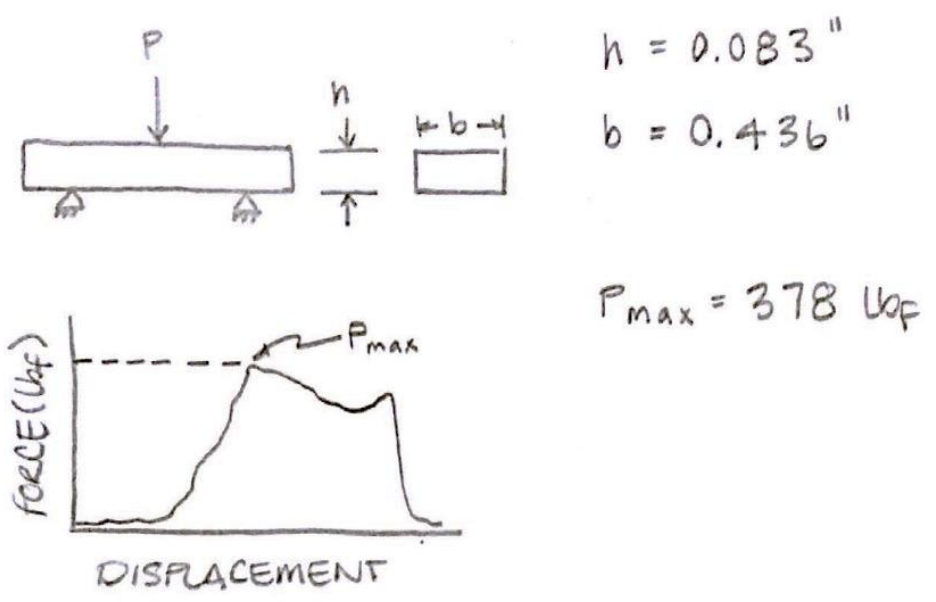

SHORT-BEAM STRENGTH

$$
F_{\text {sbs }}=0.75\left(\frac{P_{\text {max }}}{b h}\right)=0.75\left(\frac{378 U_{p q}}{\left(0.436^{\prime \prime}\right)\left(0.083^{\prime \prime}\right)}\right)=7830 \text { psi }
$$




\section{C.4. Heat Transfer Coefficient for Natural Convection}

OBJECTIVE: CALCULATE THE HEAT TRANSFER COEFFICIENT

FORNATURAL CONVECTION BETWEEN THE MOLD SURFACE AND THE SURROUNDING, STATIONARY AIR.

MATERIAL PROPERTIES

$$
\text { AIR: } \begin{aligned}
\rho_{0} & =1.1855 \frac{\mathrm{kg}}{\mathrm{m}^{3}} \\
c_{p} & =1006.2 \frac{\mathrm{J}}{\mathrm{gg}} \\
k & =0.025887 \frac{\mathrm{w}}{\mathrm{mk}} \\
\nu & =1.5469 \times 10^{-5} \frac{\mathrm{kg}}{\mathrm{ms}} \\
\beta & =3.3666 \times 10^{-3} \frac{1}{\mathrm{k}}
\end{aligned}
$$

SYSTEM PARAMETERS

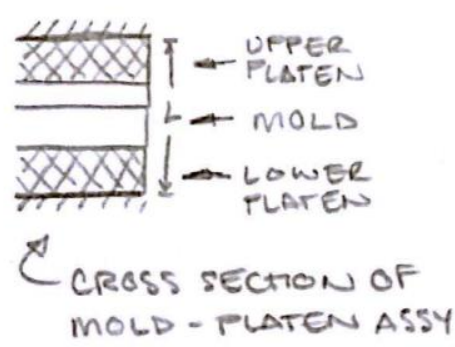

$$
\begin{aligned}
& T_{S}=285^{\circ} \mathrm{F}=413.7 \mathrm{~K} \\
& T_{\infty}=75^{\circ} \mathrm{F}=297 \mathrm{~K} \\
& L=3.25 \mathrm{in}=0.08255 \mathrm{~m}
\end{aligned}
$$$$
\text { MOLD - PLATEN ASSY }
$$

BOUSSINESQ APPROXIMATION OF AIR DENSITY

VALIDITY CHECK: $\beta\left(T_{S}-T_{\infty}\right)=0.39<1$, OKAY TO APPROXIMATE.

$\rho=\rho_{0}(1-\beta \Delta T)=0.7197 \frac{\mathrm{kg}}{\mathrm{m}^{3}}$

GRASHOF NUMBER

$$
G r_{x}=\frac{\rho^{2} g \beta}{\mu^{2}}\left(T_{s}-T_{\omega 0}\right) L^{3}=9.06 \times 10^{6}<10^{9} \text {, LAMINAR }
$$

PRANDTL NUMBER

$$
P_{r}=\frac{P C_{p} \nu}{k}=0.43
$$

RAYLEIGH NUMBER

$$
R_{a_{x}}=\operatorname{Gr} \operatorname{Pr}=3.92 \times 10^{6}
$$


NUSSELT NUMBER (FOR R $a_{x}<10^{9}$ )

$N U_{L}=0.68+\frac{0.61 R a_{x}^{\frac{1}{4}}}{\left(1+\left(0.492 / P_{r}\right)^{9 / 16}\right)^{4 / 9}}=0.84$

CONVECTIVE HEAT TRANSFER CUEFFICIENT

$$
n=\frac{N U_{L} K}{L}=0.26 \frac{\mathrm{W}}{\mathrm{m}^{2} \mathrm{~K}}
$$




\section{C.5. Thermal Contact Resistance}

oBjective: calculate the thermal contact resistance EETWEEN THE MOLD-MOLD AND MOLD-PLATEN IMTERFACES MATERIAL PROPERTIES (FROM asm. Matweb. cOM)

$$
\begin{aligned}
& 6061-T 6: E_{1}=10000 \mathrm{ks} 1 \\
& \nu_{1}=0.33 \\
& k_{1}=1160 \text { BTU-in/hr. Ft }{ }^{2} \cdot \text { of } \\
& \text { 7050. T7651: } E_{2}=10400 \mathrm{ksi} \\
& \nu_{2}=0.33 \\
& k_{2}=1060 \mathrm{BrU}-\mathrm{in} / \mathrm{hr}-\mathrm{ft}^{2}-{ }^{\circ} \mathrm{F} \\
& \text { ROUGHWESS (ESTMATED FROM FIGURE 3.10) } \\
& R_{a}=100 \mu \text { in } \\
& R_{q}=1.11 R_{a}=1.11(100 \mathrm{~min})=111 \text { uin }=1.11 \times 10^{-4} \mathrm{ln}
\end{aligned}
$$

EFFECTIVE THERMAL COWDUCTIVITY

$$
k_{s}=\frac{2 k_{1} k_{2}}{k_{1}+k_{2}}=1108 \mathrm{BTU}-\mathrm{in} / \mathrm{hr}-\mathrm{ft} \mathrm{t}^{2} \mathrm{OF}
$$

e' parameter

$$
E^{\prime}=\frac{E_{1} E_{2}}{E_{2}\left(1-\nu_{1}^{2}\right)+E_{1}\left(1-\nu_{2}^{2}\right)}=5721 \mathrm{ks}
$$

EXERTED PRESSURE PM 120 PSI

thermal contact conductance

$$
\begin{aligned}
& h_{c}=1.9 \frac{\mathrm{kg}}{R_{x}}\left(\frac{P}{E^{\prime}}\right)^{0.94}=0.967 \frac{8 T U}{8.1 \mathrm{n}^{2}}
\end{aligned}
$$

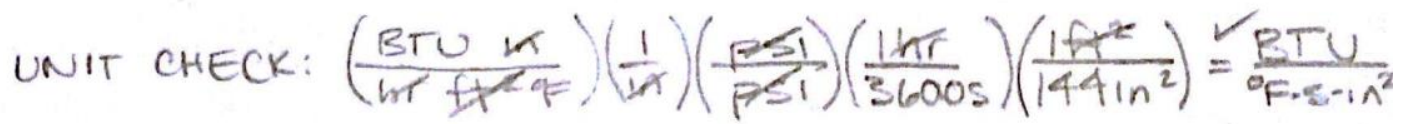

THERMAL CONTACT RESISTANCE

$$
\frac{1}{h_{C}}=1.033 \frac{{ }^{\circ}-12}{8 T U / S}
$$




\section{Appendix D. Data Reduction for M46J/TC250 Cure Cycle Analysis}

A response surface analysis was performed to ascertain the effect of each factor on the resulting specimen mechanical properties from each cure cycle. Each of the three responses were considered separately. As a factor was deemed insignificant to that response, it was removed from analysis to more accurately model the response with significant factors. The raw data for the analysis is given in Table D.1. A level of "1" for time indicates full time while a level of "-1" indicates half time. For all analyses, the confidence level was set to $95 \%(\alpha=0.05)$. The process for reducing data was outlined in Cal Poly's IME 427 class and in Design and Analysis of Experiments [33].

Table D.1. Factors, levels, and responses for M46J/TC250 cure cycle analysis.

\begin{tabular}{|c|c|c|c|c|c|c|}
\hline Temp & Plies & Time & Strength & Strain & Modulus & $\mathbf{F}_{\text {sbs }}$ \\
\hline 265 & 10 & 1 & 124844.9 & 0.007289 & 17353428 & 7704.186 \\
\hline 265 & 10 & 1 & 132995.4 & 0.010528 & 14699493 & 8020.67 \\
\hline 265 & 12 & 1 & 118990.5 & 0.006795 & 17592848 & 8573.992 \\
\hline 265 & 12 & 1 & 118301.7 & 0.006874 & 17542912 & 8447.633 \\
\hline 265 & 10 & -1 & 108173.6 & 0.007733 & 13916695 & 7474.645 \\
\hline 265 & 10 & -1 & 104399.2 & 0.008099 & 12560586 & 7606.817 \\
\hline 265 & 12 & -1 & 125893.3 & 0.007835 & 16637931 & 8568.378 \\
\hline 265 & 12 & -1 & 126564.9 & 0.008211 & 15914339 & 8736.743 \\
\hline 285 & 10 & 1 & 121081.7 & 0.006749 & 17262914 & 8002.034 \\
\hline 285 & 10 & 1 & 114318.6 & 0.007829 & 14722423 & 7941.081 \\
\hline 285 & 12 & 1 & 126125.4 & 0.00802 & 16399956 & 8803.386 \\
\hline 285 & 12 & 1 & 139041.3 & 0.008777 & 17348976 & 8762.231 \\
\hline 285 & 10 & -1 & 127548.9 & 0.007733 & 16807880 & 7510.862 \\
\hline 285 & 10 & -1 & 104399.2 & 0.008099 & 12560586 & 7762.378 \\
\hline 285 & 12 & -1 & 129046.8 & 0.008494 & 16303823 & 8465.191 \\
\hline 285 & 12 & -1 & 114488.5 & 0.007733 & 15220238 & 8488.989 \\
\hline 300 & 10 & 1 & 112330.2 & 0.008639 & 16365936 & 7814.271 \\
\hline 300 & 10 & 1 & 118712.8 & 0.008099 & 15550428 & 8122.996 \\
\hline 300 & 12 & 1 & 124201.2 & 0.008306 & 16114276 & 8548.562 \\
\hline 300 & 12 & 1 & 142456.6 & 0.010311 & 15789816 & 8825.486 \\
\hline 300 & 10 & -1 & 134717.9 & 0.010667 & 14565071 & 7901.836 \\
\hline 300 & 10 & -1 & 122892.5 & 0.007829 & 16327397 & 7728.685 \\
\hline 300 & 12 & -1 & 124843.3 & 0.008879 & 15113561 & 8088.384 \\
\hline 300 & 12 & -1 & 123555.4 & 0.00802 & 16877004 & 8440.244 \\
\hline
\end{tabular}




\section{D.1. Factor Effects on Flexural Strength}

The residual plots for strength show relatively constant variance, but do not show a normal distribution. This may be remedied by the removal of insignificant factors. The Minitab output shows that the square factors of Plies*Plies and Time*Time have been removed from analysis.

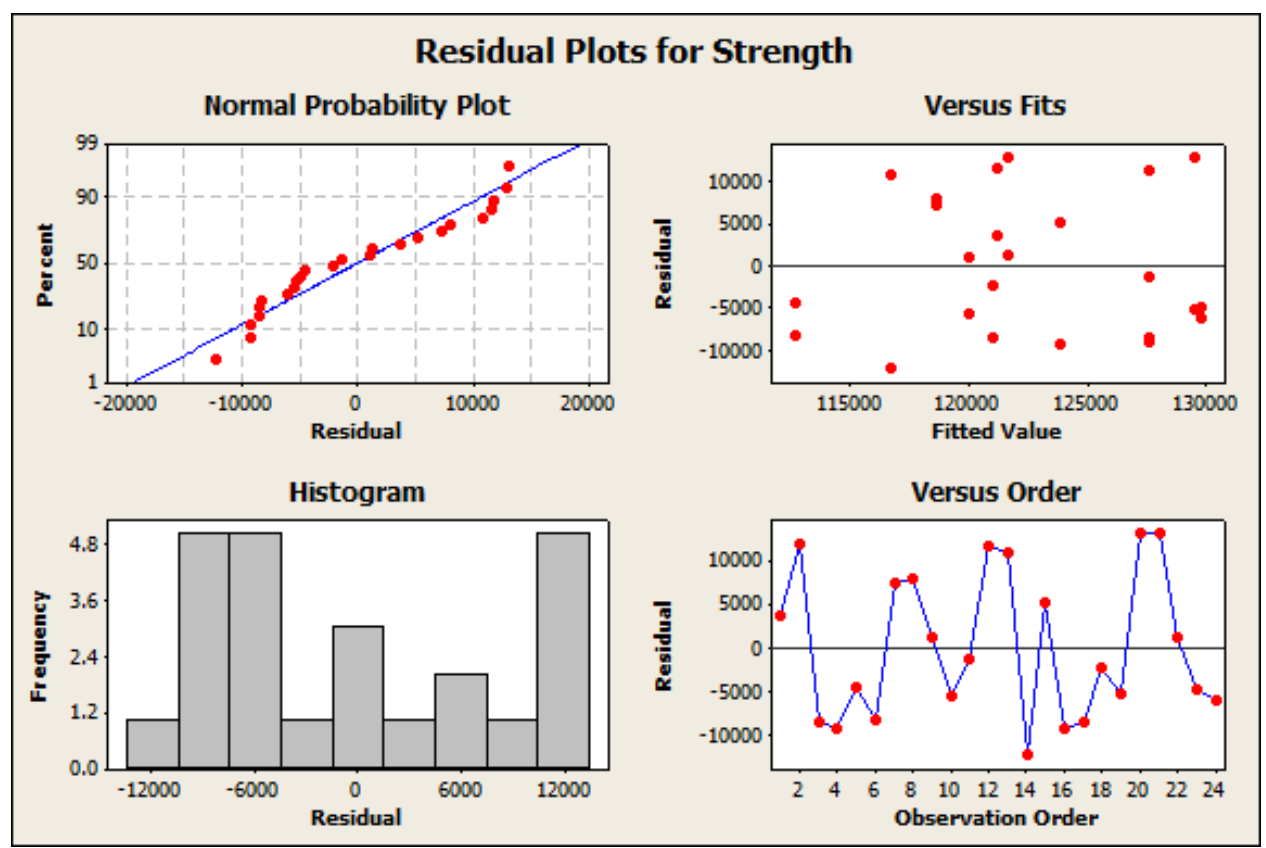

\section{Response Surface Regression: Strength versus Temp, Plies, Time}

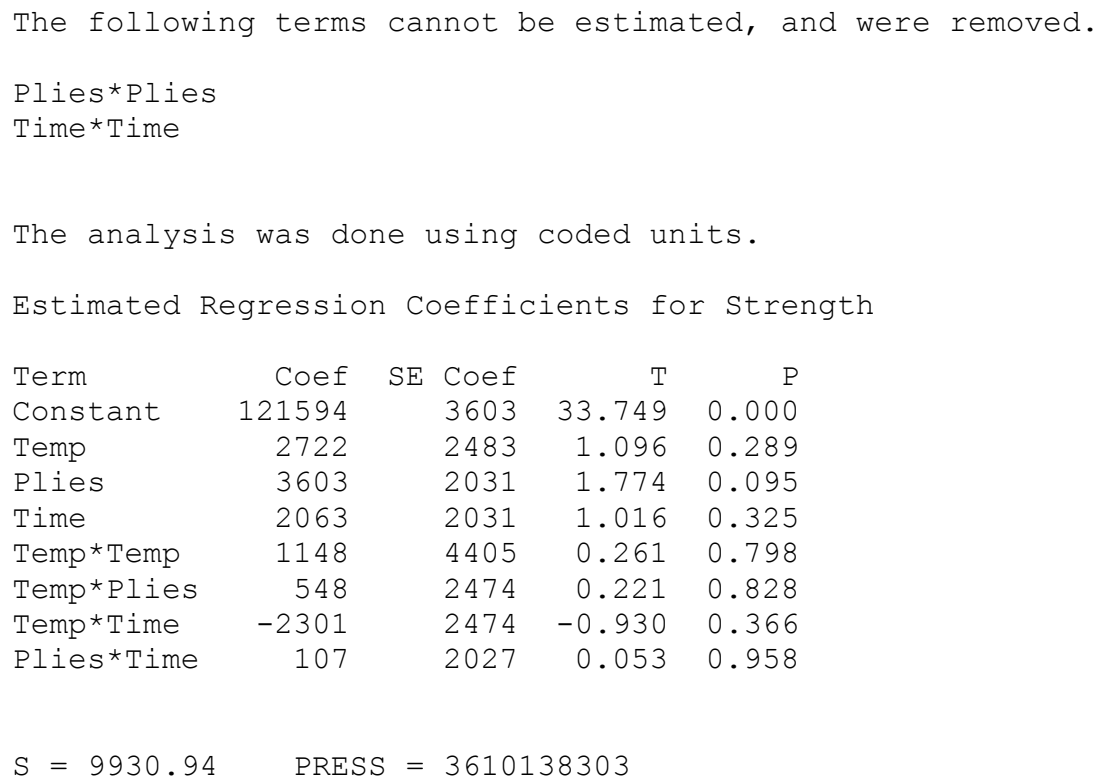




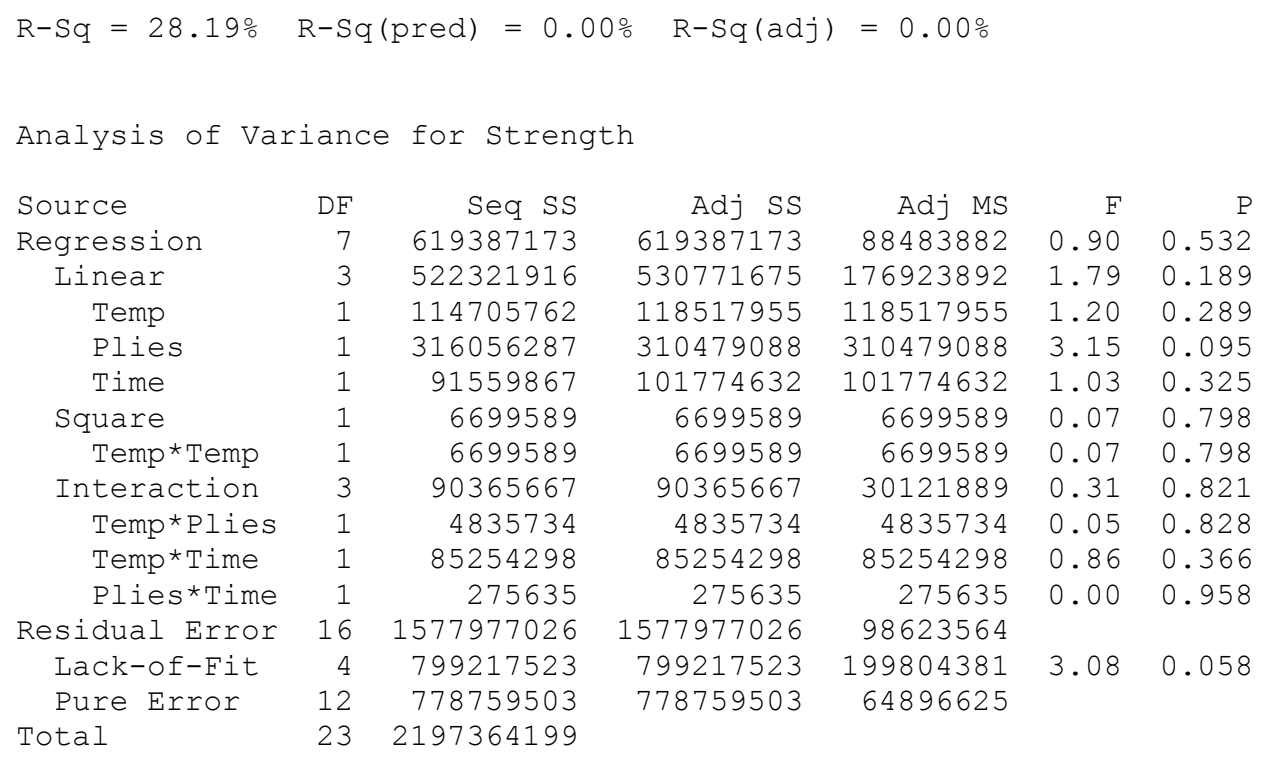

From the Minitab output, it appears that none of the factors is significant as none of the P-values are less than $\alpha=0.05$. This is reinforced by the fact that the adjusted $R^{2}$ value is zero.

Removal of the remaining square term and all interactions gives residual plots which still satisfy the constant variance requirement and which are more normal than the full-quadratic analysis.

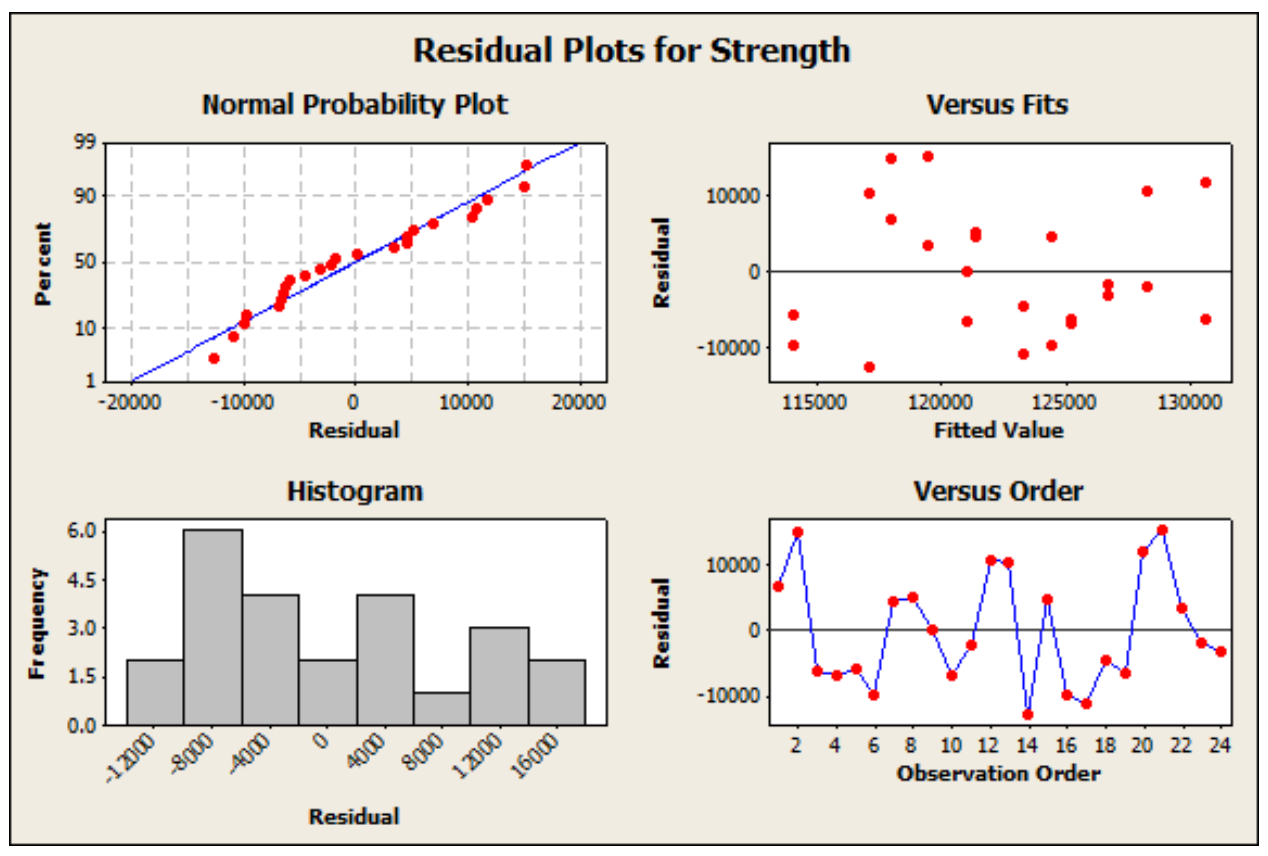




\section{Response Surface Regression: Strength versus Temp, Plies, Time}

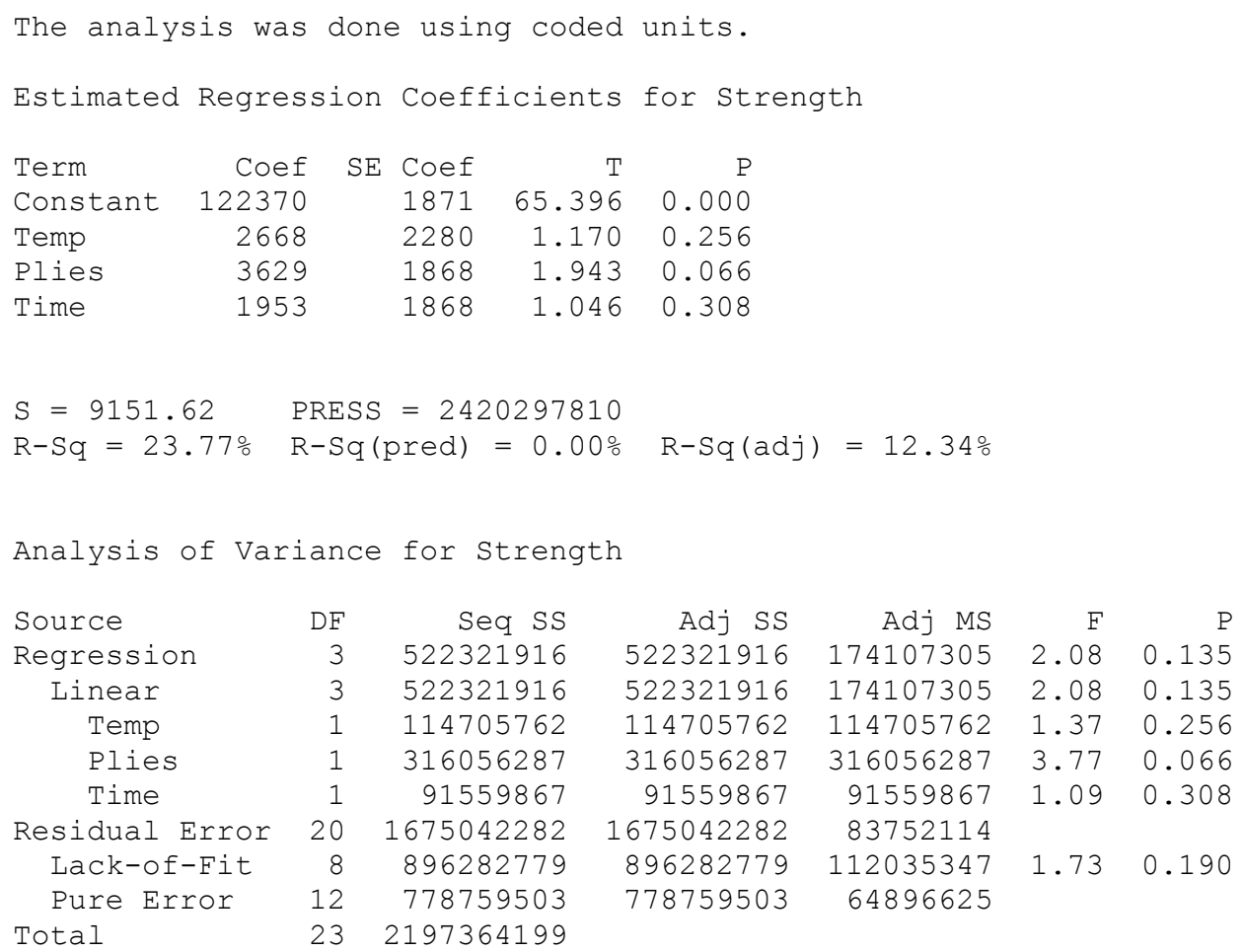

The main effects analysis reveals a slight increase in the adjusted $R^{2}$ value to $12.34 \%$, but all of the factors remain insignificant. The number of plies in the laminate appear to have the most significant effect on the resultant flexural strength, which makes sense since the flexural strength is largely a factor of the fiber properties in the composite. However, the factor is still not significant within the $95 \%$ confidence interval.

Since the main effects are the most significant factors, the main effects plots may be considered to glean information about the trends in the flexural strength as it was affected by each factor. 


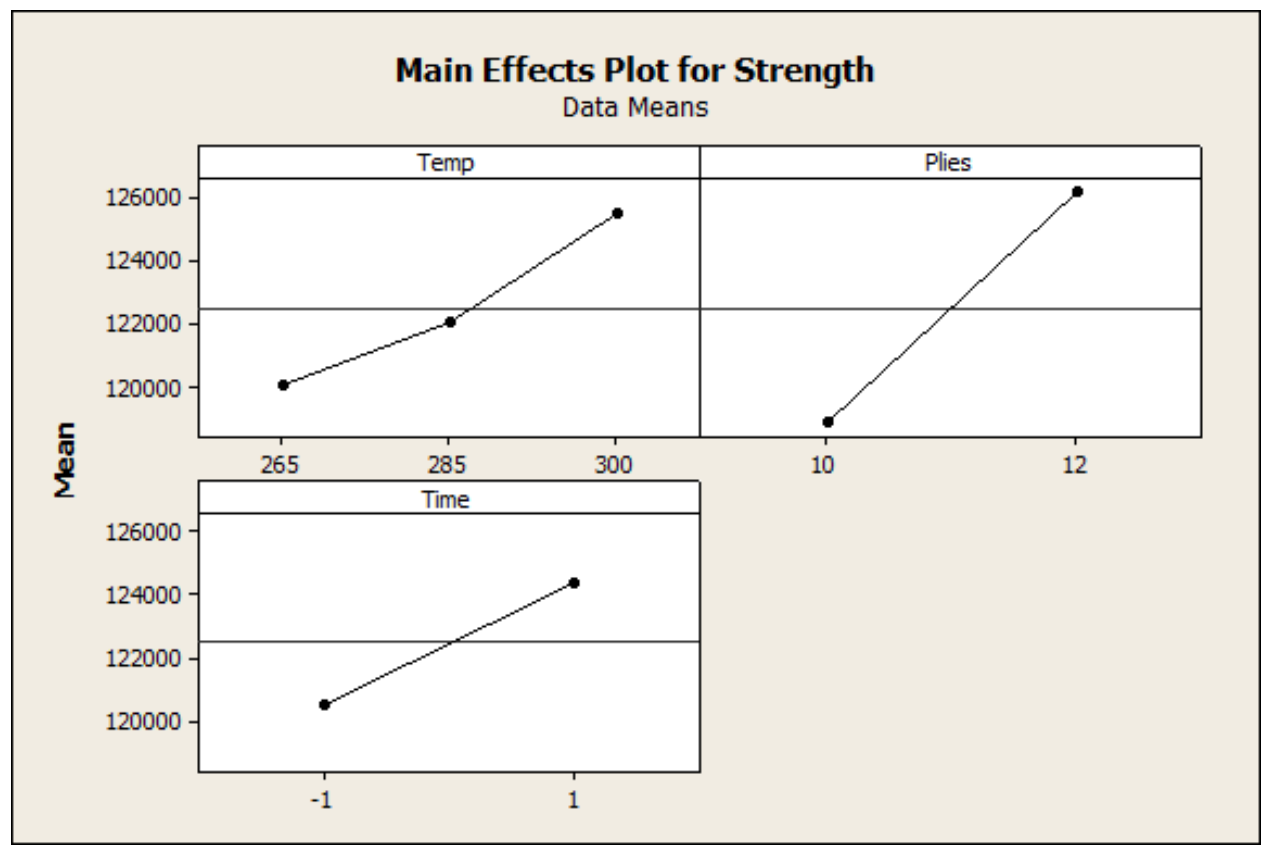

The main effects plot for flexural strength indicates that a high temperature cure with more plies and more time results in an overall stronger part in flexure. 


\section{D.2. Factor Effects on Tangent Modulus}

The residual plots for tangent modulus show a relatively normal distribution with a tightly grouped variance. Removal of insignificant factors may spread out the variance. Once again, the factors of Plies*Plies and Time*Time could not be analyzed.

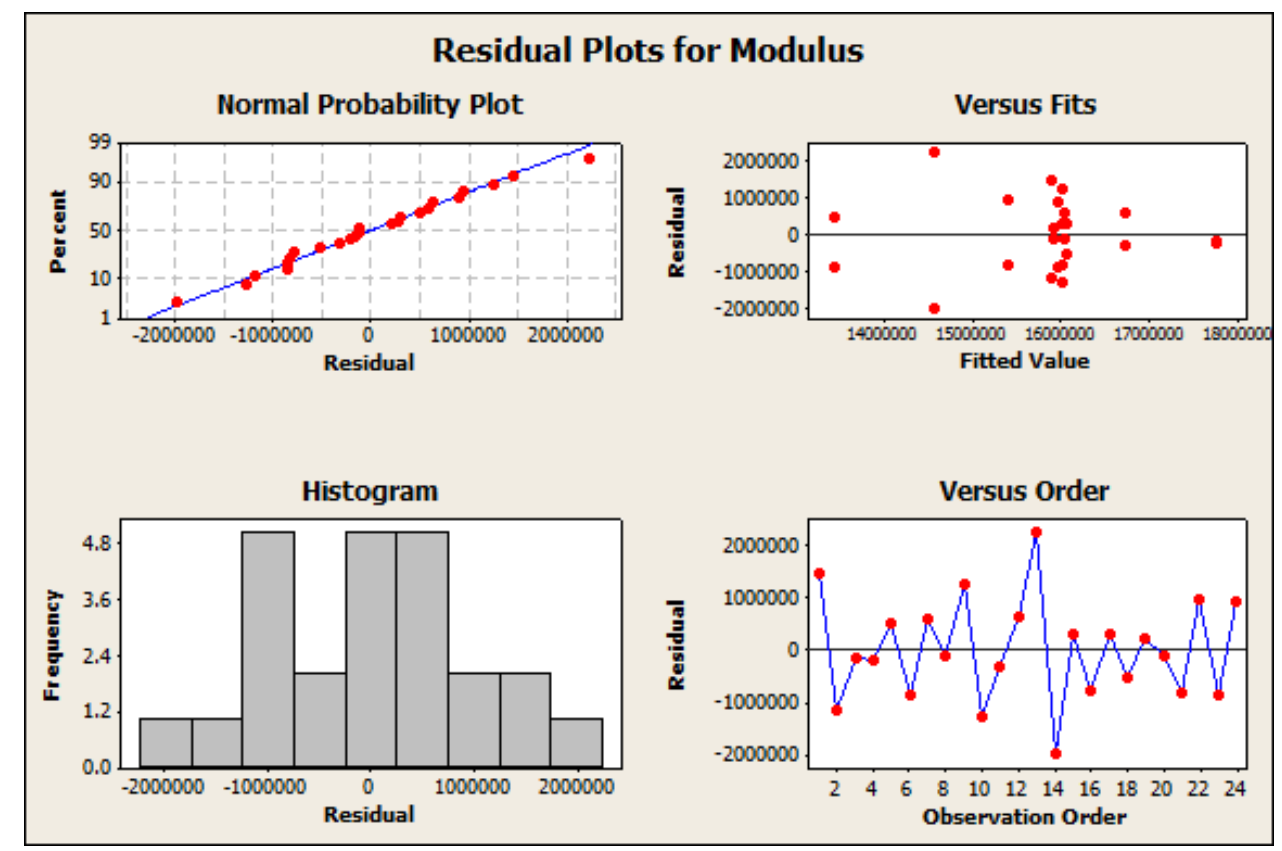

\section{Response Surface Regression: Modulus versus Temp, Plies, Time}

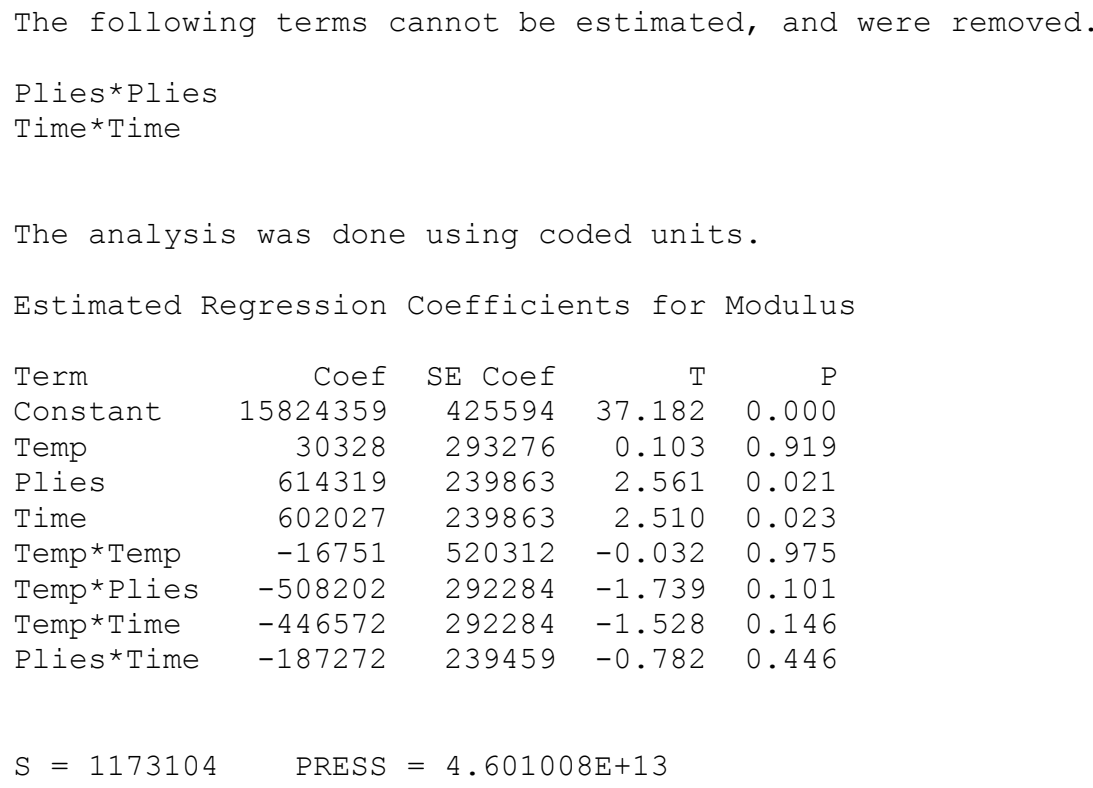




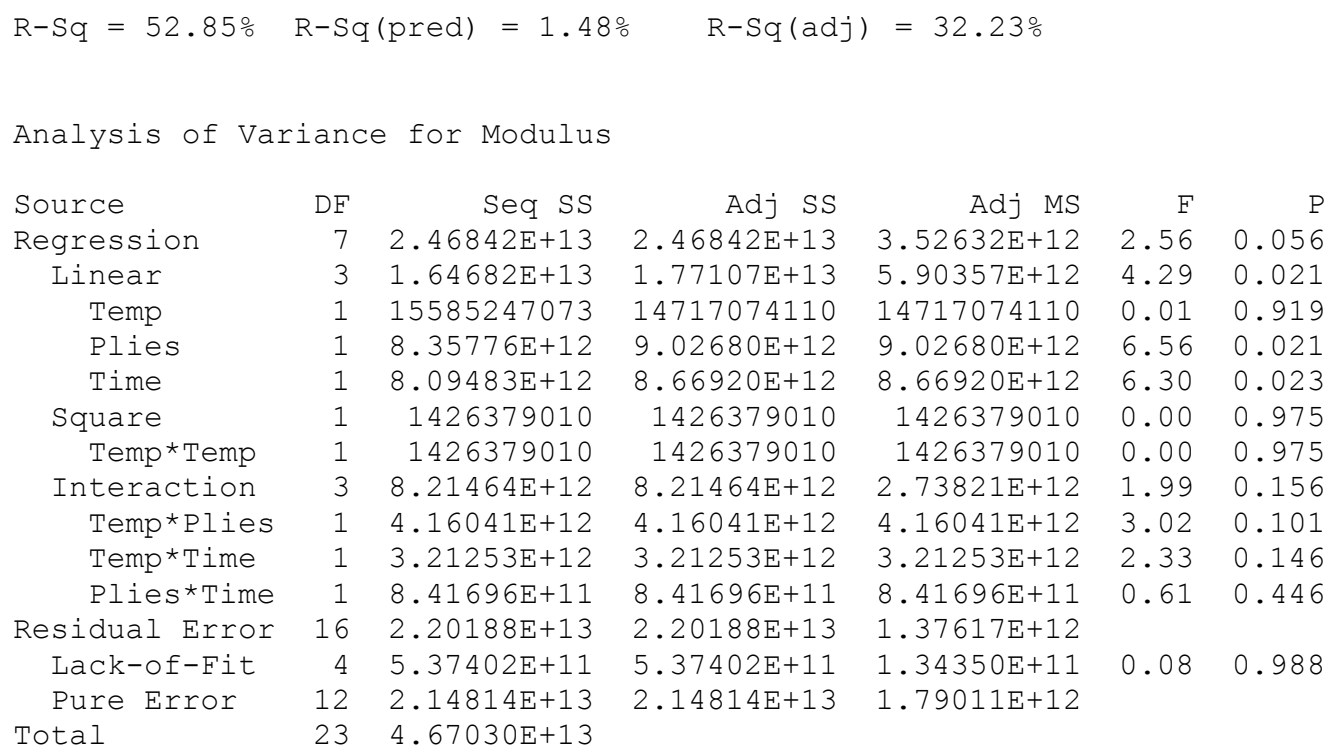

From the Minitab output, the linear terms appear to be significant while the remaining square term is the least significant. Removing the square and interaction terms gives a residual plot which is still normal and is closer to the constant variance requirement.

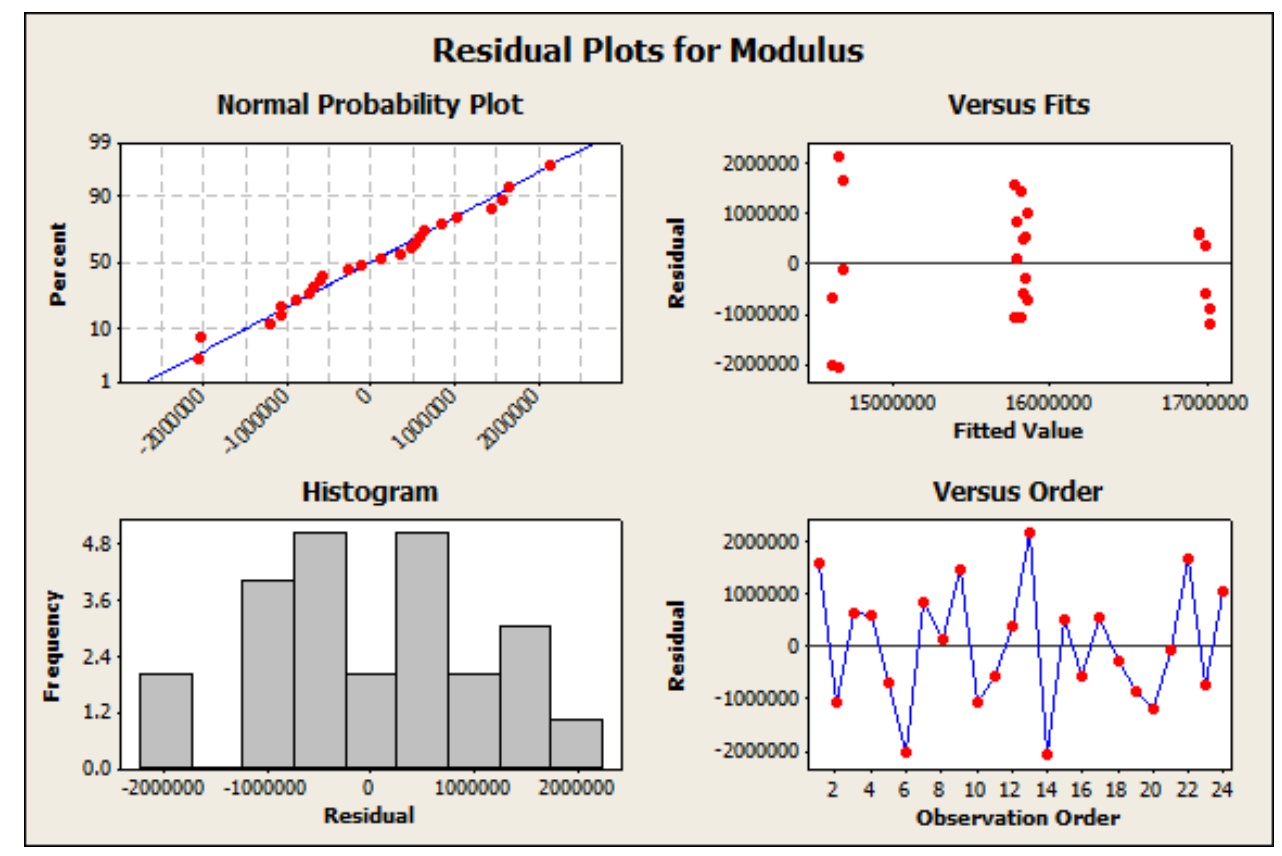

\section{Response Surface Regression: Modulus versus Temp, Plies, Time}

The analysis was done using coded units. 


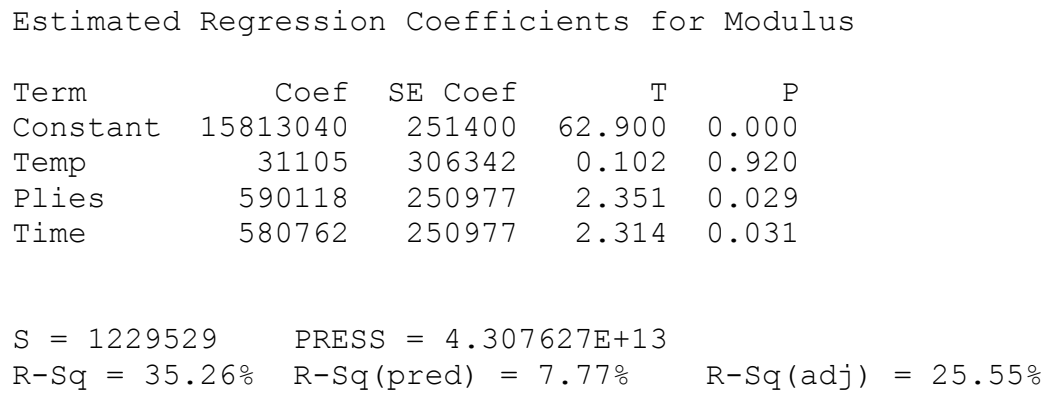

While the main effect of temperature remained insignificant, the main effects of number of plies and time at temperature were both significant. The main effects plots for the analysis again indicate that the 12-ply beams had a higher modulus than the 10-ply beams and that the full-time cure resulted in high-modulus specimens.

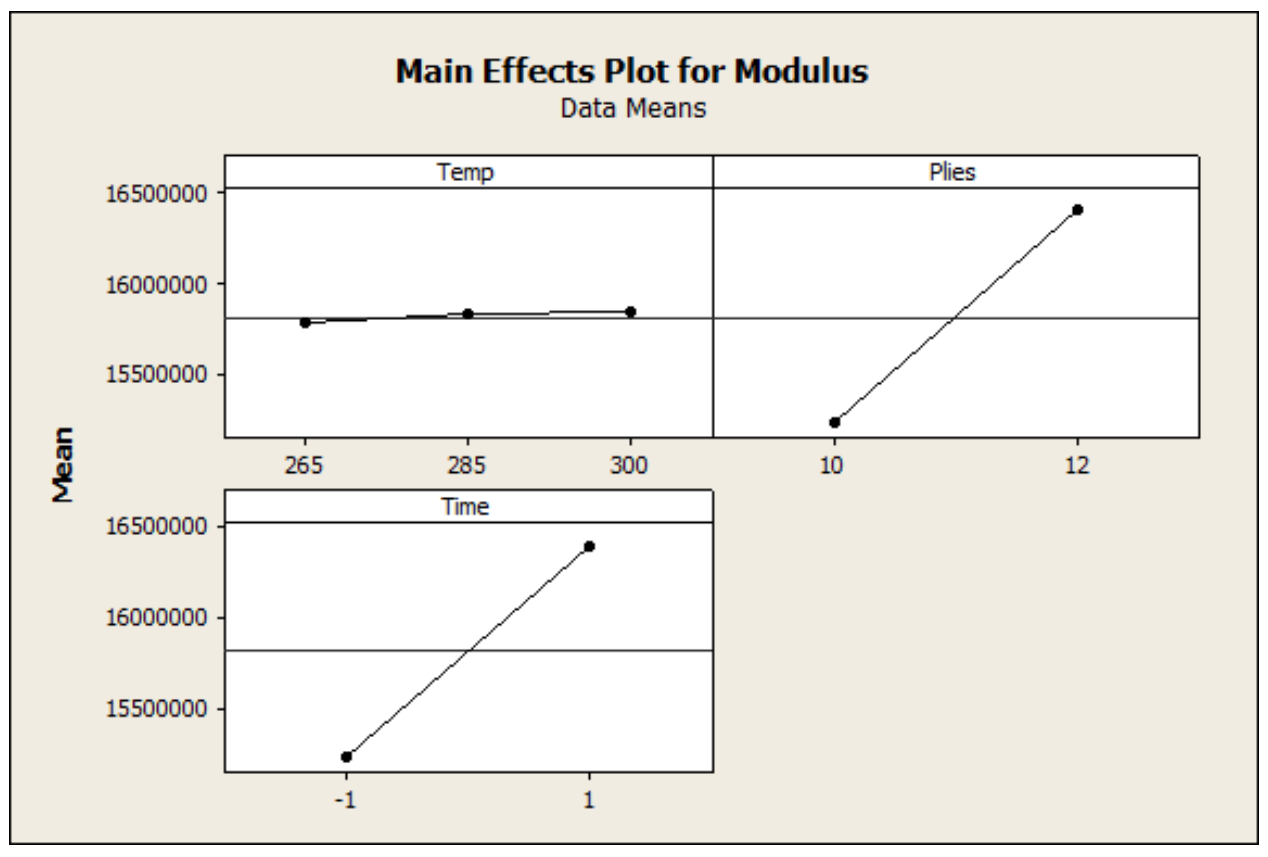




\section{D.3. Factor Effects on Short-Beam Strength}

The residual plots for short-beam shear strength show a normal response distribution with constant variance.

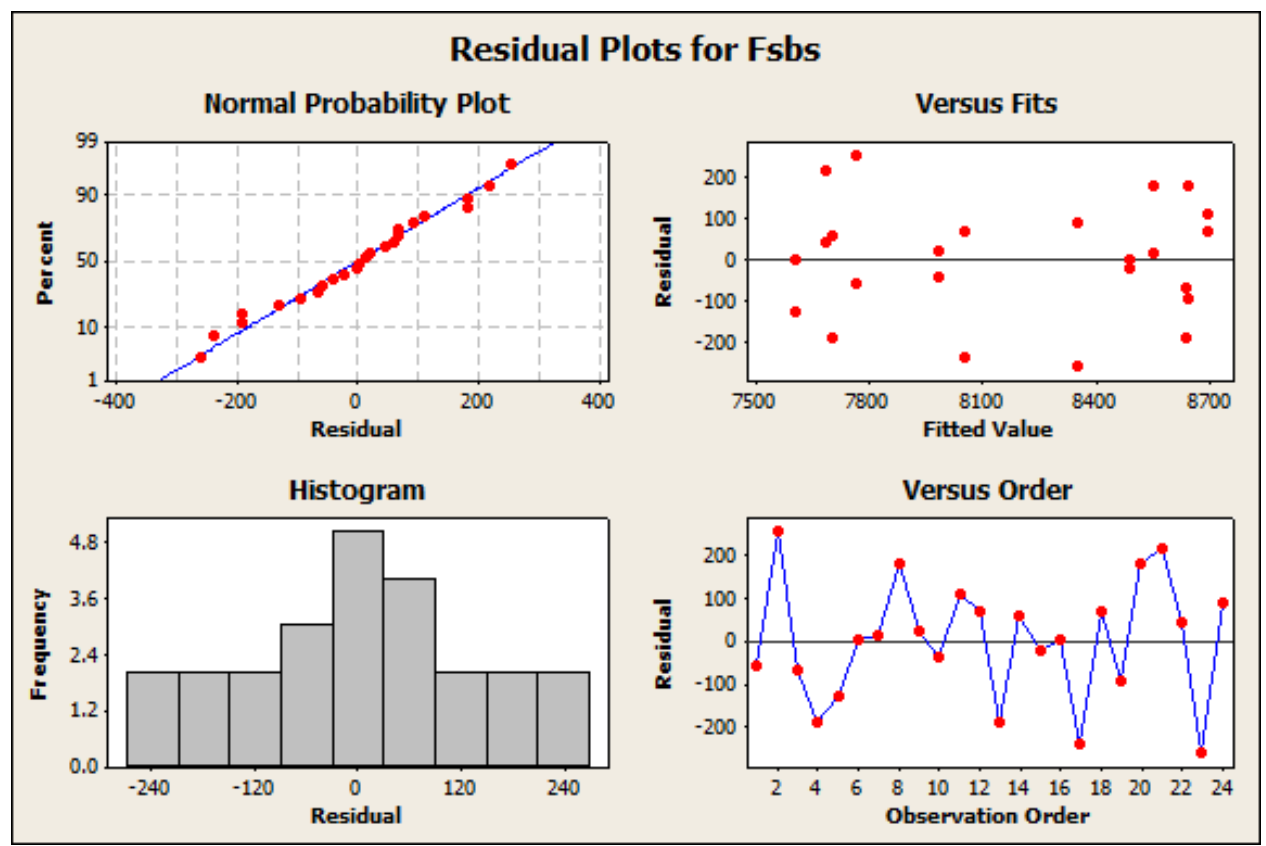

\section{Response Surface Regression: Fsbs versus Temp, Plies, Time}

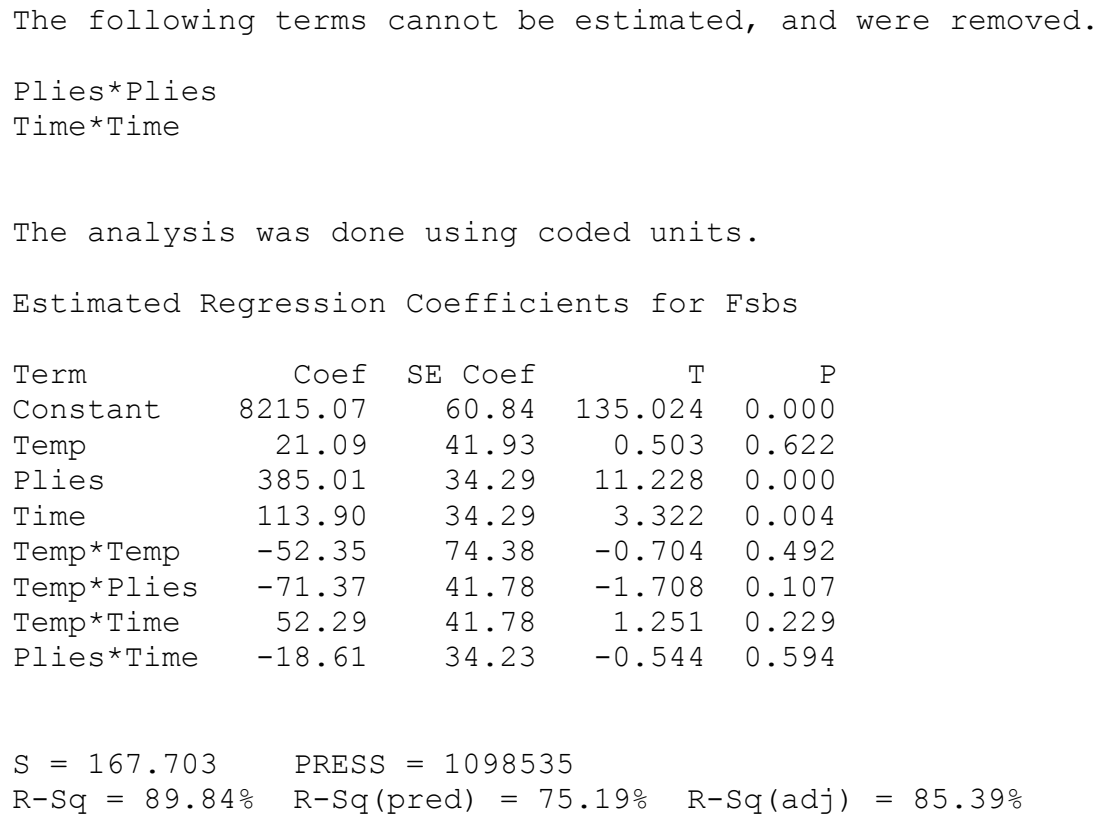




$\begin{array}{lrrrrrr}\text { Analysis of Variance for Fsbs } \\ \begin{array}{l}\text { DF } \\ \text { Source }\end{array} & \text { Seq SS } & \text { Adj SS } & \text { Adj MS } & \text { F } & \text { P } \\ \text { Regression } & 7 & 3977497 & 3977497 & 568214 & 20.20 & 0.000 \\ \quad \text { Linear } & 3 & 3829147 & 3863101 & 1287700 & 45.79 & 0.000 \\ \quad \text { Temp } & 1 & 8906 & 7115 & 7115 & 0.25 & 0.622 \\ \quad \text { Plies } & 1 & 3495119 & 3545674 & 3545674 & 126.07 & 0.000 \\ \quad \text { Time } & 1 & 325123 & 310313 & 310313 & 11.03 & 0.004 \\ \text { Square } & 1 & 13933 & 13933 & 13933 & 0.50 & 0.492 \\ \quad \text { Temp*Temp } & 1 & 13933 & 13933 & 13933 & 0.50 & 0.492 \\ \text { Interaction } & 3 & 134416 & 134416 & 44805 & 1.59 & 0.230 \\ \quad \text { Temp*Plies } & 1 & 82062 & 82062 & 82062 & 2.92 & 0.107 \\ \quad \text { Temp*Time } & 1 & 44042 & 44042 & 44042 & 1.57 & 0.229 \\ \quad \text { Plies*Time } & 1 & 8313 & 8313 & 8313 & 0.30 & 0.594 \\ \text { Residual Error } & 16 & 449991 & 449991 & 28124 & & \\ \quad \text { Lack-of-Fit } & 4 & 171508 & 171508 & 42877 & 1.85 & 0.185 \\ \text { Pure Error } & 12 & 278483 & 278483 & 23207 & & \\ \text { Total } & 23 & 4427488 & & & & \end{array}$

Similar to the flexural strength and tangent modulus analyses, the only significant factors are the linear factors. Removing the square and interaction terms gives residual plots which are still relatively normal with constant variance.

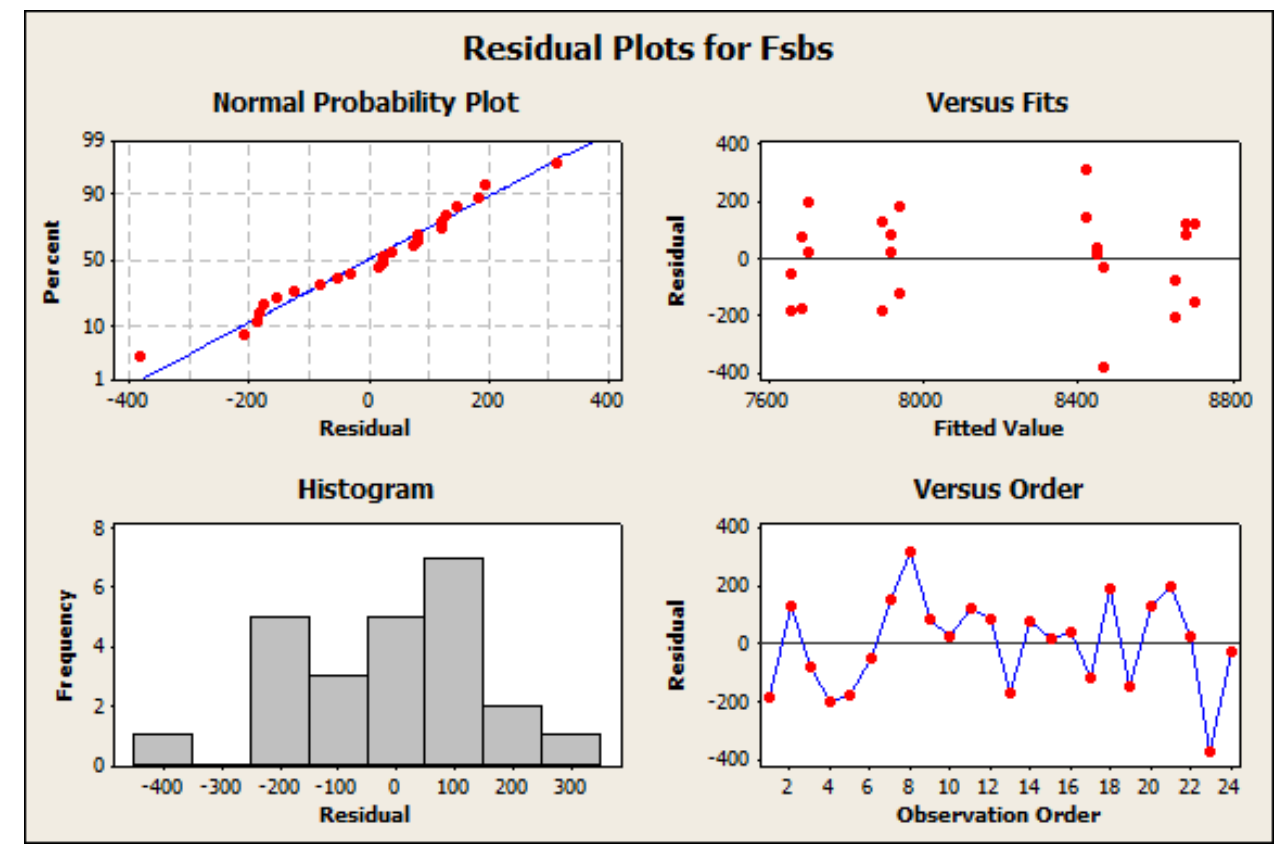

\section{Response Surface Regression: Fsbs versus Temp, Plies, Time}

The analysis was done using coded units. 


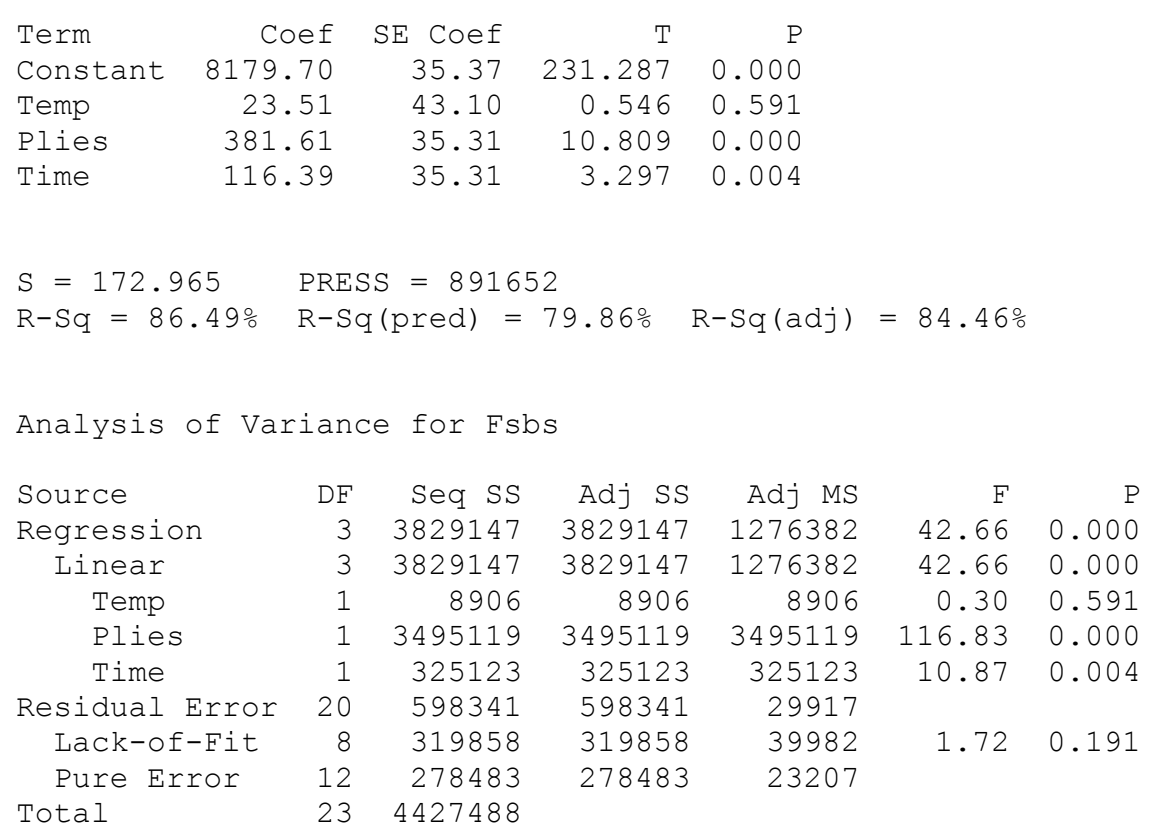

Again, the Plies and Time terms are both very significant while the temperature term is still insignificant. The main effects plot shows that more material and more time increase the shortbeam strength. In this case, it also appears that there is a slight peak in $F_{s b s}$ for Temp $=285^{\circ} \mathrm{F}$.

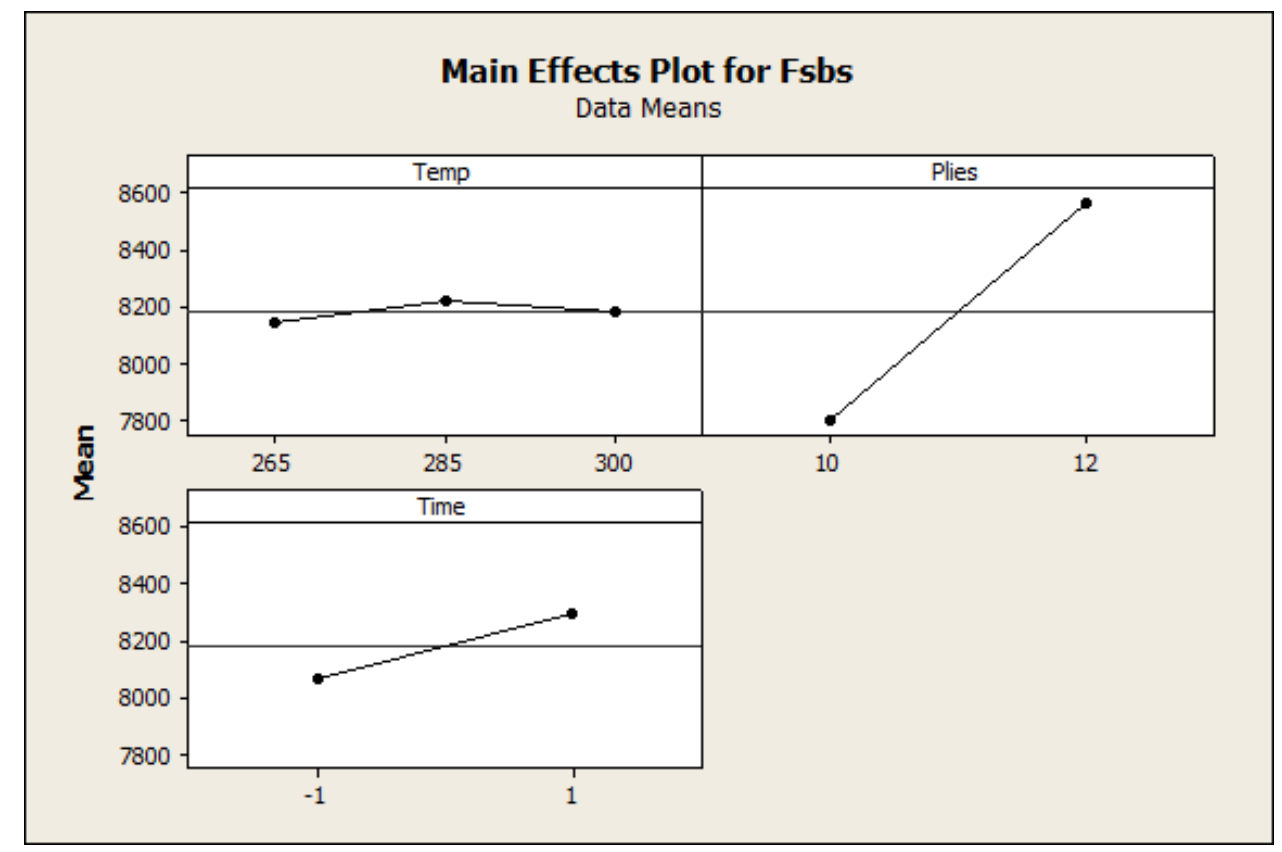




\section{Appendix E. Raw Data}

\section{E.1. P35/Z03 Tensile Mold Specimens}

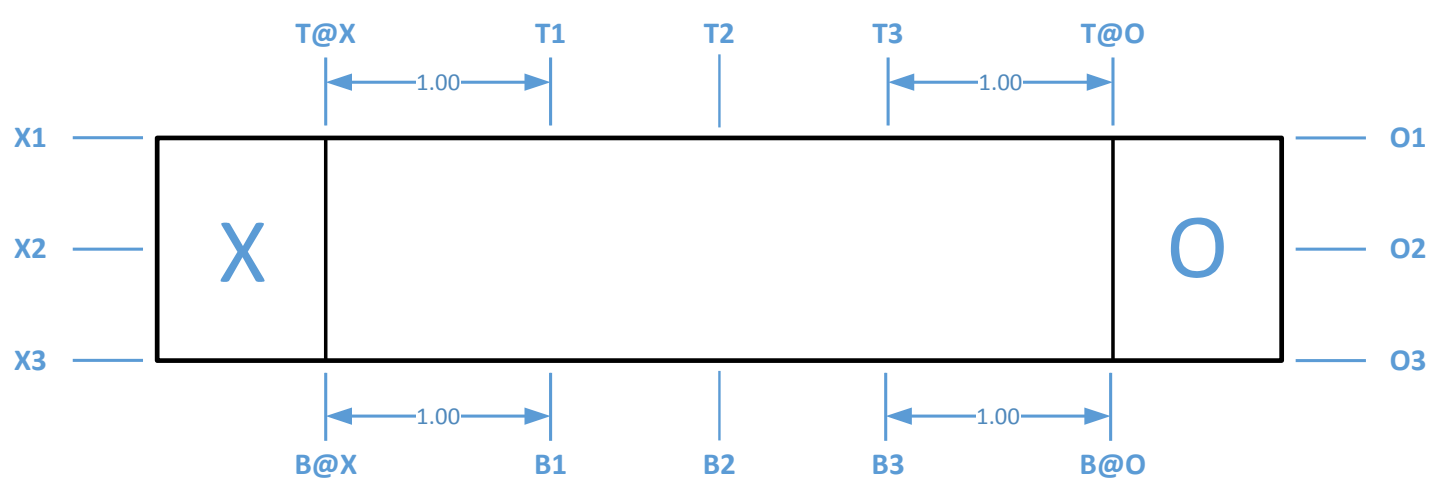

Table E.1. Consistency measurements for P35/Z03 specimens.

\begin{tabular}{|c|c|c|c|c|c|c|}
\hline Dimension & 14 ply & 15 ply & R1L & R1R & R2L & R2R \\
\hline $\mathbf{T} @ \mathbf{X}$ & 0.094 & 0.094 & 0.095 & 0.094 & 0.094 & 0.095 \\
\hline T1 & 0.095 & 0.094 & 0.095 & 0.094 & 0.095 & 0.094 \\
\hline $\mathbf{T 2}$ & 0.095 & 0.094 & 0.095 & 0.094 & 0.095 & 0.094 \\
\hline T3 & 0.095 & 0.094 & 0.095 & 0.093 & 0.095 & 0.094 \\
\hline $\mathbf{T} @ \mathbf{O}$ & 0.094 & 0.094 & 0.094 & 0.094 & 0.094 & 0.093 \\
\hline $\mathbf{B} @ \mathbf{X}$ & 0.094 & 0.094 & 0.095 & 0.094 & 0.094 & 0.094 \\
\hline B1 & 0.094 & 0.094 & 0.094 & 0.094 & 0.094 & 0.095 \\
\hline B2 & 0.094 & 0.095 & 0.094 & 0.094 & 0.094 & 0.095 \\
\hline B3 & 0.094 & 0.094 & 0.094 & 0.094 & 0.093 & 0.094 \\
\hline $\mathbf{B} @ \mathbf{O}$ & 0.095 & 0.093 & 0.094 & 0.094 & 0.094 & 0.094 \\
\hline $\mathbf{W X}$ & 0.997 & 0.985 & 0.983 & 0.998 & 0.995 & 0.996 \\
\hline W1 & 0.997 & 0.983 & 0.989 & 0.998 & 0.998 & 0.998 \\
\hline W2 & 0.998 & 0.985 & 0.994 & 0.998 & 0.999 & 0.998 \\
\hline W3 & 0.997 & 0.981 & 0.996 & 0.999 & 0.998 & 0.998 \\
\hline WO & 0.996 & 0.984 & 0.996 & 0.997 & 0.996 & 0.996 \\
\hline $\mathbf{X 1}$ & 0.225 & 0.225 & 0.228 & 0.226 & 0.227 & 0.226 \\
\hline $\mathrm{X} 2$ & 0.226 & 0.228 & 0.227 & 0.227 & 0.227 & 0.226 \\
\hline $\mathrm{X3}$ & 0.226 & 0.227 & 0.227 & 0.226 & 0.227 & 0.226 \\
\hline 01 & 0.233 & 0.230 & 0.231 & 0.230 & 0.231 & 0.230 \\
\hline $\mathrm{O2}$ & 0.231 & 0.230 & 0.231 & 0.229 & 0.230 & 0.230 \\
\hline $\mathbf{O 3}$ & 0.229 & 0.229 & 0.231 & 0.230 & 0.231 & 0.230 \\
\hline LX & 0.807 & 0.815 & 0.813 & 0.818 & 0.809 & 0.805 \\
\hline LO & 0.817 & 0.813 & 0.813 & 0.812 & 0.819 & 0.812 \\
\hline $\mathbf{L}$ & 5.257 & 5.254 & 5.255 & 5.258 & 5.255 & 5.254 \\
\hline
\end{tabular}




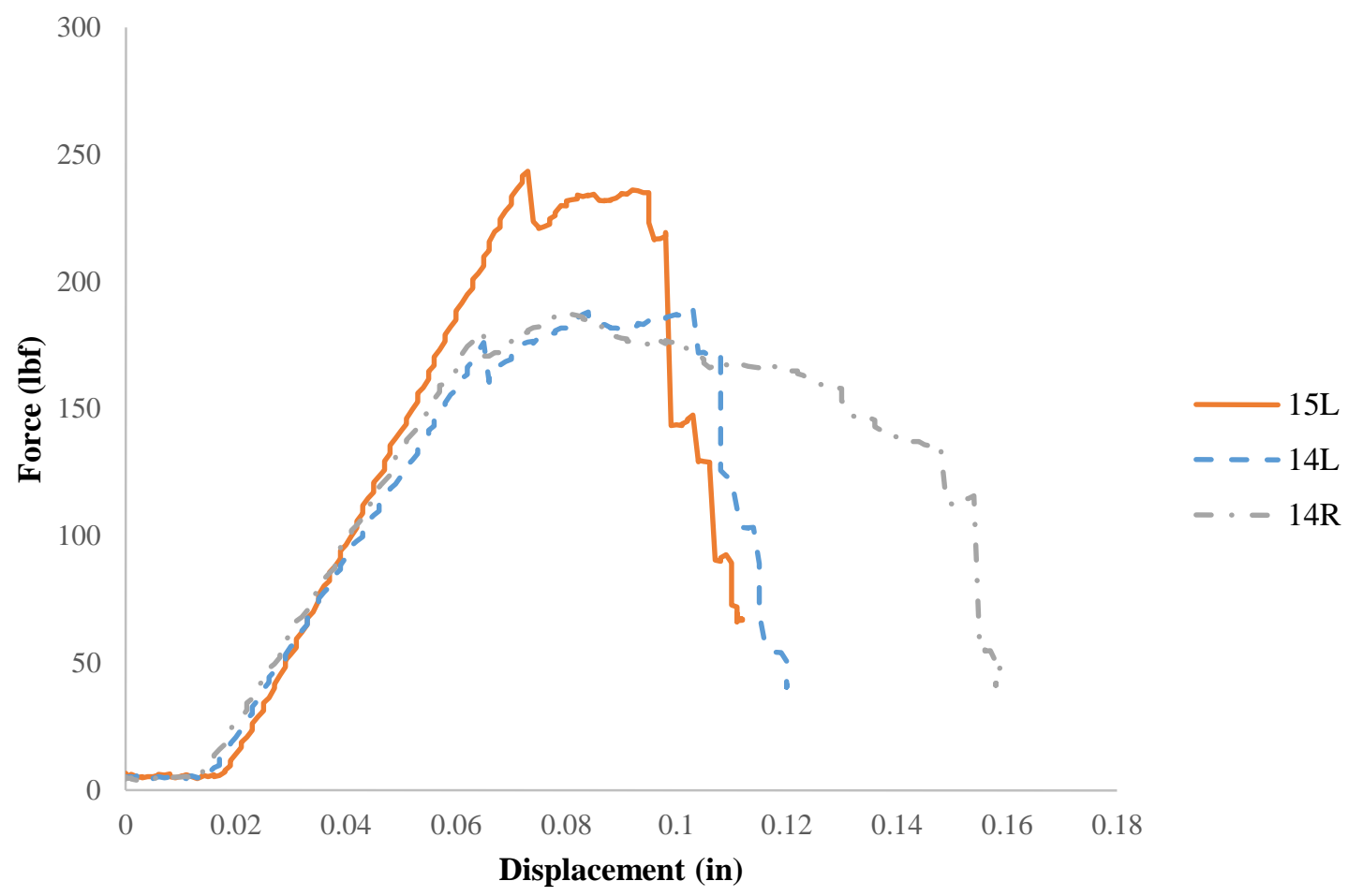

Figure E.1. 3-point bend data for P35/Z03: specimen lot \#1.

\begin{tabular}{|c|c|c|c|}
\hline Property & 15R & 14L & 14R \\
\hline Maximum Force (lbf) & 243.391 & 176.068 & 179.608 \\
\hline Max. Displacement (in) & 0.073 & 0.103 & 0.08 \\
\hline Span (in) & 1.6 & 1.6 & 1.6 \\
\hline Width (in) & 0.458 & 0.484 & 0.44 \\
\hline Depth (in) & 0.095 & 0.095 & 0.094 \\
\hline Slope (lbf/in) & --- & 3409.3 & 3520.5 \\
\hline Flexural Strength (psi) & $1.41 \mathrm{E}+05$ & $9.67 \mathrm{E}+04$ & $1.11 \mathrm{E}+05$ \\
\hline Flexural Strain (psi) & 0.0163 & 0.0229 & 0.0176 \\
\hline Tangent Modulus (psi) & --- & $8.41 \mathrm{E}+06$ & $9.86 \mathrm{E}+06$ \\
\hline
\end{tabular}




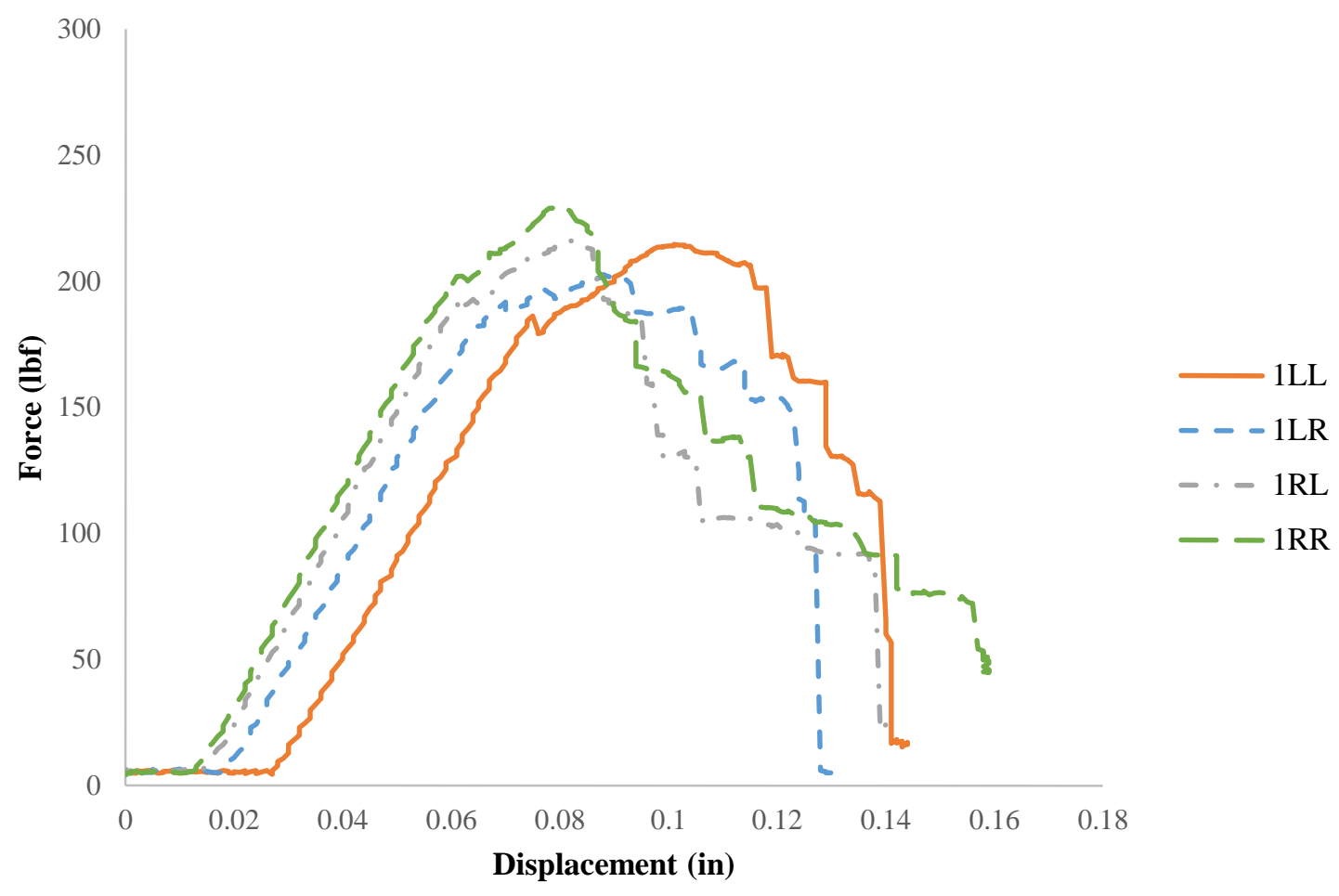

Figure E.2. 3-point bend data for P35/Z03: specimen lot \#2.

\begin{tabular}{|c|c|c|c|c|}
\hline Property & 1LL & 1LR & 1RL & 1RR \\
\hline Maximum Force (lbf) & 186.261 & 191.754 & 191.327 & 196.454 \\
\hline Max. Displacement (in) & 0.101 & 0.088 & 0.082 & 0.08 \\
\hline Span (in) & 1.6 & 1.6 & 1.6 & 1.6 \\
\hline Width (in) & 0.477 & 0.45 & 0.444 & 0.466 \\
\hline Depth (in) & 0.094 & 0.094 & 0.095 & 0.095 \\
\hline Slope (lbf/in) & 3879.1 & 3944.0 & 4103.0 & 4189.1 \\
\hline Flexural Strength (psi) & $1.06 \mathrm{E}+05$ & $1.16 \mathrm{E}+05$ & $1.15 \mathrm{E}+05$ & $1.12 \mathrm{E}+05$ \\
\hline Flexural Strain (psi) & 0.0223 & 0.0194 & 0.0183 & 0.0178 \\
\hline Tangent Modulus (psi) & $1.00 \mathrm{E}+07$ & $1.08 \mathrm{E}+07$ & $1.10 \mathrm{E}+07$ & $1.07 \mathrm{E}+07$ \\
\hline
\end{tabular}




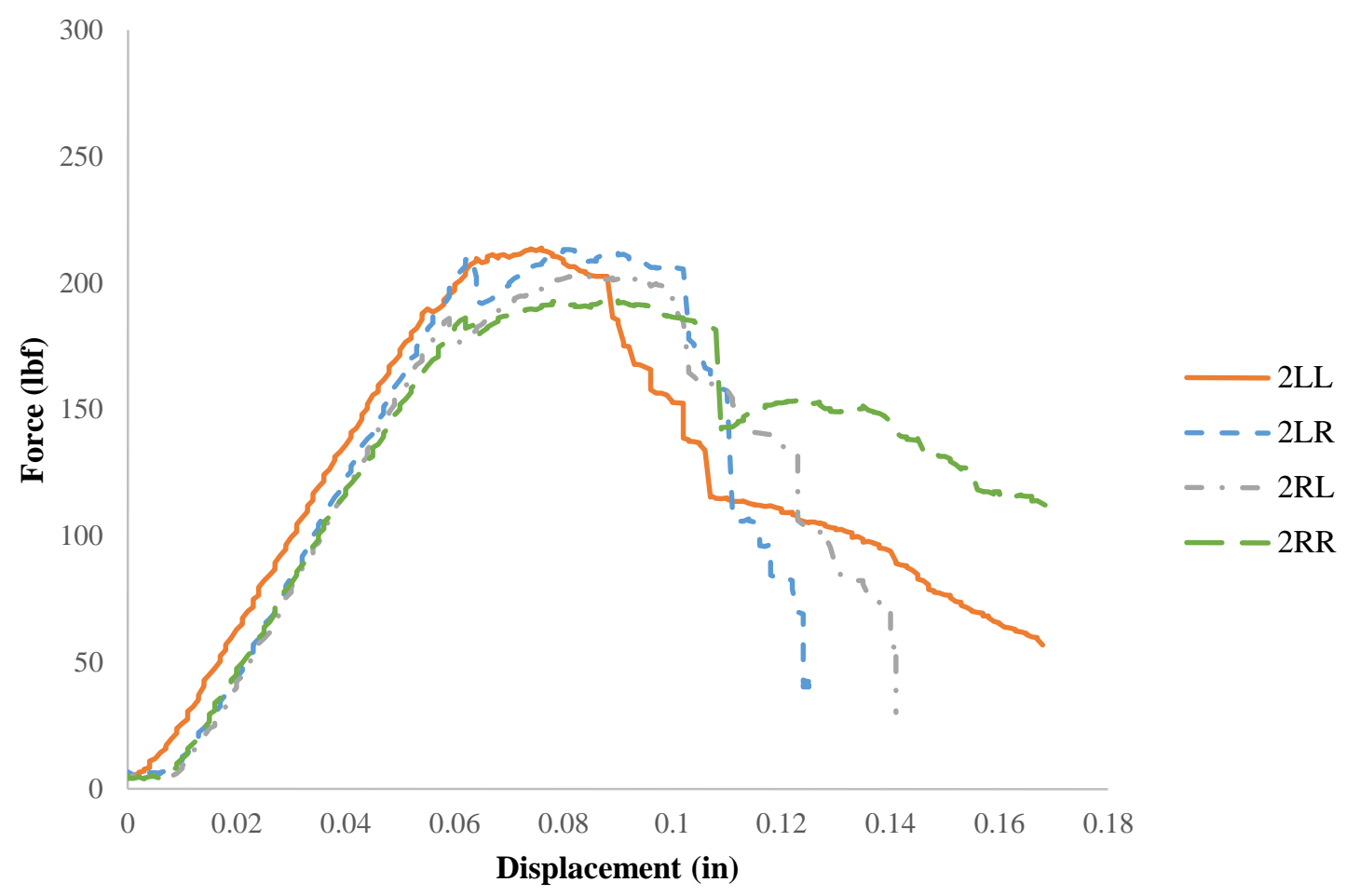

Figure E.3. 3-point bend data for P35/Z03: specimen lot \#3.

\begin{tabular}{|c|c|c|c|c|}
\hline Property & 2LL & 2LR & 2RL & 2RR \\
\hline Maximum Force (lbf) & 171.43 & 210.676 & 186.017 & 186.261 \\
\hline Max. Displacement (in) & 0.076 & 0.08 & 0.083 & 0.08 \\
\hline Span (in) & 1.6 & 1.6 & 1.6 & 1.6 \\
\hline Width (in) & 0.476 & 0.455 & 0.477 & 0.452 \\
\hline Depth (in) & 0.095 & 0.094 & 0.094 & 0.095 \\
\hline Slope (lbf/in) & 3527.3 & 3835.7 & 3762.3 & 3443.7 \\
\hline Flexural Strength (psi) & $9.58 \mathrm{E}+04$ & $1.26 \mathrm{E}+05$ & $1.06 \mathrm{E}+05$ & $1.10 \mathrm{E}+05$ \\
\hline Flexural Strain (psi) & 0.0169 & 0.0176 & 0.0183 & 0.0178 \\
\hline Tangent Modulus (psi) & $8.85 \mathrm{E}+06$ & $1.04 \mathrm{E}+07$ & $9.72 \mathrm{E}+06$ & $9.10 \mathrm{E}+06$ \\
\hline
\end{tabular}




\section{E.2. M46J/TC250 Tensile Mold Specimens}

Table E.2. Consistency measurements for M46J/TC250 specimens.

\begin{tabular}{|c|c|c|c|c|c|c|c|c|}
\hline Specimen & Wavg & Tavg & WX & WM & WO & TX & TM & TO \\
\hline 265-10-L-120 & 0.459 & 0.082 & 0.457 & 0.458 & 0.462 & 0.084 & 0.082 & 0.080 \\
\hline 265-10-R-120 & 0.444 & 0.082 & 0.440 & 0.443 & 0.449 & 0.084 & 0.082 & 0.080 \\
\hline 265-12-L-120 & 0.461 & 0.086 & 0.461 & 0.461 & 0.462 & 0.087 & 0.087 & 0.085 \\
\hline 265-12-R-120 & 0.431 & 0.087 & 0.431 & 0.431 & 0.431 & 0.088 & 0.088 & 0.086 \\
\hline 285-10-L-70 & 0.430 & 0.082 & 0.442 & 0.432 & 0.417 & 0.084 & 0.082 & 0.080 \\
\hline 285-10-R-70 & 0.488 & 0.082 & 0.488 & 0.491 & 0.484 & 0.084 & 0.083 & 0.080 \\
\hline 285-12-L-70 & 0.469 & 0.087 & 0.471 & 0.469 & 0.467 & 0.087 & 0.087 & 0.086 \\
\hline 285-12-R-70 & 0.445 & 0.086 & 0.438 & 0.446 & 0.450 & 0.086 & 0.087 & 0.086 \\
\hline $300-10-L-30$ & 0.486 & 0.082 & 0.472 & 0.490 & 0.495 & 0.085 & 0.082 & 0.080 \\
\hline $300-10-R-30$ & 0.432 & 0.082 & 0.434 & 0.432 & 0.429 & 0.083 & 0.082 & 0.080 \\
\hline $300-12-L-30$ & 0.495 & 0.087 & 0.500 & 0.495 & 0.490 & 0.088 & 0.088 & 0.086 \\
\hline $300-12-R-30$ & 0.433 & 0.087 & 0.419 & 0.435 & 0.445 & 0.088 & 0.088 & 0.086 \\
\hline 265-10-L-60 & 0.487 & 0.081 & 0.486 & 0.485 & 0.490 & 0.083 & 0.082 & 0.079 \\
\hline 265-10-R-60 & 0.437 & 0.082 & 0.441 & 0.434 & 0.436 & 0.083 & 0.083 & 0.080 \\
\hline $265-12-L-60$ & 0.469 & 0.085 & 0.475 & 0.469 & 0.463 & 0.086 & 0.086 & 0.083 \\
\hline $265-12-R-60$ & 0.448 & 0.086 & 0.445 & 0.448 & 0.451 & 0.087 & 0.087 & 0.084 \\
\hline $285-10-L-35$ & 0.468 & 0.081 & 0.467 & 0.469 & 0.469 & 0.083 & 0.082 & 0.079 \\
\hline $285-10-R-35$ & 0.432 & 0.082 & 0.430 & 0.433 & 0.432 & 0.083 & 0.083 & 0.081 \\
\hline $285-12-L-35$ & 0.476 & 0.086 & 0.472 & 0.475 & 0.482 & 0.088 & 0.087 & 0.084 \\
\hline $285-12-R-35$ & 0.445 & 0.087 & 0.445 & 0.445 & 0.445 & 0.087 & 0.088 & 0.086 \\
\hline $300-10-L-15$ & 0.469 & 0.081 & 0.467 & 0.471 & 0.470 & 0.083 & 0.082 & 0.079 \\
\hline $300-10-R-15$ & 0.455 & 0.082 & 0.453 & 0.458 & 0.454 & 0.084 & 0.083 & 0.079 \\
\hline $300-12-L-15$ & 0.454 & 0.087 & 0.458 & 0.454 & 0.450 & 0.087 & 0.087 & 0.087 \\
\hline $300-12-R-15$ & 0.451 & 0.087 & 0.449 & 0.452 & 0.451 & 0.088 & 0.088 & 0.085 \\
\hline
\end{tabular}




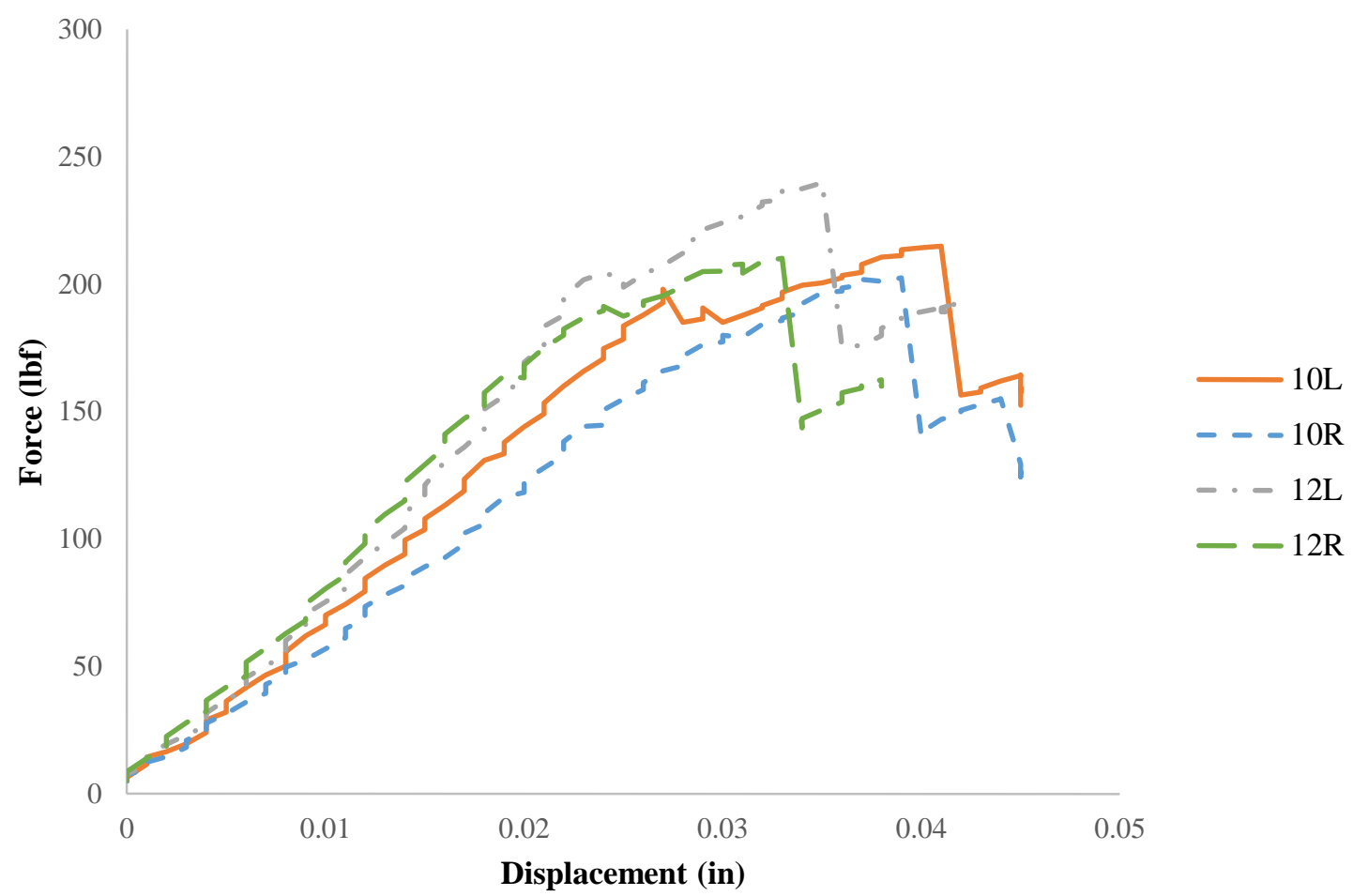

Figure E.4. 3-point bend data for M46J/TC250: $265^{\circ} \mathrm{F}, 120 \mathrm{~min}$.

\begin{tabular}{|c|c|c|c|c|}
\hline Property & 10L & 10R & 12L & 12R \\
\hline Maximum Force (lbf) & 198 & 202 & 204 & 191 \\
\hline Max. Displacement (in) & 0.027 & 0.039 & 0.024 & 0.024 \\
\hline Width (in) & 0.459 & 0.444 & 0.461 & 0.431 \\
\hline Depth (in) & 0.082 & 0.082 & 0.086 & 0.087 \\
\hline Span (in) & 1.35 & 1.35 & 1.35 & 1.35 \\
\hline Slope (lbf/in) & 7140.0 & 5850.4 & 8386.7 & 8094.6 \\
\hline Flexural Strength (psi) & $1.30 \mathrm{E}+05$ & $1.37 \mathrm{E}+05$ & $1.21 \mathrm{E}+05$ & $1.19 \mathrm{E}+05$ \\
\hline Flexural Strain (psi) & 0.00729 & 0.01053 & 0.00680 & 0.00687 \\
\hline Tangent Modulus (psi) & $1.74 \mathrm{E}+07$ & $1.47 \mathrm{E}+07$ & $1.76 \mathrm{E}+07$ & $1.75 \mathrm{E}+07$ \\
\hline
\end{tabular}




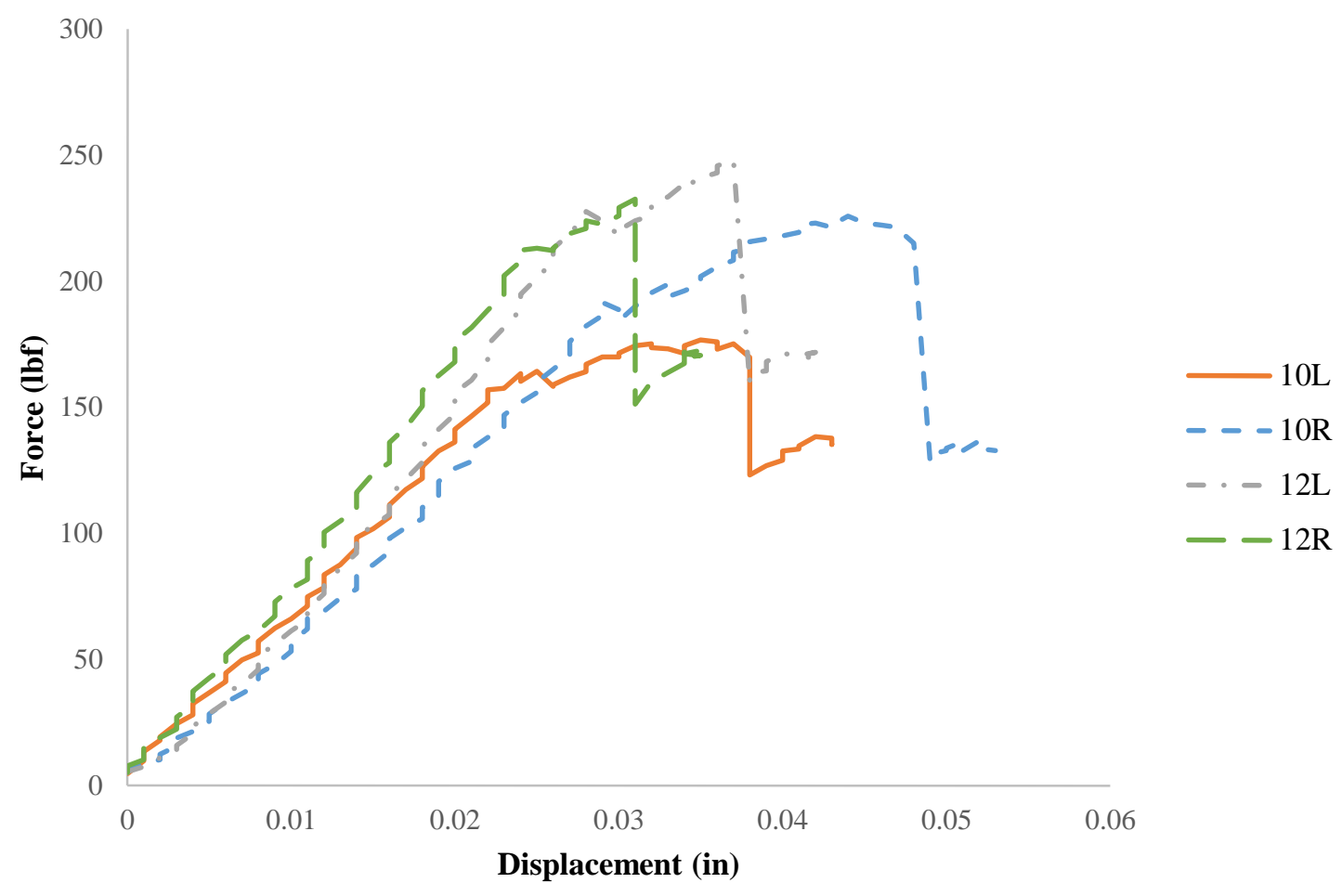

Figure E.5. 3-point bend data for M46J/TC250: $285^{\circ} \mathrm{F}, 70 \mathrm{~min}$.

\begin{tabular}{|c|c|c|c|c|}
\hline Property & $\mathbf{1 0 L}$ & $\mathbf{1 0 R}$ & $\mathbf{1 2 L}$ & 12R \\
\hline Maximum Force (lbf) & 164 & 192 & 228 & 233 \\
\hline Max. Displacement (in) & 0.025 & 0.029 & 0.028 & 0.031 \\
\hline Width (in) & 0.43 & 0.488 & 0.469 & 0.445 \\
\hline Depth (in) & 0.082 & 0.082 & 0.087 & 0.086 \\
\hline Span (in) & 1.35 & 1.35 & 1.35 & 1.35 \\
\hline Slope (lbf/in) & 6654.0 & 6440.2 & 8234.4 & 7983.4 \\
\hline Flexural Strength (psi) & $1.15 \mathrm{E}+05$ & $1.18 \mathrm{E}+05$ & $1.30 \mathrm{E}+05$ & $1.43 \mathrm{E}+05$ \\
\hline Flexural Strain (psi) & 0.00675 & 0.00783 & 0.00802 & 0.00878 \\
\hline Tangent Modulus (psi) & $1.73 \mathrm{E}+07$ & $1.47 \mathrm{E}+07$ & $1.64 \mathrm{E}+07$ & $1.73 \mathrm{E}+07$ \\
\hline
\end{tabular}




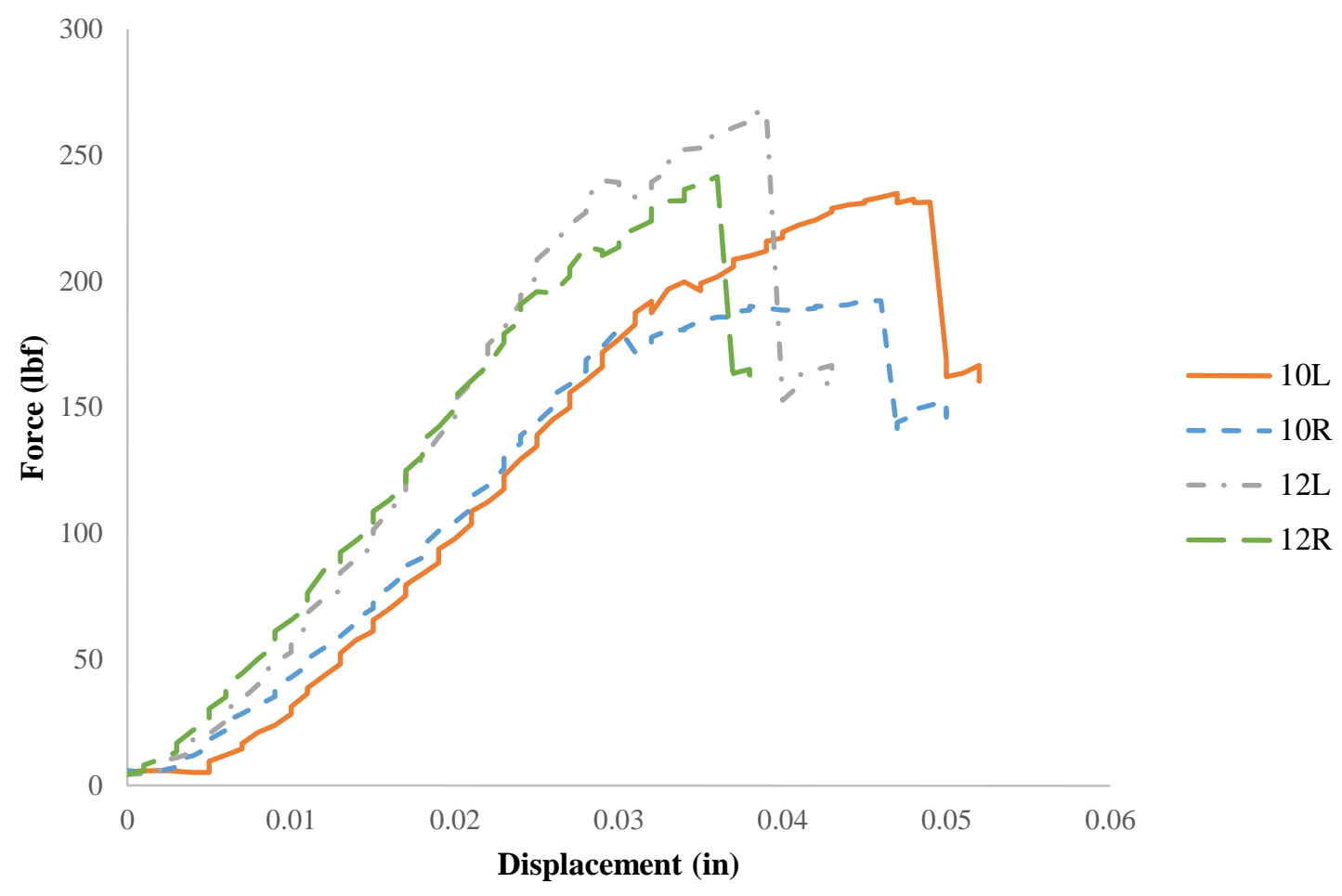

Figure E.6. 3-point bend data for M46J/TC250: $300^{\circ} \mathrm{F}, 30 \mathrm{~min}$.

\begin{tabular}{|c|c|c|c|c|}
\hline Property & 10L & 10R & 12L & 12R \\
\hline Maximum Force (lbf) & 192 & 181 & 240 & 241 \\
\hline Max. Displacement (in) & 0.032 & 0.030 & 0.029 & 0.036 \\
\hline Width (in) & 0.486 & 0.432 & 0.495 & 0.433 \\
\hline Depth (in) & 0.082 & 0.082 & 0.087 & 0.087 \\
\hline Span (in) & 1.35 & 1.35 & 1.35 & 1.35 \\
\hline Slope (lbf/in) & 7129.8 & 6021.8 & 8539.5 & 7319.5 \\
\hline Flexural Strength (psi) & $1.19 \mathrm{E}+05$ & $1.26 \mathrm{E}+05$ & $1.30 \mathrm{E}+05$ & $1.49 \mathrm{E}+05$ \\
\hline Flexural Strain (psi) & 0.00864 & 0.00810 & 0.00831 & 0.01031 \\
\hline Tangent Modulus (psi) & $1.64 \mathrm{E}+07$ & $1.56 \mathrm{E}+07$ & $1.61 \mathrm{E}+07$ & $1.58 \mathrm{E}+07$ \\
\hline
\end{tabular}




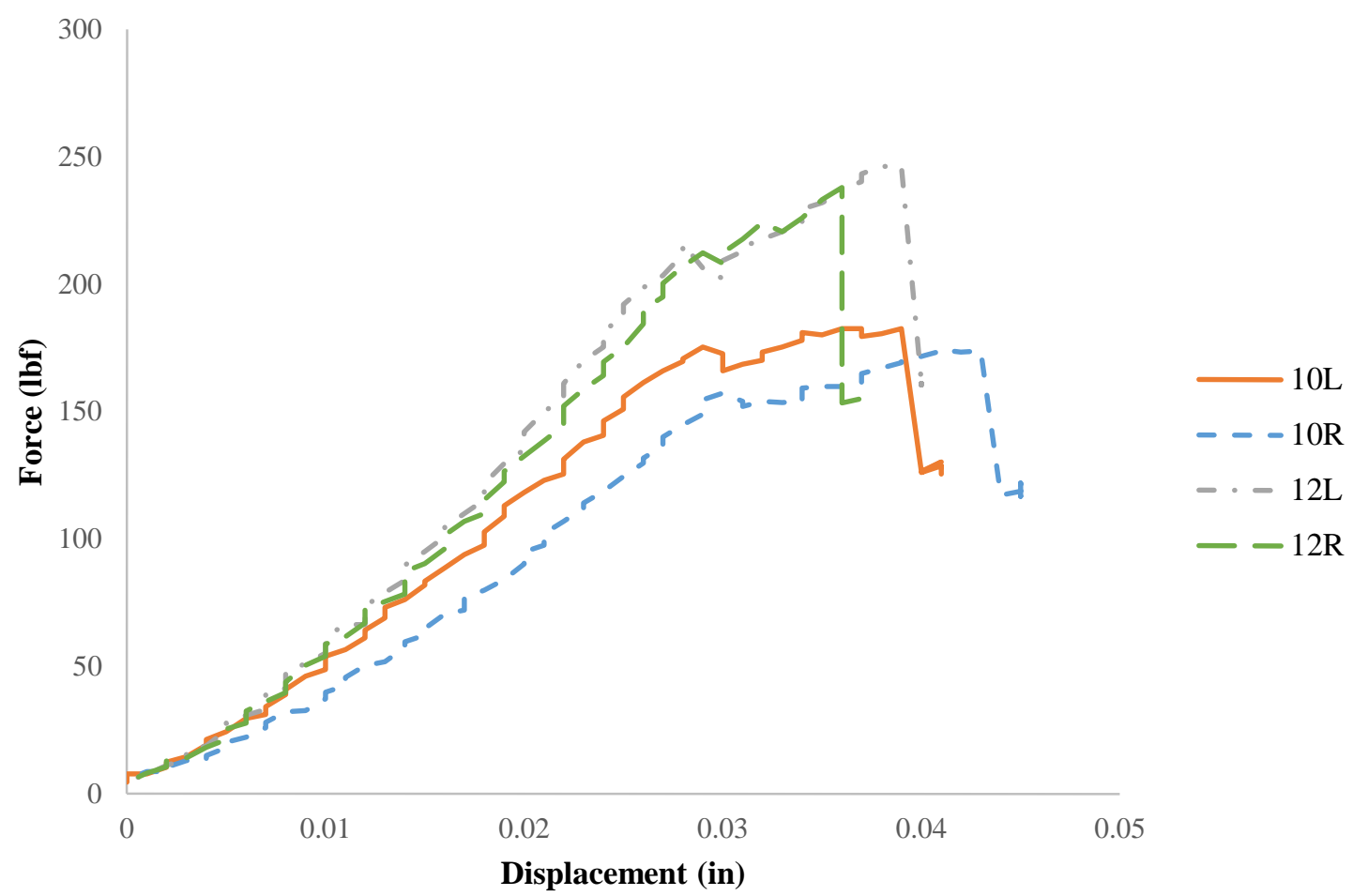

Figure E.7. 3-point bend data for M46J/TC250: $265^{\circ} \mathrm{F}, 60 \mathrm{~min}$.

\begin{tabular}{|c|c|c|c|c|}
\hline Property & 10L & 10R & 12L & 12R \\
\hline Maximum Force (lbf) & 175 & 157 & 216 & 212 \\
\hline Max. Displacement (in) & 0.029 & 0.030 & 0.028 & 0.029 \\
\hline Width (in) & 0.487 & 0.437 & 0.469 & 0.448 \\
\hline Depth (in) & 0.081 & 0.082 & 0.085 & 0.086 \\
\hline Span (in) & 1.35 & 1.35 & 1.35 & 1.35 \\
\hline Slope (lbf/in) & 5855.7 & 4920.3 & 7790.9 & 7372.6 \\
\hline Flexural Strength (psi) & $1.11 \mathrm{E}+05$ & $1.08 \mathrm{E}+05$ & $1.29 \mathrm{E}+05$ & $1.30 \mathrm{E}+05$ \\
\hline Flexural Strain (psi) & 0.00773 & 0.00810 & 0.00784 & 0.00821 \\
\hline Tangent Modulus (psi) & $1.39 \mathrm{E}+07$ & $1.26 \mathrm{E}+07$ & $1.66 \mathrm{E}+07$ & $1.59 \mathrm{E}+07$ \\
\hline
\end{tabular}




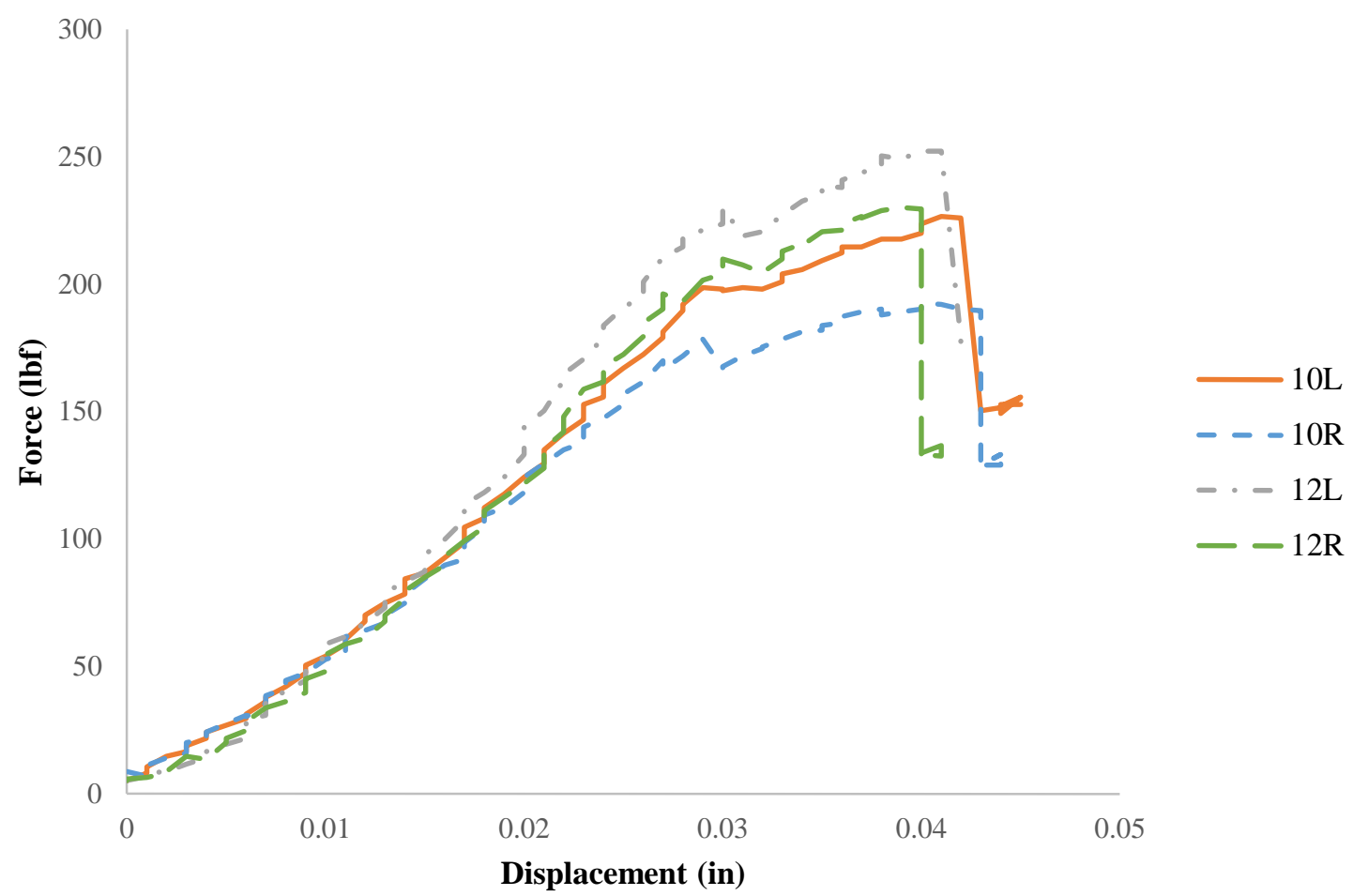

Figure E.8. 3-point bend data for M46J/TC250: $285^{\circ} \mathrm{F}, 35 \mathrm{~min}$.

\begin{tabular}{|c|c|c|c|c|}
\hline Property & 10L & 10R & 12L & 12R \\
\hline Maximum Force (lbf) & 199 & 157 & 230 & 196 \\
\hline Max. Displacement (in) & 0.029 & 0.030 & 0.030 & 0.027 \\
\hline Width (in) & 0.468 & 0.437 & 0.476 & 0.445 \\
\hline Depth (in) & 0.081 & 0.082 & 0.086 & 0.087 \\
\hline Span (in) & 1.35 & 1.35 & 1.35 & 1.35 \\
\hline Slope (lbf/in) & 6796.3 & 4920.3 & 8025.1 & 7251.0 \\
\hline Flexural Strength (psi) & $1.31 \mathrm{E}+05$ & $1.08 \mathrm{E}+05$ & $1.32 \mathrm{E}+05$ & $1.18 \mathrm{E}+05$ \\
\hline Flexural Strain (psi) & 0.00773 & 0.00810 & 0.00849 & 0.00773 \\
\hline Tangent Modulus (psi) & $1.68 \mathrm{E}+07$ & $1.26 \mathrm{E}+07$ & $1.63 \mathrm{E}+07$ & $1.52 \mathrm{E}+07$ \\
\hline
\end{tabular}




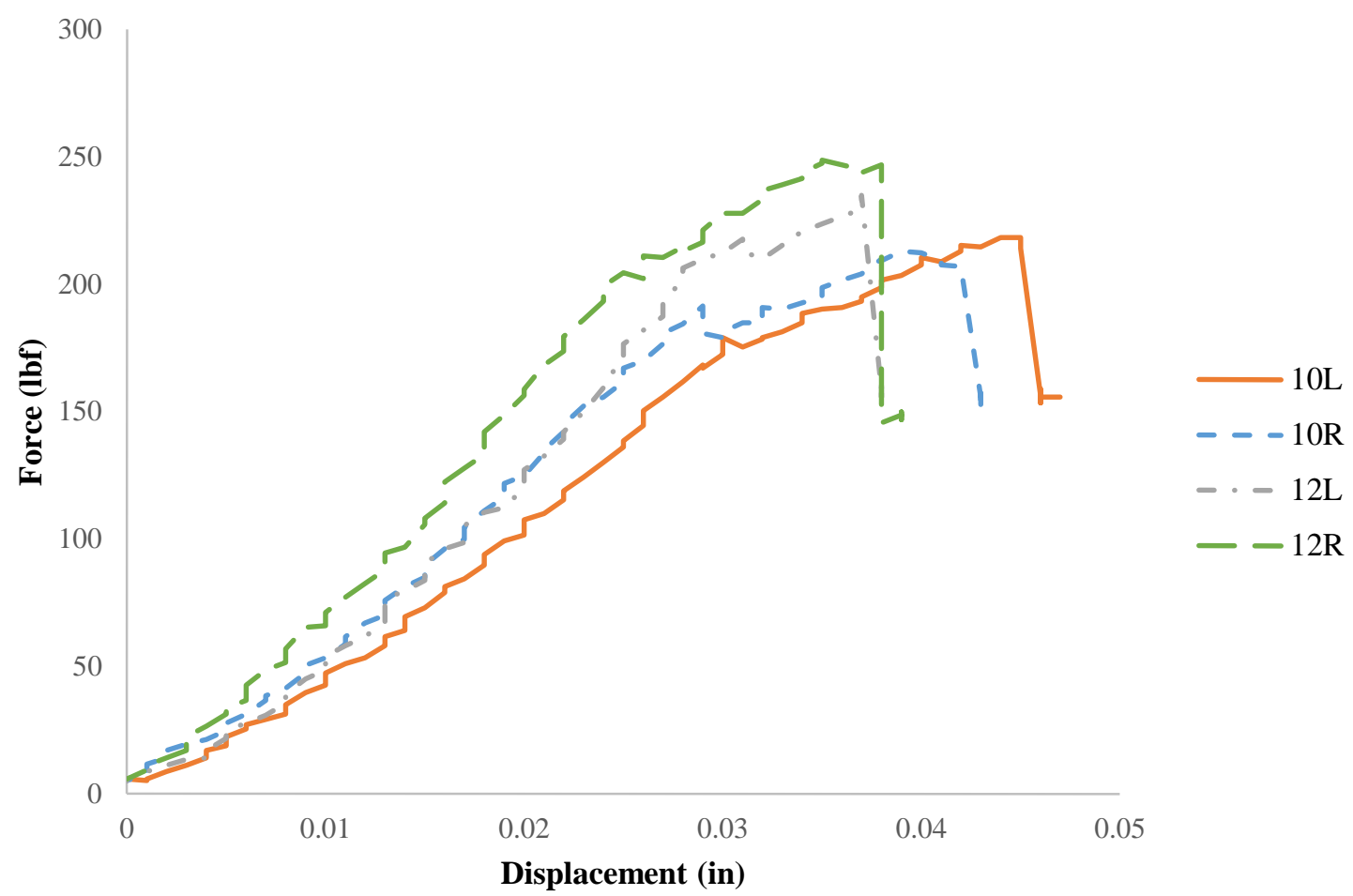

Figure E.9. 3-point bend data for M46J/TC250: $300^{\circ} \mathrm{F}, 15 \mathrm{~min}$.

\begin{tabular}{|c|c|c|c|c|}
\hline Property & 10L & 10R & 12L & 12R \\
\hline Maximum Force (lbf) & 210 & 191 & 218 & 215 \\
\hline Max. Displacement (in) & 0.040 & 0.029 & 0.031 & 0.028 \\
\hline Width (in) & 0.469 & 0.455 & 0.454 & 0.451 \\
\hline Depth (in) & 0.081 & 0.082 & 0.087 & 0.087 \\
\hline Span (in) & 1.35 & 1.35 & 1.35 & 1.35 \\
\hline Slope (lbf/in) & 5902.0 & 6659.3 & 7345.8 & 8148.7 \\
\hline Flexural Strength (psi) & $1.39 \mathrm{E}+05$ & $1.27 \mathrm{E}+05$ & $1.28 \mathrm{E}+05$ & $1.27 \mathrm{E}+05$ \\
\hline Flexural Strain (psi) & 0.01067 & 0.00783 & 0.00888 & 0.00802 \\
\hline Tangent Modulus (psi) & $1.46 \mathrm{E}+07$ & $1.63 \mathrm{E}+07$ & $1.51 \mathrm{E}+07$ & $1.69 \mathrm{E}+07$ \\
\hline
\end{tabular}




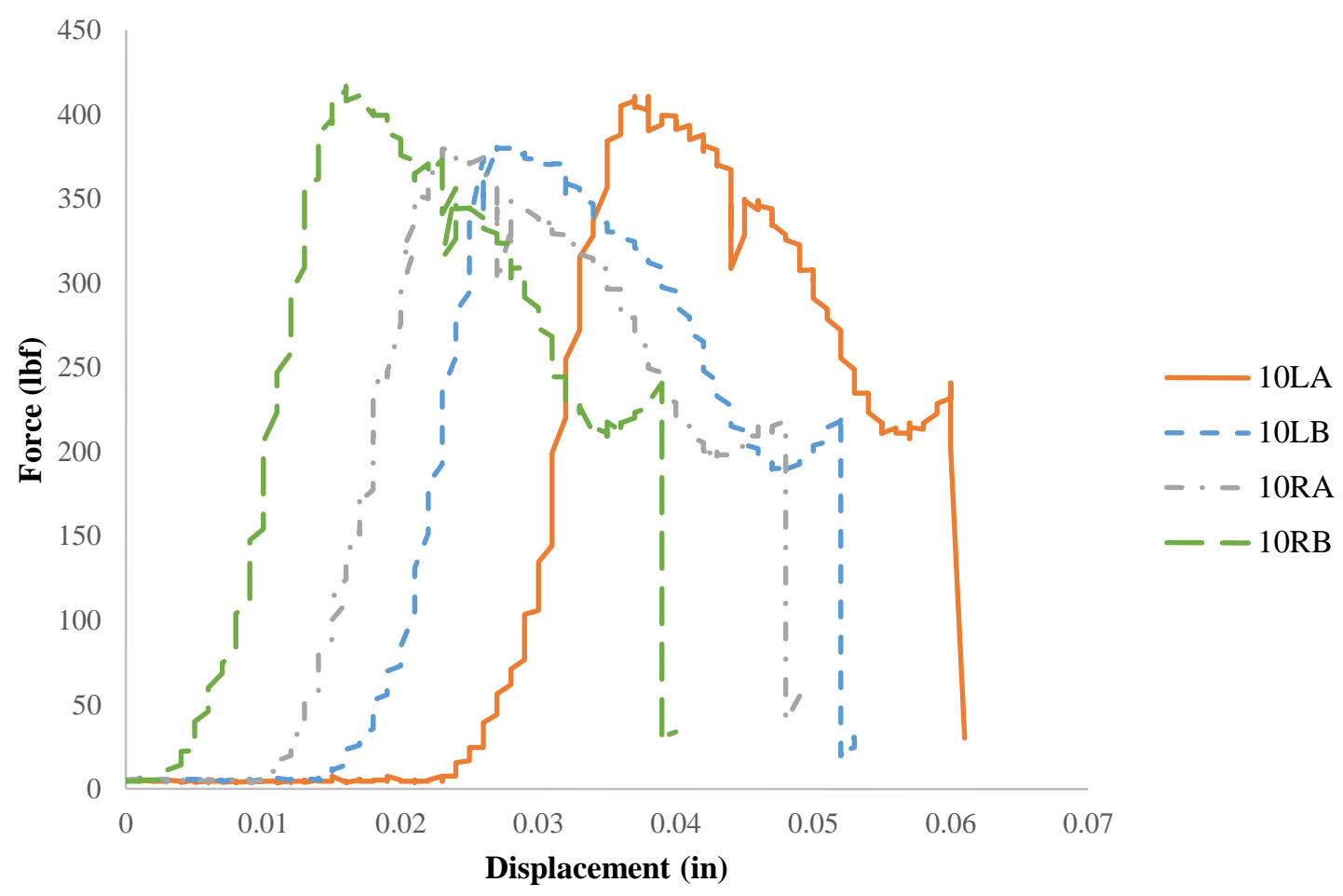

Figure E.10. Short-beam shear data for M46J/TC250: $265^{\circ}$ F, 120 min, 10-ply.

\begin{tabular}{|c|c|c|c|c|}
\hline Property & 10LA & 10LB & 10RA & 10RB \\
\hline Short-Beam Strength (psi) & $7.93 \mathrm{E}+03$ & $7.68 \mathrm{E}+03$ & $7.86 \mathrm{E}+03$ & $8.40 \mathrm{E}+03$ \\
\hline Maximum Load (lbf) & 410 & 382 & 379 & 417 \\
\hline Width (in) & 0.462 & 0.461 & 0.447 & 0.443 \\
\hline Depth (in) & 0.084 & 0.081 & 0.081 & 0.084 \\
\hline
\end{tabular}




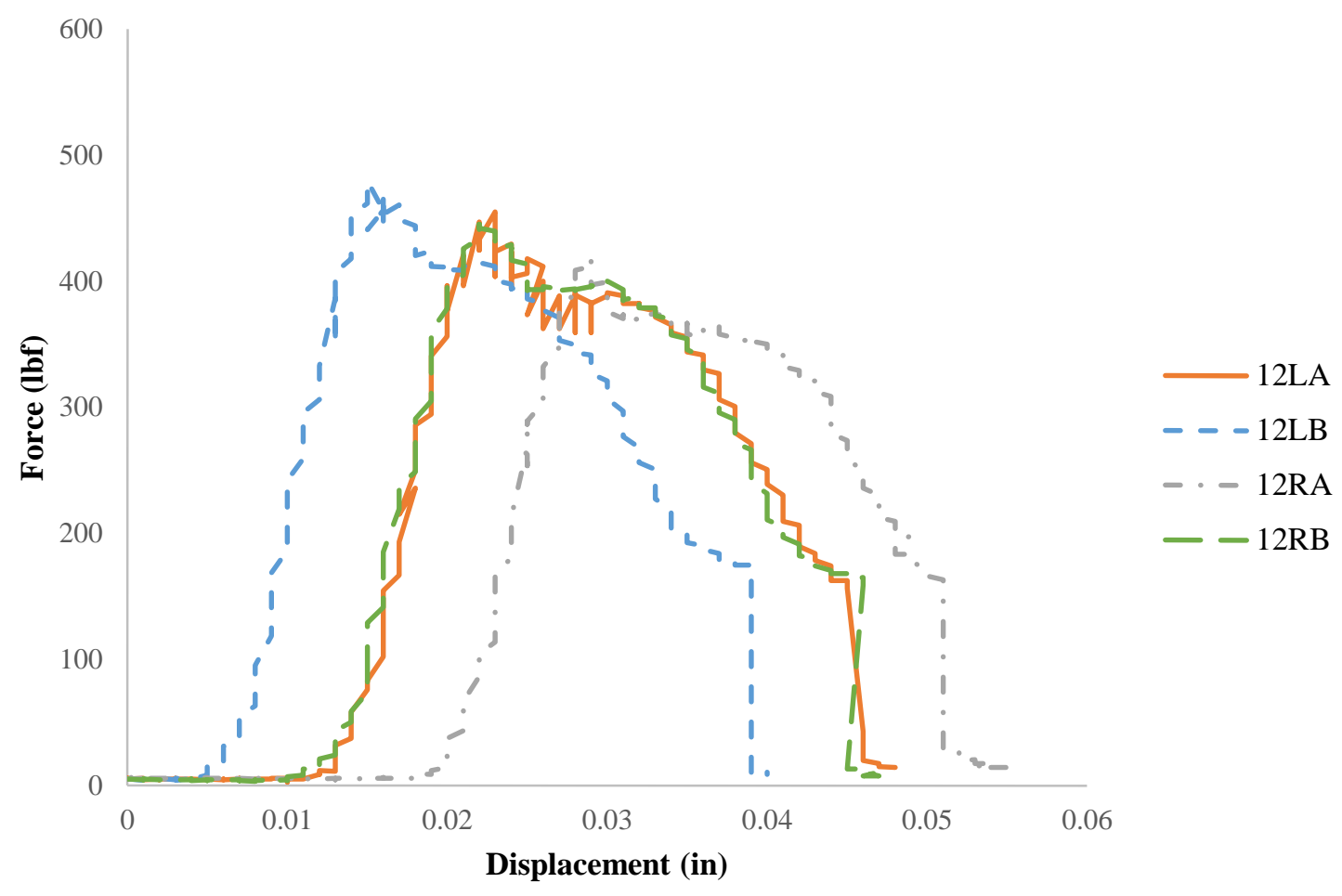

Figure E.11. Short-beam shear data for M46J/TC250: $265^{\circ} \mathrm{F}, 120$ min, 12-ply.

\begin{tabular}{|c|c|c|c|c|}
\hline Property & 12LA & 12LB & 12RA & 12RB \\
\hline Short-Beam Strength (psi) & $8.52 \mathrm{E}+03$ & $8.82 \mathrm{E}+03$ & $8.34 \mathrm{E}+03$ & $8.76 \mathrm{E}+03$ \\
\hline Maximum Load (lbf) & 455 & 479 & 418 & 445 \\
\hline Width (in) & 0.466 & 0.463 & 0.432 & 0.433 \\
\hline Depth (in) & 0.086 & 0.088 & 0.087 & 0.088 \\
\hline
\end{tabular}




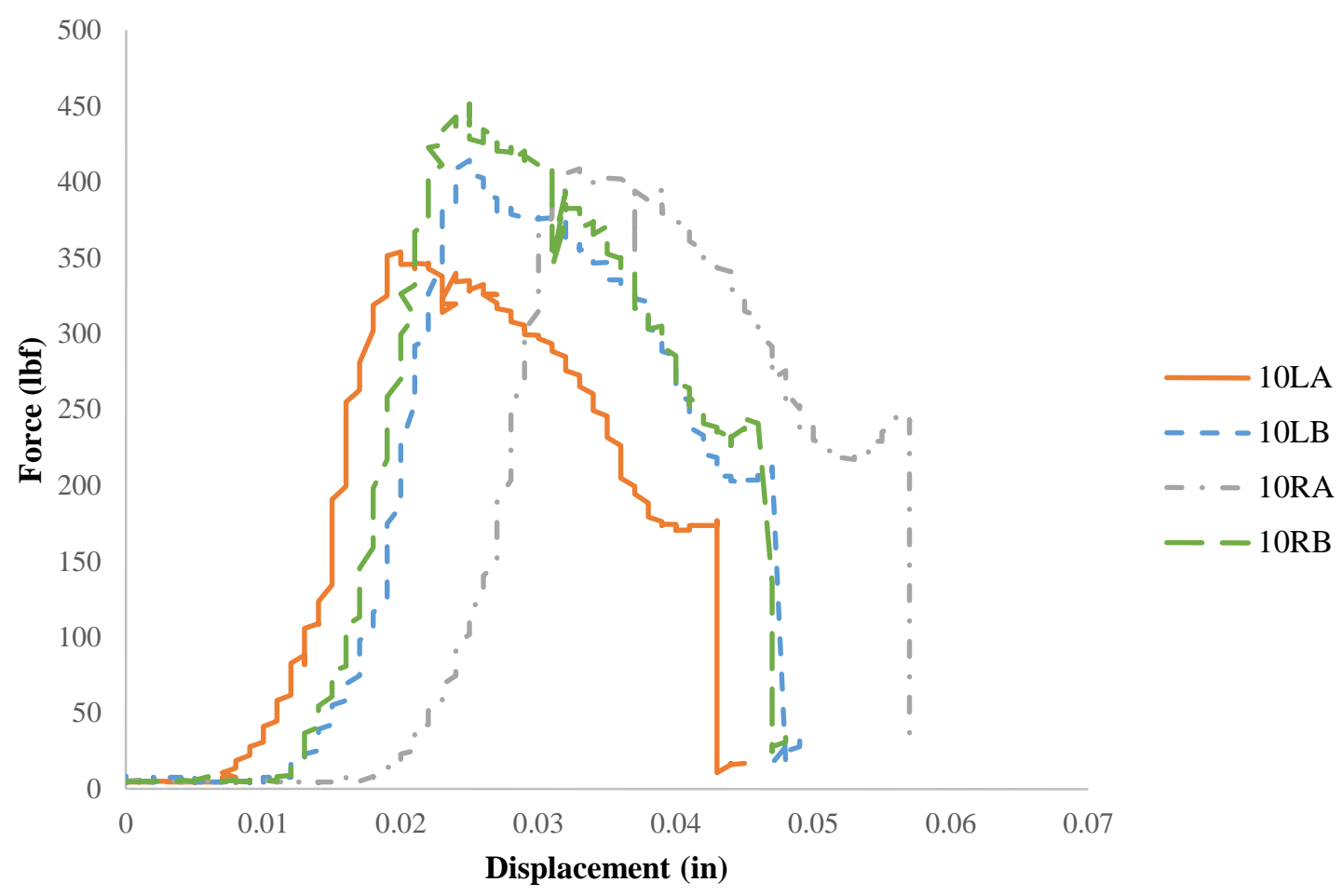

Figure E.12. Short-beam shear data for M46J/TC250: $285^{\circ} \mathrm{F}, 70$ min, 10-ply.

\begin{tabular}{|c|c|c|c|c|}
\hline Property & 10LA & 10LB & 10RA & 10RB \\
\hline Short-Beam Strength (psi) & $7.82 \mathrm{E}+03$ & $8.40 \mathrm{E}+03$ & $7.80 \mathrm{E}+03$ & $8.27 \mathrm{E}+03$ \\
\hline Maximum Load (lbf) & 354 & 414 & 409 & 451 \\
\hline Width (in) & 0.424 & 0.440 & 0.485 & 0.487 \\
\hline Depth (in) & 0.080 & 0.084 & 0.081 & 0.084 \\
\hline
\end{tabular}




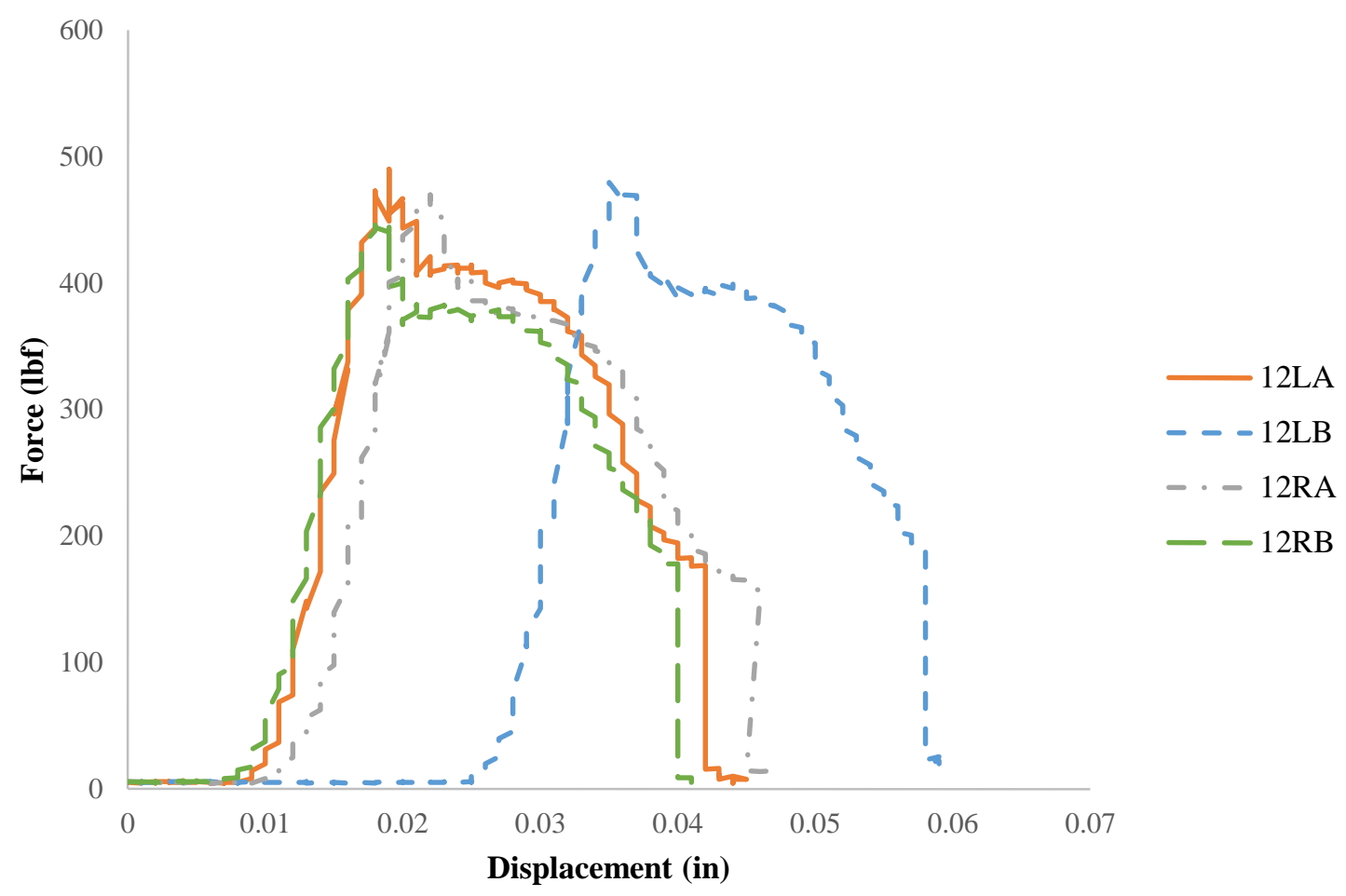

Figure E.13. Short-beam shear data for M46J/TC250: $285^{\circ} \mathrm{F}, 70$ min, 12-ply.

\begin{tabular}{|c|c|c|c|c|}
\hline Property & 12LA & 12LB & 12RA & 12RB \\
\hline Short-Beam Strength (psi) & $8.84 \mathrm{E}+03$ & $8.95 \mathrm{E}+03$ & $9.04 \mathrm{E}+03$ & $8.69 \mathrm{E}+03$ \\
\hline Maximum Load (lbf) & 490 & 479 & 470 & 450 \\
\hline Width (in) & 0.472 & 0.467 & 0.443 & 0.446 \\
\hline Depth (in) & 0.088 & 0.086 & 0.088 & 0.087 \\
\hline
\end{tabular}




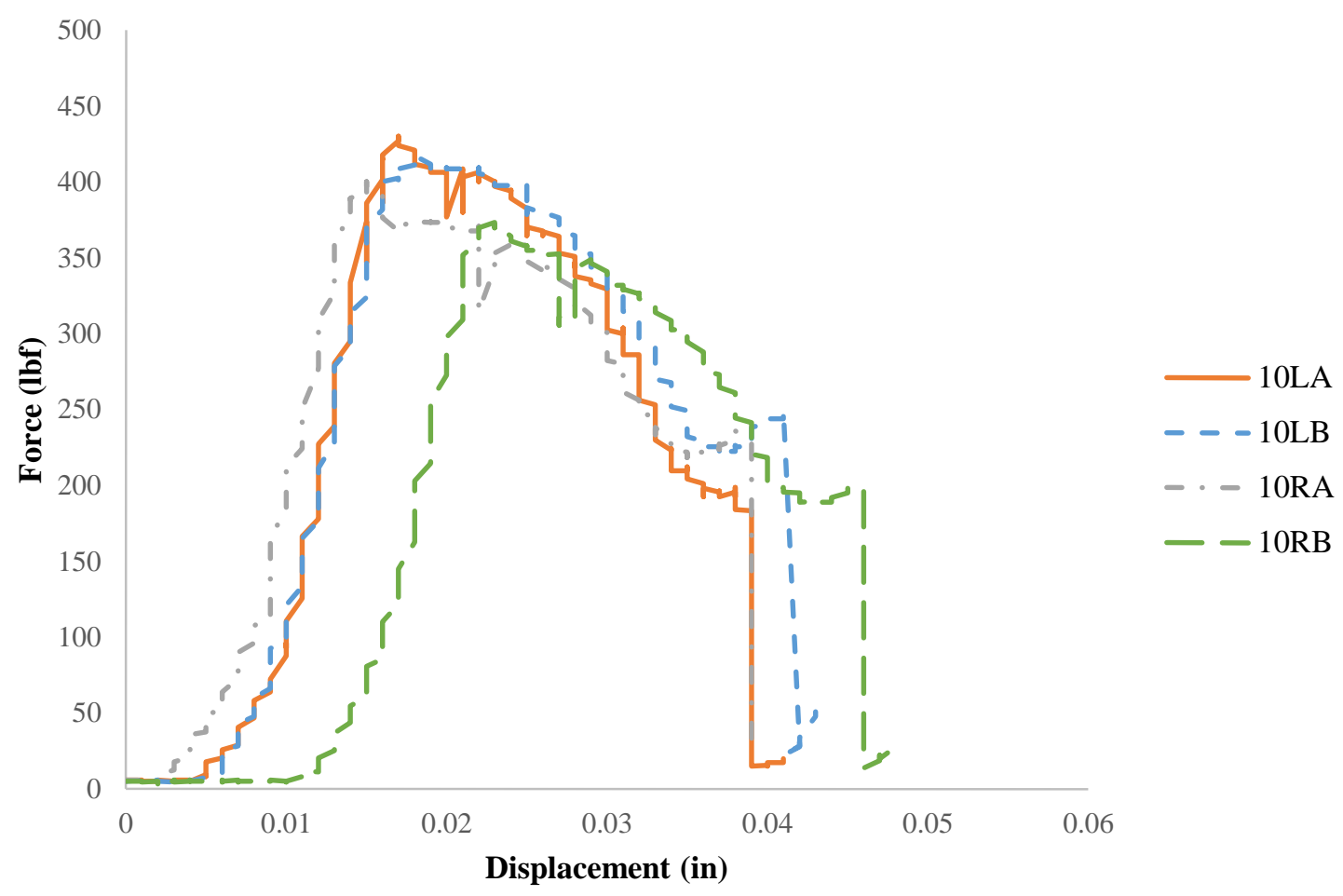

Figure E.14. Short-beam shear data for M46J/TC250: $300^{\circ} \mathrm{F}, 30$ min, 10-ply.

\begin{tabular}{|c|c|c|c|c|}
\hline Property & 10LA & 10LB & 10RA & 10RB \\
\hline Short-Beam Strength (psi) & $8.06 \mathrm{E}+03$ & $7.76 \mathrm{E}+03$ & $8.31 \mathrm{E}+03$ & $8.16 \mathrm{E}+03$ \\
\hline Maximum Load (lbf) & 430 & 417 & 400 & 373 \\
\hline Width (in) & 0.500 & 0.480 & 0.435 & 0.429 \\
\hline Depth (in) & 0.080 & 0.084 & 0.083 & 0.080 \\
\hline
\end{tabular}




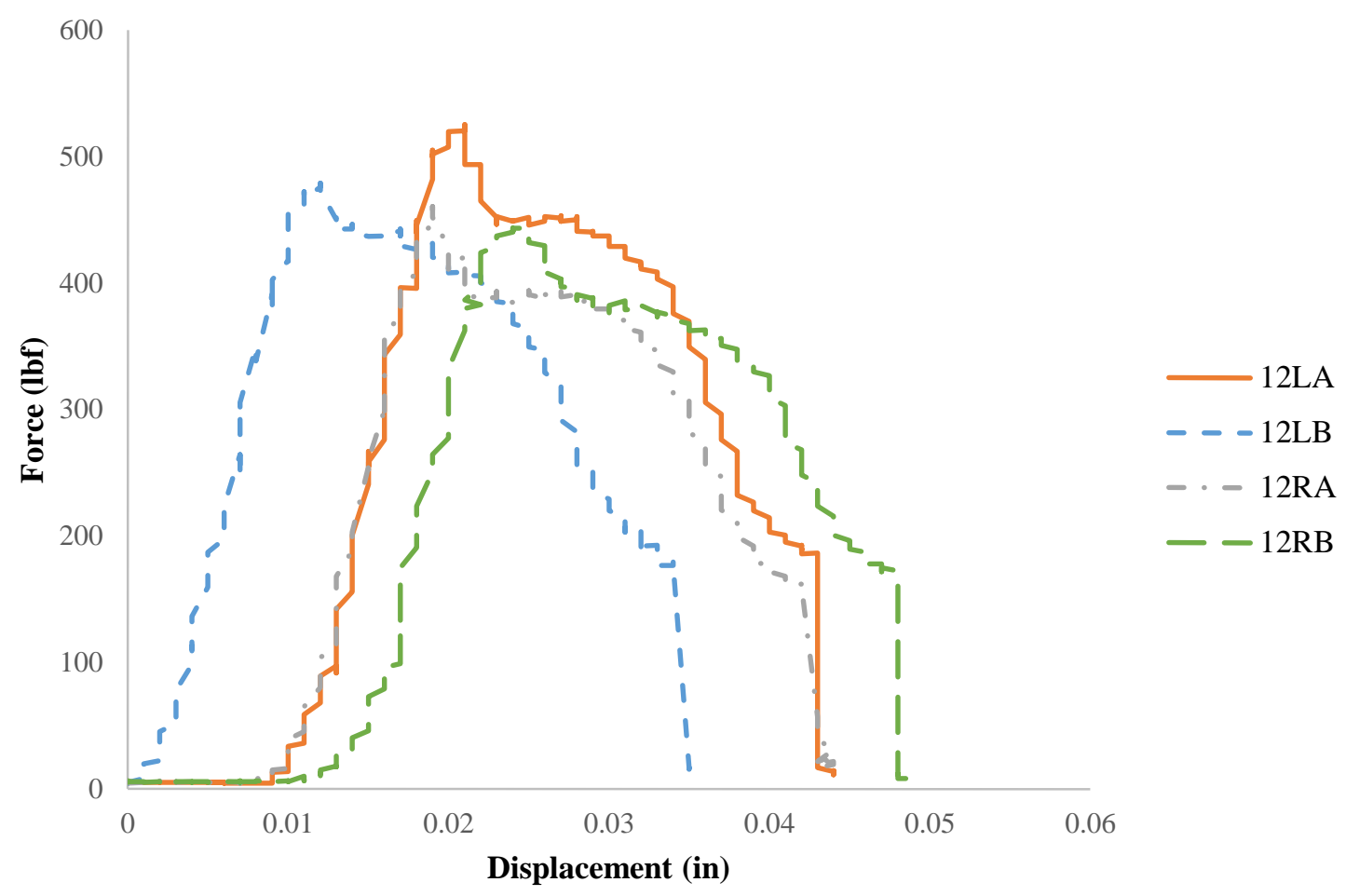

Figure E.15. Short-beam shear data for M46J/TC250: $300^{\circ} \mathrm{F}, 30$ min, 12-ply.

\begin{tabular}{|c|c|c|c|c|}
\hline Property & 12LA & 12LB & 12RA & 12RB \\
\hline Short-Beam Strength (psi) & $8.85 \mathrm{E}+03$ & $8.42 \mathrm{E}+03$ & $9.06 \mathrm{E}+03$ & $8.79 \mathrm{E}+03$ \\
\hline Maximum Load (lbf) & 525 & 479 & 460 & 443 \\
\hline Width (in) & 0.500 & 0.490 & 0.438 & 0.425 \\
\hline Depth (in) & 0.089 & 0.087 & 0.087 & 0.089 \\
\hline
\end{tabular}




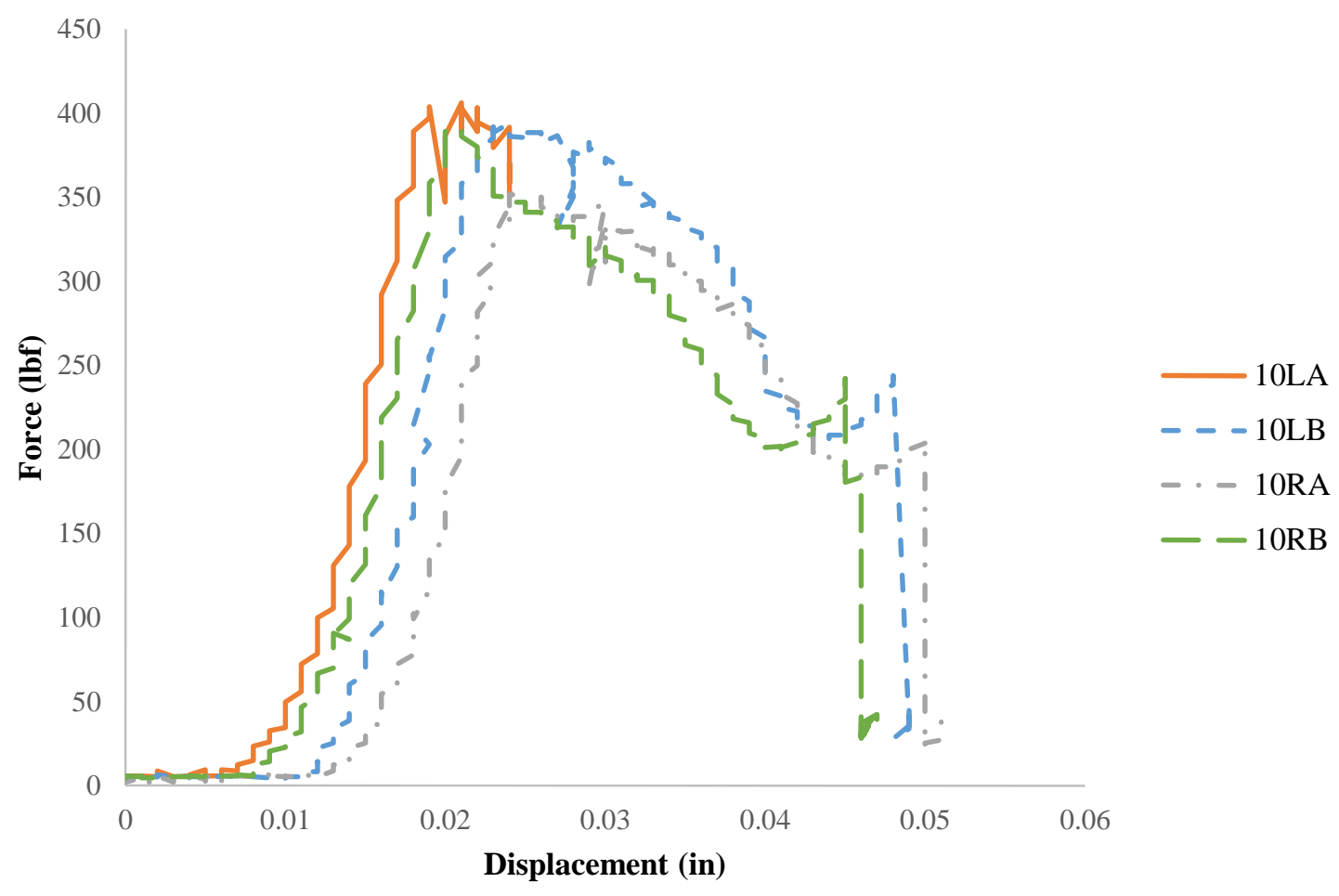

Figure E.16. Short-beam shear data for M46J/TC250: $265^{\circ} \mathrm{F}, 60$ min, 10-ply.

\begin{tabular}{|c|c|c|c|c|}
\hline Property & 10LA & 10LB & 10RA & 10RB \\
\hline Short-Beam Strength (psi) & $7.52 \mathrm{E}+03$ & $7.62 \mathrm{E}+03$ & $7.51 \mathrm{E}+03$ & $7.91 \mathrm{E}+03$ \\
\hline Maximum Load (lbf) & 406 & 398 & 352 & 392 \\
\hline Width (in) & 0.488 & 0.489 & 0.439 & 0.447 \\
\hline Depth (in) & 0.083 & 0.08 & 0.08 & 0.083 \\
\hline
\end{tabular}




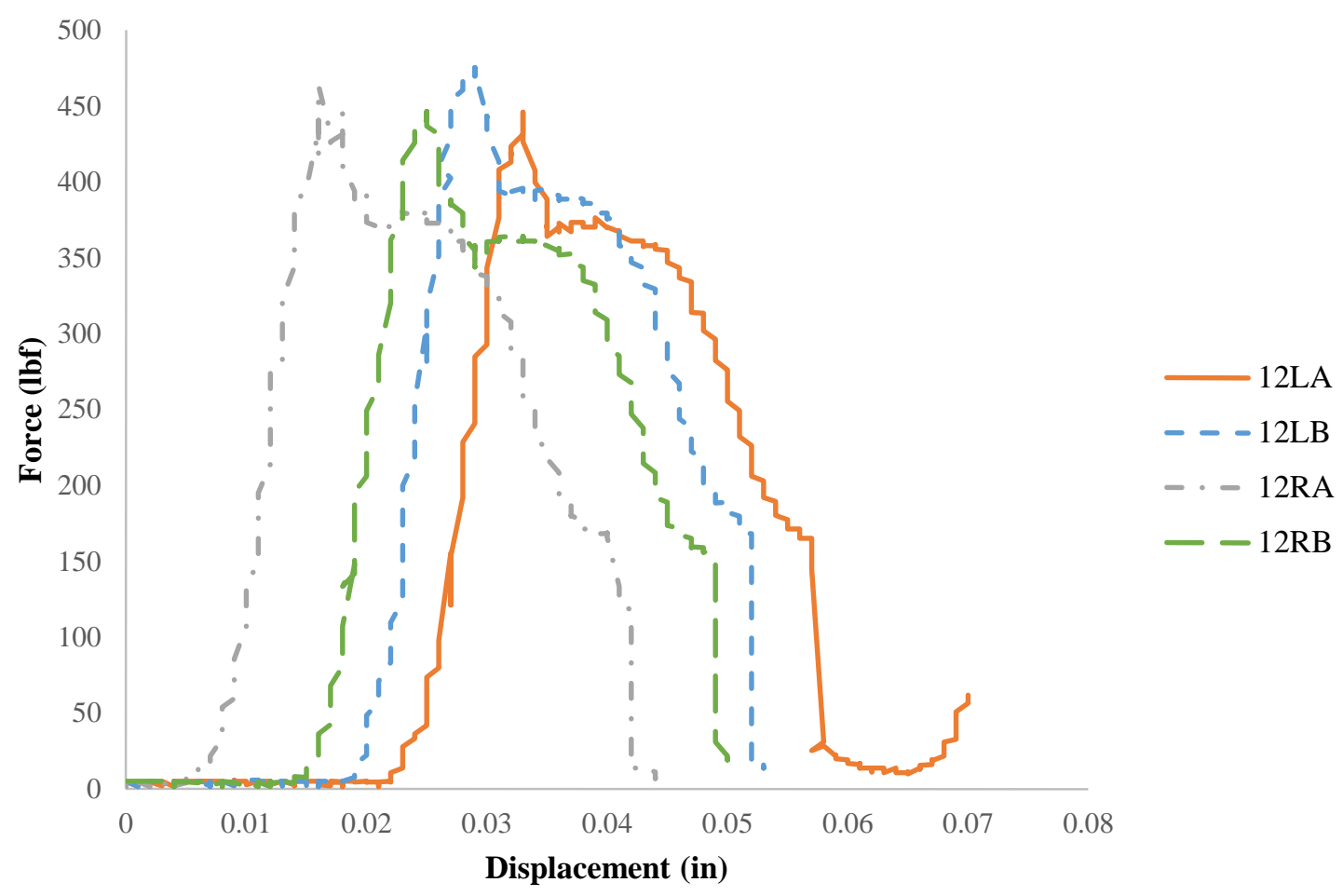

Figure E.17. Short-beam shear data for M46J/TC250: $265^{\circ} \mathrm{F}, 60$ min, 12-ply.

\begin{tabular}{|c|c|c|c|c|}
\hline Property & 12LA & 12LB & 12RA & 12RB \\
\hline Short-Beam Strength (psi) & $8.64 \mathrm{E}+03$ & $8.70 \mathrm{E}+03$ & $8.94 \mathrm{E}+03$ & $8.73 \mathrm{E}+03$ \\
\hline Maximum Load (lbf) & 446 & 475 & 464 & 446 \\
\hline Width (in) & 0.461 & 0.471 & 0.447 & 0.451 \\
\hline Depth (in) & 0.084 & 0.087 & 0.087 & 0.085 \\
\hline
\end{tabular}




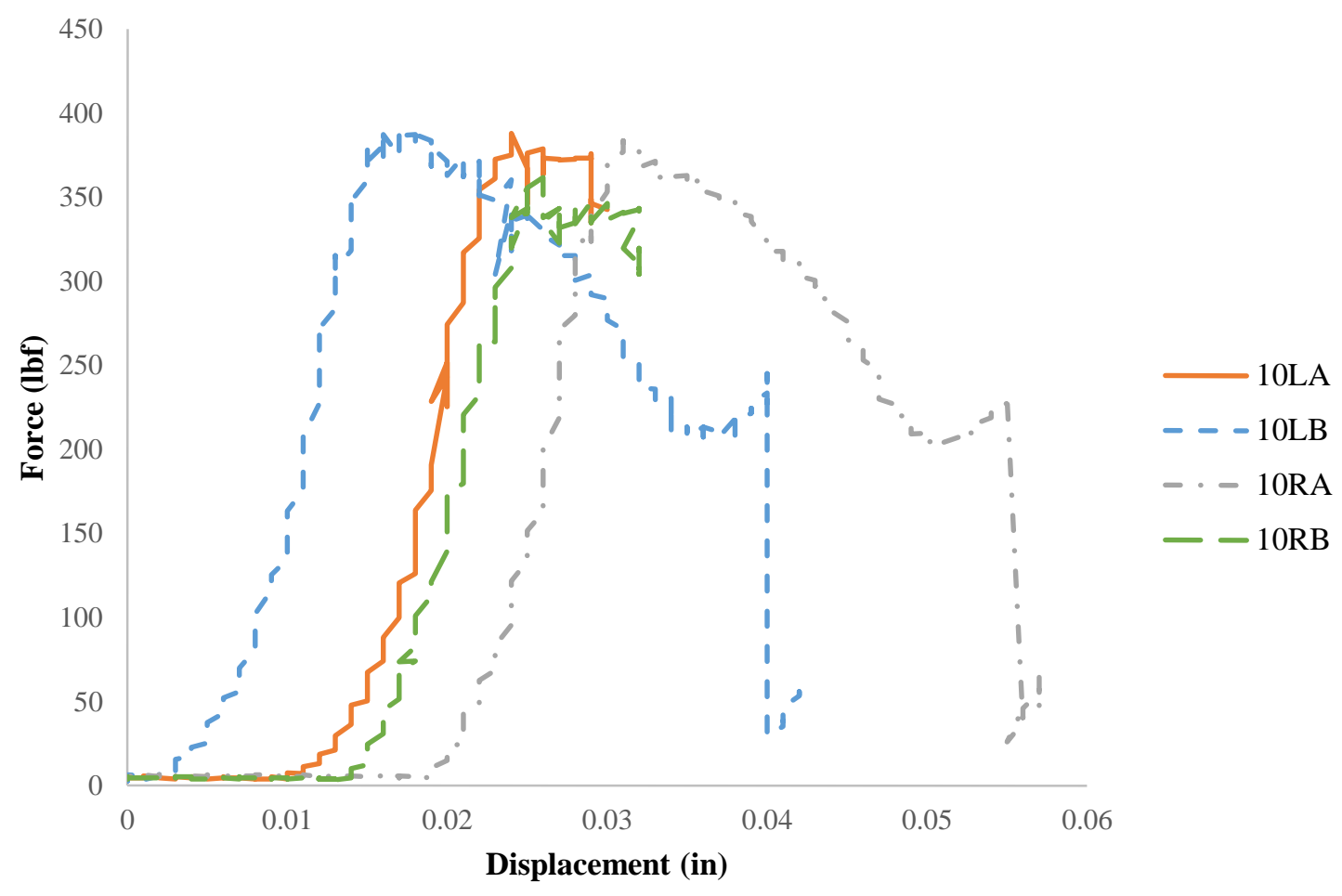

Figure E.18. Short-beam shear data for M46J/TC250: $285^{\circ} \mathrm{F}, 35$ min, 10-ply.

\begin{tabular}{|c|c|c|c|c|}
\hline Property & 10LA & 10LB & 10RA & 10RB \\
\hline Short-Beam Strength (psi) & $7.72 \mathrm{E}+03$ & $7.50 \mathrm{E}+03$ & $7.95 \mathrm{E}+03$ & $7.79 \mathrm{E}+03$ \\
\hline Maximum Load (lbf) & 388 & 390 & 384 & 362 \\
\hline Width (in) & 0.471 & 0.470 & 0.436 & 0.435 \\
\hline Depth (in) & 0.080 & 0.083 & 0.083 & 0.080 \\
\hline
\end{tabular}




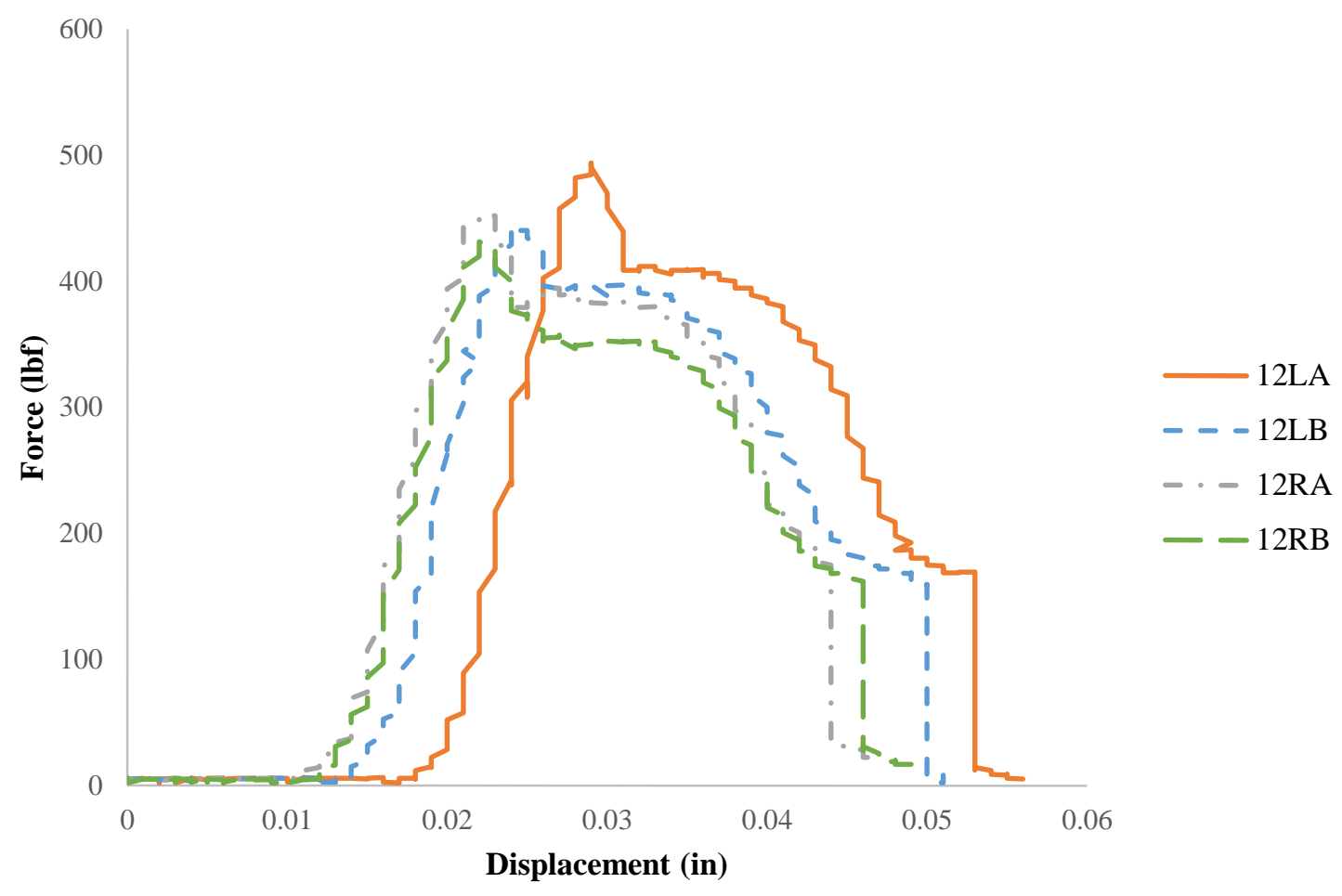

Figure E.19. Short-beam shear data for M46J/TC250: $285^{\circ} \mathrm{F}, 35$ min, 12-ply.

\begin{tabular}{|c|c|c|c|c|}
\hline Property & 12LA & 12LB & 12RA & 12RB \\
\hline Short-Beam Strength (psi) & $8.97 \mathrm{E}+03$ & $8.15 \mathrm{E}+03$ & $8.67 \mathrm{E}+03$ & $8.51 \mathrm{E}+03$ \\
\hline Maximum Load (lbf) & 493 & 440 & 453 & 431 \\
\hline Width (in) & 0.474 & 0.477 & 0.445 & 0.447 \\
\hline Depth (in) & 0.087 & 0.085 & 0.088 & 0.085 \\
\hline
\end{tabular}




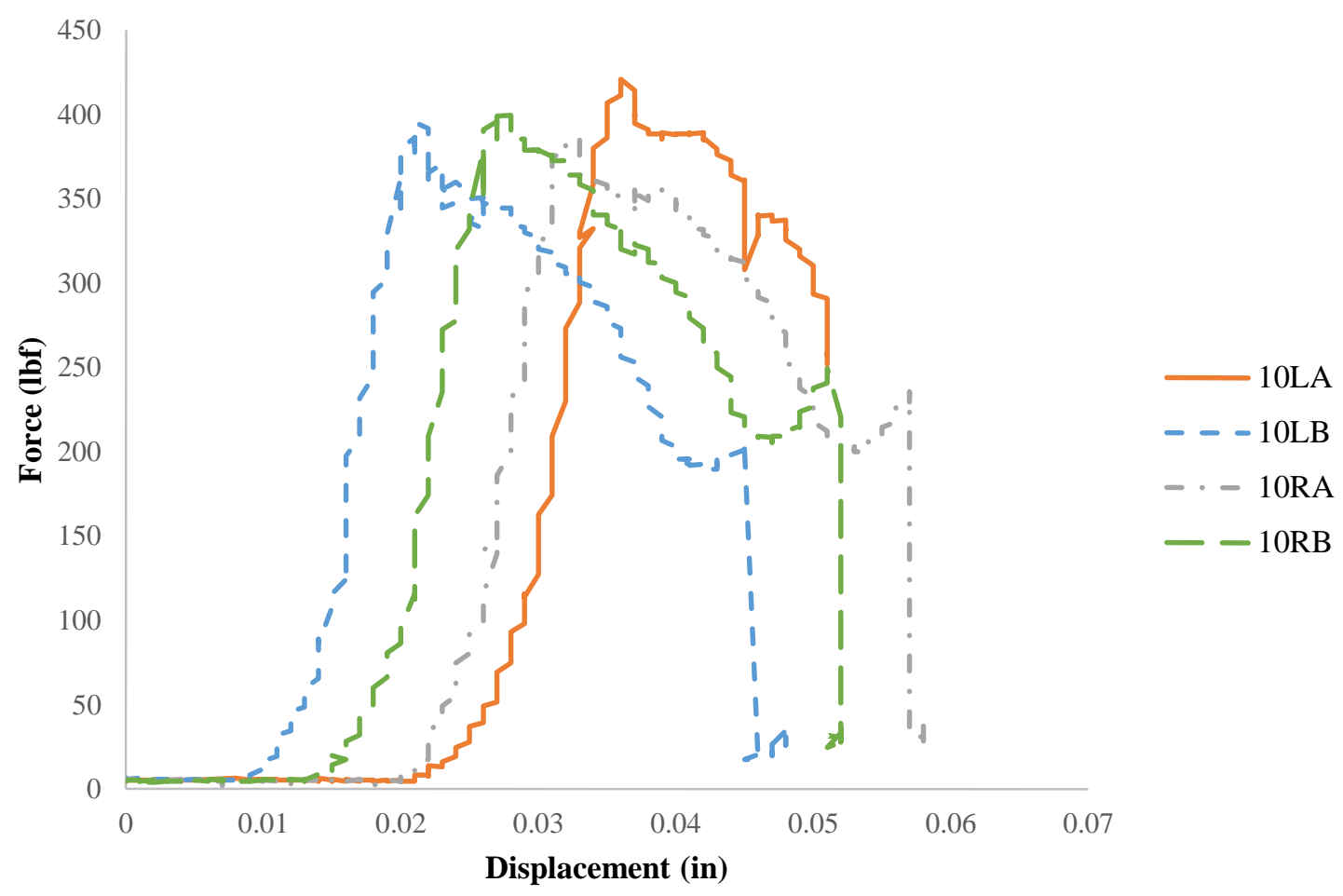

Figure E.20. Short-beam shear data for M46J/TC250: $300^{\circ} \mathrm{F}, 15$ min, 10-ply.

\begin{tabular}{|c|c|c|c|c|}
\hline Property & 10LA & 10LB & 10RA & 10RB \\
\hline Short-Beam Strength (psi) & $8.06 \mathrm{E}+03$ & $7.95 \mathrm{E}+03$ & $7.86 \mathrm{E}+03$ & $7.80 \mathrm{E}+03$ \\
\hline Maximum Load (lbf) & 421 & 395 & 385 & 399 \\
\hline Width (in) & 0.472 & 0.466 & 0.459 & 0.457 \\
\hline Depth (in) & 0.083 & 0.080 & 0.080 & 0.084 \\
\hline
\end{tabular}




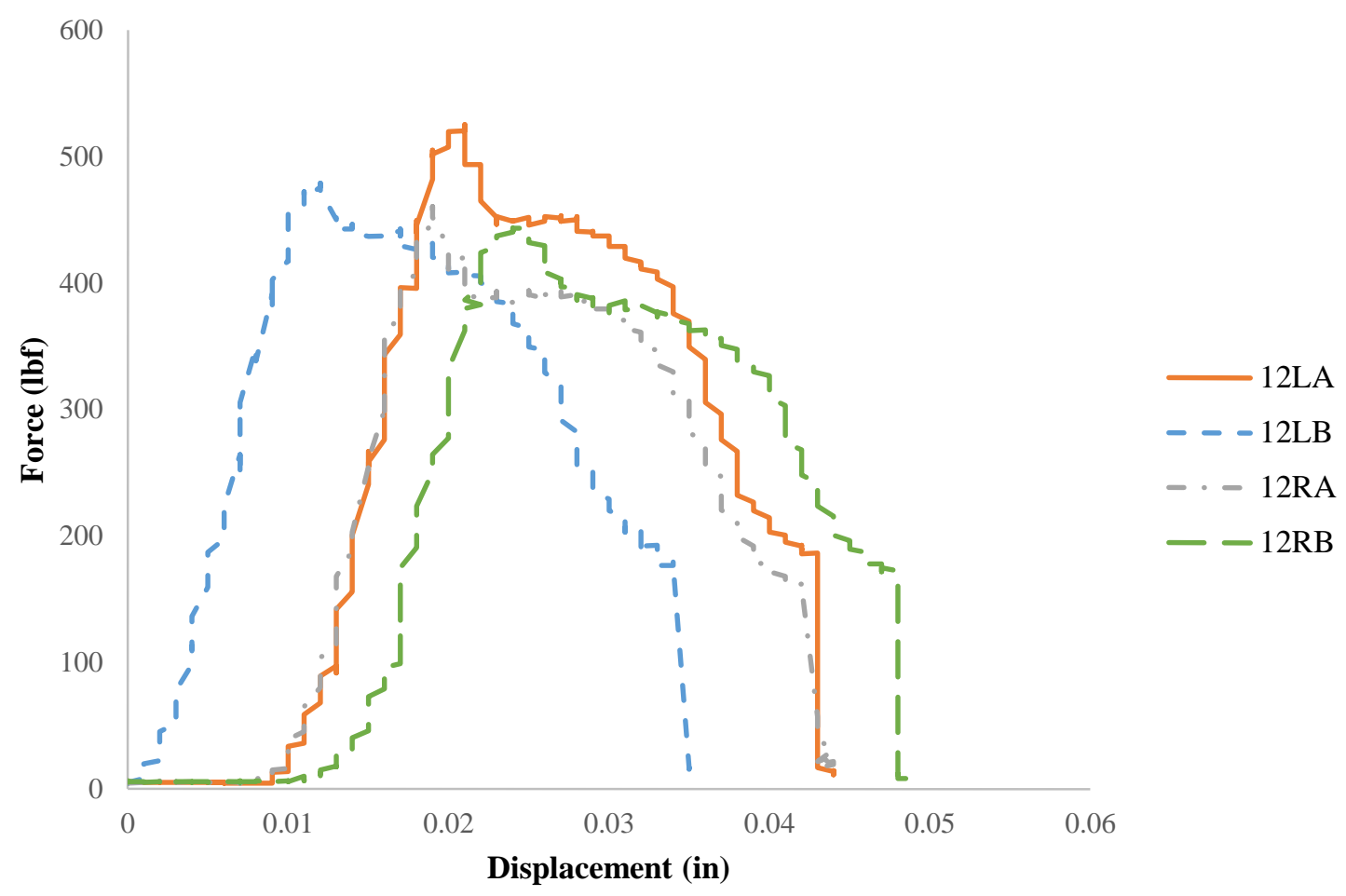

Figure E.21. Short-beam shear data for M46J/TC250: $300^{\circ} \mathrm{F}, 15$ min, 12-ply.

\begin{tabular}{|c|c|c|c|c|}
\hline Property & 12LA & 12LB & 12RA & 12RB \\
\hline Short-Beam Strength (psi) & $8.31 \mathrm{E}+03$ & $8.06 \mathrm{E}+03$ & $8.70 \mathrm{E}+03$ & $8.37 \mathrm{E}+03$ \\
\hline Maximum Load (lbf) & 446 & 411 & 460 & 438 \\
\hline Width (in) & 0.457 & 0.450 & 0.451 & 0.456 \\
\hline Depth (in) & 0.088 & 0.085 & 0.088 & 0.086 \\
\hline
\end{tabular}




\section{E.3. M46J/TC250 Autoclave Specimens}

Table E.3. Consistency measurements for M46J/TC250 autoclave specimens.

\begin{tabular}{|c|c|c|c|c|}
\hline Dimension & $\mathbf{1 0 L}$ & $\mathbf{1 2 L}$ & $\mathbf{1 2 R}$ & 10R \\
\hline T1 & 0.085 & 0.108 & 0.103 & 0.086 \\
\hline T2 & 0.090 & 0.108 & 0.095 & 0.086 \\
\hline T3 & 0.082 & 0.102 & 0.099 & 0.084 \\
\hline B1 & 0.083 & 0.105 & 0.103 & 0.087 \\
\hline B2 & 0.085 & 0.104 & 0.100 & 0.086 \\
\hline B3 & 0.081 & 0.102 & 0.100 & 0.086 \\
\hline
\end{tabular}




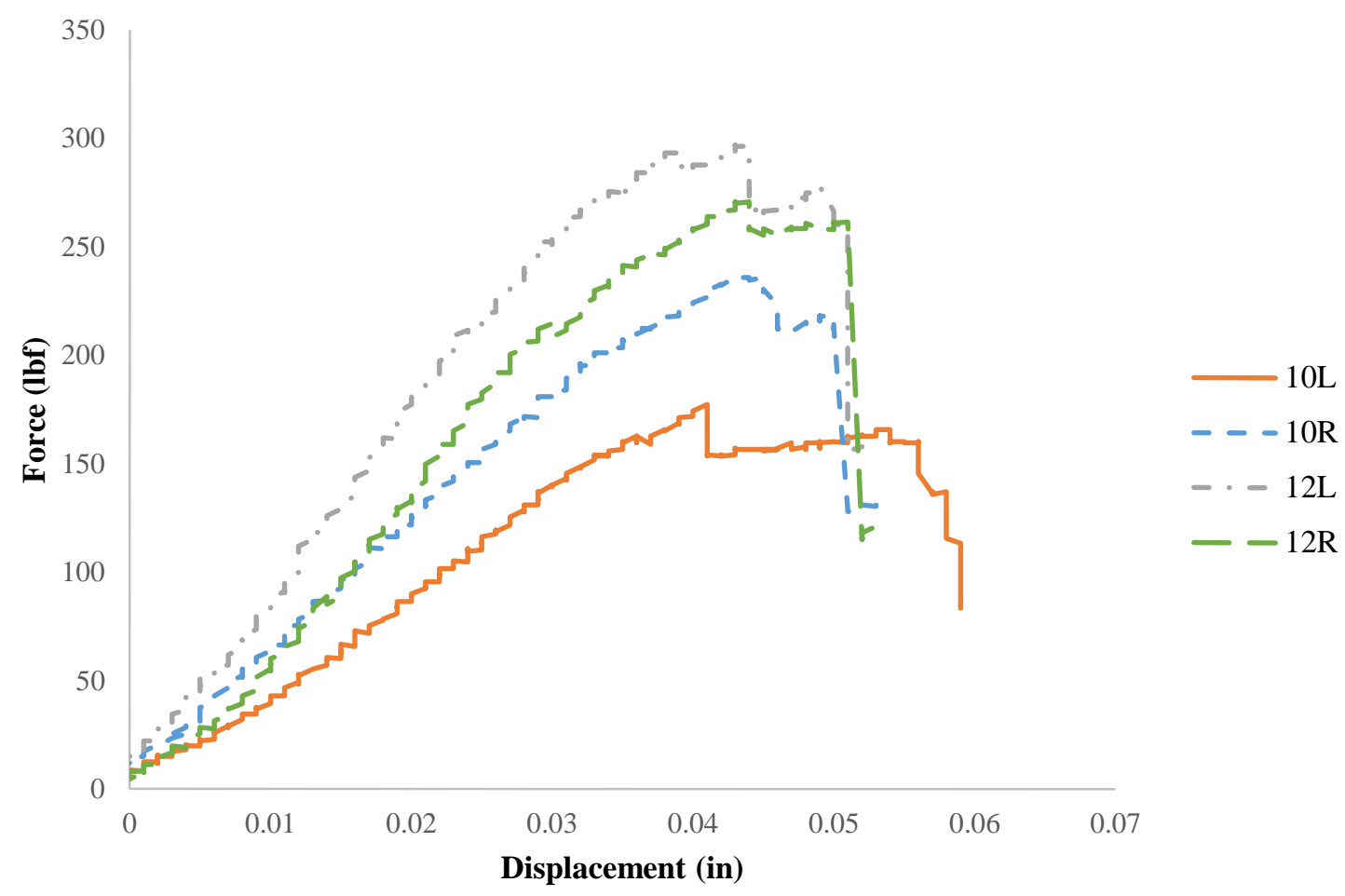

Figure E.22. 3-point bend data for M46J/TC250: autoclave, left side.

\begin{tabular}{|c|c|c|c|c|}
\hline Property & $\mathbf{1 0 L}$ & $\mathbf{1 0 R}$ & $\mathbf{1 2 L}$ & 12R \\
\hline Maximum Force (lbf) & 177 & 236 & 293 & 271 \\
\hline Max. Displacement (in) & 0.041 & 0.045 & 0.039 & 0.044 \\
\hline Width (in) & 0.465 & 0.5 & 0.496 & 0.466 \\
\hline Depth (in) & 0.088 & 0.092 & 0.105 & 0.104 \\
\hline Span (in) & 1.678 & 1.678 & 1.678 & 1.678 \\
\hline Slope (lbf/in) & 4489.4 & 5404.3 & 8168.9 & 7558.6 \\
\hline Flexural Strength (psi) & $1.24 \mathrm{E}+05$ & $1.40 \mathrm{E}+05$ & $1.35 \mathrm{E}+05$ & $1.35 \mathrm{E}+05$ \\
\hline Flexural Strain (psi) & 0.00769 & 0.00882 & 0.00873 & 0.00975 \\
\hline Tangent Modulus (psi) & $1.67 \mathrm{E}+07$ & $1.64 \mathrm{E}+07$ & $1.68 \mathrm{E}+07$ & $1.70 \mathrm{E}+07$ \\
\hline
\end{tabular}




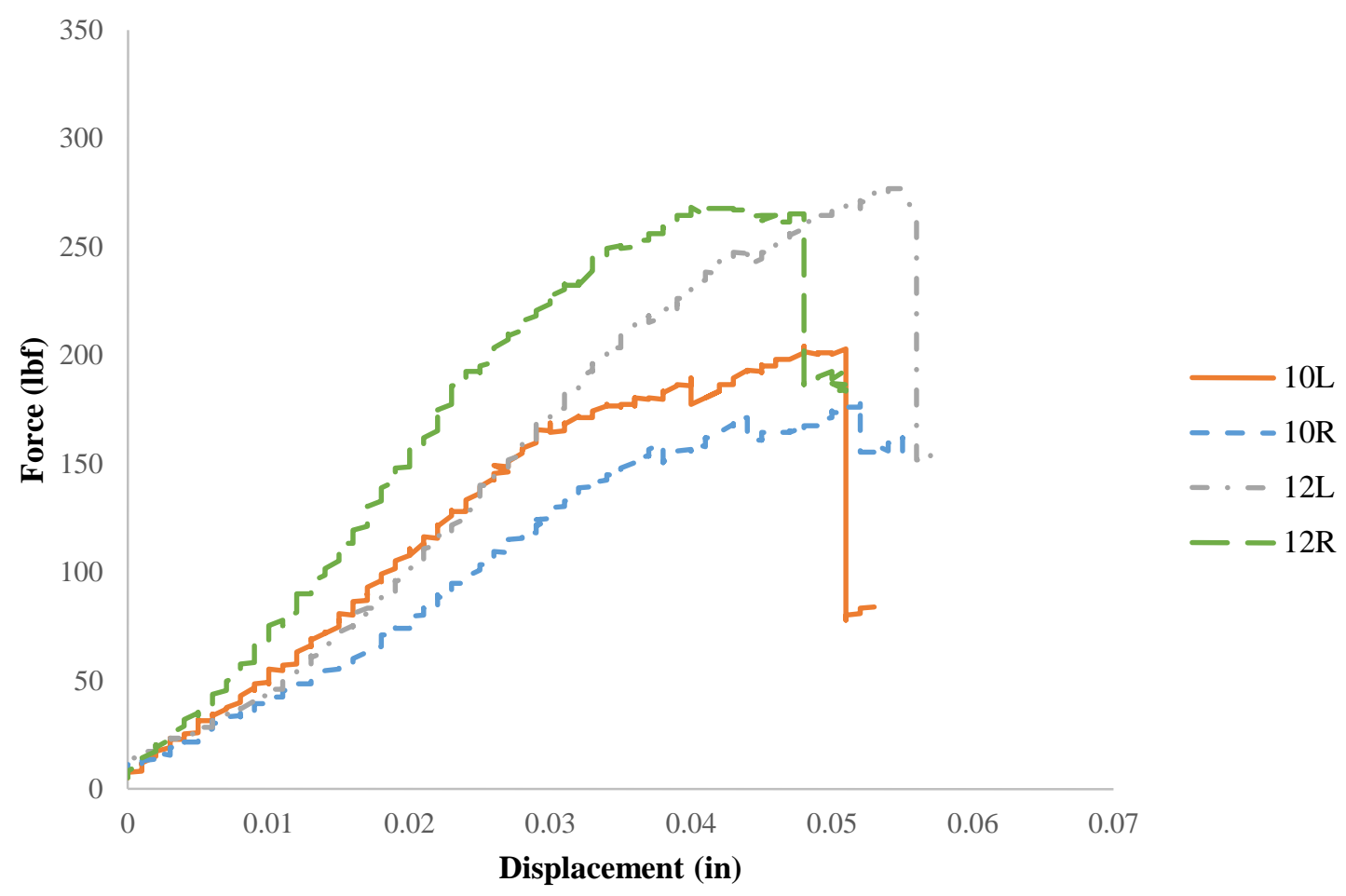

Figure E.23. 3-point bend data for M46J/TC250: autoclave, right side.

\begin{tabular}{|c|c|c|c|c|}
\hline Property & 10L & 10R & 12L & 12R \\
\hline Maximum Force (lbf) & 189 & 160 & 277 & 268 \\
\hline Max. Displacement (in) & 0.040 & 0.038 & 0.055 & 0.040 \\
\hline Width (in) & 0.48 & 0.495 & 0.485 & 0.489 \\
\hline Depth (in) & 0.092 & 0.086 & 0.1 & 0.105 \\
\hline Span (in) & 1.678 & 1.678 & 1.678 & 1.678 \\
\hline Slope (lbf/in) & 5264.7 & 4074.2 & 5841.3 & 7577.3 \\
\hline Flexural Strength (psi) & $1.17 \mathrm{E}+05$ & $1.10 \mathrm{E}+05$ & $1.44 \mathrm{E}+05$ & $1.25 \mathrm{E}+05$ \\
\hline Flexural Strain (psi) & 0.00784 & 0.00696 & 0.01172 & 0.00895 \\
\hline Tangent Modulus (psi) & $1.66 \mathrm{E}+07$ & $1.53 \mathrm{E}+07$ & $1.42 \mathrm{E}+07$ & $1.58 \mathrm{E}+07$ \\
\hline
\end{tabular}




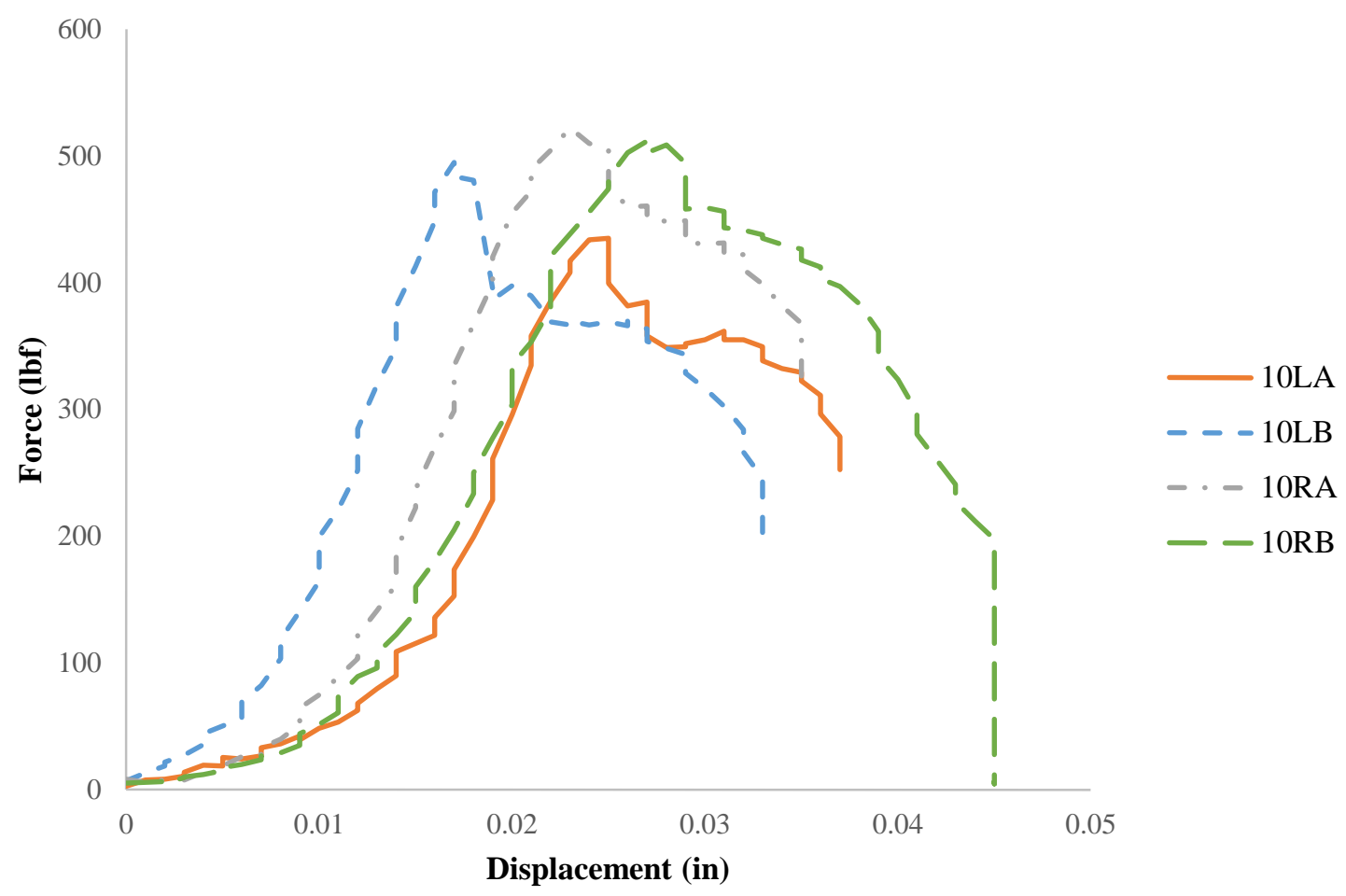

Figure E.24. Short-beam shear data for M46J/TC250: autoclave, left side, 10-ply.

\begin{tabular}{|c|c|c|c|c|}
\hline Property & 10LA & 10LB & 10RA & 10RB \\
\hline Short-Beam Strength (psi) & $8.83 \mathrm{E}+03$ & $9.77 \mathrm{E}+03$ & $8.86 \mathrm{E}+03$ & $9.85 \mathrm{E}+03$ \\
\hline Maximum Load (lbf) & 435 & 495 & 522 & 512 \\
\hline Width (in) & 0.445 & 0.469 & 0.520 & 0.475 \\
\hline Depth (in) & 0.083 & 0.081 & 0.085 & 0.082 \\
\hline
\end{tabular}




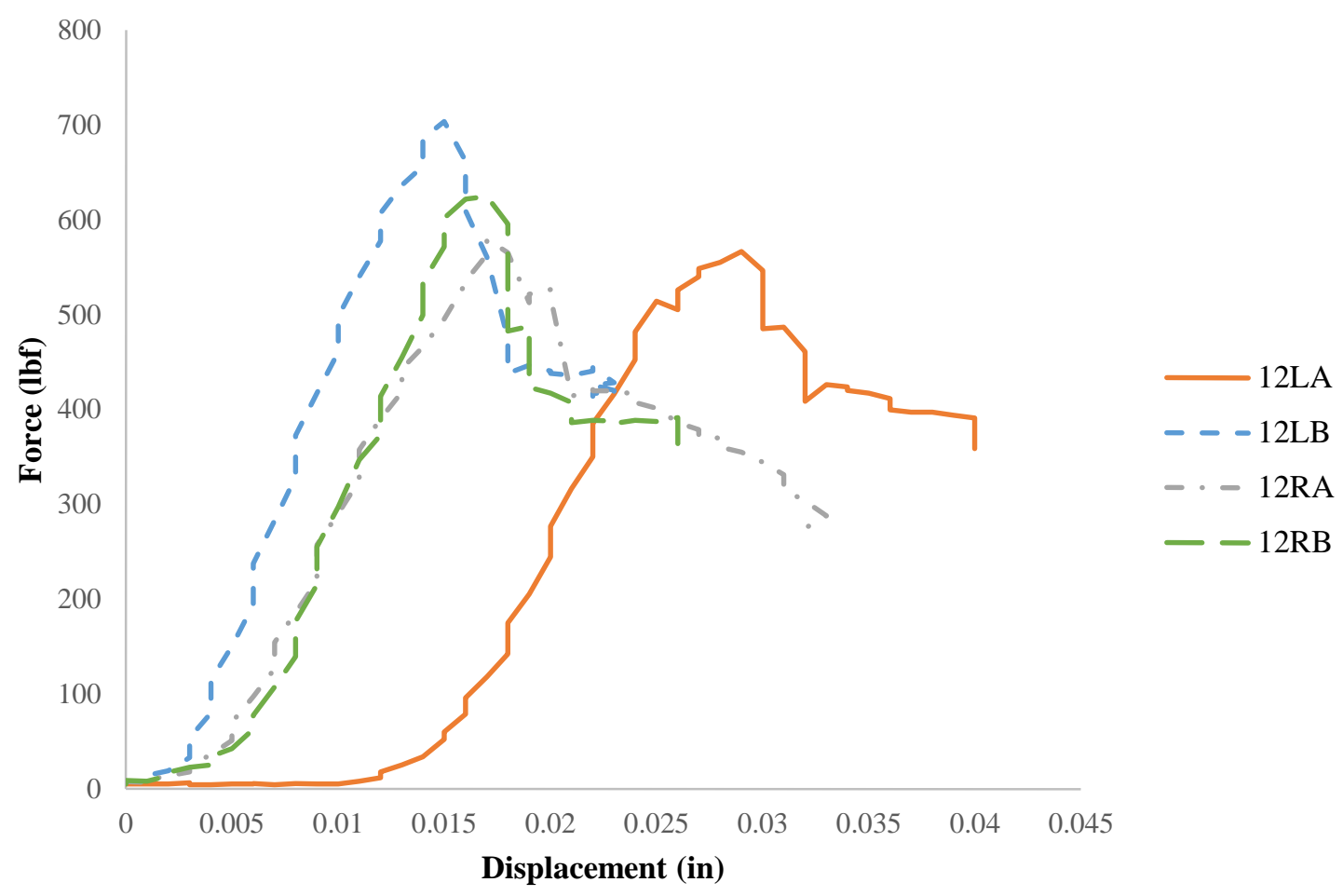

Figure E.25. Short-beam shear data for M46J/TC250: autoclave, left side, 12-ply.

\begin{tabular}{|c|c|c|c|c|}
\hline Property & 12LA & 12LB & 12RA & 12RB \\
\hline Short-Beam Strength (psi) & $8.70 \mathrm{E}+03$ & $1.00 \mathrm{E}+04$ & $8.67 \mathrm{E}+03$ & $9.59 \mathrm{E}+03$ \\
\hline Maximum Load (lbf) & 567 & 703 & 580 & 625 \\
\hline Width (in) & 0.479 & 0.500 & 0.464 & 0.479 \\
\hline Depth (in) & 0.102 & 0.105 & 0.108 & 0.102 \\
\hline
\end{tabular}




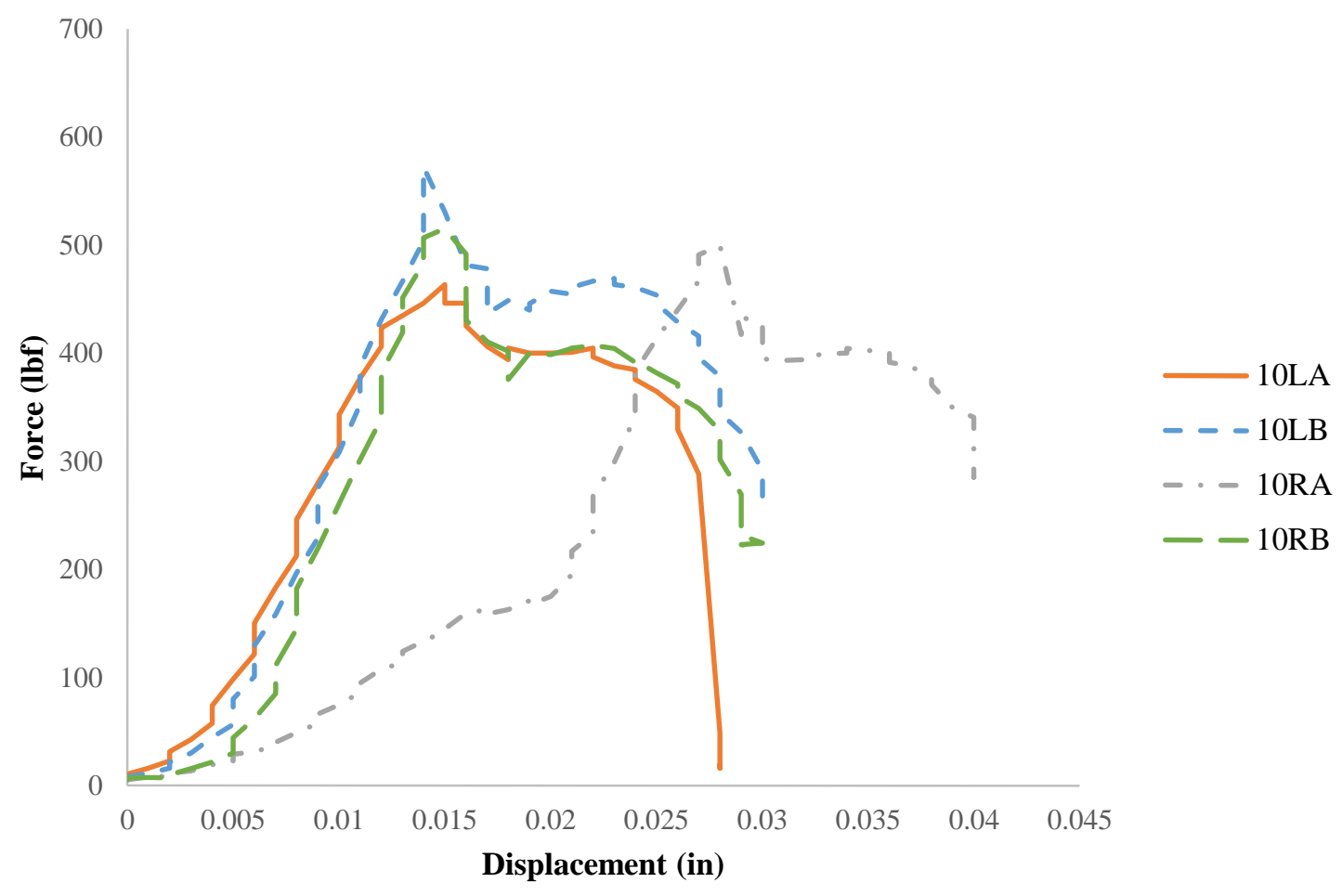

Figure E.26. Short-beam shear data for M46J/TC250: autoclave, right side, 10-ply.

\begin{tabular}{|c|c|c|c|c|}
\hline Property & 10LA & 10LB & 10RA & 10RB \\
\hline Short-Beam Strength (psi) & $8.47 \mathrm{E}+03$ & $1.09 \mathrm{E}+04$ & $9.07 \mathrm{E}+03$ & $9.14 \mathrm{E}+03$ \\
\hline Maximum Load (lbf) & 464 & 572 & 500 & 515 \\
\hline Width (in) & 0.477 & 0.451 & 0.492 & 0.492 \\
\hline Depth (in) & 0.086 & 0.087 & 0.084 & 0.086 \\
\hline
\end{tabular}




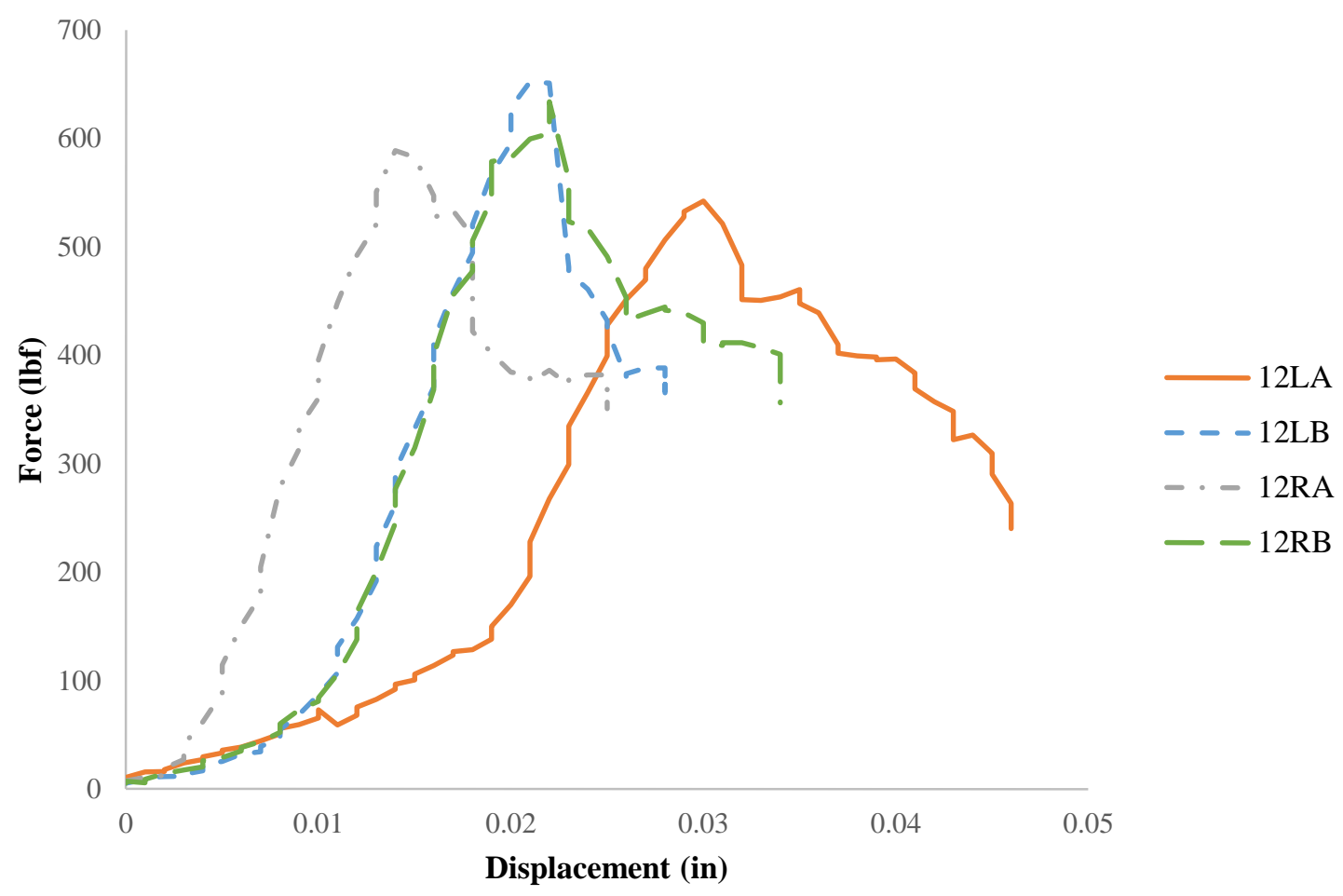

Figure E.27. Short-beam shear data for M46J/TC250: autoclave, right side, 12-ply.

\begin{tabular}{|c|c|c|c|c|}
\hline Property & 12LA & 12LB & 12RA & 12RB \\
\hline Short-Beam Strength (psi) & $8.33 \mathrm{E}+03$ & $9.83 \mathrm{E}+03$ & $9.18 \mathrm{E}+03$ & $9.48 \mathrm{E}+03$ \\
\hline Maximum Load (lbf) & 542 & 652 & 589 & 634 \\
\hline Width (in) & 0.488 & 0.483 & 0.486 & 0.487 \\
\hline Depth (in) & 0.100 & 0.103 & 0.099 & 0.103 \\
\hline
\end{tabular}




\section{E.4. M46J/TC250 3-Point Bend Mold Specimens}

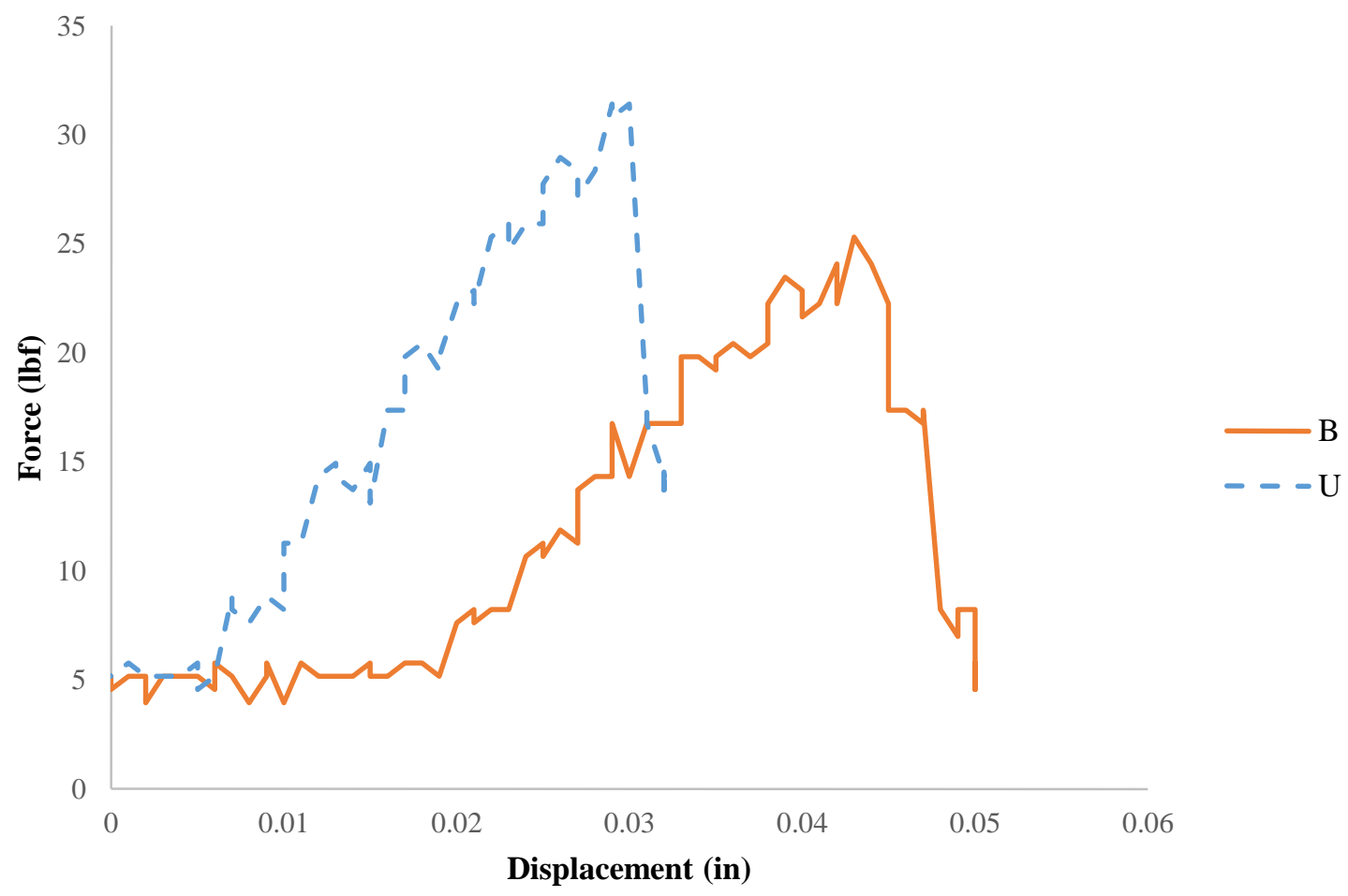

Figure E.28. 3-point bend data for chopped M46J/TC250: $200 \mathrm{lbf}$ closing force, $0 \mathrm{~min}$.

\begin{tabular}{|c|c|c|}
\hline Property & B & U \\
\hline Maximum Force (lbf) & 25.3 & 31.4 \\
\hline Max. Displacement (in) & 0.043 & 0.03 \\
\hline Width (in) & 0.5 & 0.5 \\
\hline Depth (in) & 0.1 & 0.1 \\
\hline Span (in) & 1.6 & 1.6 \\
\hline Slope (lbf/in) & 774.17 & 1089.2 \\
\hline Flexural Strength (psi) & $1.21 \mathrm{E}+04$ & $1.51 \mathrm{E}+04$ \\
\hline Flexural Strain (psi) & 0.0101 & 0.0070 \\
\hline Tangent Modulus (psi) & $1.59 \mathrm{E}+06$ & $2.23 \mathrm{E}+06$ \\
\hline
\end{tabular}




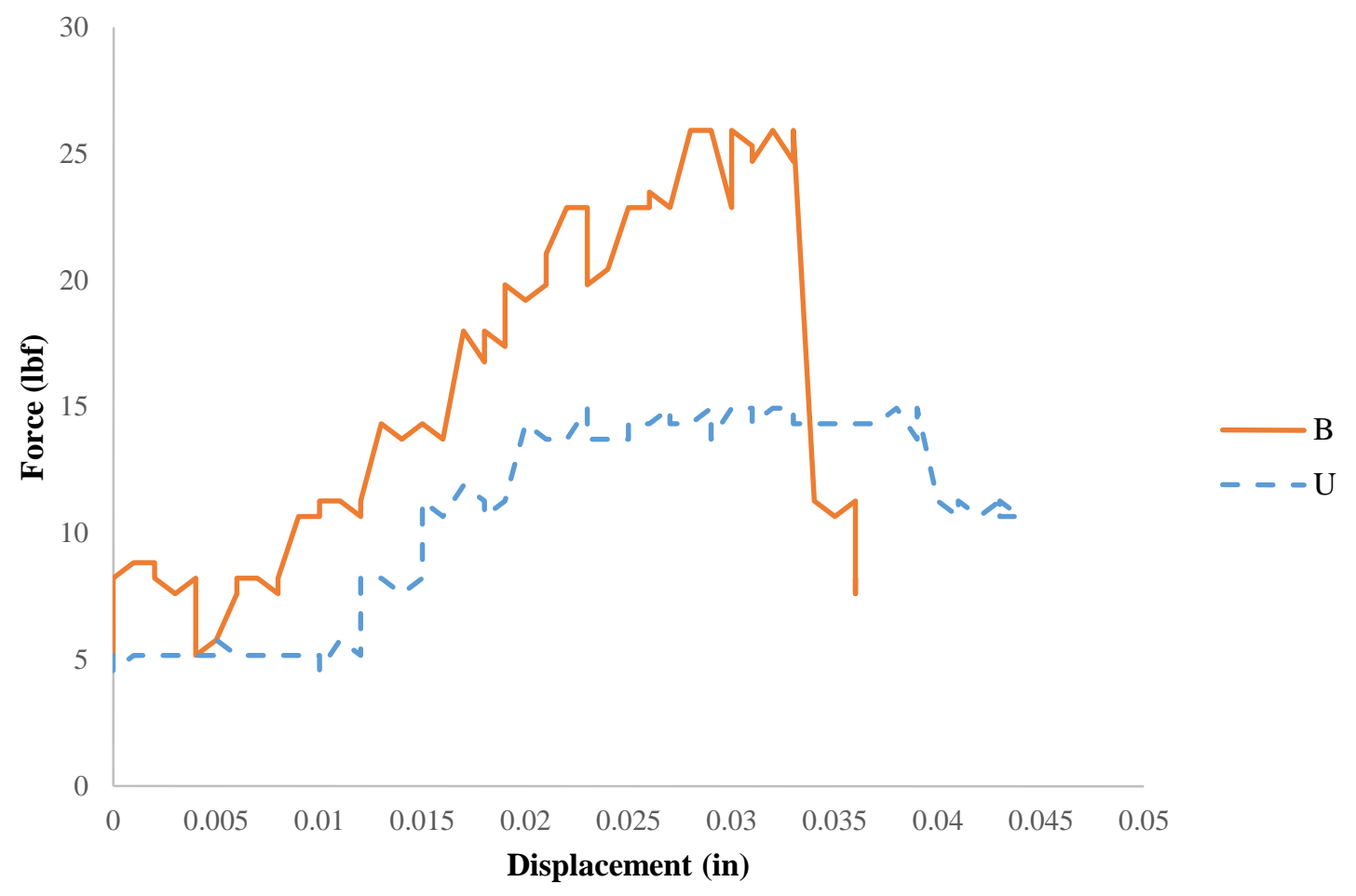

Figure E.29. 3-point bend data for chopped M46J/TC250: $200 \mathrm{lbf}$ closing force, $2 \mathrm{~min}$.

\begin{tabular}{|c|c|c|}
\hline Property & B & U \\
\hline Maximum Force (lbf) & 25.9 & 14.9 \\
\hline Max. Displacement (in) & 0.033 & 0.039 \\
\hline Width (in) & 0.5 & 0.5 \\
\hline Depth (in) & 0.1 & 0.1 \\
\hline Span (in) & 1.6 & 1.6 \\
\hline Slope (lbf/in) & 805.48 & 739.07 \\
\hline Flexural Strength (psi) & $1.24 \mathrm{E}+04$ & $7.17 \mathrm{E}+03$ \\
\hline Flexural Strain (psi) & 0.0077 & 0.0091 \\
\hline Tangent Modulus (psi) & $1.65 \mathrm{E}+06$ & $1.51 \mathrm{E}+06$ \\
\hline
\end{tabular}




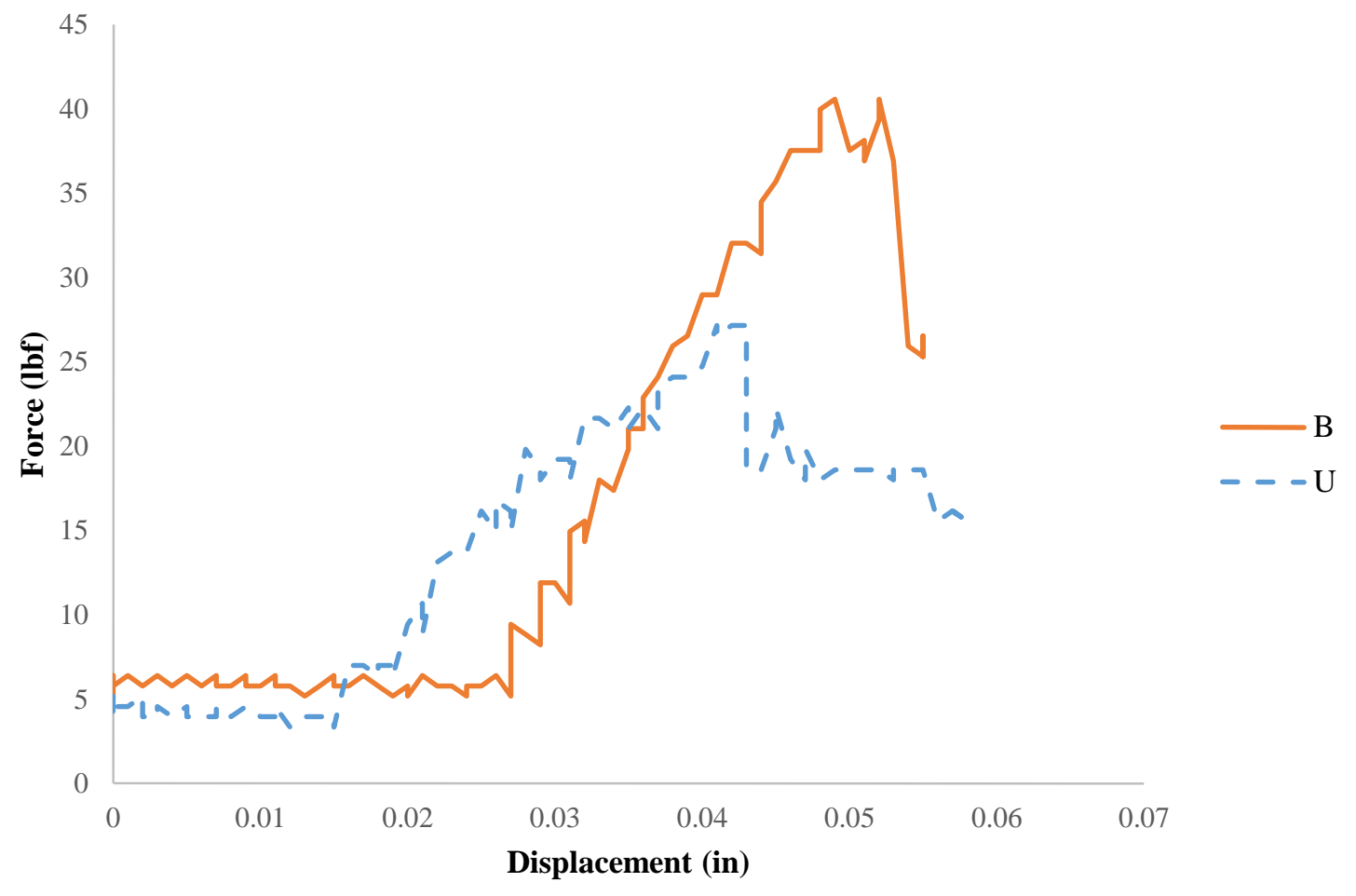

Figure E.30. 3-point bend data for chopped M46J/TC250: $200 \mathrm{lbf}$ closing force, $4 \mathrm{~min}$.

\begin{tabular}{|c|c|c|}
\hline Property & B & U \\
\hline Maximum Force (lbf) & 40.6 & 27.1 \\
\hline Max. Displacement (in) & 0.052 & 0.041 \\
\hline Width (in) & 0.5 & 0.5 \\
\hline Depth (in) & 0.1 & 0.1 \\
\hline Span (in) & 1.6 & 1.6 \\
\hline Slope (lbf/in) & 1523.1 & 781.32 \\
\hline Flexural Strength (psi) & $1.95 \mathrm{E}+04$ & $1.30 \mathrm{E}+04$ \\
\hline Flexural Strain (psi) & 0.0122 & 0.0096 \\
\hline Tangent Modulus (psi) & $3.12 \mathrm{E}+06$ & $1.60 \mathrm{E}+06$ \\
\hline
\end{tabular}




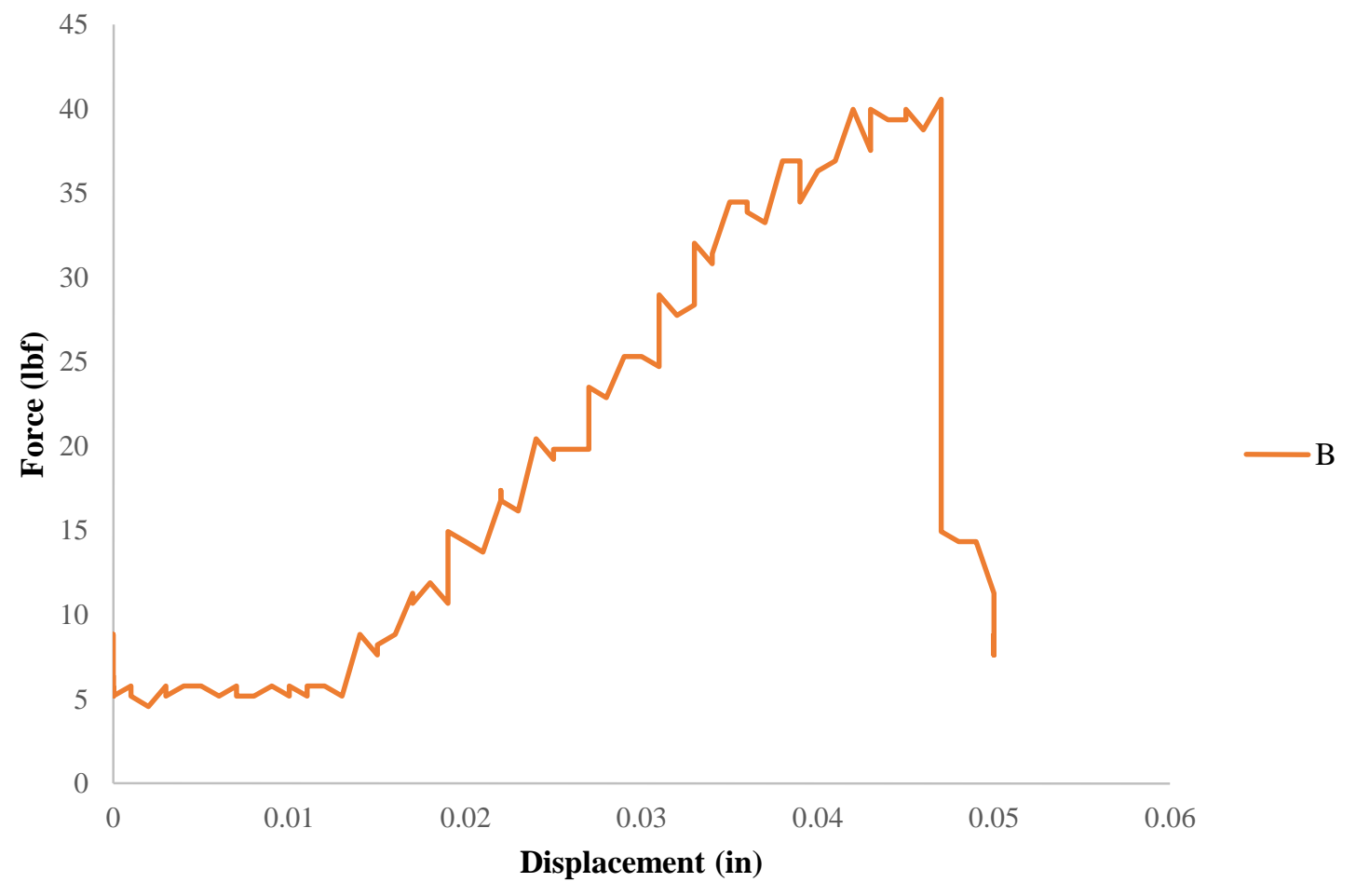

Figure E.31. 3-point bend data for chopped M46J/TC250: $4000 \mathrm{lbf}$ closing force, $0 \mathrm{~min}$.

\begin{tabular}{|c|c|}
\hline Property & B \\
\hline Maximum Force (lbf) & 40.6 \\
\hline Max. Displacement (in) & 0.047 \\
\hline Width (in) & 0.5 \\
\hline Depth (in) & 0.1 \\
\hline Span (in) & 1.6 \\
\hline Slope (lbf/in) & 1086.4 \\
\hline Flexural Strength (psi) & $1.95 \mathrm{E}+04$ \\
\hline Flexural Strain (psi) & 0.0110 \\
\hline Tangent Modulus (psi) & $2.22 \mathrm{E}+06$ \\
\hline
\end{tabular}




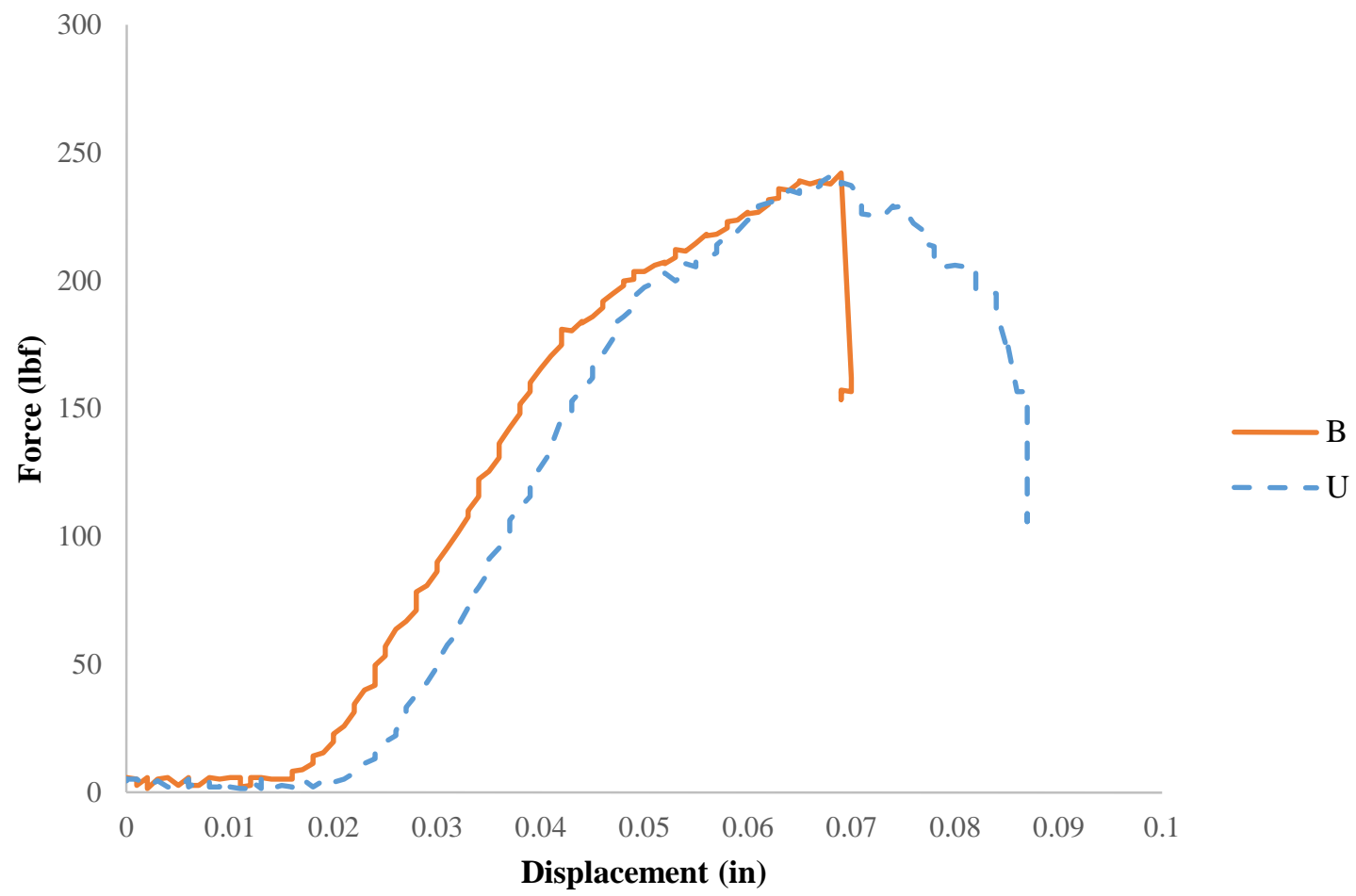

Figure E.32. 3-point bend data for continuous M46J/TC250: 10-ply.

\begin{tabular}{|c|c|c|}
\hline Property & B & U \\
\hline Maximum Force (lbf) & 242 & 241 \\
\hline Max. Displacement (in) & 0.069 & 0.068 \\
\hline Width (in) & 0.5 & 0.5 \\
\hline Depth (in) & 0.1 & 0.1 \\
\hline Span (in) & 1.6 & 1.6 \\
\hline Slope (lbf/in) & 7011.6 & 7189.3 \\
\hline Flexural Strength (psi) & $1.16 \mathrm{E}+05$ & $1.16 \mathrm{E}+05$ \\
\hline Flexural Strain (psi) & 0.0162 & 0.0159 \\
\hline Tangent Modulus (psi) & $1.44 \mathrm{E}+07$ & $1.47 \mathrm{E}+07$ \\
\hline
\end{tabular}




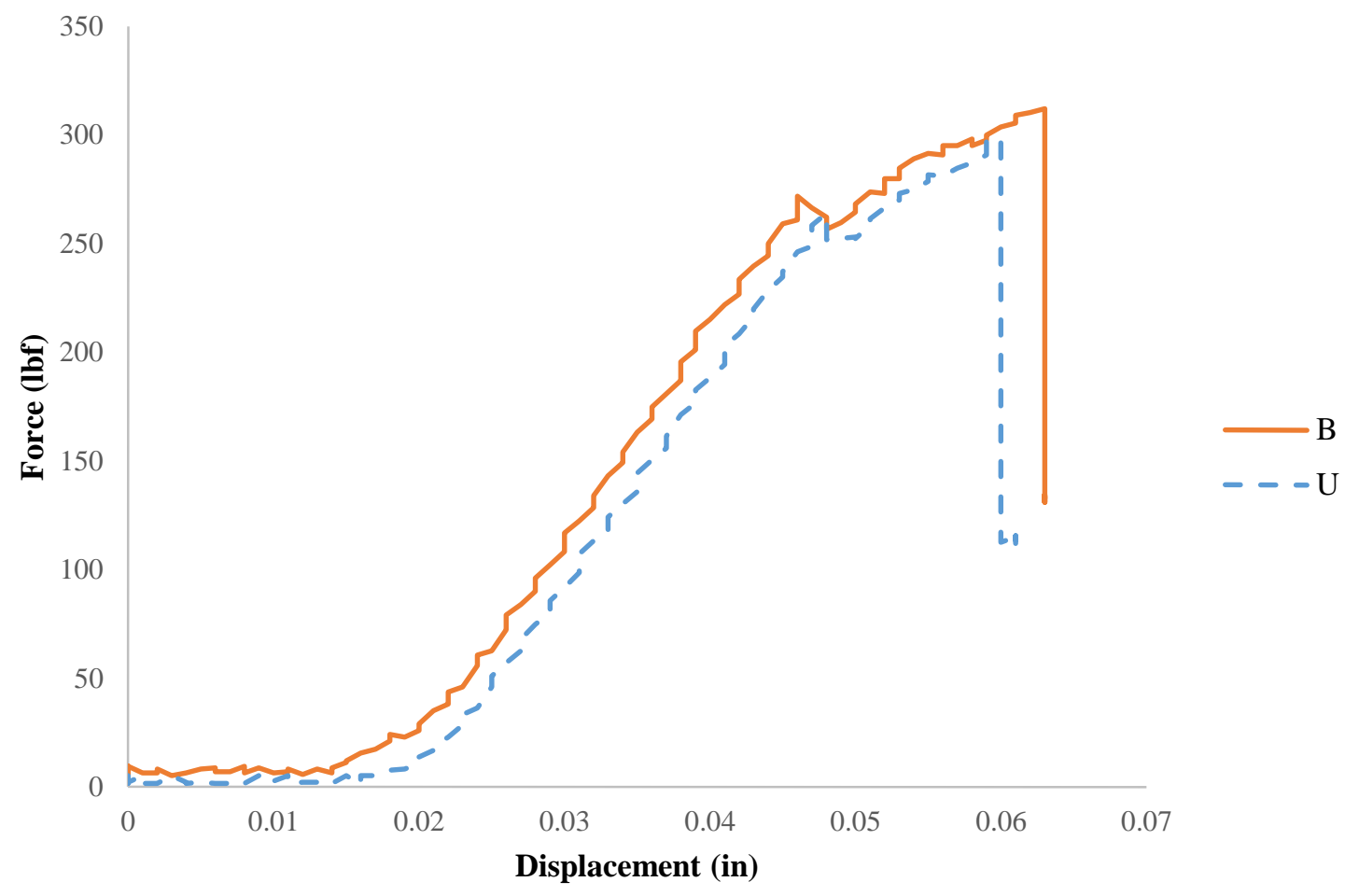

Figure E.33. 3-point bend data for continuous M46J/TC250: 12-ply.

\begin{tabular}{|c|c|c|}
\hline Property & B & U \\
\hline Maximum Force (lbf) & 312 & 299 \\
\hline Max. Displacement (in) & 0.063 & 0.06 \\
\hline Width (in) & 0.5 & 0.5 \\
\hline Depth (in) & 0.1 & 0.1 \\
\hline Span (in) & 1.6 & 1.6 \\
\hline Slope (lbf/in) & 9164.2 & 9250.1 \\
\hline Flexural Strength (psi) & $1.50 \mathrm{E}+05$ & $1.43 \mathrm{E}+05$ \\
\hline Flexural Strain (psi) & 0.0148 & 0.0141 \\
\hline Tangent Modulus (psi) & $1.88 \mathrm{E}+07$ & $1.89 \mathrm{E}+07$ \\
\hline
\end{tabular}




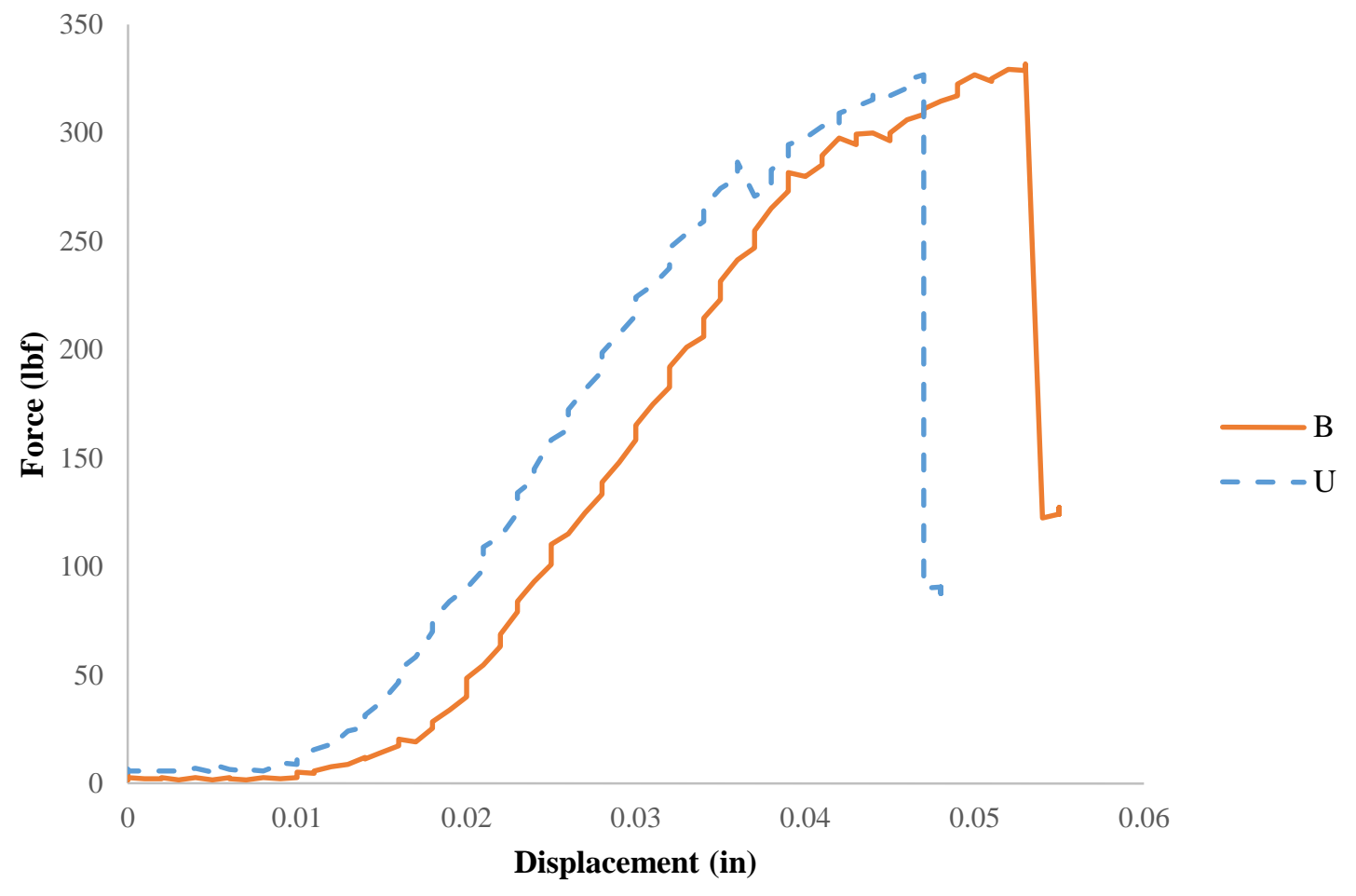

Figure E.34. 3-point bend data for continuous M46J/TC250: 14-ply.

\begin{tabular}{|c|c|c|}
\hline Property & B & U \\
\hline Maximum Force (lbf) & 332 & 327 \\
\hline Max. Displacement (in) & 0.053 & 0.047 \\
\hline Width (in) & 0.5 & 0.5 \\
\hline Depth (in) & 0.1 & 0.1 \\
\hline Span (in) & 1.6 & 1.6 \\
\hline Slope (lbf/in) & 11389 & 11874 \\
\hline Flexural Strength (psi) & $1.59 \mathrm{E}+05$ & $1.57 \mathrm{E}+05$ \\
\hline Flexural Strain (psi) & 0.0124 & 0.0110 \\
\hline Tangent Modulus (psi) & $2.33 \mathrm{E}+07$ & $2.43 \mathrm{E}+07$ \\
\hline
\end{tabular}




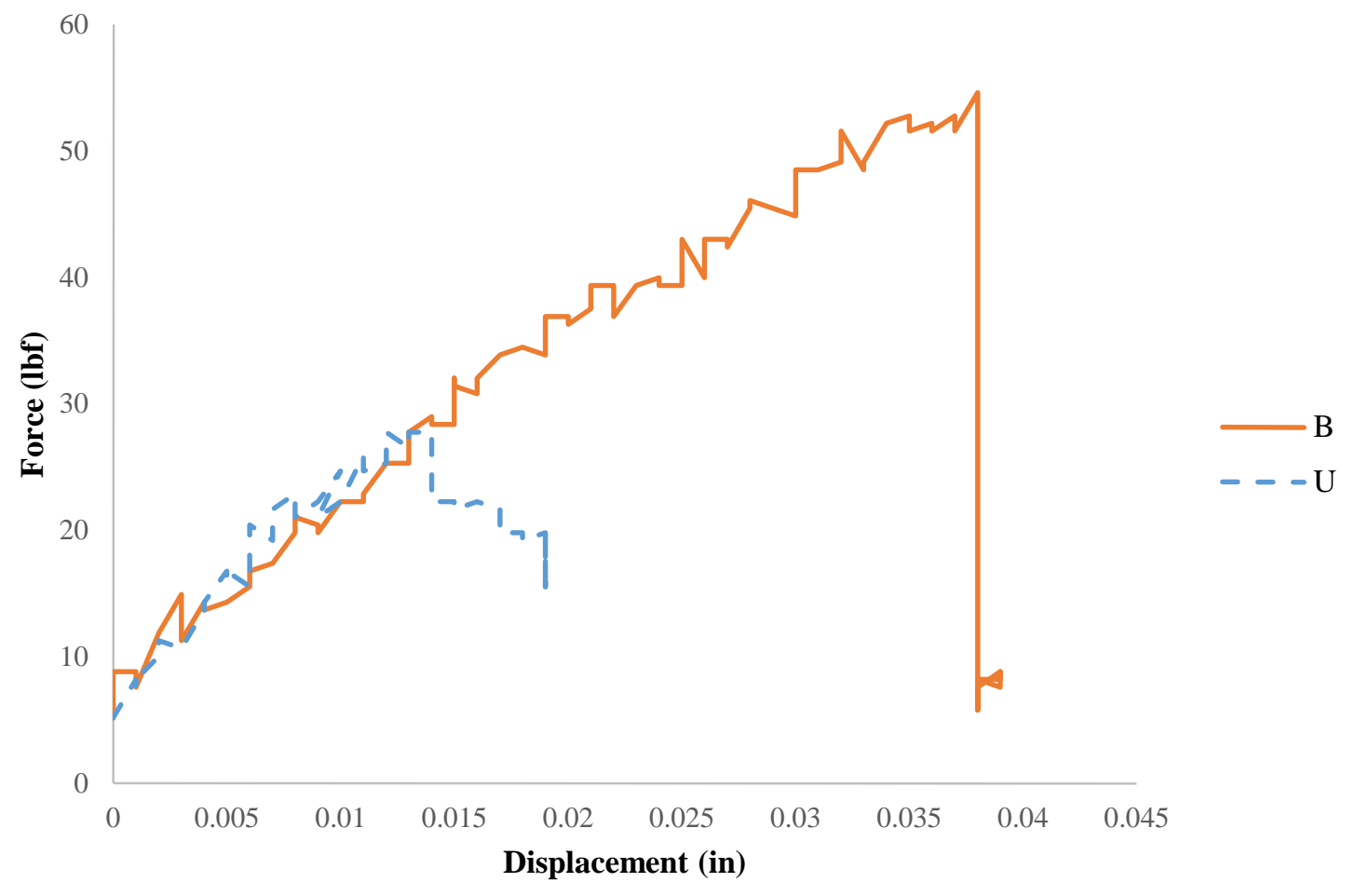

Figure E.35. 4-point bend data for chopped M46J/TC250: $200 \mathrm{lbf}$ closing force, $1 \mathrm{~min}$.

\begin{tabular}{|c|c|c|}
\hline Property & B & U \\
\hline Maximum Force (lbf) & 54.6 & 27.8 \\
\hline Max. Displacement (in) & 0.038 & 0.014 \\
\hline Width (in) & 0.5 & 0.5 \\
\hline Depth (in) & 0.1 & 0.1 \\
\hline Span (in) & 1.6 & 1.6 \\
\hline Slope (lbf/in) & 1421.4 & 1626.3 \\
\hline Flexural Strength (psi) & $1.31 \mathrm{E}+04$ & $6.66 \mathrm{E}+03$ \\
\hline Flexural Strain (psi) & 0.00647 & 0.00238 \\
\hline Tangent Modulus (psi) & $1.98 \mathrm{E}+06$ & $2.26 \mathrm{E}+06$ \\
\hline
\end{tabular}




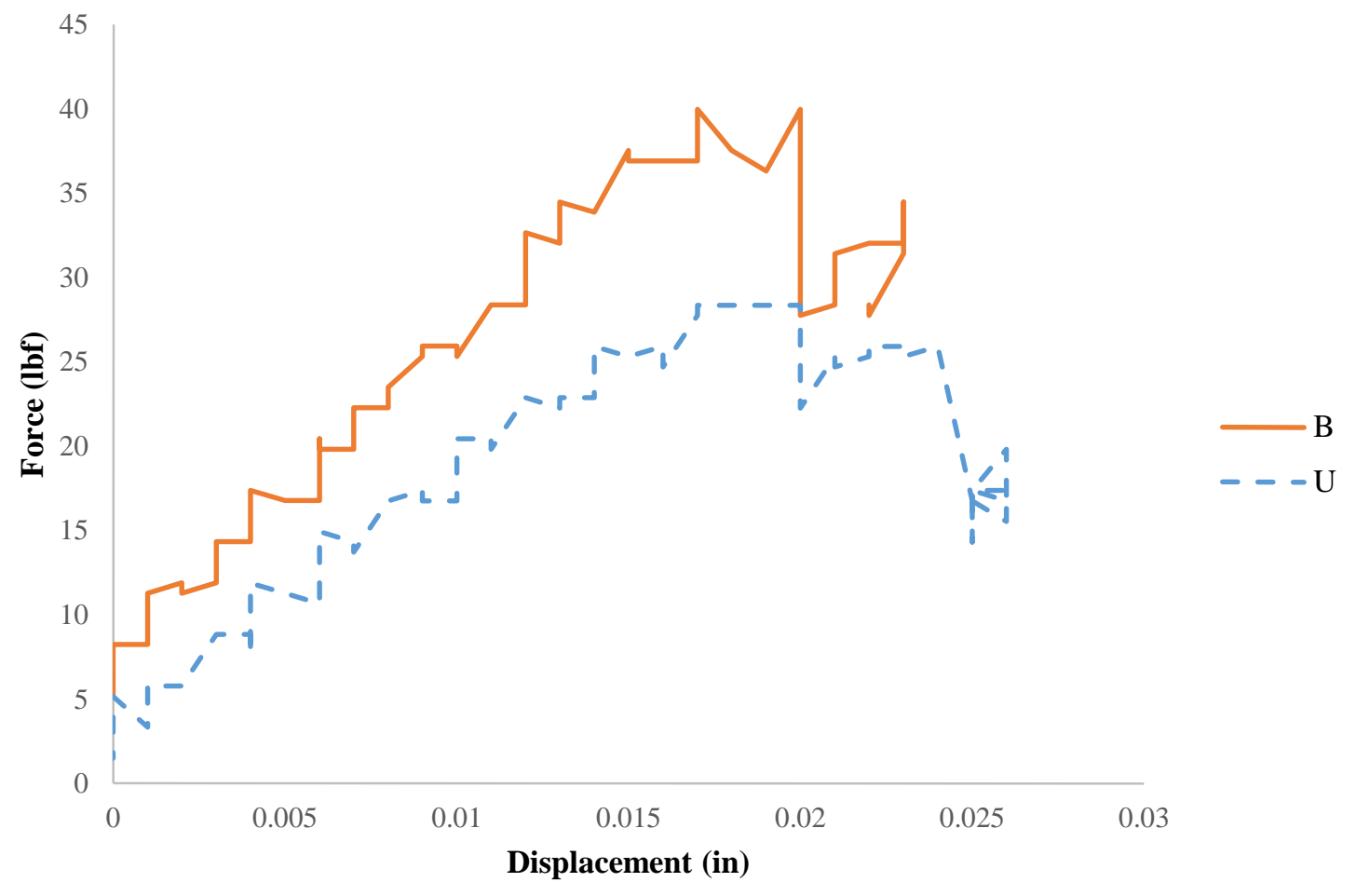

Figure E.36. 4-point bend data for chopped M46J/TC250: $200 \mathrm{lbf}$ closing force, $2 \mathrm{~min}$.

\begin{tabular}{|c|c|c|}
\hline Property & B & U \\
\hline Maximum Force (lbf) & 40.0 & 28.4 \\
\hline Max. Displacement (in) & 0.020 & 0.020 \\
\hline Width (in) & 0.5 & 0.5 \\
\hline Depth (in) & 0.1 & 0.1 \\
\hline Span (in) & 1.6 & 1.6 \\
\hline Slope (lbf/in) & 1898.5 & 1425 \\
\hline Flexural Strength (psi) & $9.59 \mathrm{E}+03$ & $6.81 \mathrm{E}+03$ \\
\hline Flexural Strain (psi) & 0.00341 & 0.00341 \\
\hline Tangent Modulus (psi) & $2.64 \mathrm{E}+06$ & $1.98 \mathrm{E}+06$ \\
\hline
\end{tabular}




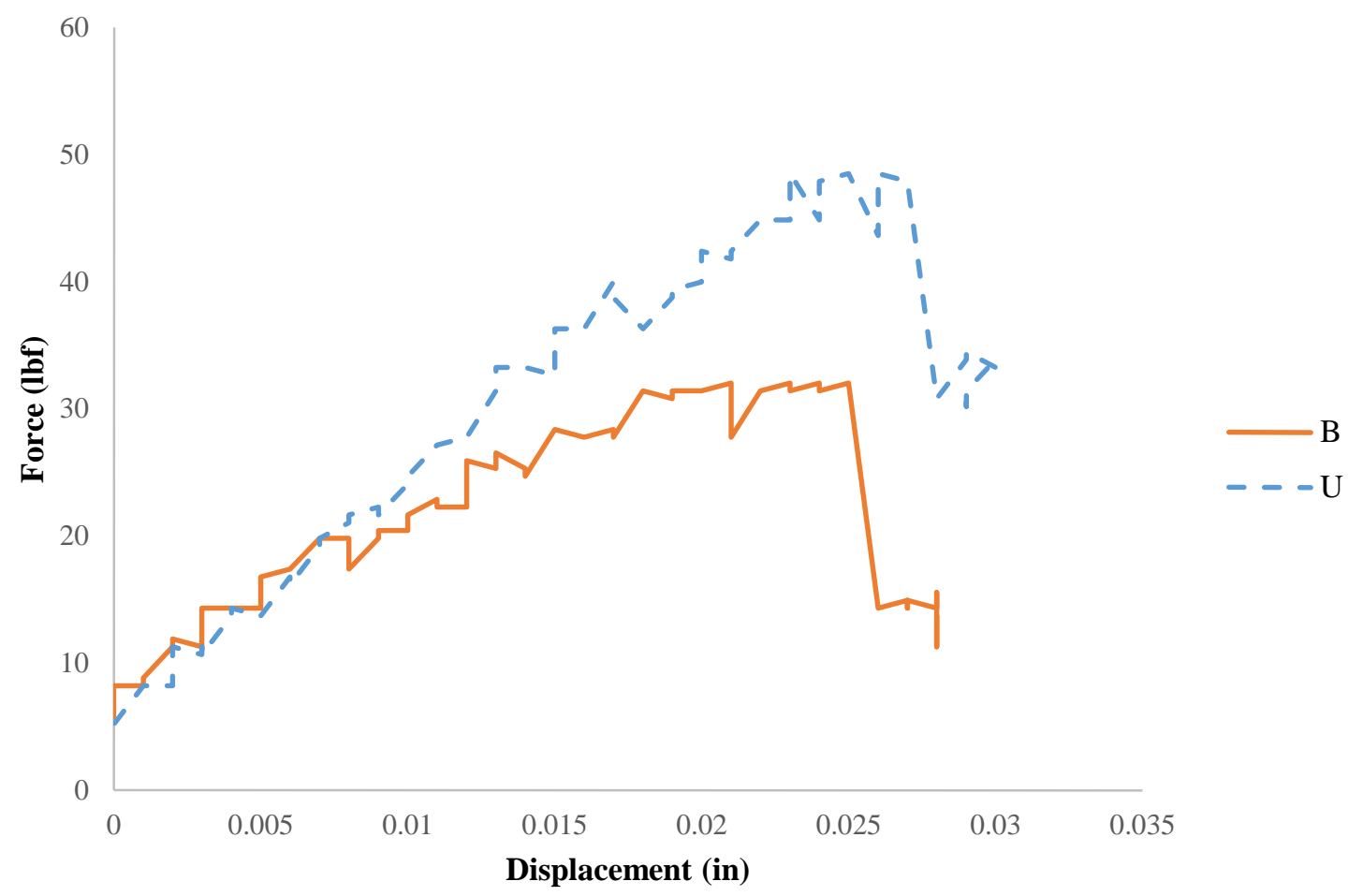

Figure E.37. 4-point bend data for chopped M46J/TC250: $200 \mathrm{lbf}$ closing force, $3 \mathrm{~min}$.

\begin{tabular}{|c|c|c|}
\hline Property & B & U \\
\hline Maximum Force (lbf) & 32.0 & 48.5 \\
\hline Max. Displacement (in) & 0.025 & 0.026 \\
\hline Width (in) & 0.5 & 0.5 \\
\hline Depth (in) & 0.1 & 0.1 \\
\hline Span (in) & 1.6 & 1.6 \\
\hline Slope (lbf/in) & 1240.2 & 1739.1 \\
\hline Flexural Strength (psi) & $7.69 \mathrm{E}+03$ & $1.16 \mathrm{E}+04$ \\
\hline Flexural Strain (psi) & 0.00426 & 0.00443 \\
\hline Tangent Modulus (psi) & $1.73 \mathrm{E}+06$ & $2.42 \mathrm{E}+06$ \\
\hline
\end{tabular}




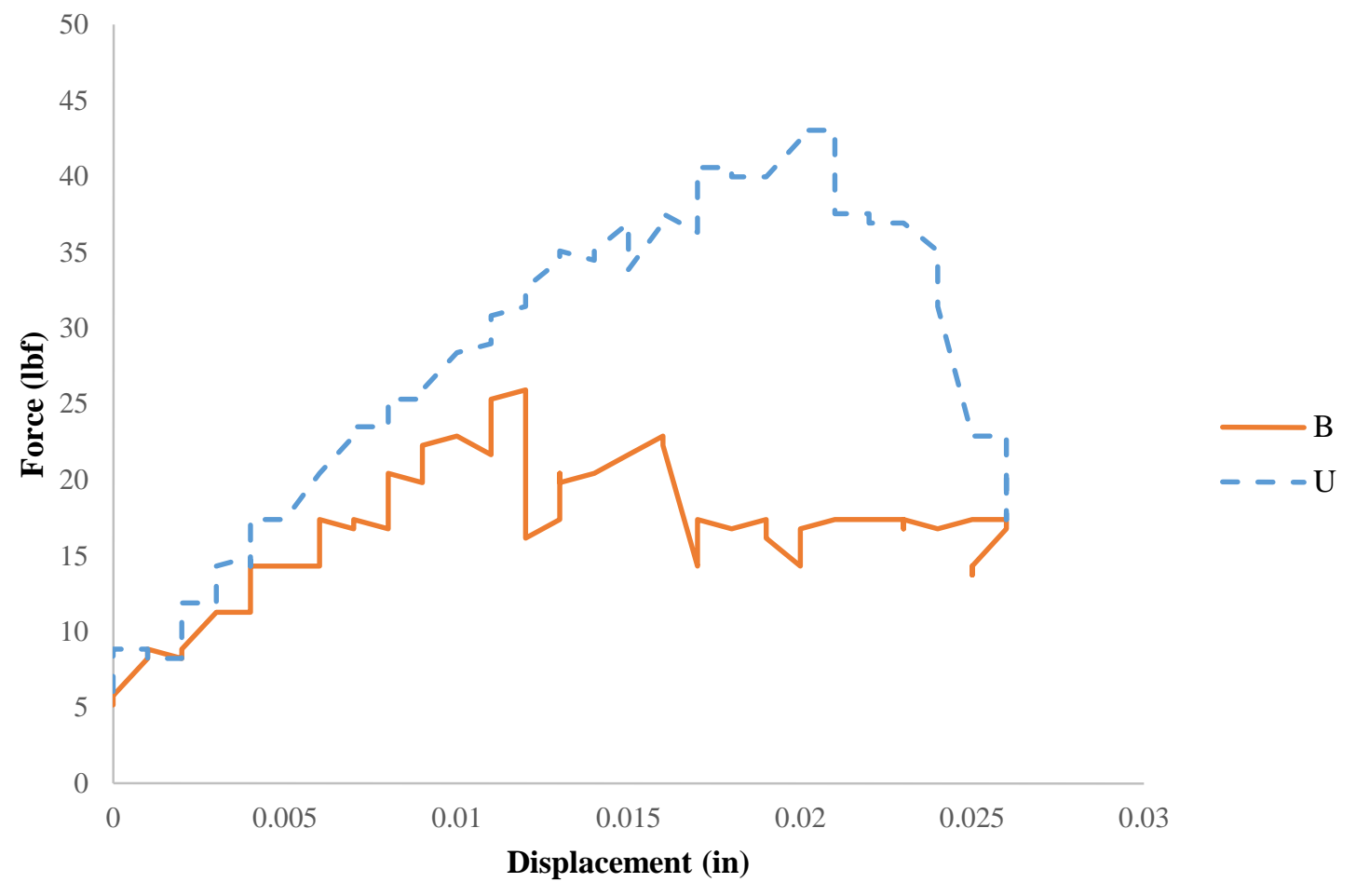

Figure E.38. 4-point bend data for chopped M46J/TC250: $200 \mathrm{lbf}$ closing force, $4 \mathrm{~min}$.

\begin{tabular}{|c|c|c|}
\hline Property & B & U \\
\hline Maximum Force (lbf) & 25.9 & 43.0 \\
\hline Max. Displacement (in) & 0.012 & 0.021 \\
\hline Width (in) & 0.5 & 0.5 \\
\hline Depth (in) & 0.1 & 0.1 \\
\hline Span (in) & 1.6 & 1.6 \\
\hline Slope (lbf/in) & 1626.9 & 1786.4 \\
\hline Flexural Strength (psi) & $6.22 \mathrm{E}+03$ & $1.03 \mathrm{E}+04$ \\
\hline Flexural Strain (psi) & 0.00204 & 0.00358 \\
\hline Tangent Modulus (psi) & $2.27 \mathrm{E}+06$ & $2.49 \mathrm{E}+06$ \\
\hline
\end{tabular}




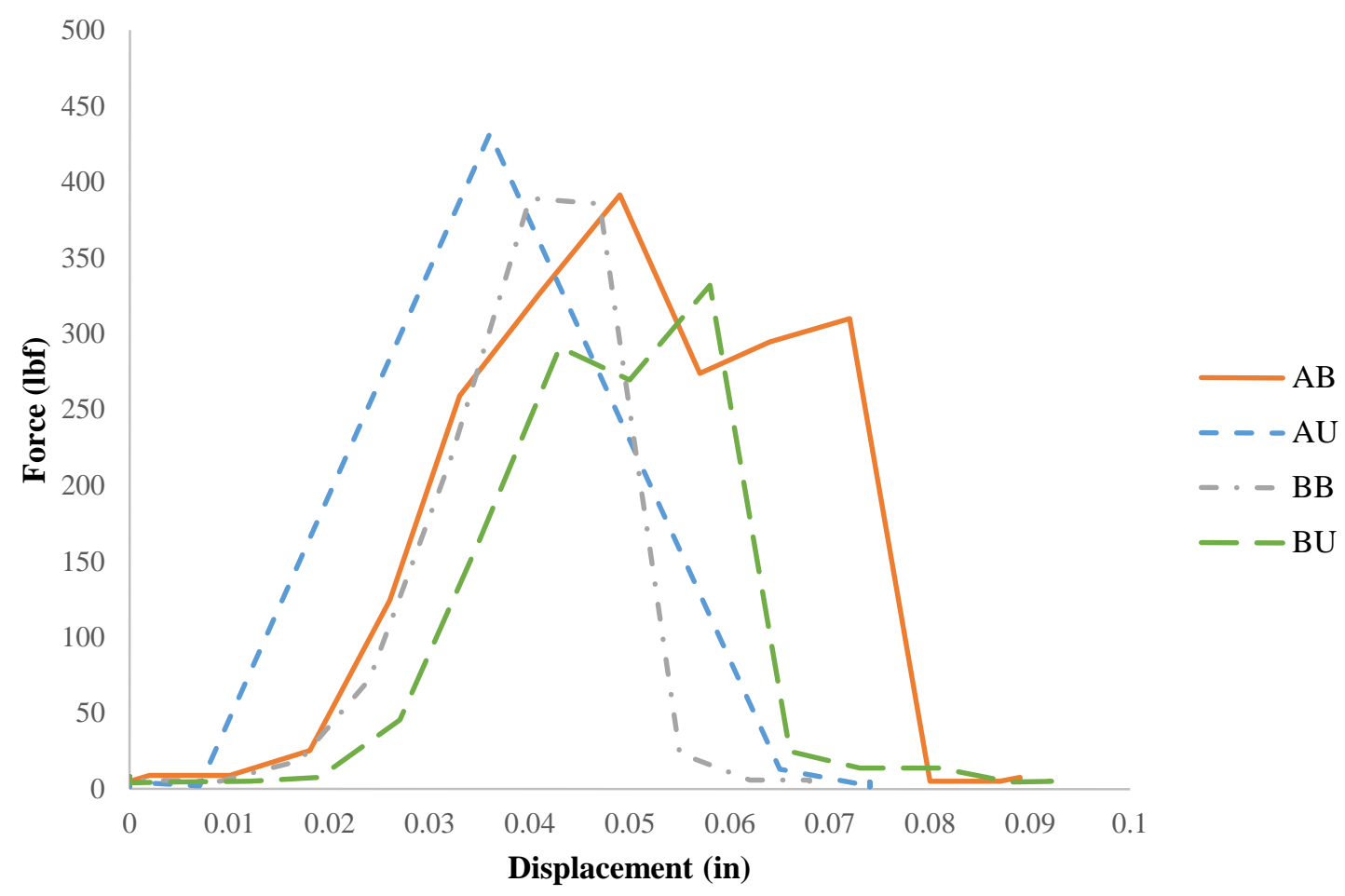

Figure E.39. 4-point bend data for M46J/TC250 sandwich: 1-ply face sheets.

\begin{tabular}{|c|c|c|c|c|}
\hline Property & AB & AU & BB & BU \\
\hline Maximum Force (lbf) & 392 & 432 & 389 & 332 \\
\hline Max. Displacement (in) & 0.049 & 0.036 & 0.040 & 0.058 \\
\hline Width (in) & 0.5 & 0.5 & 0.5 & 0.5 \\
\hline Depth (in) & 0.1 & 0.1 & 0.1 & 0.1 \\
\hline Span (in) & 1.6 & 1.6 & 1.6 & 1.6 \\
\hline Slope (lbf/in) & 12102 & 14817 & 19798 & 12108 \\
\hline Flexural Strength (psi) & $9.40 \mathrm{E}+04$ & $1.04 \mathrm{E}+05$ & $9.34 \mathrm{E}+04$ & $7.96 \mathrm{E}+04$ \\
\hline Flexural Strain (psi) & 0.00835 & 0.00613 & 0.00681 & 0.00988 \\
\hline Tangent Modulus (psi) & $1.69 \mathrm{E}+07$ & $2.06 \mathrm{E}+07$ & $2.76 \mathrm{E}+07$ & $1.69 \mathrm{E}+07$ \\
\hline
\end{tabular}




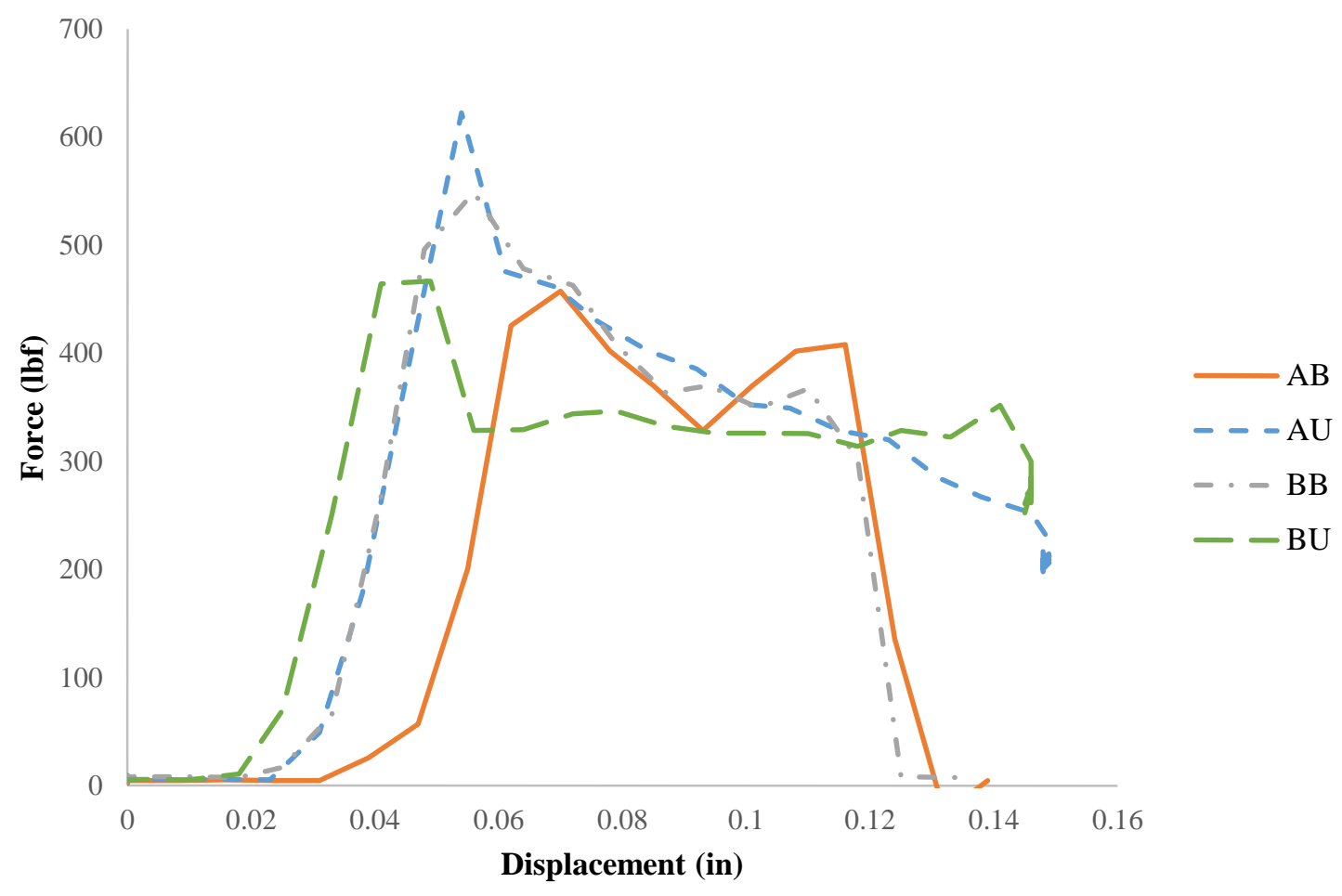

Figure E.40. 4-point bend data for M46J/TC250 sandwich: 2-ply face sheets.

\begin{tabular}{|c|c|c|c|c|}
\hline Property & AB & AU & BB & BU \\
\hline Maximum Force (lbf) & 457 & 622 & 549 & 467 \\
\hline Max. Displacement (in) & 0.070 & 0.054 & 0.056 & 0.049 \\
\hline Width (in) & 0.5 & 0.5 & 0.5 & 0.5 \\
\hline Depth (in) & 0.1 & 0.1 & 0.1 & 0.1 \\
\hline Span (in) & 1.6 & 1.6 & 1.6 & 1.6 \\
\hline Slope (lbf/in) & 24419 & 25322 & 28603 & 24681 \\
\hline Flexural Strength (psi) & $1.10 \mathrm{E}+05$ & $1.49 \mathrm{E}+05$ & $1.32 \mathrm{E}+05$ & $1.12 \mathrm{E}+05$ \\
\hline Flexural Strain (psi) & 0.01192 & 0.00920 & 0.00954 & 0.00835 \\
\hline Tangent Modulus (psi) & $3.40 \mathrm{E}+07$ & $3.53 \mathrm{E}+07$ & $3.98 \mathrm{E}+07$ & $3.44 \mathrm{E}+07$ \\
\hline
\end{tabular}




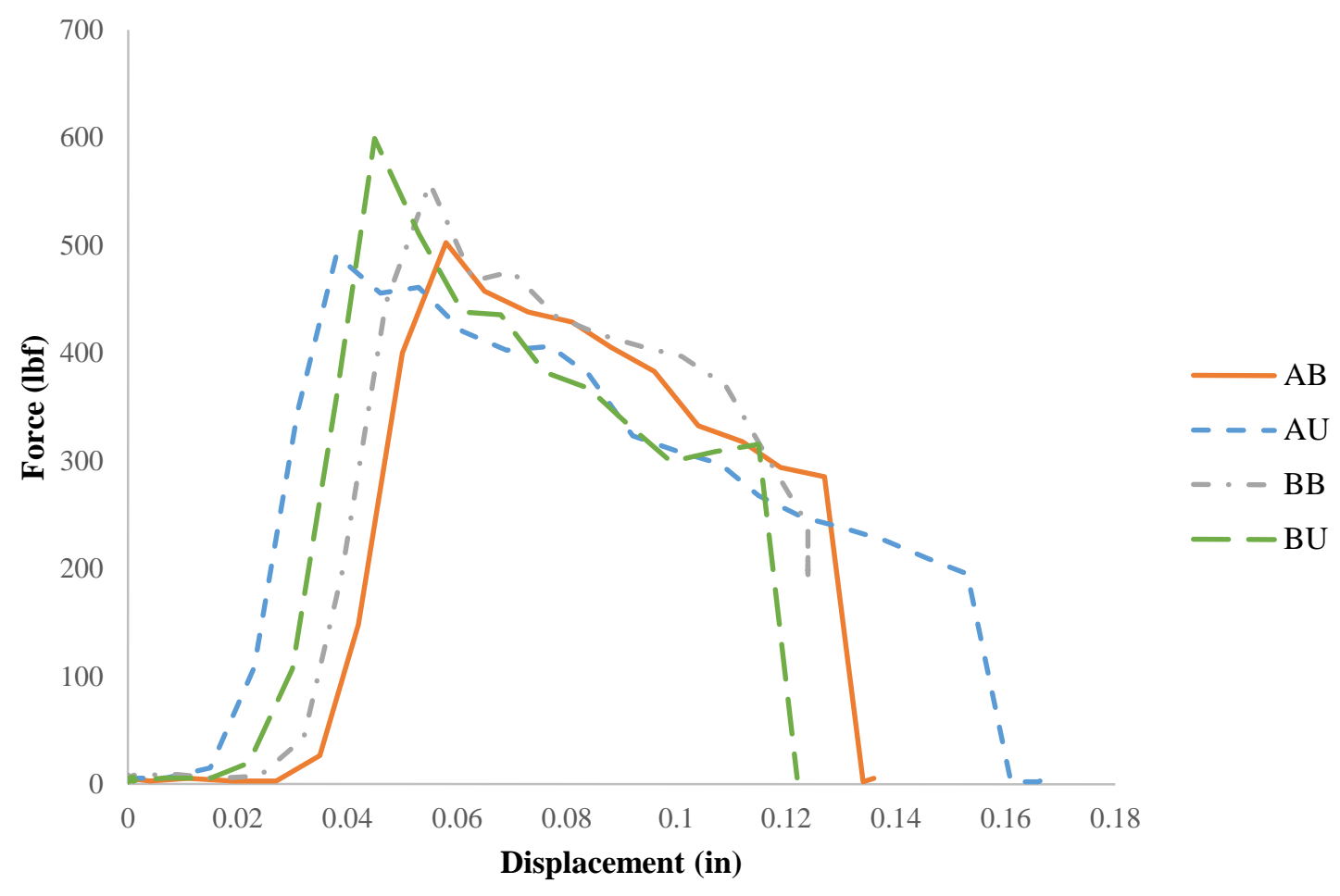

Figure E.41. 4-point bend data for M46J/TC250 sandwich: 3-ply face sheets.

\begin{tabular}{|c|c|c|c|c|}
\hline Property & AB & AU & BB & BU \\
\hline Maximum Force (lbf) & 491 & 503 & 558 & 599 \\
\hline Max. Displacement (in) & 0.038 & 0.058 & 0.055 & 0.045 \\
\hline Width (in) & 0.5 & 0.5 & 0.5 & 0.5 \\
\hline Depth (in) & 0.1 & 0.1 & 0.1 & 0.1 \\
\hline Span (in) & 1.6 & 1.6 & 1.6 & 1.6 \\
\hline Slope (lbf/in) & 21624 & 21831 & 23318 & 32764 \\
\hline Flexural Strength (psi) & $1.18 \mathrm{E}+05$ & $1.21 \mathrm{E}+05$ & $1.34 \mathrm{E}+05$ & $1.44 \mathrm{E}+05$ \\
\hline Flexural Strain (psi) & 0.00647 & 0.00988 & 0.00937 & 0.00766 \\
\hline Tangent Modulus (psi) & $3.01 \mathrm{E}+07$ & $3.04 \mathrm{E}+07$ & $3.25 \mathrm{E}+07$ & $4.56 \mathrm{E}+07$ \\
\hline
\end{tabular}




\section{E.5. M46J/TC250 Lug Mold Specimens}

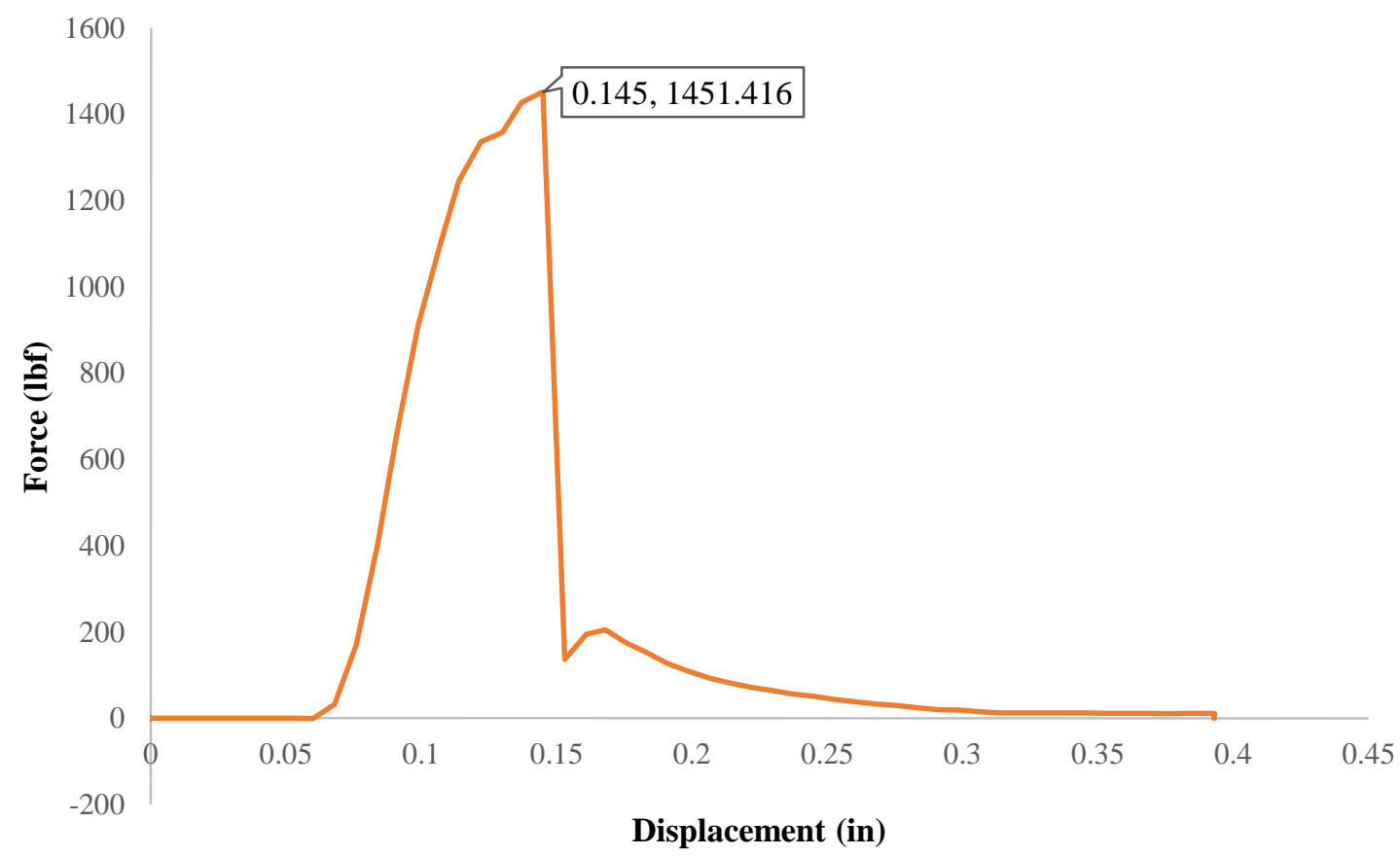

Figure E.42. Force-displacement data for Lug \#1.
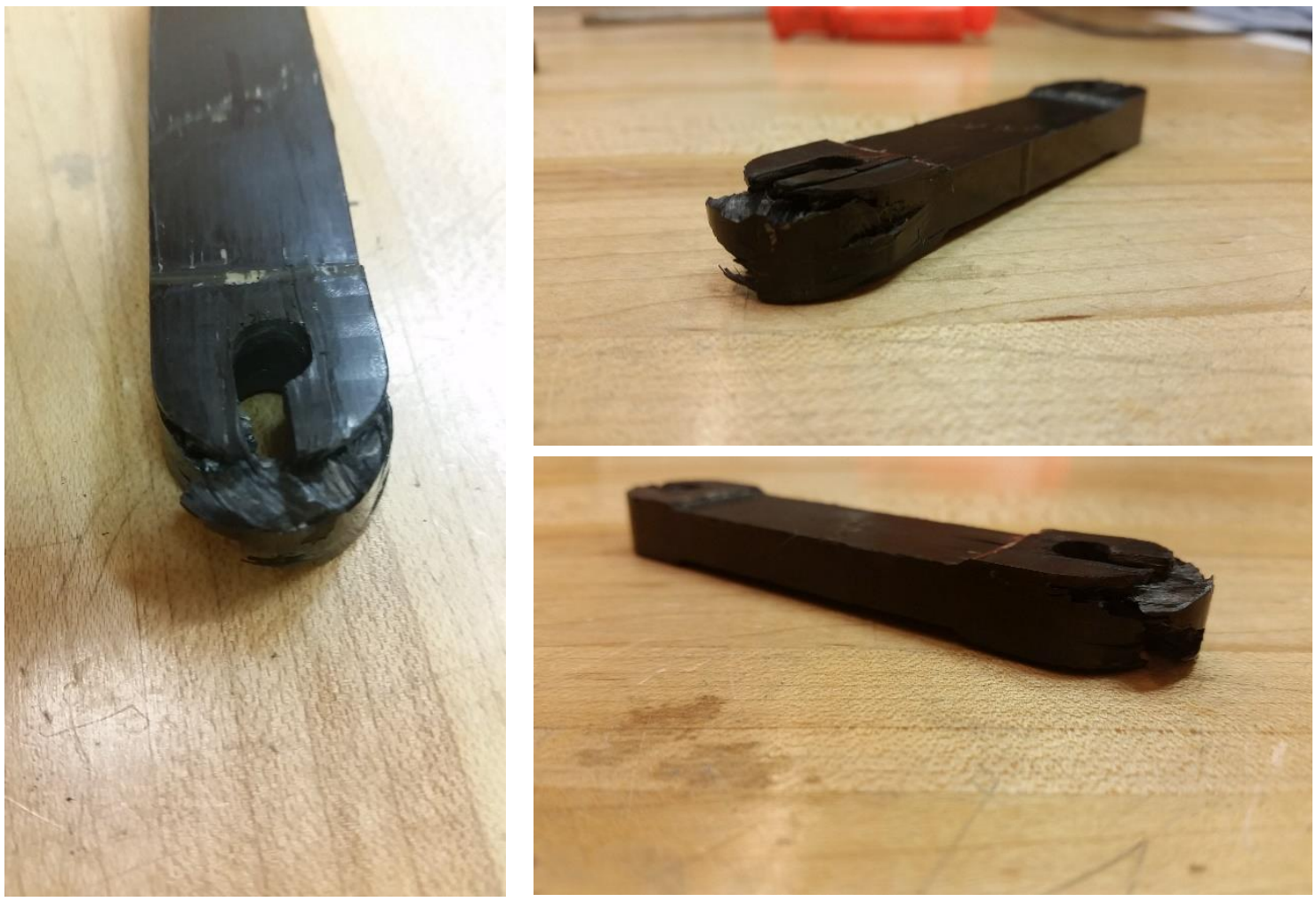


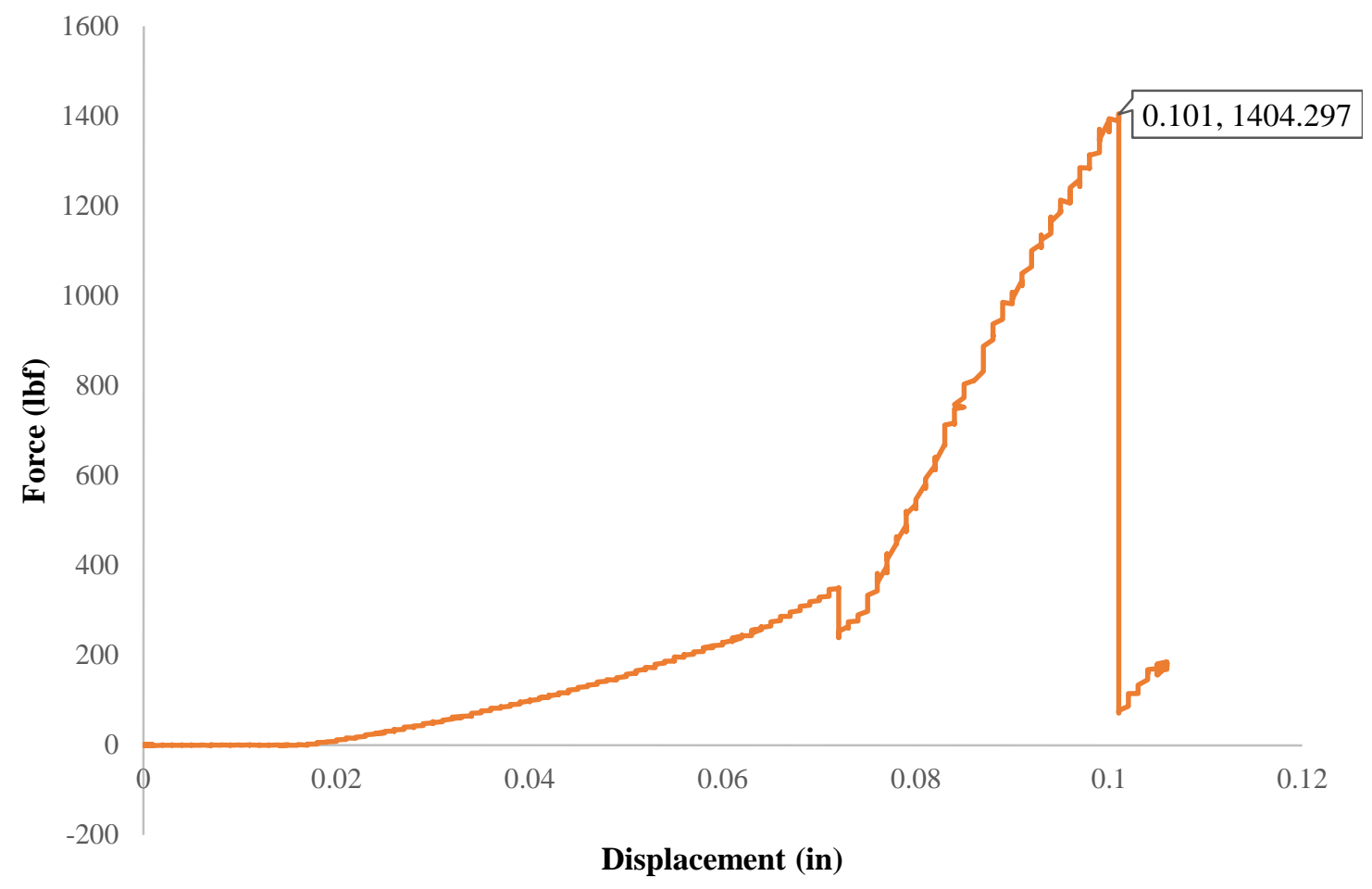

Figure E.43. Force-displacement data for Lug \#2.
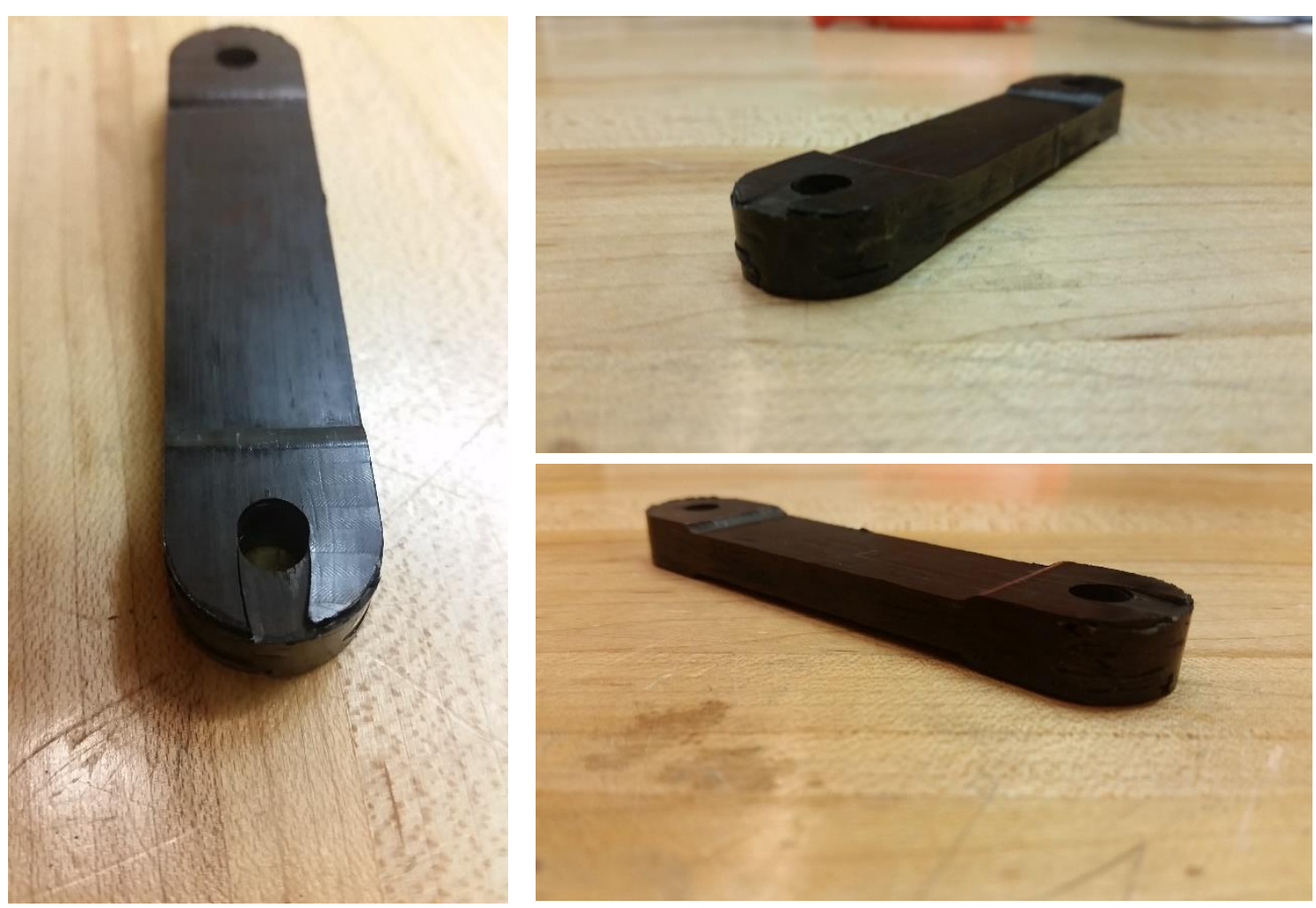


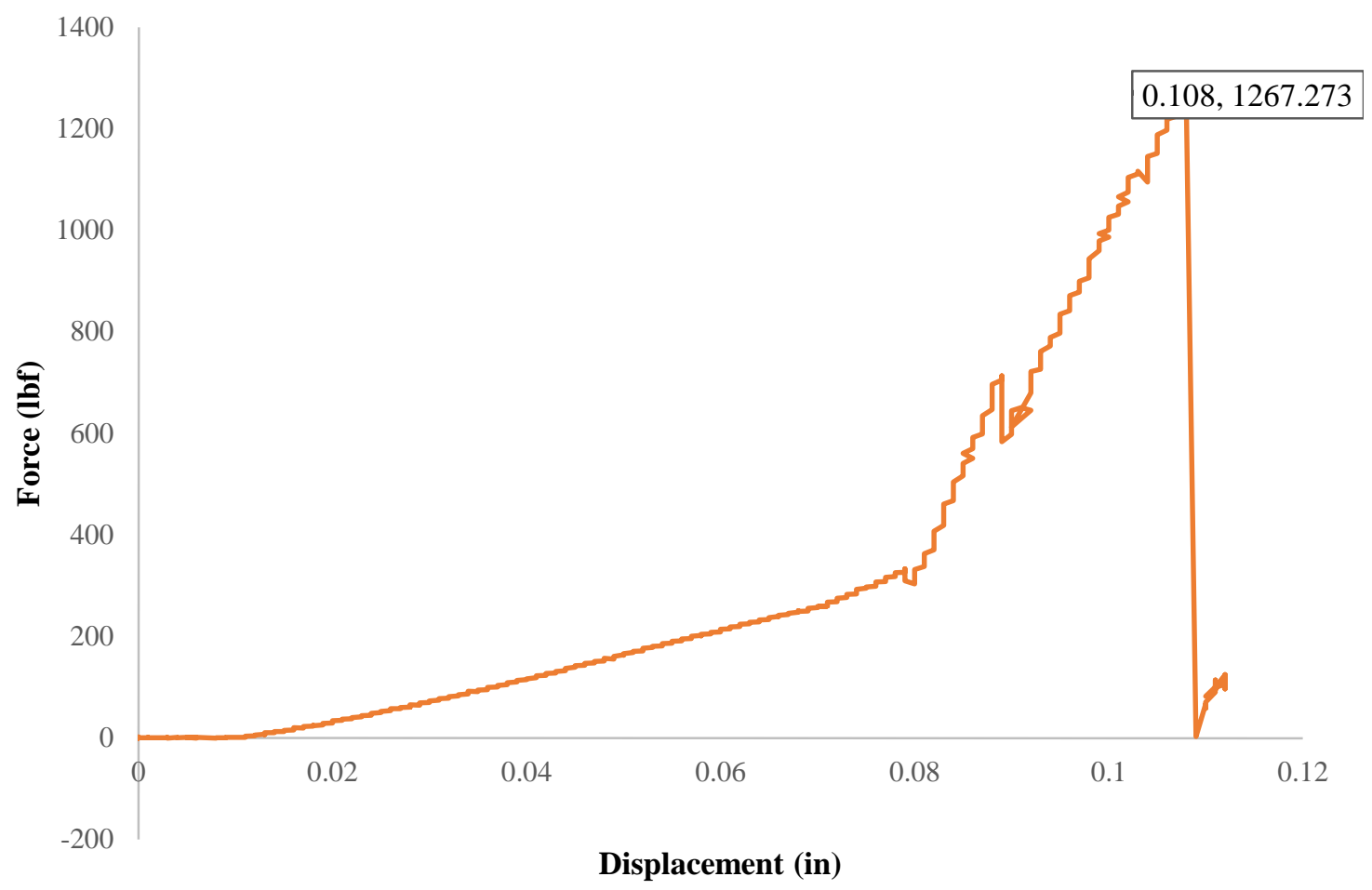

Figure E.44. Force-displacement data for Lug \#3.
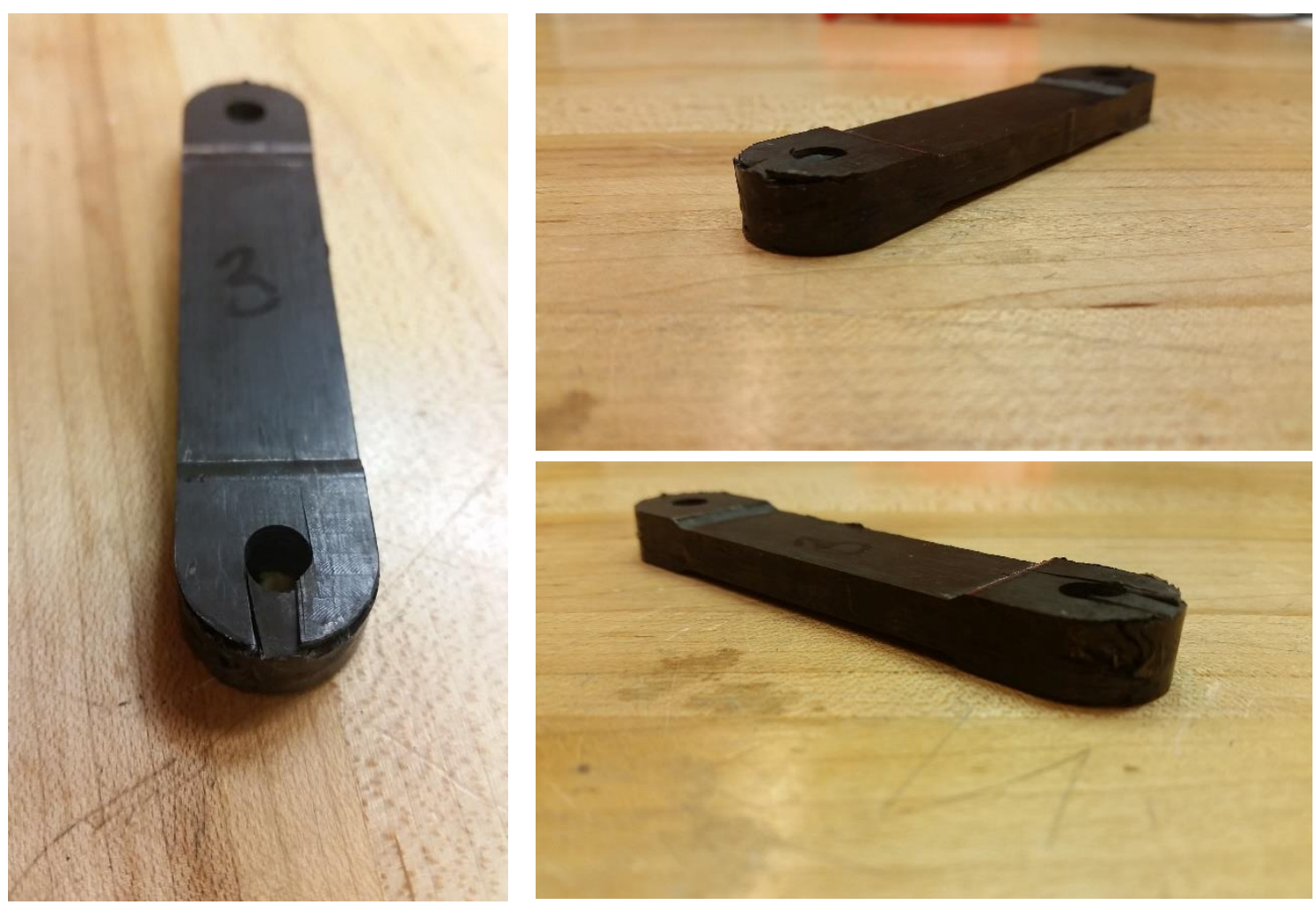


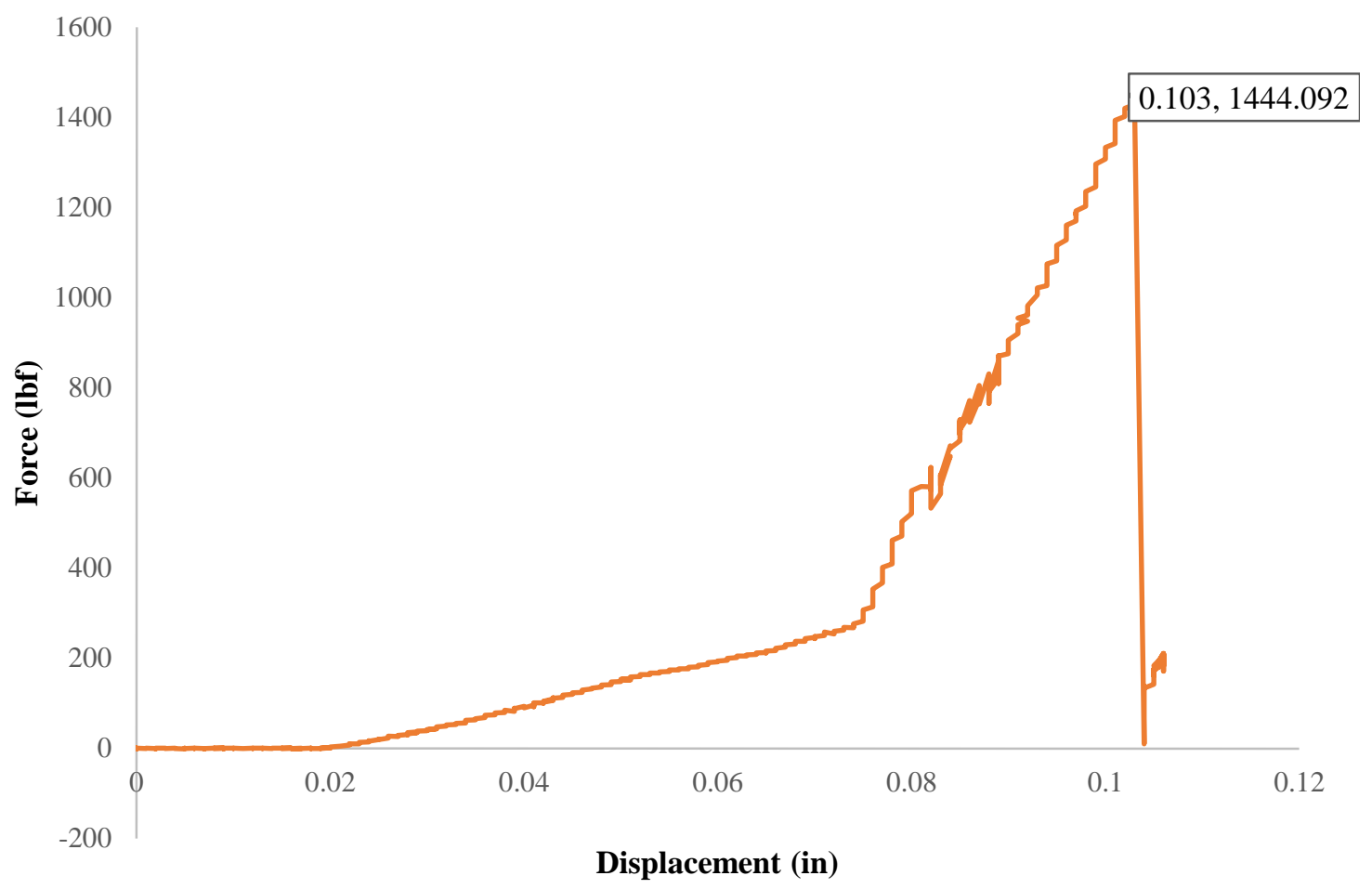

Figure E.45. Force-displacement data for Lug \#4.
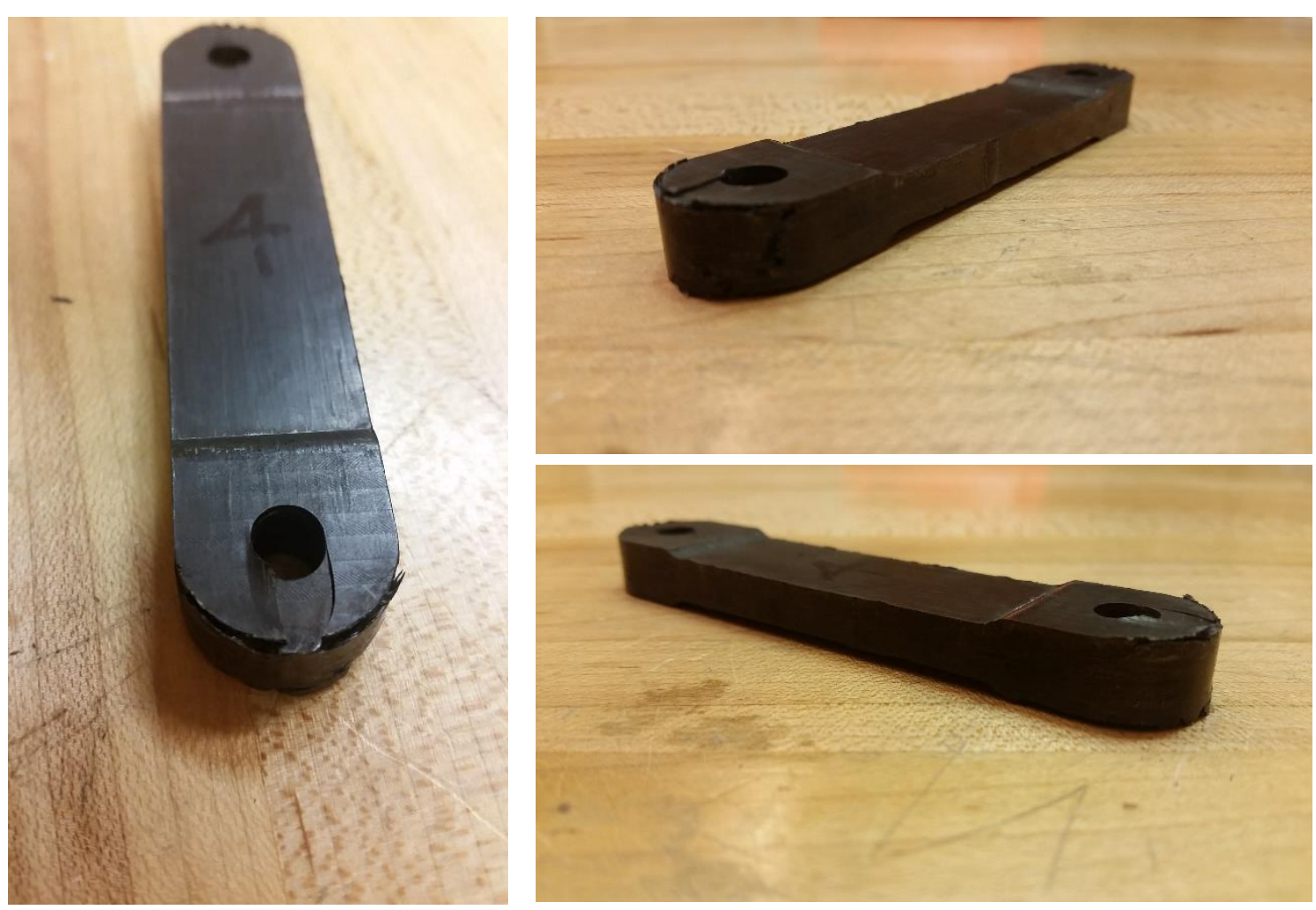


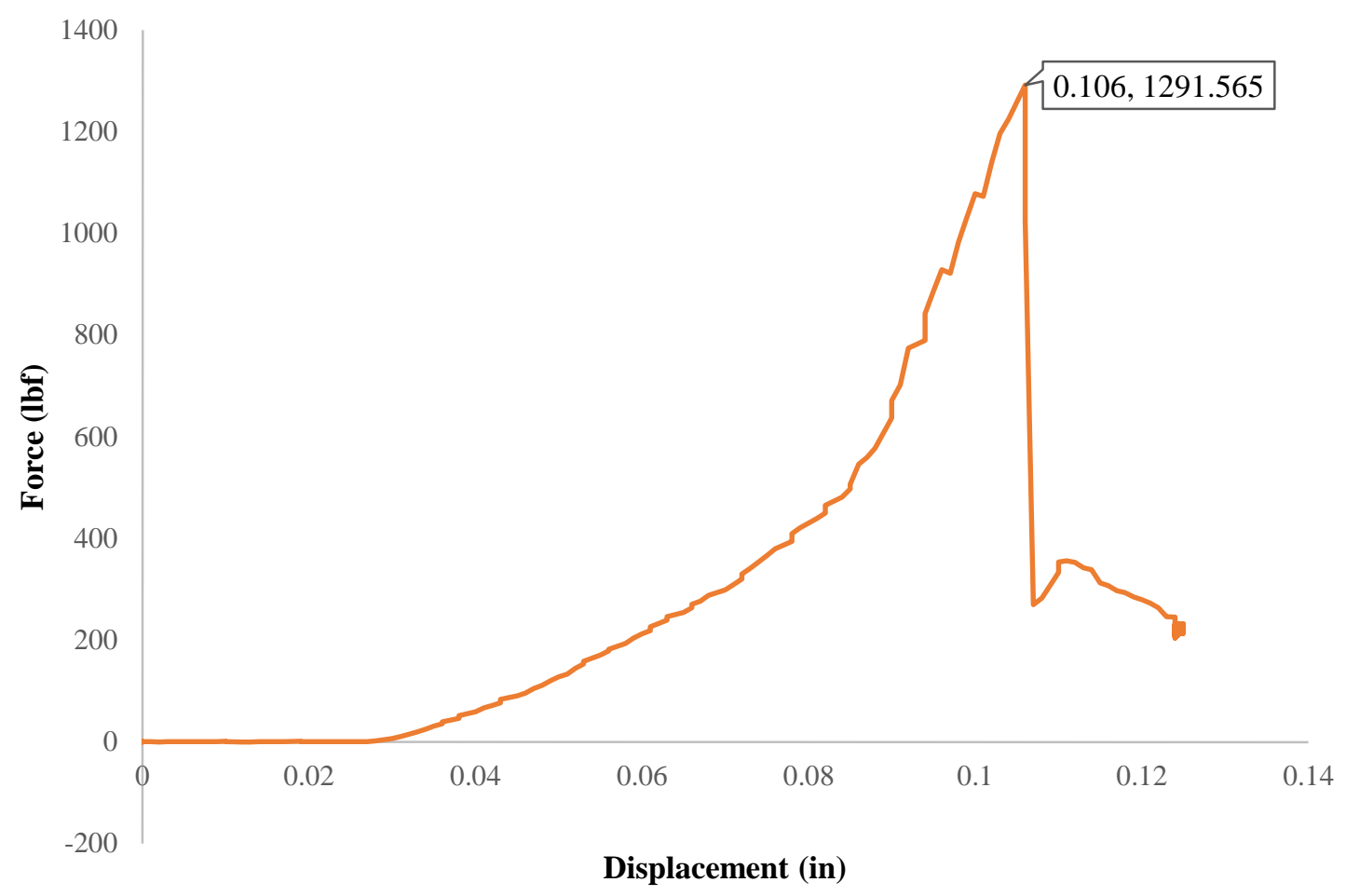

Figure E.46. Force-displacement data for Lug \#5.
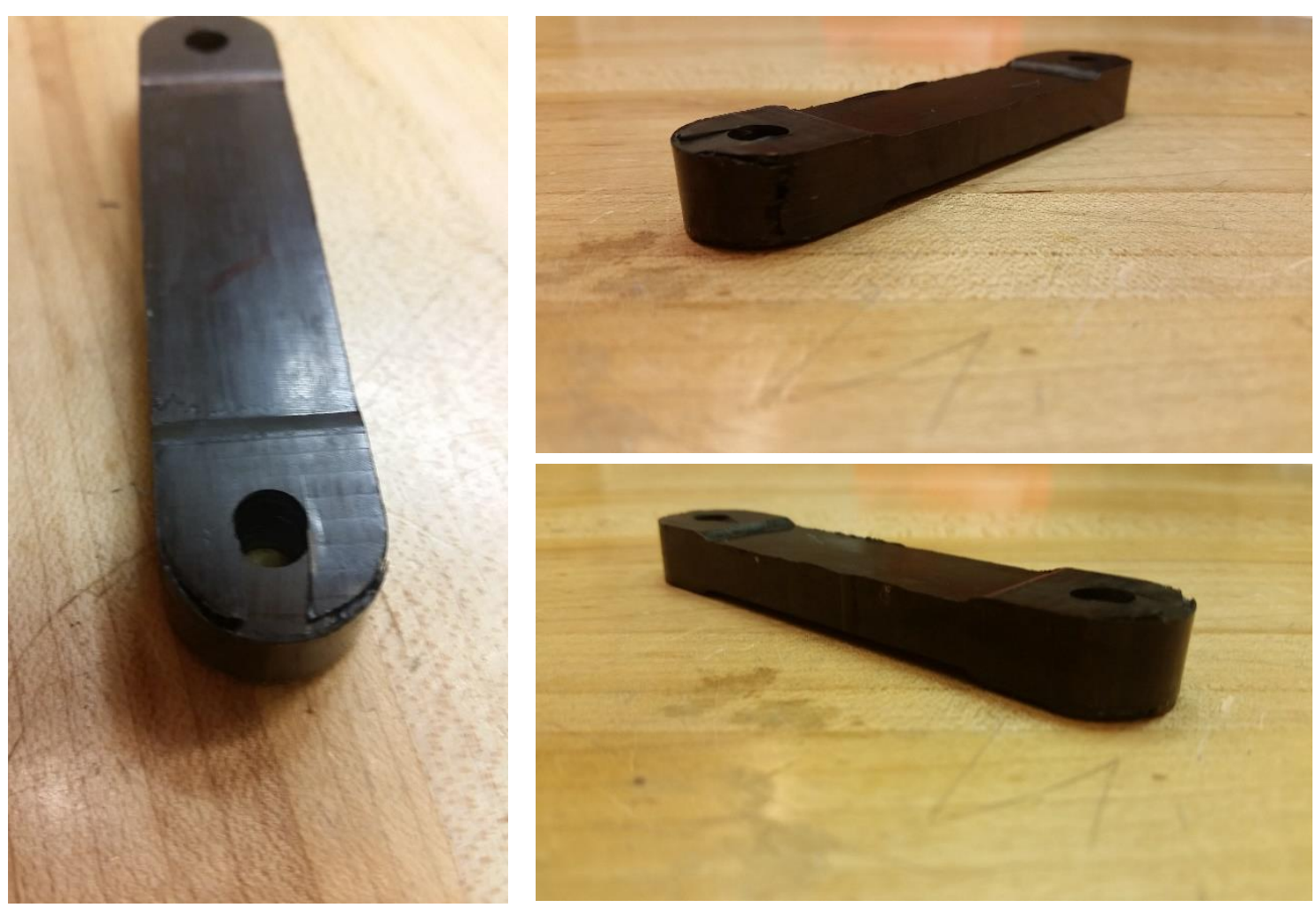